\title{
Synthese und Untersuchung von Alanyl-PNA Oligomeren und deren Einfluß auf $\beta$-Faltblatt Strukturen
}

\author{
Dissertation \\ zur Erlangung des Doktorgrades \\ der Mathematisch-Naturwissenschaftlichen Fakultäten \\ der Georg-August-Universität zu Göttingen
}

vorgelegt von

Ružica Ranevski

aus Arnsberg

Göttingen 2006 
D 7

Referent:

Prof. Dr. Ulf Diederichsen

Korreferent:

Prof. Dr. Axel Zeeck

Tag der mündlichen Prüfung: 04. 05. 2006 
Die vorliegende Arbeit wurde in der Zeit von Dezember 2002 bis Februar 2006 unter der Leitung von Prof. Dr. U. Diederichsen am Institut für Organische und Biomolekulare Chemie der Universität Göttingen angefertigt.

Mein besonderer Dank gilt Prof. Dr. U. Diederichsen für die interessante Themenstellung sowie für die Unterstützung und Förderung während des Fortgangs dieser Arbeit. 


\section{meinen Eltern, Stanko und Holger}


Da ersann die zeusentsprossene Helena andres

Und sie warf in den

Wein, von welchem sie tranken, ein Mittel gegen Kummer und Grole und aller üblen Gedächnis 
Da bi mogao raditi sve ono što želi, treba se roditi ili kao kralj ili kao ludak.

\section{Aristotel}

Jači je ko pobedi sebe nego onaj ko savlada najjačem bedeme. 


\section{Inhaltsverzeichnis}

\section{ALLGEMEINER TEIL}

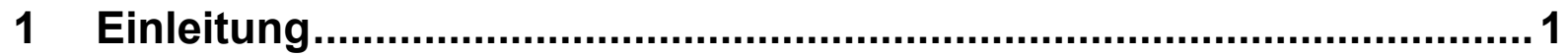

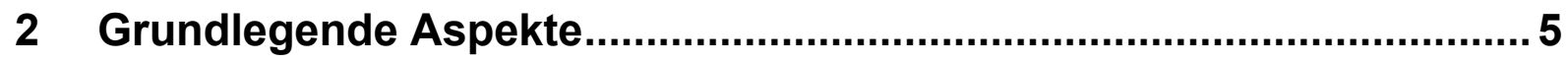

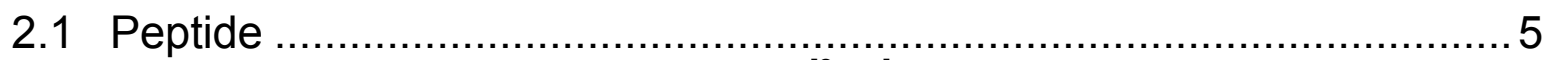

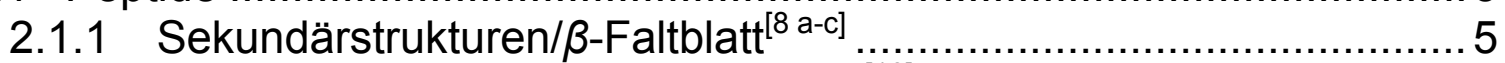

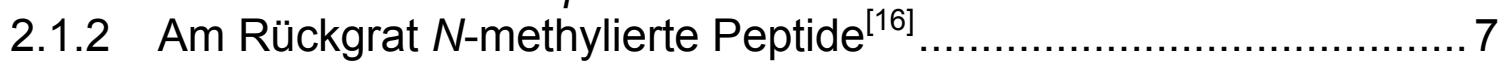

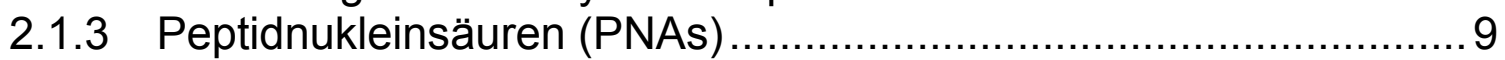

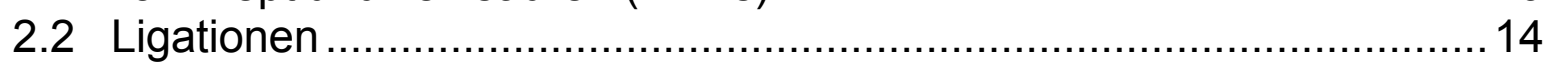

2.3 Humanes Interleukin-8 Derivat (hIL-8) ........................................ 19

3 Synthese von Nucleoaminosäuren ................................................... 21

3.1 Synthese der Monomerbausteine ...............................................21

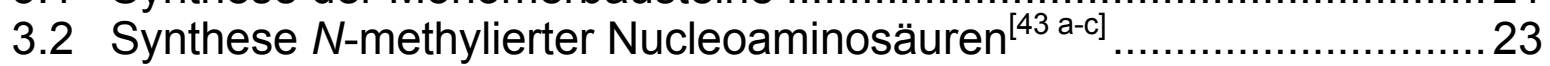

3.3 Synthese von $N$-methylierten und Seitenketten-geschützten

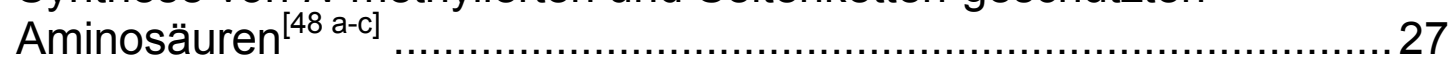

4 AlanyI-PNA Doppelstränge mit Basenfehlstellen und deren Stabilität

$\left(T_{m}\right)$ 28

4.1 Basenfehlstellen in der Sequenz der Alanyl-PNA Oligomere ..............28

4.2 Modifikationen im Rückgrat: $N$-methylierte Alanyl-PNA Oligomere ..... 45

$5 \quad \alpha$-Peptid/Alanyl-Peptidnucleinsäure-Chimäre .................................... 48

5.1 Synthese und Stabilitätsverhalten der $\alpha$-Peptid/Alanyl-

Peptidnucleinsäuren. .48

6 Synthese des Interleukin-8 (hIL-8)/Alanyl-PNA Derivats .59

7 Ligationsverfahren nach Bordusa mit Alanyl-PNA 64

8 Zusammenfassung und Ausblick 68

9 Summary and Outlook.

II. EXPERIMENTELLER TEIL 


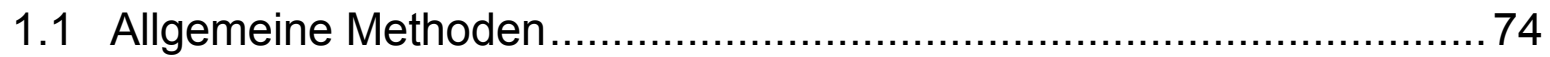

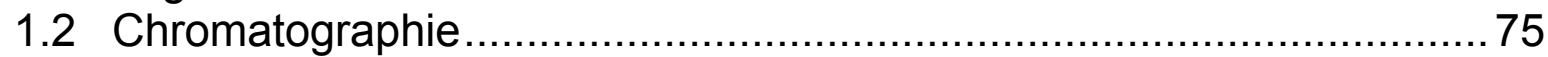

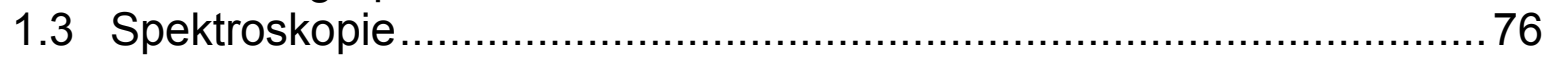

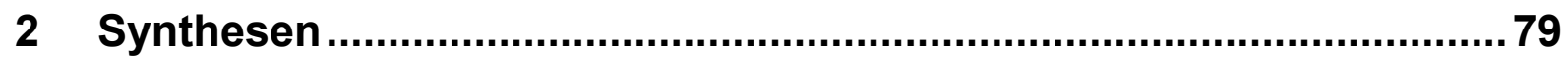

2.1 Allgemeine Arbeitsvorschriften(AAV) .......................................... 79

2.1.1 AAV1: Bestimmung der Enantiomerenreinheit in Anlehnung an

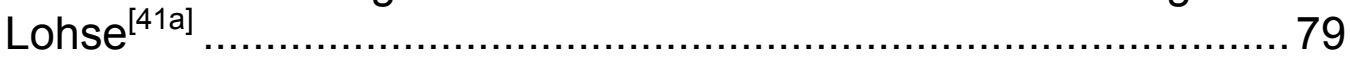

2.1.2 AAV2: Kupplung der ersten Aminosäure an das Harz ..................79

2.1.3 AAV3: Manuelle Synthese der Peptidnucleinsäure - Oligomere

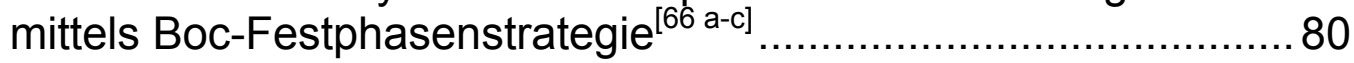

2.1.3.1 AAV3.1: Allgemeines Kupplungsprotokoll ............................... 80

2.1.3.2 AAV3.2: Kupplungsprotokoll beim Einsatz von Aminosäuren mit Fehlstellungen:

2.1.3.3 AAV3.3: Manuelle Synthese des Peptides mittels

Fmoc-Festphasen-strategie ${ }^{[66 \text { a] }}$

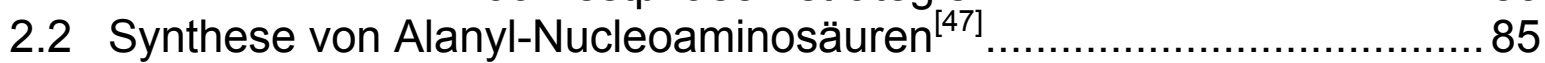

2.2.1 (S)- $N$-tert-Butoxycarbonyl- $\beta$-( $N$-4-benzyloxycarbonyl-1-cytosinyl)-

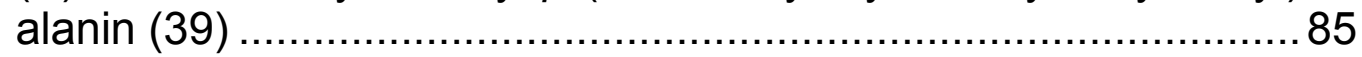

2.2.2 (R)- $N$-tert-Butoxycarbonyl- $\beta$-( $N$-4-benzyloxycarbonyl-1-cytosinyl)-

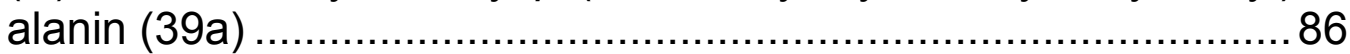

2.2.3 (S)-N-tert-Butoxycarbonyl- $\beta$-(2-amino-6-chlor-9-purinyl)-alanin $(36)^{[47]}$

2.2.4 (R)-N-tert-Butoxycarbonyl- $\beta$-(2-amino-6-chlor-9-purinyl)-alanin

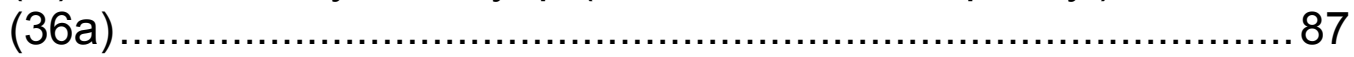

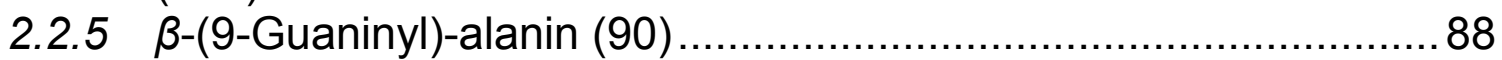

2.2.6 (S)-N-tert-Butoxycarbonyl- $\beta$-(9-guaninyl)-alanin (37)................... 89

2.2.7 (R)- $N$-tert-Butoxycarbonyl- $\beta$-(9-guaninyl)-alanin (37a) ................. 90

2.2 .8 (S)- $N$-Butoxycarbonyl- $\beta$-(1-thyminyl)-L-alanin (38) ….................90

2.2 .9 (S)-N-Butoxycarbonyl- $\beta$-(9-adeninyl)-L-alanin $(40)^{[47] \ldots \ldots \ldots \ldots \ldots . . .} 92$

2.3 Synthese von $N$-methylierten Alanyl-Nucleoaminosäuren ...................93

2.3.1 (S)-N-Butoxycarbonyl- $N$-methyl-L-serinlacton (42) …................... 93

2.3.2 (S)- $N$-tert-Butoxycarbonyl- $N$-methyl- $\beta$-( $N$-4-benzyloxycarbonyl-1cytosinyl)-alanin (45) ..................................................... 94

2.3.3 (S)- $N$-tert-Butoxycarbonyl- $N$-methyl- $\beta$-(2-amino-6-chlor-9-purinyl)-

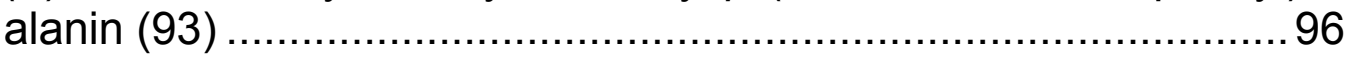

2.3.4 N-Methyl- $\beta$-(9-guaninyl)-alanin (94) _................................. 97

2.3.5 (S)- $N$-tert-Butoxycarbonyl- $N$-methyl- $\beta$-(9-guaninyl)-alanin (43) $\ldots . .98$

2.3.6 (S)- $N$-Butoxycarbonyl- $N$-methyl- $\beta$-(1-thyminyl)-L-alanin (44) $\ldots \ldots . .100$

2.3.7 (S)- $N$-Butoxycarbonyl- $N$-methyl- $\beta$-(9-adeninyl)-L-alanin (46)...... 102

2.4 Synthesen von geschützten $N$-methylierten Aminosäuren................. 103

2.4.1 (S)-N- $\alpha$-tert-Butoxycarbonyl- $N$-methyl-benzyl-cystein (56) ......... 103

2.4.2 3-(Benzylamino)-2-(tert-

butoxycarbonyl)(methyl)amino)propansäure $(57)^{[67 \mathrm{a}-\mathrm{c}]} \ldots \ldots \ldots \ldots . . . . . .105$

2.5 Synthese der Alanyl-Peptidnucleinsäuren (Alanyl-PNAs) ..................106

2.5.1 H-AlaC-AlaC-AlaT-AlaC-AlaG-AlaG-Lys-NH ${ }_{2}$ (59)....................106

2.5.2 H-AlaC-AlaC-AlaG-AlaT-AlaG-AlaG-Lys- $\mathrm{NH}_{2}(60) \ldots \ldots \ldots \ldots \ldots \ldots . . . . .107$ 
2.5.3 H-AlaC-AlaC-Glu-AlaC-AlaG-AlaG-Lys- $\mathrm{NH}_{2}(61) \ldots \ldots \ldots \ldots \ldots \ldots . . . . .109$

2.5.4 H-AlaC-AlaC-Glu-AlaC-AlaG-AlaG-Lys-Lys- $\mathrm{NH}_{2}(63) \ldots \ldots \ldots \ldots \ldots . . . .110$

2.5.5 H-AlaC-AlaC-AlaG-Lys-AlaG-AlaG-Lys- $\mathrm{NH}_{2}(62) \ldots \ldots \ldots \ldots \ldots \ldots \ldots . . . . .111$

2.5.6 H-Lys-AlaG-AlaC-AlaC-Glu-AlaC-AlaG-AlaG-Lys-NH ${ }_{2}(65) \ldots \ldots 112$

2.5.7 H-AlaC-AlaC-AlaG-Lys-AlaG-AlaG-AlaC-Lys- $\mathrm{NH}_{2}(64) \ldots \ldots \ldots \ldots . . . .113$

2.5.8 H-AlaC-AlaC-AlaG-AlaC-AlaG-AlaG-Lys-OH (80) ..................... 114

2.5.9 H-AlaC-AlaC-AlaG-Glu-AlaG-AlaG-Gly-OH (66) ...................... 115

2.5.10 H-AlaG-AlaG-AlaC-AlaG-AlaC-AlaC-Gly-OH (81) ................... 116

2.5.11 H-AlaT-AlaG-AlaG-AlaC-AlaG-AlaC-AlaC-Gly-OH (93)............. 117

2.5.12 H-(Me)AlaCAlaC-AlaC-AlaC-AlaG-AlaG-Lys-NH ${ }_{2}(67) \ldots \ldots \ldots \ldots . . . .118$

2.5.13 H-AlaC-AlaC-(Me)AlaG-AlaC-AlaG-AlaG-Lys-NH ${ }_{2}(68) \ldots \ldots \ldots \ldots . . .119$

2.6 Synthese der Peptid/Alanyl-PNA Sequenz ................................. 121

2.6.1 Ac-SPGKTYTEVPGOKILQVGPGG-AlaC-AlaC-AlaG-AlaC-AlaG-

AlaG-K (72) ............................................................. 121

2.6.2 Ac-OKILQVGNGG-AlaC-AlaC-AlaG-AlaC-AlaG-AlaG-K (73).... 123

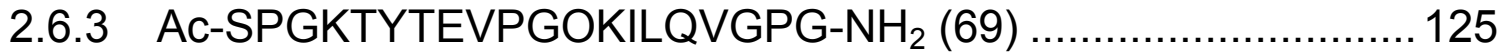

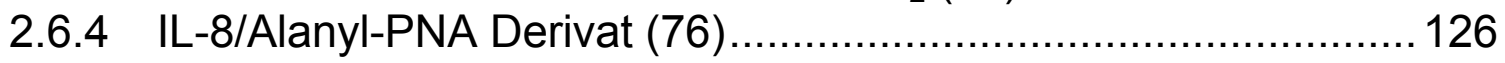

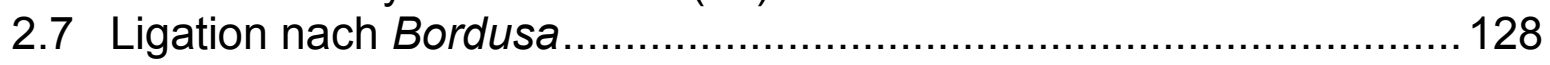

III. ABKÜRZUNGSVERZEICHNIS ..................................130

IV. LITERATURVERZEICHNIS 



\section{Allgemeiner Teil}

\section{Einleitung}

Die meisten der heute gegen die verschiedensten Krankheiten eingesetzten Arzneimittel entfalten ihre Wirkung durch Wechselwirkungen mit Proteinen, insbesondere mit Enzymen und Rezeptoren, die mit der jeweiligen Krankheit in Zusammenhang stehen. ${ }^{[1]}$ Ursache für viele Krankheiten sind fehlerhafte genetische Informationen. Die Funktion und Eigenschaften von Proteinen sind eng mit der dreidimensionalen Anordnung ihrer Sekundärstrukturen und ihrer Konformationsänderungen verbunden. Eine Veränderung der dreidimensionalen Struktur eines Proteins ist ein essentieller Vorgang bei der Proteinerkennung durch kleine Moleküle sowie bei Protein-Protein und Protein-DNA Wechselwirkungen. ${ }^{[2]}$ Eine kontrollierbare Veränderung in der Konformation stellt ein wichtiges Werkzeug für die Steuerung einer Proteinfunktion und deren Eigenschaft dar. Es ist daher von großem Interesse die spezifische Erkennung von Proteinen sowie Proteindomänen zu kontrollieren. Hierbei sind nicht nur die erwähnten Konformationswechsel bei der Entwicklung neuer molekularer Schalter und Erkennungseinheiten von Bedeutung, sondern auch die Wechselwirkungen zwischen den einzelnen Proteinen. Die entwickelten Erkennungsdomänen können als Hilfswerkzeuge bei der Untersuchung von Proteinfunktionen und deren Mechanismen sowie bei Interaktionen zwischen Proteinen, zum Beispiel der Signaltransduktion, dienen. Ein Ziel dieser Arbeit ist es, modifizierte kleine Proteine mit Erkennungseinheiten darzustellen, welche mit komplementären Molekülen in Wechselwirkung treten und somit eine Konformationsänderung induzieren können. Dazu sollen Alanyl-Peptidnucleinsäuren (Alanyl-PNAs) als molekulare Schalter für $\beta$-Faltblatt-Sekundärstrukturen dienen. Alanyl-PNAs bestehen aus Alanyl-Aminosäuren, die in ihrer Seitenkette verschiedene Nucleobasen tragen. 


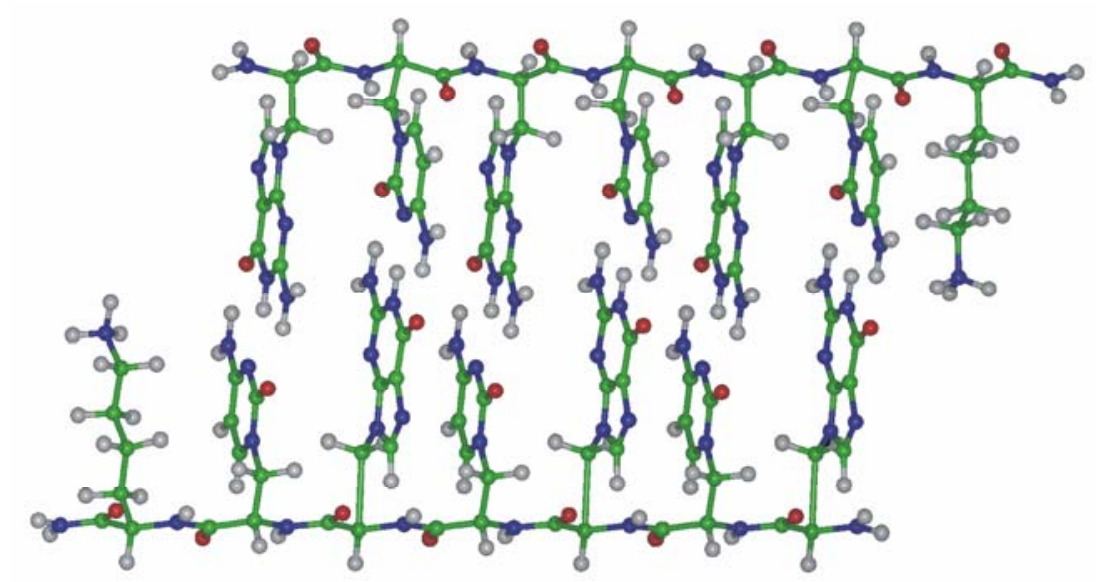

Abb. 1 Darstellung des linearen Doppelstranges der Alanyl-PNA. ${ }^{[3 a, 3 b]}$

Bei der Alanyl-PNA handelt es sich um ein alternierend aufgebautes Peptid, deren Seitenketten sich aufgrund der Alternanz der Aminosäuren auf eine Seite des Rückgrates orientieren und durch Wasserstoffbrückenbindungen einen linearen Doppelstrang ausbilden können (Abb. 1). Die in der Alanyl-PNA vorkommenden Nucleoaminosäuren treten mit einer komplementären Nucleobase bzw. einem komplementären Strang in Wechselwirkung. Komplementäre Alanyl-PNA Hexamere bilden stabile Doppelstränge mit linearer Topologie aus (Abb. 1). Die Doppelstrangstabilisierung kommt durch die Ausbildung von Wasserstoffbrückenbindungen und Stapelungen der Nucleobasen zustande. Im gepaarten Zustand liegt das Rückgrat des Hexamers in einer $\beta$-Faltblatt Konformation vor, während der Einzelstrang in einer zufällig ausgebildeten Anordnung vorliegt, so dass das „Schalten“ durch das Paaren bzw. Entpaaren ermöglicht wird. Im Rahmen dieser Arbeit werden die Stabiliesierungseigenschaft und die Ausbildung einer $\beta$-Faltblattstruktur der Alanyl-PNA Hexamere zu nutze gemacht. Ein Alanyl-PNA Hexamer (z.B. Alanyl-PNA Oligomer 2 in Abb. 2) wird als Teil einer $\beta$-Faltblattestruktur eines Peptids (z.B. Peptid 1 Abb. 2) bzw. Proteins eingebaut. Das Alanyl-PNA Oligomer wird als Doppelstrang oder bei einer "gestörten" $\beta$-Faltblattstruktur eines Peptids bzw. Proteins, als Alanyl-PNA Hexamer Einzelstrang, eingebaut. Durch den Einbau kommt es zum Einfluss bzw. zu einer Wechselwirkung der Alanyl-PNA und damit zu einer Schaltfunktionen durch Stabilisierung bzw. Destabilisierung der dreidimensionalen Struktur der Peptide bzw. Proteine. ${ }^{[4}$ a-g] 
Somit werden komplementäre Alanyl-PNA Oligomere als neue molekulare konformationellen „Schalter“ in der Peptidchemie eingeführt.

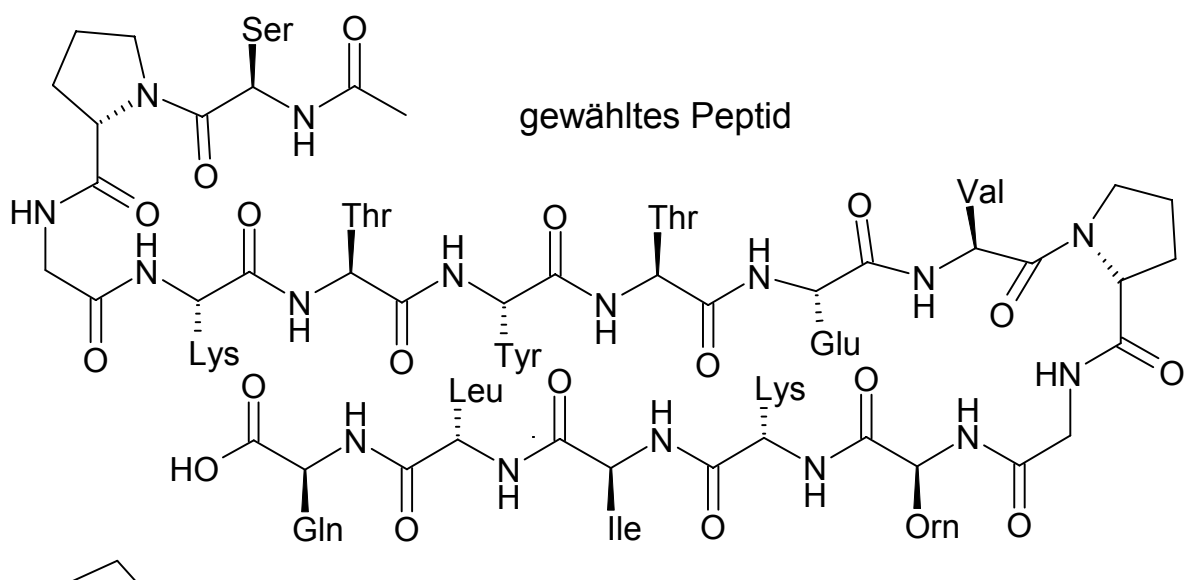

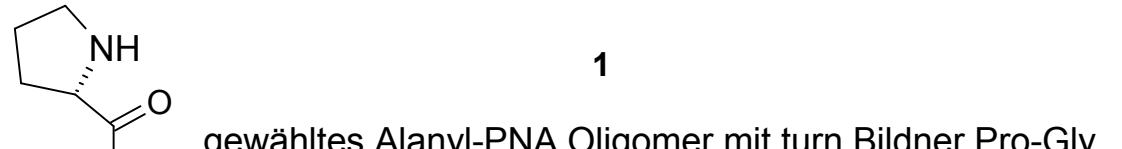<smiles>C[C@H](NC(=O)[C@H](C)NC(=O)[C@H](C)NC(=O)[C@H](C)NC(=O)[C@H](C)NC(=O)[C@H](C)NC(=O)[C@H](C)NC(=O)CN)C(N)=O</smiles>

2

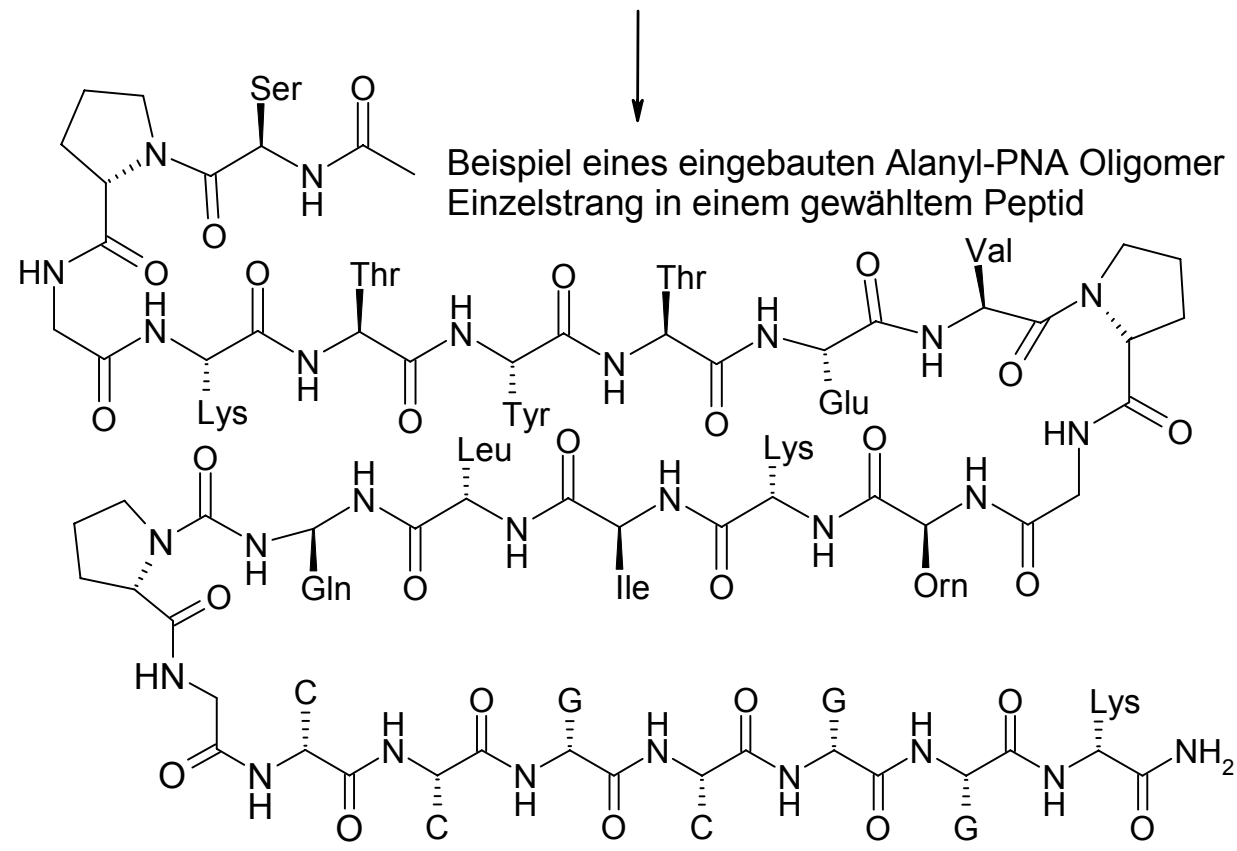

3

Abb. 2 Beispiel eines gewählten Alanyl-PNA Oligomers mit turn Bildner Pro-Gly 2, welches in ein $\beta$-Faltblatt Peptid 1 eingebaut wird und Einfluss ausüben kann ( $G=$ Guanin, $C=$ Cytosin). 
Als Protein wurde das menschliche Cytokin Interleukin 8 (hIL-8) und ein Peptid 1, welches Gellmann et al. NMR-spektroskopisch charakterisiert haben, verwendet. $^{[5]}$

Einen weiteren Teil dieser Arbeit stellte die Entwicklung der Synthese $\mathrm{N}$-methylierter Nucleobasen dar, welche in die Alanyl-PNA eingebaut werden sollten, um eventuell auftretende Rückgrataggregationen zu vermeiden. Ferner sollten NMR-spektroskopische Untersuchungen eines solchen AlanylPNA Doppelstranges und seines Paarungsverhaltens durchgeführt werden. Die biologische Aktivität $\mathrm{N}$-methylierter Peptide, sowie deren therapeutischer Nutzen werden von Fairlie et al. zurzeit maßgeblich diskutiert. ${ }^{[6 \text { a-d] }}$ So wird die $N$-Methylierung des Rückgrates von Peptiden in vielen Arbeiten vorgestellt und ist bei der Synthese aggregationsarmer Proteine und Peptide von großem Nutzen. ${ }^{[7 \text { a-e }]}$ Jedoch sind die Synthesewege mit Schwierigkeiten behaftet, die sich in geringen Ausbeuten, Racemisierung oder teuren Reagenzien wiederspiegeln. Im Rahmen dieser Arbeit sollte eine optimierte Synthese zur Darstellung $\mathrm{N}$-methylierter Nucleoaminosäuren und weiterer Aminosäuren entwickelt werden. 


\section{Grundlegende Aspekte}

\subsection{Peptide}

\subsubsection{Sekundärstrukturen/ $\beta$-Faltblatt ${ }^{[8 \mathrm{a}-\mathrm{c}]}$}

Die Funktion von Proteinen hängt im wesentlichem von ihrer dreidimensionalen Struktur und der Konformation innerhalb des Proteins ab. Die spezifische Erkennung unterschiedlicher Proteine oder derer Domänen würde einen erheblichen Fortschritt bedeuten. Hierbei sind Protein-Protein- bzw. Protein-DNA-Wechselwirkungen ein wesentliches Interessengebiet. Es steht zu hoffen, dass durch bessere Kenntnisse in diesem Bereich neue künstliche Erkennungseinheiten und Schalter entwickelt und diese auf molekularer Ebene kontrolliert werden können. Diese Schalter könnten dann als Werkzeuge bei der Untersuchung der Proteinfunktionen und ihrer Mechanismen fungieren. Weiterhin wären sie in der Interaktion zwischen Proteinen beispielsweise bei der Signaltransduktion einsetzbar.

Es ist bekannt, dass Konformationsübergänge, Faltungen und Fehlfaltungen von Proteinen und Peptiden bei der Entstehung neurodegenerativer Erkrankungen eine große Rolle spielen. ${ }^{[9]}$ Als Beispiel sei hier die Konformationsänderung in löslichen Amyloid- $\beta$-Vorstufen erwähnt, die zu einer aggregierten $\beta$-Faltblattstruktur führt und eine Schlüsselfunktion bei der Entstehung von zerebralen Ablagerungen hat und damit charakteristisch für die Alzheimer-Erkrankung ist. ${ }^{[10 \mathrm{a}-\mathrm{c}]}$ Oligo- und Polypeptide mit ausgeprägter Tendenz zur Ausbildung einer $\beta$-Faltblattstruktur neigen zu irreversibler Selbstaggregation. Dies geschieht aufgrund der engen Verknüpfung von Sekundärstruktur, Tertiärstruktur und den physikochemischen Eigenschaften dieser Peptide, wodurch eine Untersuchung dieser Peptide sehr aufwendig ist. ${ }^{[9]}$ Weiterhin ist die Stabilität der $\beta$-Faltblattstruktur, wie auch die der $\alpha$-Helices, abhängig von der Länge des Peptids. Ferner müssen bei der $\beta$-Faltblattstruktur zwei orthogonale „Dimensionen“ betrachtet werden, die zum einen entlang des Stranges verlaufen bzw. senkrecht darauf zeigen. Im Unterschied dazu ist bei den $\alpha$-Helices nur eine eindimensionale Betrachtung entlang der 
Achse von Bedeutung. ${ }^{[11]}$ Ein dritter wichtiger Faktor bei den $\beta$ Faltblattstrukturen sind deren turn Bildner. Es ist bekannt, dass D-Pro-Gly sowie Asn-Gly gerade für kleine Moleküle gute turn Bildner darstellen, wobei Asn-Gly der schwächere turn Bildner der beiden ist. ${ }^{[12 \mathrm{a}-\mathrm{c}, 13]} \mathrm{Um}$ die schwachen Interaktionen während einer Faltung zu betrachten, wurde ein $\beta$-hairpin (zwei anti-parallele Stränge, die mit einem reverse $\beta$-turn verknüpft sind) als einfaches System ausgewählt. 1998 stellte Searle et al. das Model eines $\beta$ Faltblattes aus 16 Aminosäuren vor. Die beiden $\beta$-Faltblatt-Sequenzen wurden mittels Asn-Gly verknüpft. Der Ans-Gly turn stellt den turn-Typ I' dar (Abb. 3). ${ }^{[14]}$

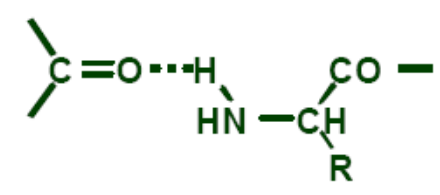

W assers toffb rücke

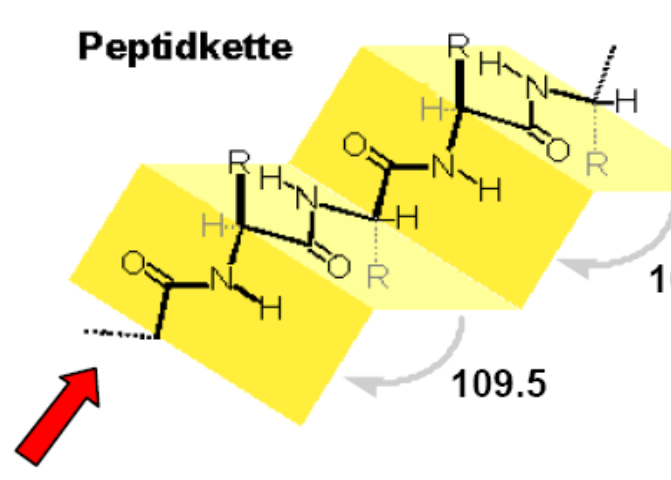

4 Amidbindungen

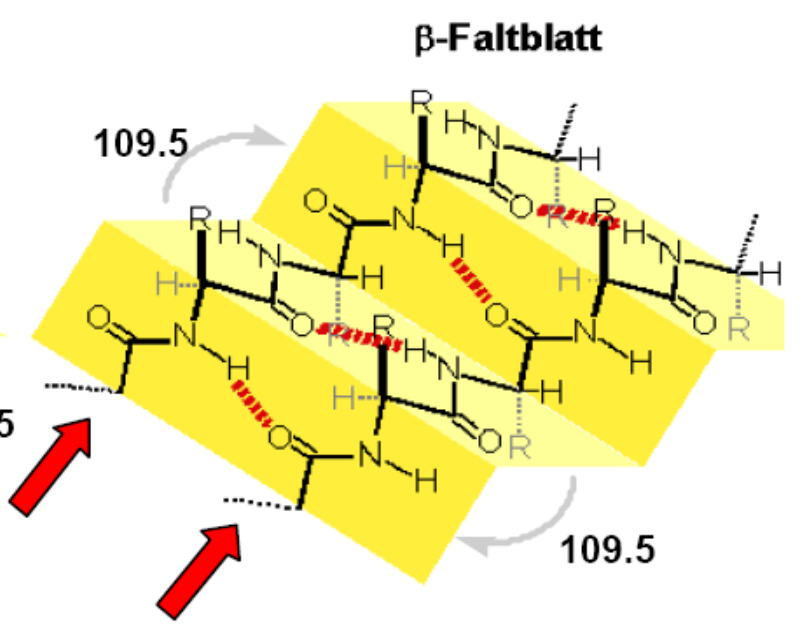

Abb. $3 \beta$-Faltblattstruktur von Proteinen, deren Winkel und Wasserstoffbrückenbindungen.

Die Sequenz von Polypeptiden hat einen maßgebenden Einfluss auf die Sekundär-, Tertiär- und ggf. Quartärstrukturen, da sich die Aminosäuren nur durch ihre Seitenkettenfunktionen (eine Ausnahme bildet Prolin) unterscheiden. Folglich können sich Modifizierungen der Aminosäureseitenketten, wie die Phosphorylierung, direkt auf die Struktur dieser Peptide auswirken. ${ }^{[15]}$ Die Modifizierungen stellen meist einen reversiblen Prozess dar, so dass die Natur ein sehr effizientes Werkzeug zur gezielten Beeinflussung 
der Struktur und damit letztlich der Funktion von Polypeptiden zur Verfügung hat.

\subsubsection{Am Rückgrat $N$-methylierte Peptide ${ }^{[16]}$}

Wie schon erwähnt ist die dreidimensionale Struktur von Polypeptiden im Wesentlichen von der Aminosäure Sequenz abhängig. Ferner wirken sich Modifikationen des Rückgrats auf die dreidimensionale Struktur aus. Es werden in der Natur sehr häufig lineare sowie helicale Peptide mit $\mathrm{N}$ methylieren Aminosäuren vorgefunden. ${ }^{[17]}$ Diese besitzen interessante biologische Aktivitäten, wie antifungale, anti-inflammatorische und immunsuppresive Eigenschaften. Als Beispiel soll das Cyclosporin aus dem fungus Beauveria nivea genannt werden. ${ }^{[18 \mathrm{a}, 18 \mathrm{~b}]}$ Die Synthese solcher Peptide ist mit Problemen verbunden, dass sich z.B. häufig Aggregate ausbilden oder es zu ungewollten Nebenreaktionen kommt, welche im Anschluss besprochen werden.

Säuren wie TFA, welche bei der Entschützung, sowie bei der Abspaltung vom Harz eingesetzt werden, fördern die Hydrolyse des $N$-methylierten Peptides 4. Außerdem wird unter sauren Bedingungen die Racemisierung begünstigt, da der methylierte Stickstoff deutlich basischer ist und die Tautomerisierung zum Oxazoloniumion 9 (Abb. 4), welches eine pseudo aromatische Struktur bildet, fördert. ${ }^{[19}$ a-d] Um solch eine Racmisierung zu vermeiden, kann der $\alpha$-Stickstoff durch Urethane geschützt werden. Es ist ebenso bekannt, dass die Acylierung eines Peptides am $\mathrm{N}$-Terminus den Prozess der Oxazoloniumionenbildung fördert. Bei der Synthese des Peptides nach 9-Fluorenylmethoxycarbonyl (Fmoc) Strategie kann auf Säure zur Entschützung verzichtet werden, zur Kupplung $\mathrm{N}$-methylierter Aminosäuren ist sie gegenüber der tert.- Butoxycarbonyl (Boc) Strategie zu bevorzugen. ${ }^{\text {[20 a-b] }}$ 

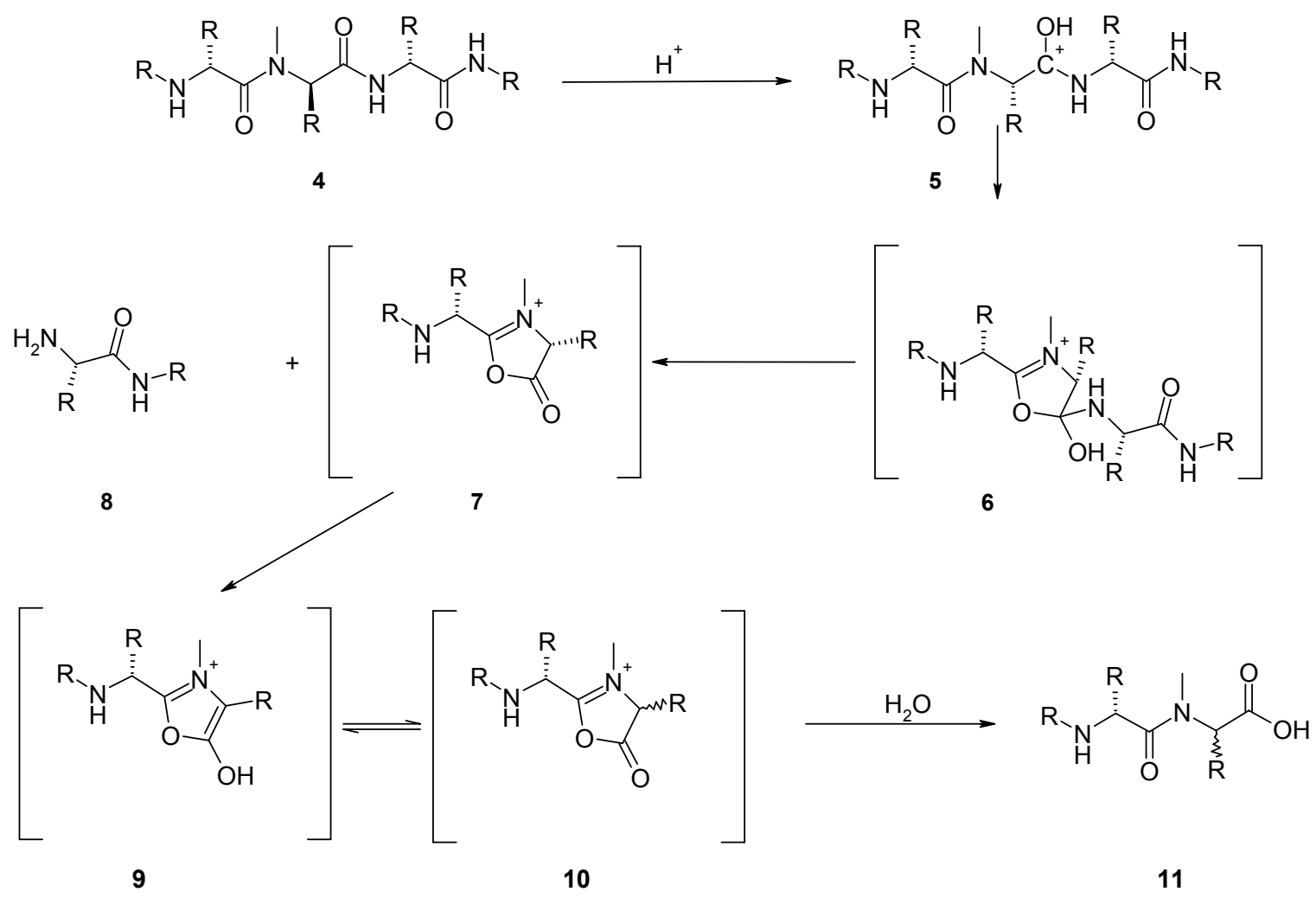

Abb. 4 Beschriebener Mechanismus der Hydrolyse von N-methylierten Peptidsequenzen. ${ }^{\text {20a] }}$

Für die Sekundärstruktur und die Eigenschaften von Peptiden und Proteinen spielt neben der Seitenkette auch das Rückgrat eine wesentliche Rolle. Durch den Austausch des Sauerstoffatoms am Carbonyl-Kohlenstoff der Peptidbindung durch Schwefel wird unter Bildung einer Thioxamidbindung eine höhere Stabilität generiert. Auch der Einbau einer $N$-methylierten Aminosäure kann Einfluss auf die Strukturbildung, z.B. als $\beta$-Faltblatt „Destabilisator“, haben. ${ }^{[21}$ a-b] Eine Rückgrataggregation kann auf diese Weise verhindert werden (Abb. 5). 
<smiles>[R]C(N)C(=O)NC([R])C(=O)NC([R2])C(=O)NC([R])C(=O)NC([R4])C(=O)NC([R5])C(N)=O</smiles><smiles>[R]C(N)C(=O)NC([R])C(=O)NC([R])C(=O)N(C)C([R])C(=O)NC([R4])C(=O)NC([R5])C(N)=O</smiles><smiles>[V]C1(I)CO1</smiles>

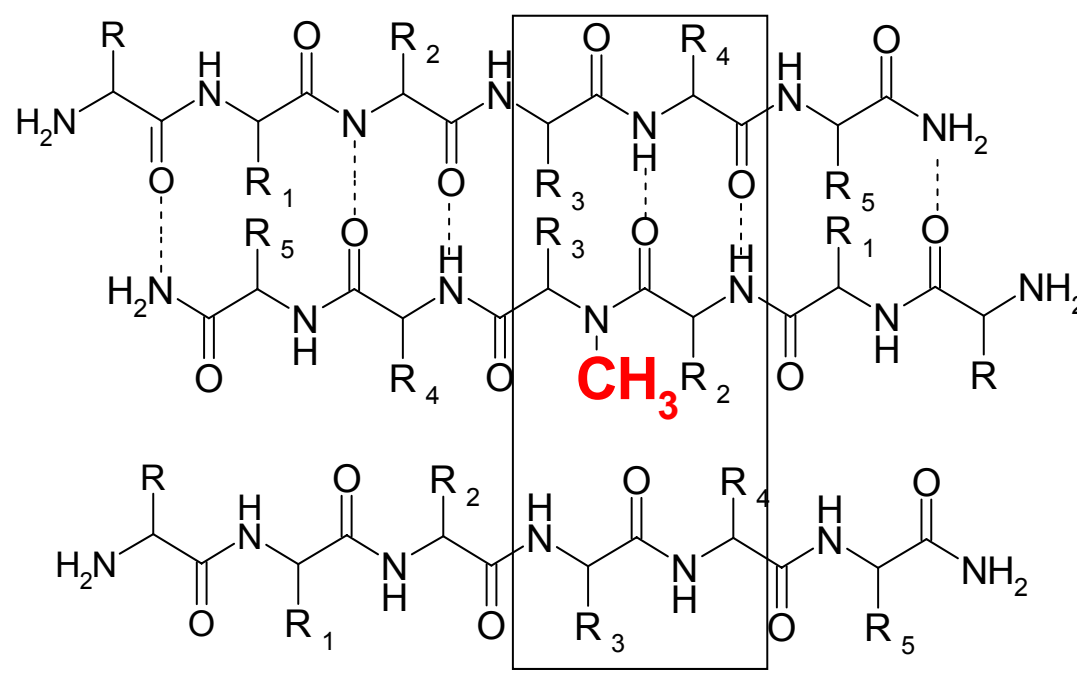

Abb. 5 Peptid mit $N$-metyliertem Rückgrat: $\beta$-Faltblatt Aggregation kann verhindert werden.

Dabei reicht nur eine $N$-alkylierte Stelle aus, um beispielsweise eine $\beta$-Faltblattstapelung zu umgehen. ${ }^{[22]}$

\subsubsection{Peptidnukleinsäuren (PNAs)}

Peptidnucleinsäuren (PNAs) wurden erstmals von einer dänischen Arbeitsgruppe um Buchardt, Nielsen, Egholm und Berg beschrieben. ${ }^{[23 \mathrm{a}-\mathrm{c}]}$ Es wurde mittels Computergestützten Designs eine auf Aminoethylglycineinheiten basierende PNA (Nielsen-PNA) 13 entwickelt, die eine effiziente Hybridisierung mit komplementären DNA und RNA-Strängen ausbildet. Die Aminoethylglycin-PNA hat sich als gutes DNA- und RNA-komplementäres 
System erwiesen, welches eine gute Bindungsaffinität aufweist. Jedoch besitzt Nielsen-PNA unter physiologischen Bedingungen eine schlechte Löslichkeit

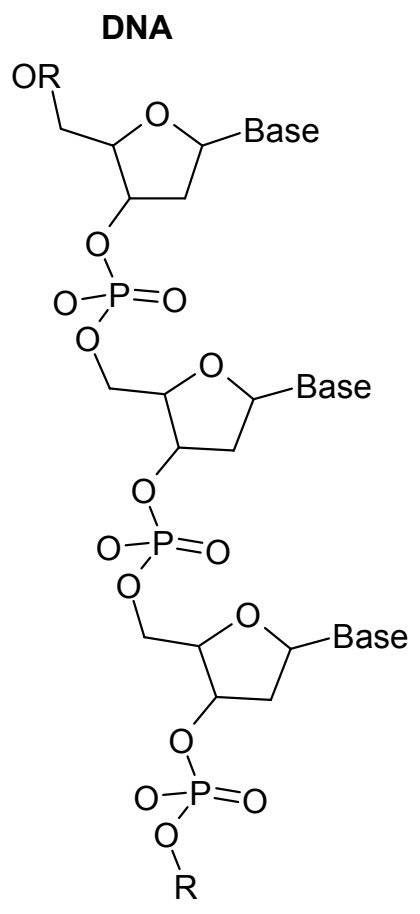

12
Aminoethylglycin-PNA

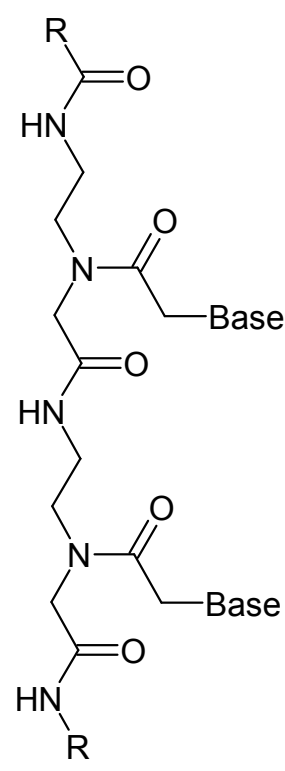

13

\section{Alanyl-PNA}

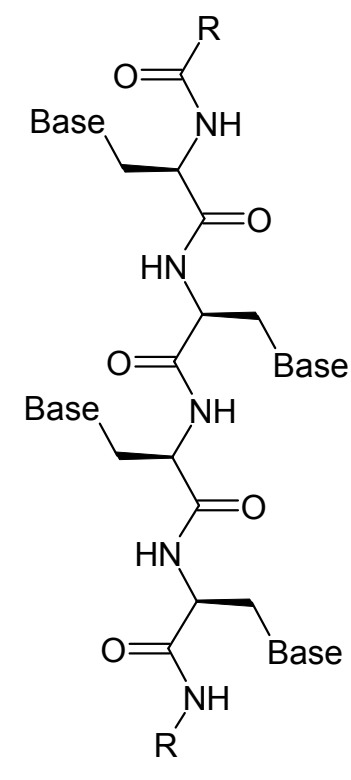

14

Abb. 6 Darstellung der DNA, Aminoethylglycin-PNA (Nielsen-PNA) und Alanyl-PNA.

Eine weitere Peptidnukleinsäure stellt die Alanyl-PNA 14 dar (Abb. 6). Die Alanyl-PNA bindet, obwohl die Isosteriekriterien erfüllt sind, nicht an DNA oder RNA. ${ }^{[24]}$ Die Nucleobasen sind über die $\beta$-Position des Alanins mit dem Peptidrückgrat alternierend verknüpft, wodurch sich alle Nucleobasen auf eine Seite orientieren (Abb. 7). Dies führt dazu, dass sich ein linearer Doppelstrang mit einem komplementären Oligomer ausbilden kann. Der Abstand der einzelnen Nucleobasen zueinander beträgt 3.6 $\AA$. Dieses entspricht in etwa dem idealen Basenabstand von $3.4 \AA$ einer B-DNA. Die Stabilisierung des Dopplestrangs und dessen hohe Rigidität beruht auf Wasserstoffbrückenbindungen, Dipol-Wechselwirkungen, Solvenseffekten und Stapelung der Nucleobasen. 


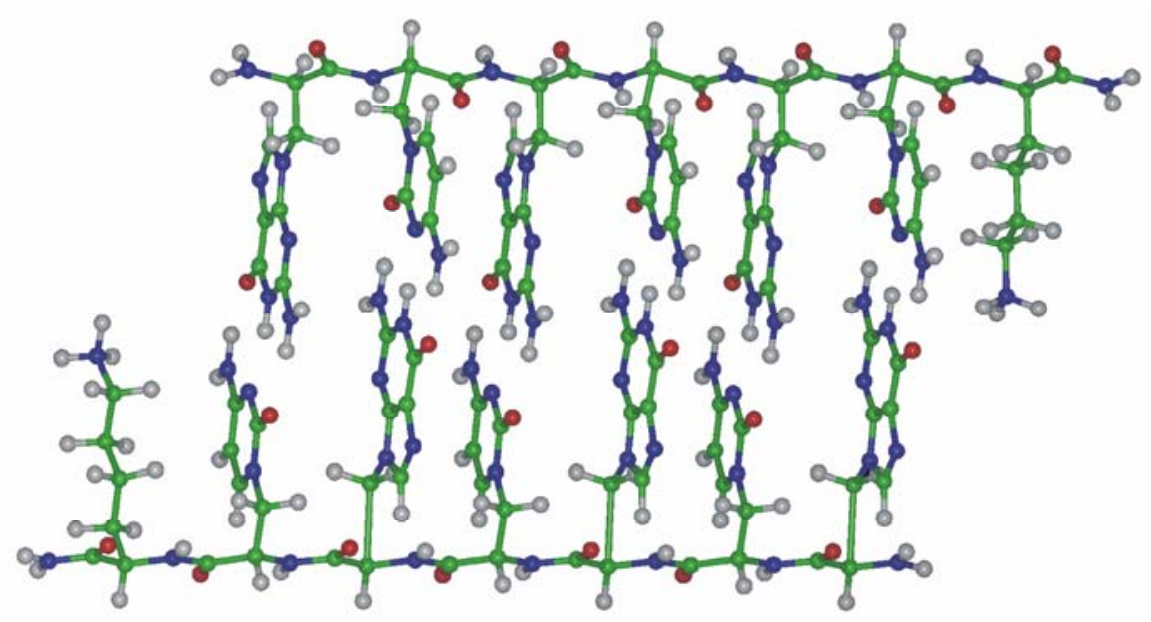

Abb. 7 Darstellung des linearen Doppelstranges der Alanyl-PNA ${ }^{[3 a-b]}$

Da die linearen Paarungskomplexe der Alanyl-PNA keinen topologischen Zwängen durch Helicität unterliegen, sind prinzipiell alle Orientierungen der Basenpaare erlaubt. Im Gegensatz zur DNA, welche aufgrund ihrer helicalen Topologie ausschließlich im Watson-Crick Paarungsmodus paaren kann. So sind, neben einer Watsen-Crick, reverse Watson-Crick auch noch eine Hoogsteen und reverse Hoogsteen Paarungen möglich (Abb. 8). ${ }^{[3 a-b, 25]}$<smiles></smiles>

Watson-Crick

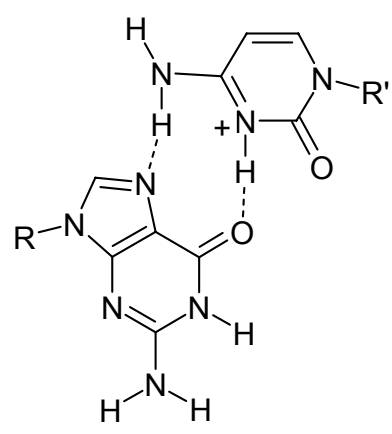

Hoogsteen<smiles></smiles>

reverse Watson-Crick

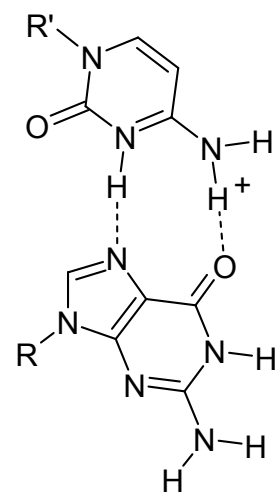

reverse Hoogsteen 
Abb. 8 Basenpaarungsmodi für ein GC Alanyl-PNA Basenpaar ( $G=$ Guanin, $C=$ Cytosin). Die Hoogsteen Basenpaarungen kommen nur im sauren Millieu vor.

Der jeweilige reverse Paarungsmodus wird durch eine Spiegelung einer der beiden Nucleobasen erhalten, wodurch die Ausrichtung der komplementären Nucleobasen und die relative Lage des Rückgrats zueinander geändert wird. Die Verteilung der Donor- bzw. Akzeptor-Funktionalitäten an den Nucleobasen und die Rückgrat-Topologie legen die Paarungsselektivitäten fest. Durch die Orientierung der paarenden Oligomere (parallel oder antiparallel) und die Konfiguration miteinander paarender Nucleoaminosäuren im Doppelstrang (homochiral oder heterochiral) wird der Paarungsmodus festgelegt. Die linearen, rigiden und stabielen Paarungskomplexeigenschaften der AlanylPNA Oligomere machen diese für Untersuchungen als Modell eines Nucleobasenstapels interessant. Durch Modifikationen der Alanyl-PNA Oligomere kann das Paarungsverhalten und damit die Wechselwirkungen bzw. die entstandenen Einflüsse Untersucht werden.

Die Sequenzen der Alanyl-PNA werden so gewählt, dass die Doppelstränge antiparallel orientiert sind. ${ }^{[3-b]}$ Die Bevorzugung der antiparallelen Orientierung beruht unter anderem auf der Abstoßung der positiv geladenen C-terminalen Lysine. Den Beitrag der verschiedenen Paarungsmodi an der Stabilität der Alanyl-PNA wird durch mehrere Oligomere unterschiedlicher Orientierungs-selektivität durch die UV-Schmelztemperatur $\mathrm{T}_{m}$ ermittelt. $^{[3 \mathrm{a}-\mathrm{b}, 4} 4 \mathrm{a}$ g] Die durch die UV-Schmelzkurven ermittelte Stabilitätsverhalten der zwei folgenden Oligomere H-AlaC-AlaC-AlaG-AlaC-AlaG-AlaG-Lys- $\mathrm{NH}_{2}(15)$ und $\mathrm{H}$ AlaC-AlaC-AlaG-AlaC-AlaG-AlaG-Lys- $\mathrm{NH}_{2}$ (16) zeigen eine zu erwartendes Ergebnis von $\mathrm{T}_{m}=58^{\circ} \mathrm{C}$. Die Selbstpaarung von 15 bzw. 16 kann nur im reverse Watson-Crick Modus verwirklicht werden. Die Schmelztemperaturen liegen erwartungsgemäß niedriger als bei dem Heterodimer. Die Alanyl-PNA 15 weist eine Schmelztemperatur von $T_{m}=41{ }^{\circ} \mathrm{C}$ und die Alanyl-PNA 16 eine von $\mathrm{T}_{m}=40^{\circ} \mathrm{C}$ auf. Die Enantiomerenpaarung nahm hingegen einen WatsonCrick Modus ein, wodurch die höhere Stabilität erklärt werden kann. ${ }^{[3 \text { a] }}$ Die Alanyl-PNA besteht, wie bereits erwähnt, aus einem regulären Peptid mit alternierenden konfiguierten Alanyl-Einheiten, deren Seitenketten kovalent mit 
Nucleobasen substituiert sind. Komplementäre Alanyl-PNA Hexamere bilden stabile lineare Doppelstränge basierend auf spezifischer NucleobasenErkennung aus. Da das Peptid-Rückgrat im Alanyl-PNA Duplex eine $\beta$-Faltblatt-Konformation einnimmt, hingegen im Einzelstrang als random coil vorliegt, kann von einem molekularen konformationeller "Schalter" in Bezug auf das Peptidrückgrat gesteuert werden. Dieser kann durch Paarung bzw. Entpaarung eingesetzt werden. 


\subsection{Ligationen}

Bei der Untersuchung von biologischen Systemen stellt sich Molekularbiologen und Chemikern immer wieder auf die Aufgabe, zwei molekulare Einheiten miteinander zu verknüpfen, etwa ein komplexes Kohlenhydrat mit einem Peptid, eine molekulare Sonde mit einem Biopolymer oder einfach zwei Peptide. ${ }^{[26]}$ Biologische Systeme sind nicht nur strukturell sehr komplex, sondern auch divers in ihrer funktionellen Reaktivität. Aus diesem Grund ist es von Interesse chemoselektive Ligationsreaktionen zu entwickeln, in denen selektiv zwei funktionelle Gruppen in einer wässrigen Umgebung zur Reaktion gebracht werden sollen. Diese ausgewählten funktionellen Gruppen müssen dabei nicht nur wechselseitig selektiv sein, sondern auch andere Funktionalitäten tolerieren. Auf diese Weise würde sich eine Schutzgruppenstrategie erübrigen, wodurch die Synthese um einige Reaktionsschritte verkürzt würde. Ein weiterer Vorteil der Ligationsmethoden ist, dass Peptide, die mittels SPPS eine Größe von maximal 40-50 Aminosäuren erreichen können, durch die entsprechenden Ligationen beliebig vergrößert werden können. ${ }^{[27]}$ So können via native chemical ligation (NCL) 100-150 bzw. bei der expressed protein ligation über 500 Aminosäuren aneinander gekuppelt werden. ${ }^{[2]}$ Die Mechanismen einiger bekannter Ligationsmethoden seien im Folgenden genannt.

Die native chemical ligation nach Kent et. al., ermöglicht die Kupplung zweier ungeschützter Peptidfragmente (gezeigt durch Peptid 1 und Peptid 2) (Abb. 10). ${ }^{[28 \text { a-e] }}$ Das Fragment 17, welches ein $N$-terminales Cystein enthält, wird mittels SPPS aufgebaut. Das zweite Fragment 18 trägt am C-Terminus einen Thioester. Durch die chemoselektive Reaktion und die irreversible S-NAcylverschiebung wird eine neue kovalente Bindung geknüpft. 


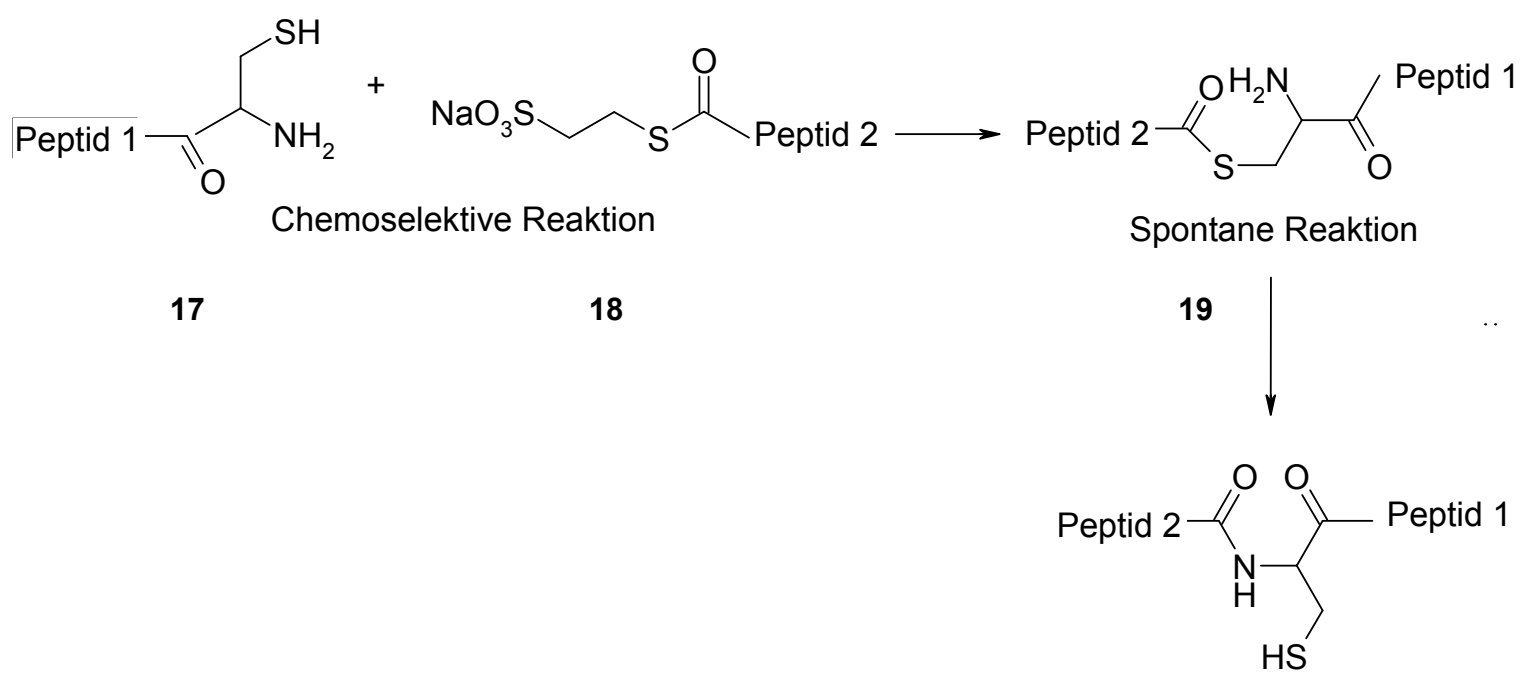

20

Abb. 9 Mechanismus der native chemical ligation von Kent. ${ }^{[29]}$

Ein viel versprechender Ansatz ist, die Kombination von biosynthetischen Methoden mit chemischen Reaktionen. Eine Möglichkeit wäre die chemische Synthese des Thioesters 18 und die Expression des an der Ligation beteiligten Peptides. Besteht die Notwendigkeit, die C-terminale Carboxylgruppe, eines Peptides in einem Thioester zu überführen, so kann auf die Strategie des Splicens zurückgegriffen werden. ${ }^{[30 \mathrm{a}-\mathrm{c}]}$ Proteine, welche einen intramolekularen Prozess des Splicens durchführen, weisen eine N-Extein-InteinC-Extein Sequenz auf. Beim Spliceprozess wird das Intein 23 aus dem System entfernt, so dass die Sequenzfolge N-Extein-C-Extein 22 im System verbleibt (Abb. 11). 
N-S-Acylwanderung
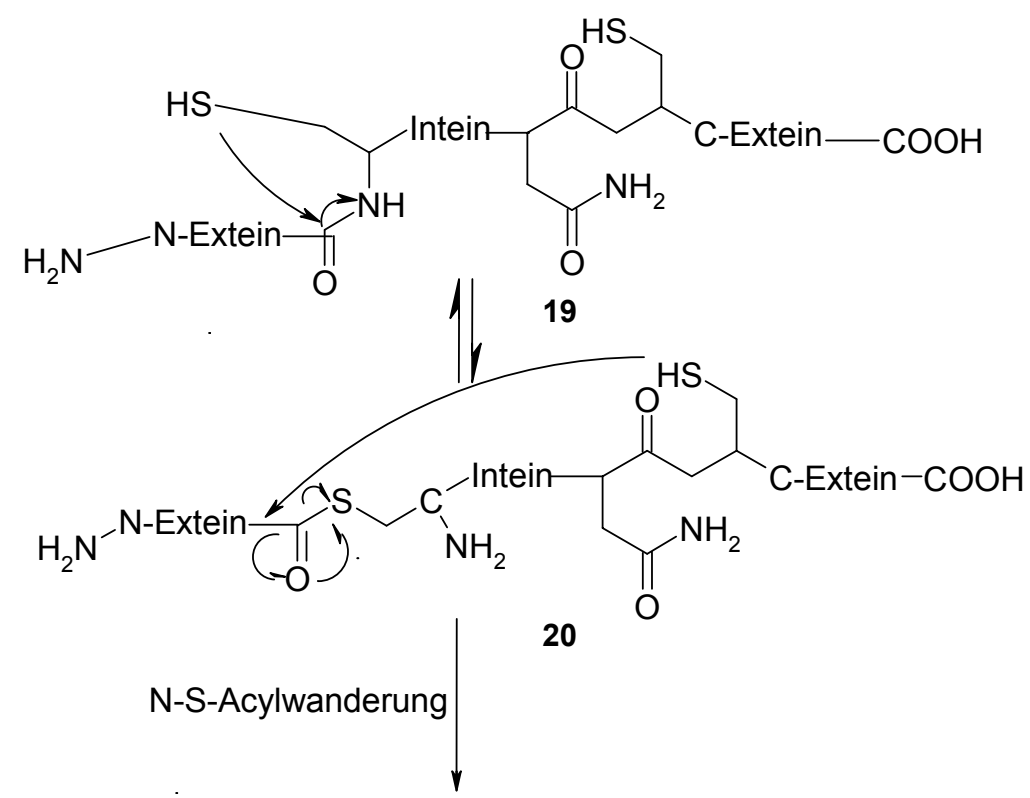

20

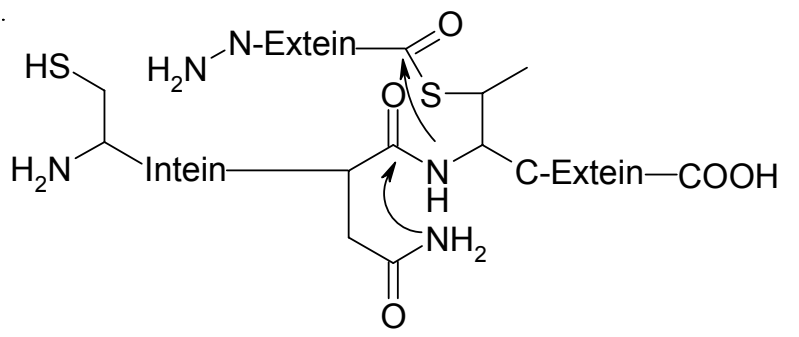

21

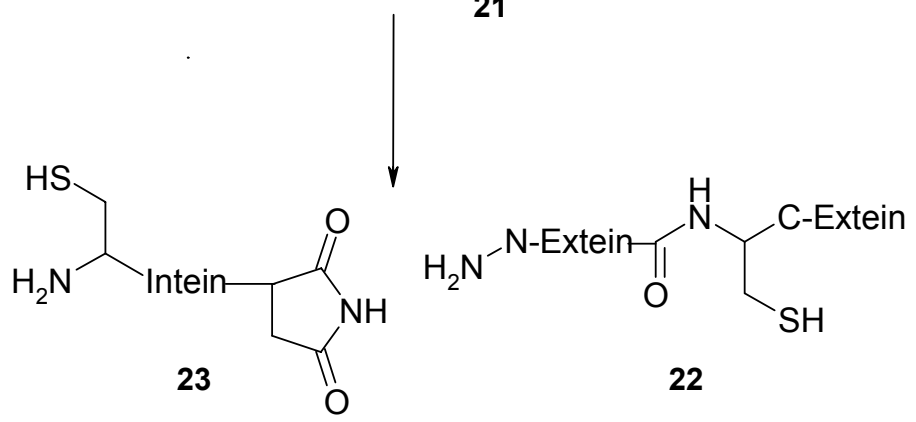

Abb. 10 Mechanismus des intramolekularen Splicens. ${ }^{[30 \mathrm{c}]}$

Setzt man bei diesem Prozess mutante Intein-Proteine ein, so stoppt der Prozess nach dem ersten Schritt. Das dabei entstandene Thioester verbrückte Protein kann mittels Thioreagenzien abgespalten werden. Es wird direkt das Thioester Produkt erhalten. ${ }^{[31]}$ Dieser Prozess wird allgemein als expressed protein ligation (EPL) bezeichnet und erlangte große Bedeutung. ${ }^{[32 \text { a-b] }}$ 
Die extendet chemical ligation beruht auf der Darstellung eines aus dem System entfernbaren $N^{\alpha}$-(1-Phenyl-2-mercaptoethyl)-Aminosäure-Derivates $\mathbf{2 8}$ (Abb. 11).<smiles>COc1ccc(C(=O)CBr)cc1</smiles>

24

25

26<smiles>COc1ccc(C(=O)CSCC2=C[C+]=C(C)C=C2)cc1</smiles>

26<smiles>CCOC(=O)C(N)C(C)C</smiles>

27
28

Abb. 11 Synthese eines $N^{\alpha}$-(1-Phenyl-2-mercaptoethyl) Valin Derivates 28. ${ }^{[33]}$

Diese Ligationsmethode bietet den Vorteil, dass kein Cystein in der Sequenz vorhanden sein, bzw. dass kein zusätzliches Cystein eingebaut werden muss. Botti et al. haben die $N^{\alpha}$-Auxiliary-Derivate Glycin und Alanin mittels reduktiver Aminierung dargestellt. Es wurden verschiedene Methoden, wie Kupplung ohne Schutzgruppen mit säure-/basenlabiler Schützung oder Schützung durch ein Thiazolidin-Derivat getestet (Abb. 11, 12). ${ }^{[3]}$<smiles>[R3]SC[C@H](c1ccc(OC)cc1)N(C([R])=O)[C@@H](CS[R3])c1ccc(OC)cc1</smiles>

32

Abb. $12 N^{\alpha}$-(1-Phenyl-2-mercaptoethyl)-Aminosäure-Derivat zur $E C L . \mathrm{R}_{1}=\mathrm{H}$ oder Schutzgruppe, $\mathrm{R}_{2}=$ Aminosäure mit Seitenkette, $R_{3}=$ Schwefel Schutzgruppe, $R_{4}=A l k y l g r u p p e, P_{1}$ und $P_{2}=$ Peptide. ${ }^{[33]}$ 
Bordusa et al. beschäftigt sich mit der Substratmimetika vermittelten Peptidsynthese, welche eine Strategie zur spezifitätsunabhängigen, irreversiblen Ligation darstellt. Diese Methode der enzymatischen Ligation bietet Vorteile zum einen durch die Tatsache, dass es nicht möglich ist, die Racemisierung bei chemischen Peptidsynthesen gänzlich zu unterdrücken, zum anderen ist der experimentelle Aufwand bei reversibler Schützung von Drittfunktionen der zu verknüpfenden Aminosäurebausteine sehr hoch. ${ }^{[34]}$ Bereits 1991 wurde über die Anwendung von Acylaminosäure-4-guanidinophenylester (33) (Abb. 13) für Trypsin katalysierte Peptidsynthesen berichtet.

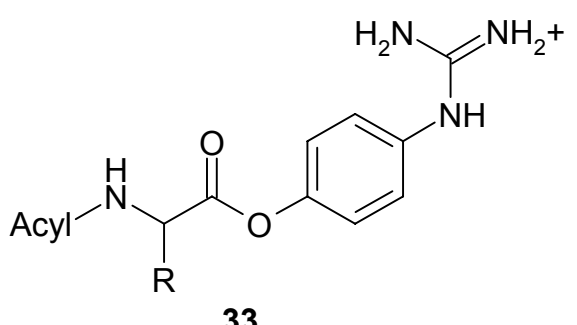

Abb. 13 Acylaminosäure-4-guanidinophenylester (33). ${ }^{[35]}$

Bei dieser Methode, wird das kationische Zentrum der 4-Guanidinophenylester(OGp)-Einheit in das aktive Zentrum von Trypsin gleichsam als Mimetikum für trypsinspezifische Aminosäureseitenketten wie Argenin oder Lysin eingepasst und somit irreversibel eine Peptidbindung dargestellt. ${ }^{[36}$ a-b] 


\subsection{Humanes Interleukin-8 Derivat (hIL-8)}

Das Immunsystem verwendet eine Reihe verschiedener Rezeptoren, um Pathogene zu erkennen und darauf zu reagieren. Die Rezeptoren, die Oberflächen von Bakterien direkt erkennen, binden häufig an Wiederholungsmuster, wie Kohlenhydrat- und Lipidgruppen, die für mikrobielle Oberflächen charakteristisch sind, aber nicht in der Körperzelle vorkommen. ${ }^{[37]}$ Die Rezeptoren, die Krankheitserreger erkennen, besitzen auch eine wichtige Funktion bei der Signalübertragung für die induzierten Antworten, die für lokale Entzündungen verantwortlich sind, bei der Mobilisierung neuer Effektorzellen, der Eindämmung von lokalen Infektionen und beim Auslösen von adaptiven Immunantworten. Die Übertragung solcher Signale kann durch eine Familie von signalgebenden Rezeptoren erfolgen, die als Toll-Rezeptoren bezeichnet werden und welche unter anderem eine Reihe von Genen aktivieren, darunter auch Gene des Cytokins, die bei der Steuerung der adaptiven Immunantwort von entscheidender Bedeutung sind. ${ }^{[38]}$ Die angeborene Immunität beruht unter anderem auf Cytokinen. Cytokine sind kleine Proteine, die im Körper von verschiedenen Zellen freigesetzt werden und durch Bindung an spezifischen Rezeptoren Reaktionen auslösen. Chemokine sind eine Klasse von Cytokinen mit der Eigenschaft von Chemoattraktoren, die Zellen veranlassen können, zur Quelle der Chemokine zu wandern (z.B. IL (Interleukin)-8). ${ }^{\text {[9 a-b] }}$

Das menschliche Interleukin 8 (hIL-8) (Abb. 14) (hier 77 Aminosäuren) stellt ein chemotaktisches Cytokin dar, welches neutrophile Aktivität aufweist. Es spielt eine wesentliche Rolle in der Pathogenese einer großen Anzahl verschiedener inflammatorischer Krankheiten. IL-8 war das erste Chemokin, das kloniert und charakterisiert wurde. Dieses Cytokin gehört zu der Gruppe der CXC Chemokine, bei denen strukturell zwei Cysteine durch eine andere Aminosäure getrennt sind. ${ }^{[39 \mathrm{a}]}$ Es entsteht nach der Abspaltung als ein prescursor aus 99 Aminosäuren. Die bekannteste Struktur besteht aus 72 Aminosäuren und beinhaltet vier Cysteine die zwei Disulfidbrücken bilden. ${ }^{[40]}$ 


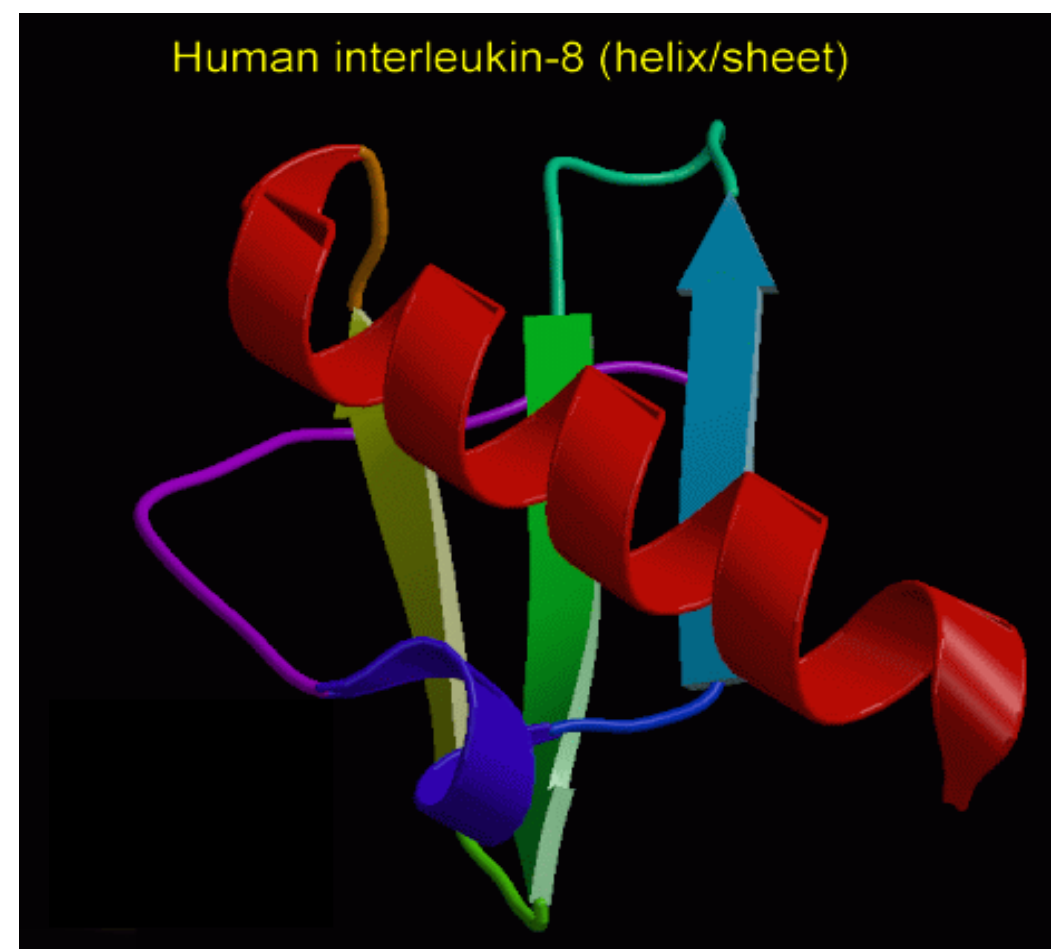

Abb. 14 Struktur des humanen Interleukin-8 (hIL-8).

Das humane Interleukin-8 (hIL-8) ist gegenüber Hitze, extremen pH-Werten, Peptidasen und Denaturierung stabil. Es besteht aus drei antiparallelen $\beta$-Faltblatt Strängen und einer $\alpha$-Helix (von Aminosäure 56 beginnend), welche durch loops miteinander verbunden sind. 


\section{Synthese von Nucleoaminosäuren}

\subsection{Synthese der Monomerbausteine}

Die Nucleoaminosäuren Boc-AlaC-OH (39), Boc-AlaT-OH (38), Boc-AlaA-OH (40) und Boc-AlaG-OH (37) wurden ausgehend von Serin (Ser) in hoher Ausbeute und hoher Enantiomerenreinheit nach $P$. Lohse synthetisiert (Abb. 15). ${ }^{[41 \text { a-b] }}$ Im ersten Schritt wird N-Boc-L-Serinlacton 35 sowie das entsprechende D-Enantiomer aus den entsprechenden von enantiomerenreinen N-Boc-L-Serin 34 bzw. dem entsprechenden DEnantiomer unter Mitsunobu-Bedingungen dargestellt. ${ }^{[42]}$ Die Ausbeute beträgt in beiden Fällen 54 \%. Die Ringöffnung erfolgt durch einen nucleophilen Angriff der Nucleobasen. Hierbei wird die Vorschrift von Lohse auf die Nucleobase Guanin und Cytosin übertragen und angepasst. Die Guaninsubstituerte Aminosäure wird über einen längeren Reaktionsweg analog zu Weicherding (Abb. 15) dargestellt, da die Nucleophilie des Guanins für eine Ringöffnung nicht ausreicht. ${ }^{[4]}$ Die Darstellung der Cytosin-Alanyl- (BocAlaC $\left.^{Z}-\mathrm{OH}\right) 39$ und der Thymin-Alanyl-Nucleaminosäuren gelang analog durch eine nucleophile Ringöffnung mit der entsprechenden Nucleobase, sowie mit DBU als Base. Bei der Verwendung von Adenin als Nucleophil wird $\mathrm{K}_{2} \mathrm{CO}_{3}$ als Base verwendet. Zur Darstellung der Guanin-substituierten Aminosäure wird 2-Amino-6-chlorpurin verwendet. Die Verwendung des geschützten Cytosins beruhte einerseits auf der besseren Löslichkeit und der resultierenden höheren Ausbeute die bei $74 \%$ lag; und andererseits ist eine geschützte exozyklische Aminofunktion in der nachfolgenden Festphasensynthese von erheblichem Vorteil, da sie so keine störenden Nebenreaktionen eingehen kann. Die nach Lohse und Weicherding synthetisierten Aminosäuren wurden in Ausbeuten von $74 \%$ für Boc-AlaC-OH (39), 86 \% für Boc-AlaT-OH (38), $31 \%$ für Boc-AlaA-OH (40) und 92 \% Boc-AlaG-OH (37) erhalten (Abb. 15). 


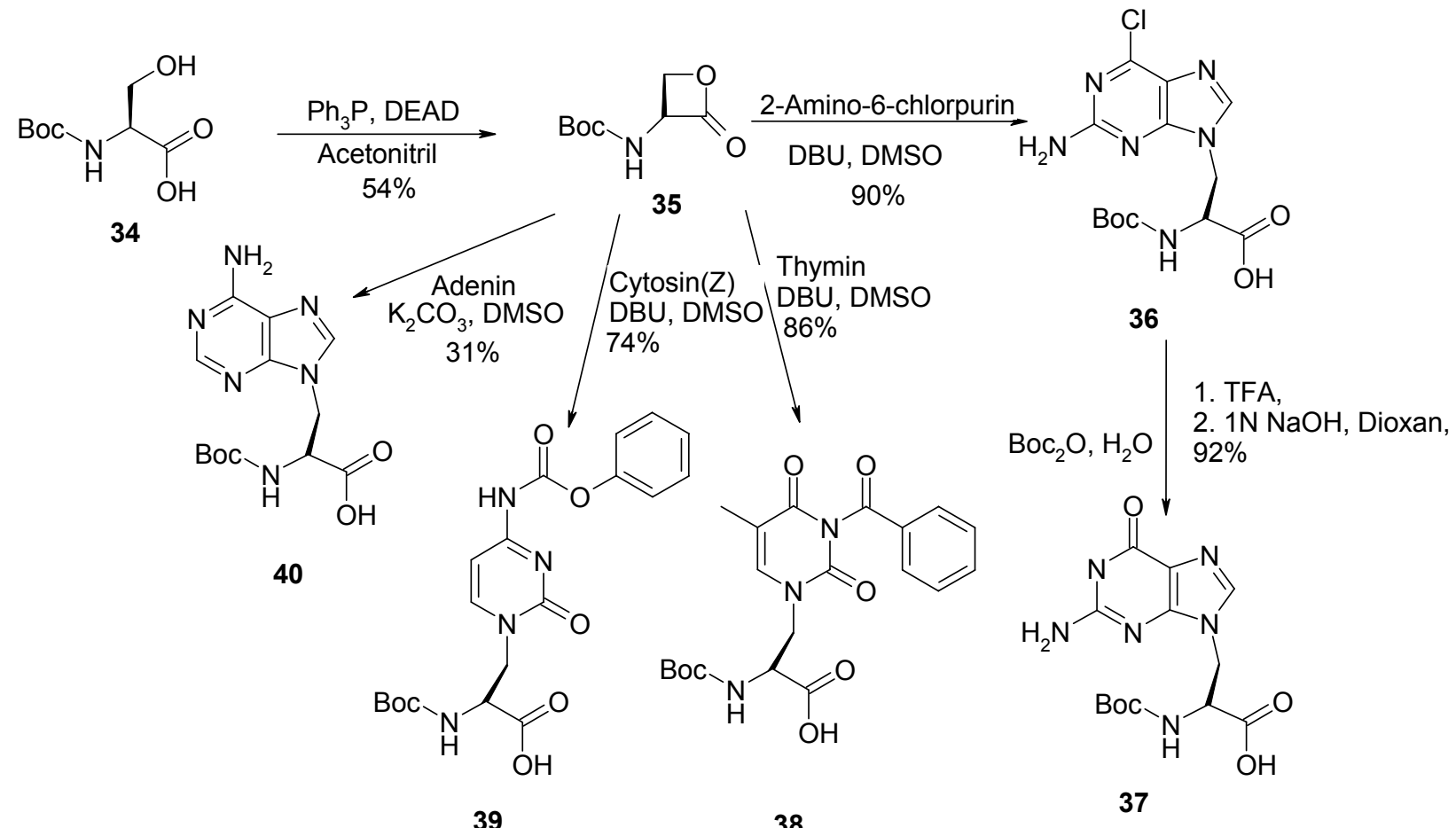

Abb. 15 Synthese der Alanyl-Aminosäuren 37-40. 


\subsection{Synthese $\mathbf{N}$-methylierter Nucleoaminosäuren ${ }^{[43}$ a-c]}

Die Synthese $N$-methylierten Nucleoaminosäuren wurde in Analogie zur Synthese entsprechender Alanyl-PNA Monomerbausteine entwickelt (Abb.

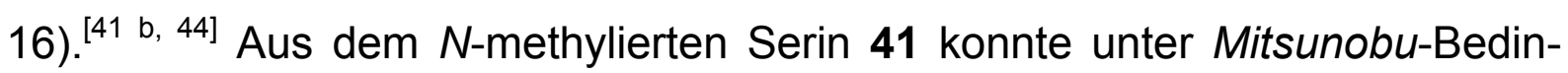
gungen das entsprechende $N$-methylierte Serinlacton (42) in sehr guter Ausbeute von 74 \% gewonnen werden. Die Ringöffnung erfolgte durch nucleophilen Angriff der Nucleobasen. Als Basen wurde DBU und $\mathrm{K}_{2} \mathrm{CO}_{3}$ eingesetzt. Es wurden Ausbeuten von Boc-(Me)AlaC-OH 46 (62\%) und Boc-(Me)AlaT-OH $44(31 \%)$ erreicht. Bei der Ringöffnung mit Adenin wurde $\mathrm{K}_{2} \mathrm{CO}_{3}$ als Base verwendet und eine Ausbeute von Boc-(Me)AlaA-OH (36\%) erlangt. Die geringe Ausbeute von 44 mit $31 \%$ ließ sich auf den ersten Versuch zurückführen, wo es sich um das Testen der Reaktion handelte und die nicht weiter optimiert wurde. Folgereaktionen wurden nicht benötigt. Die Ausbeute der $\mathrm{N}$-methylierten Nucleoaminosäure 46 ließ sich durch die geringe Nukleophilie des Adenins erklären. Schon die Ausbeute der nicht AlanylNucleoaminosäure $\mathbf{4 0}$ war gering.<smiles>CN(C(=O)OC(C)(C)C)C(CO)C(=O)O</smiles>

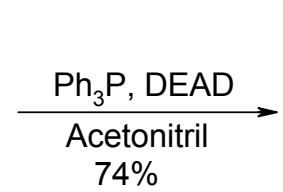

41

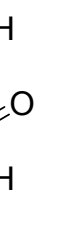<smiles>CN(C(=O)O)C(Cn1cnc2c(N)ncnc21)C(=O)O</smiles>

46<smiles>CN(C(=O)OCc1ccccc1)C1COC1=O</smiles>

42

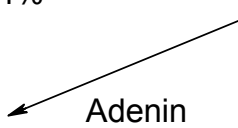
$\mathrm{K}_{2} \mathrm{CO}_{3}$, DMSO $36 \%$

a. 2-Amino-6-chlorpurin $\mathrm{DBU}, \mathrm{DMSO}$

b. 1. TFA

2. $1 \mathrm{~N} \mathrm{NaOH}$, Dioxan, $79 \%$

Benzylcarbonyl-

Thymin

DBU, DMSO

$31 \%$<smiles>C=CN1CCCN(C)C(C(=O)O)C1</smiles>

45<smiles>CN(C(=O)OC(C)(C)C)C(Cn1cnc2c(=O)[nH]c(N)nc21)C(=O)O</smiles>

43

. 
Bei der Reaktion von Guanin 47 mit (S)-N-Butoxycarbonyl- $N$-methyl-Lserinlacton 42 wurde kein Umsatz beobachtet, da Guanin zu schlecht löslich war und auch die verbesserte Elektrophilie des Lactonrings die geringe Nucleophilie des Guanins nicht ausgleichen konnte.

Es wurden sowohl DBU als auch $\mathrm{K}_{2} \mathrm{CO}_{3}$ als Base verwendet, sowie die Temperatur auf $40^{\circ} \mathrm{C} / 50^{\circ} \mathrm{C}$ und $60^{\circ} \mathrm{C}$ variiert. Die Reaktionszeit wurde jeweils bis maximal $3 \mathrm{~d}$ verlängert. Die Reaktion wurde analog zu Abbildung 16 mit einem 2-Amino-6-chlorpurin durchgeführt und führte zu einer Ausbeute von $79 \%$ nach Schritt b (Abb. 16).

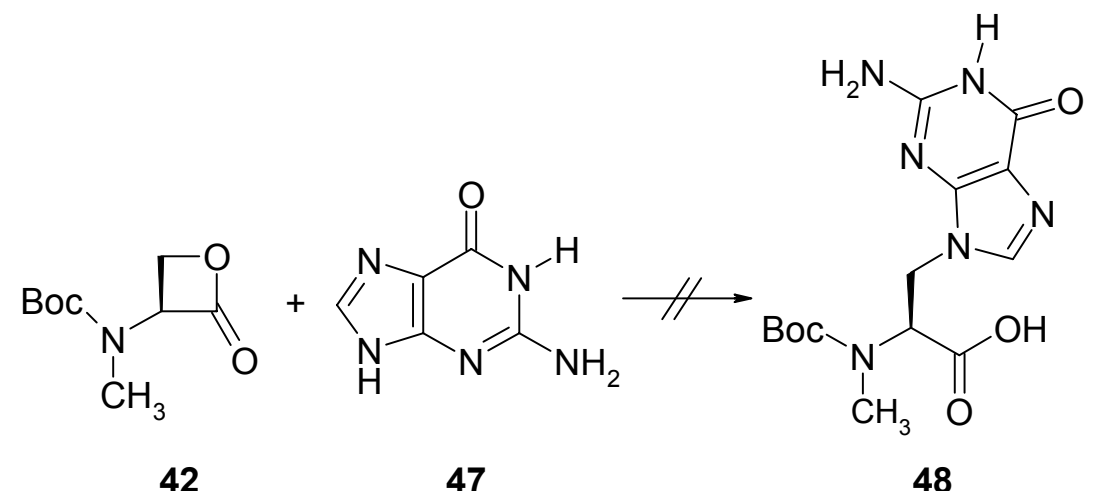

42

47

Abb. 17 Umsetzungsversuch von Guanin 47 mit (S)-N-Butoxycarbonyl- $N$-methyl-L-serinlacton 42.

Neben Guanin wurde die Synthese ebenfalls mit 7-Carbaguanin 51 durchgeführt, da hier die Hoogsteen Seite blockiert ist und nur Wasserstoffbrückenbindungen über die Watson-Crick Seite möglich sind. Somit sollte ein maximaler Aggregationsschutz in dem Oligomer vorhanden sein. Die Nucleobase wurde nach der Vorschrift von Kerwin et al., über eine Eintopfreaktion dargestellt. ${ }^{[45]}$ Hierbei wurden 2,6-Diamino-6-hydroxypyridinin 49 mit $\alpha$-Chloroacetaldehyd $\mathbf{5 0}$ in DMF umgesetzt (Abb. 18). Das Reaktionsende wurde nach $12 \mathrm{~h}$ Rühren bei Raumtemperatur mit einer Ausbeute von $75 \%$ erreicht. 
<smiles>Nc1cc(O)nc(N)n1</smiles>

49

50

51

Abb. 18 Synthese des 7-Carbaguanins 51.

Das Produkt 51 wurde mit (S)-N-Butoxycarbonyl- $N$-methyl-L-serinlacton 42 umgesetzt (Abb. 19). Es wurde $\mathrm{K}_{2} \mathrm{CO}_{3}$ als Base verwendet, jedoch kein Produkt gefunden. Es kam nicht zur gewünschten Ringöffnung. Es wurde ebenso die Base DBU verwendet. das gewünschte Produkt entstand. Es konnten mittels ESI-MS ermittelt werden. Das Produkt konnte trotz Variationen des Laufmittels nicht chromatographisch getrennt werden. Weiterhin wurden bei dem Umsetzungsversuch die Temperaturen zwischen $35-60{ }^{\circ} \mathrm{C}$ und die Reaktionszeiten zwischen $12 \mathrm{~h}-3 \mathrm{~d}$ variiert, was jedoch nicht zur Verbesserung führte.<smiles>CN(C(=O)OC(C)(C)C)C(Cn1ccc2c1N=C(N)NN(C(C(=O)O)C(=O)O)C2=O)C(=O)O</smiles>

Abb. 19 Umsetzungsversuch zur Carbaguaninnucleoaminosäure 52.

7-Deazaguanin $\mathbf{5 1}$ wurde zur Verbesserung der Löslichkeit und Nucleophilie in das chlorierte Purin 53 nach Seela und Mitarbeiter mittels TEBA und $\mathrm{POCl}_{3}$ umgewandelt (Abb. 20). ${ }^{[46}$ a-b] 


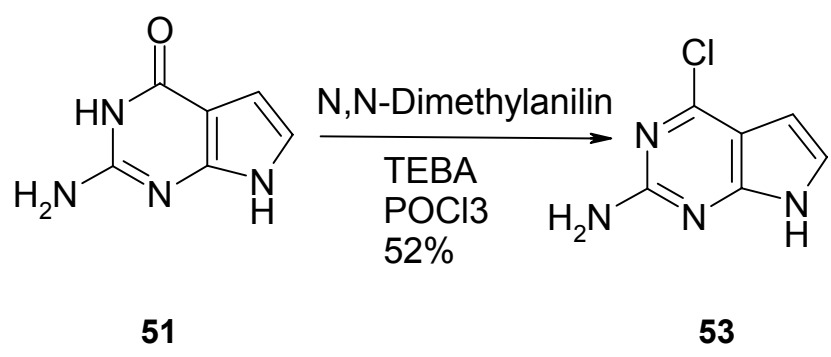

Abb. 20 Umwandlung von 7-Carbaguanin zu 2-Amino-7-carba-6-chlorpurin (53).

Das Produkt der Umwandlung wurde nach Filtration in einer Ausbeute von $52 \%$ erhalten. Das lichtempfindliche 2-Amino-7-carba-6-chlorpurin (53) erforderte ein Vorgehen unter Lichtauschluß. Die Verwendung von DBU bot sich auf Grund der guten Nucleophilie des Purinanalogons 2-Amino-6chlorpurin an. ${ }^{[47]}$ Neben dem gewünschten nucleophilen Angriff an der $\beta$-Position des Lactons bestand die Möglichkeit der Ringöffnung am CarbonylC-Atom, was sicherlich eine bedeutende Nebenreaktion sein sollte. Da die Reaktion unter Schutzgasatmosphäre und Feuchtigkeitsausschluss stattfand, ließ sich eine Zersetzung der Edukte ausschließen. Unter Einsatz von Kaliumcarbonat oder DBU als Base, temperieren auf $40-60^{\circ} \mathrm{C}$ und Verlängerung der Reaktionszeiten auf jeweils $12 \mathrm{~h}$ fand keine Reaktion statt (Abb. 23).<smiles>C=C(C)Cc1cc2c(Cl)nc(N)nc2[nH]1</smiles> 


\subsection{Synthese von $\mathbf{N}$-methylierten und Seitenketten-geschützten} Aminosäuren ${ }^{[48 \mathrm{a}-c]}$

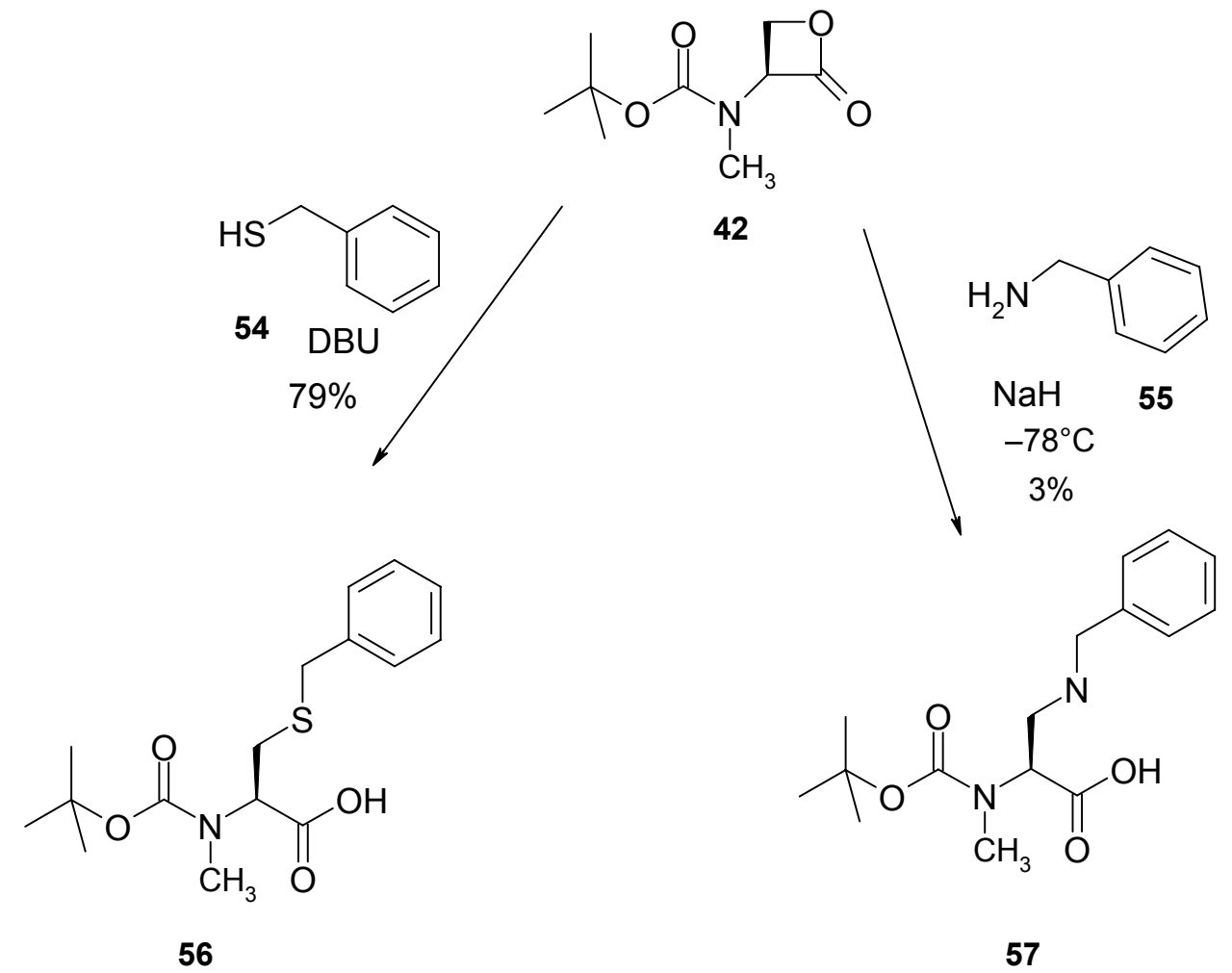

Abb. 22 Synthese der N-methylierten Aminosäuren 56-57.

Die Synthese des N-methylierten Cystein Derivats (Boc-(Me)Cys(Bzl)-OH) 56 erfolgte nach der gleichen Strategie wie die Synthese der $\mathrm{N}$-methylierten Nucleoaminosäuren. Als Base konnte hier DBU verwendet werden, wobei die alkylierte Aminosäure in einer Ausbeute von $79 \%$ erhalten wurde. Weitere Versuche mit Nucleophilen wie Benzylamin 55 und $\mathrm{N}, \mathrm{N}$-Dibenzylhydroxylamin funktionierten nicht so gut. ${ }^{[49 \text { a-c }]}$ Variationen der Synthesebedingungen bei der Umsetzung von Benzylamin mit $\mathrm{N}$-methylierten Serinlacton mit $\mathrm{NaH}$ als Base bei einer Temperatur von $-78{ }^{\circ} \mathrm{C}$ wurden durchgeführt. Das Produkt wurde in einer Ausbeute von $3 \%$ erhalten und konnte massenspektrometrisch und NMR-spektroskopisch nachgewiesen werden. ${ }^{[50 \mathrm{a}-\mathrm{c}]}$ 


\section{Alanyl-PNA Doppelstränge mit Basenfehlstellen und deren Stabilität $\left(T_{m}\right)$}

\subsection{Basenfehlstellen in der Sequenz der Alanyl-PNA Oligomere}

Der gut definierte Basenstapel der Alanyl-PNA Hexamer Doppelstränge (Kapitell 1.1) sollte mittels NMR-Spektroskopie einer Strukturaufklärung unterzogen werden. Dieses stellte sich jedoch als problematisch heraus, da die Oligomere im Gegensatz zum mikromolaren Bereich im millimolaren Bereich vermutlich aufgrund von Aggregationen nur sehr schwer löslich waren. Die Selbstpaarung des Oligomers H-Lys-AlaC-AlaC-AlaG-AlaC-AlaG-AlaGLys- $\mathrm{OH} 58$ wurde im wässrigen Medium, in einem $\mathrm{D}_{2} \mathrm{O}$ Shigemi-Röhrchen NMR-spektroskopisch untersucht (Abb. 23). Dazu wurden $3 \mathrm{~mm}$ des Oligomers 58 in $200 \mu \mathrm{L} \mathrm{D}_{2} \mathrm{O} / \mathrm{H}_{2} \mathrm{O}(1: 9)$, welches $100 \mathrm{mM} \mathrm{NaCl}$ und $10 \mathrm{~mm}$ Phosphat Puffer $(\mathrm{pH}=7)$ enthielt, vermessen. Die Messungen wurden an einem $D R X 600 \mathrm{MHz}$ und $D R X 800 \mathrm{MHz}$ Bruker Spektrometer durchgeführt. Es wurde eine WATERGATE oder/und jump and return Pulssequenz/Versuch verwendet. Vor Beginn der Messung wurde die Probe einem annealing unterworfen und anschließend $18 \mathrm{~h}$ bei $4^{\circ} \mathrm{C}$ gelagert. Das aufgenommene Spektrum wies schwache charakteristische Imino-Protonen Signale im Bereich der Watson-Crick Paarung bei $288 \mathrm{~K}$ auf. Die Signale erlitten einen Intensitätsverlust bei Erniedrigen der Temperatur. Jedoch zeigte sich eine Verbreiterung anderer Signale, was auf Aggregation hinwies. 


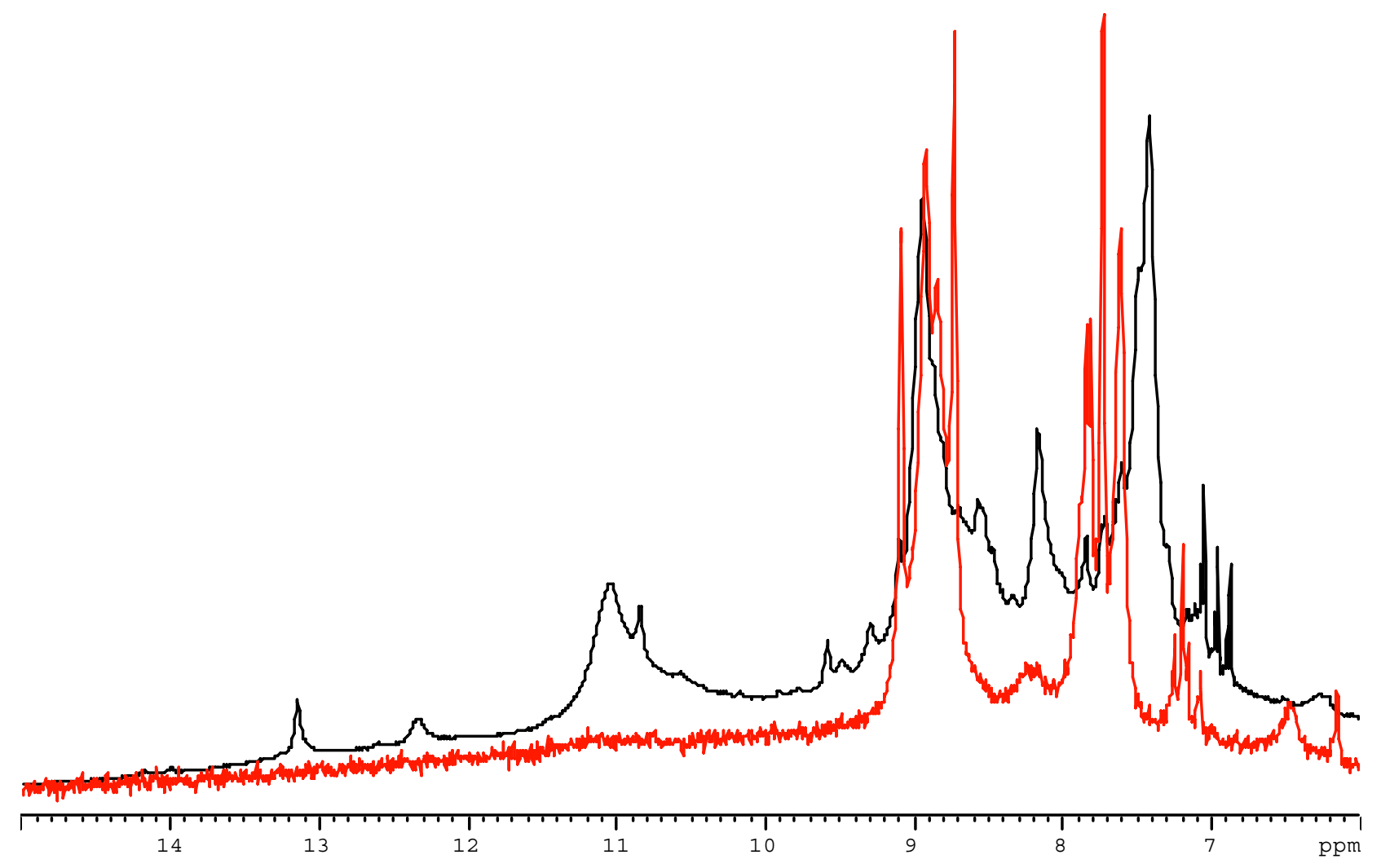

Abb. 23 1D NMR-Spektrum des H-Lys-AlaC-AlaC-AlaG-AlaC-AlaG-AlaG-Lys-OH (58) bei $274 \mathrm{~K}$ im Bereich der Iminoresonanz (Watson-Crick Base Paarungs Bereich) zwischen 11 and 14 ppm (schwarz) und bei 298 K, Signale des Alanyl-PNA Einzelstranges (rot).

Es wurde Abhilfe erhofft, indem Fehlstellen in die Alanyl-PNA-Stränge eingebaut wurden, wodurch eine geringere Stabilität der Selbstpaarung sowie eine erhöhte Löslichkeit erreicht werden sollte. Die in Tabelle 2 gezeigten Sequenzen der Alanyl-PNA Oligomere mit den angegebenen Fehlstellen wurden hergestellt. Die Schmelztemperaturen der Selbstpaarungen wurden denen der Enantiomerenpaarung gegenübergestellt. Es wurden verschiedene Puffersysteme getestet, wodurch die ideale Umgebung für die Oligomere gefunden werden sollte. Die pH-Werte der Puffer wurden zwischen $\mathrm{pH}=7-7.5$ gehalten. Die benutzen vier Systeme waren; 1. $10 \mathrm{mM} \mathrm{Na} \mathrm{HPO}_{4} / \mathrm{H}_{3} \mathrm{PO}_{4}$, $100 \mathrm{mM} \mathrm{NaCl}$; $\mathrm{pH}=7.0$; 2. $10 \mathrm{~mm} \mathrm{AcONH} / \mathrm{AcOH}, 100 \mathrm{mM} \mathrm{NaCl} ; \mathrm{pH}=7.0 ; 3$. $10 \mathrm{~mm}$; Tris $/ \mathrm{HCl}, 100 \mathrm{mM} \mathrm{NaCl} ; \mathrm{pH}=7.5$ und 4. Wasser, $100 \mathrm{~mm} \mathrm{NaCl}$. Die Oligomere wurden bei Konzentrationen zwischen 3-12 $\mu \mathrm{M}$ gemessen, wobei die gefundenen Schmelztemperaturen in den erwarteten Bereichen lagen (je höher die Konzentration, desto höher die Schmelztemperatur $T_{m}$ ). 


\begin{tabular}{|c|c|c|c|c|}
\hline & Sequenz & $\mathrm{T}_{m}\left[{ }^{\circ} \mathrm{C}\right]$ & $\mathrm{T}_{m}\left[{ }^{\circ} \mathrm{C}\right]$ & $\mathrm{T}_{m}\left[{ }^{\circ} \mathrm{C}\right]$ \\
\hline & & $\begin{array}{c}\text { Phosphat- } \\
\text { Puffer }\end{array}$ & $\begin{array}{l}\text { Tris- } \\
\text { Puffer }\end{array}$ & $\begin{array}{c}\mathrm{NH}_{4} \mathrm{OAc}- \\
\text { Puffer }\end{array}$ \\
\hline 16 & H-AlaC-AlaC-AlaG-AlaC-AlaG-AlaG-Lys-NH & 41 & & \\
\hline 15 & H-AlaC-AlaC-AlaG-AlaC-AlaG-AlaG-Lys-NH & 40 & & \\
\hline & $16+15$ & 58 & & \\
\hline 59 & H-AlaC-AlaC-AlaT-AlaC-AlaG-AlaG-Lys-NH & 12 & 16 & 16 \\
\hline 60 & H-AlaC-AlaC-AlaG-AlaT-AlaG-AlaG-Lys- $\mathrm{NH}_{2}$ & 15 & & 12 \\
\hline & $59+60$ & 15 & & \\
\hline 61 & H-AlaC-AlaC-Glu-AlaC-AlaG-AlaG-Lys- $\mathrm{NH}_{2}$ & $<5$ & 5 & 12 \\
\hline 62 & H-AlaC-AlaC-AlaG-Lys-AlaG-AlaG-Lys- $\mathrm{NH}_{2}$ & 12 & $<5$ & 12 \\
\hline & $61+62$ & 15 & 34 & 32 \\
\hline 63 & H-AlaC-AlaC-Glu-AlaC-AlaG-AlaG-Lys-Lys- & 33 & $<5$ & \\
\hline & $62+63$ & 34 & 30 & \\
\hline 64 & $\begin{array}{c}\text { H-AlaC-AlaC-AlaG-Lys-AlaG-AlaG-AlaC- } \\
\text { Lys-NH }\end{array}$ & 12 & 12 & 12 \\
\hline 65 & $\begin{array}{c}\text { H-Lys-AlaG-AlaC-AlaC-Glu-AlaC-AlaG- } \\
\text { AlaG-Lys- } \mathrm{NH}_{2}\end{array}$ & 17 & 11 & 12 \\
\hline & $64+65$ & $32^{1}$ & 19 & 11 \\
\hline 66 & H-AlaC-AlaC-AlaG-Glu-AlaG-AlaG-Gly-OH & $43^{1}$ & $54^{1}$ & 20 \\
\hline
\end{tabular}

Tab. 1 Schmelztemperatur der Alanyl-PNA Oligomere.

Wie in Abb. 24 a/b und Abb. 25 ersichtlich, wurde mit der Fehlstelle, hier durch die Nucleobase Boc-AlaT-OH, die Schmelztemperatur $\mathrm{T}_{m}$ erheblich bei der Selbstpaarung gesenkt. 
H-AlaC-AlaC-AlaT-AlaC-AlaG-AlaG-Lys- $\mathrm{NH}_{2}$ Selbstpaarung

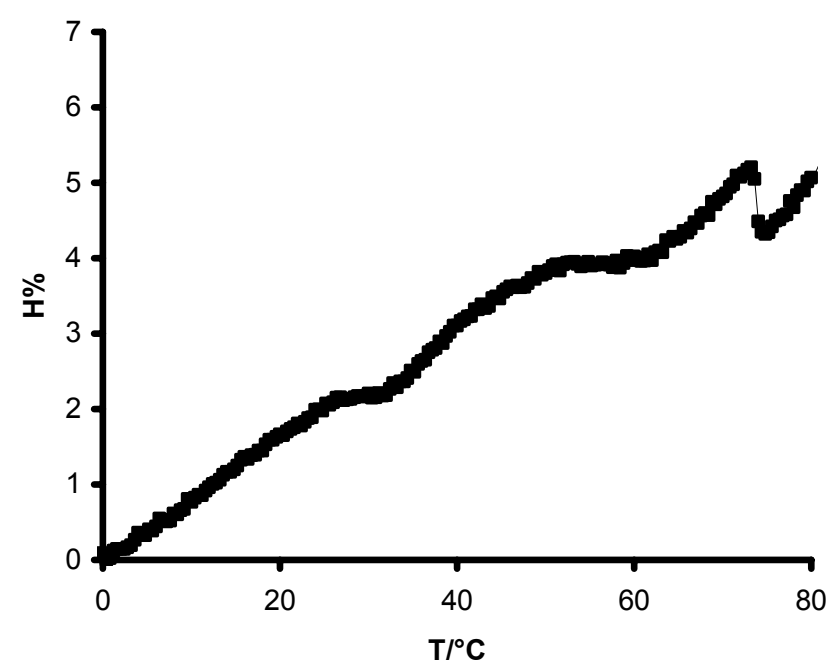

H-AlaC-AlaC-AlaT-AlaC-AlaG-AlaG-Lys- $\mathrm{NH}_{2}$ Selbstpaarung

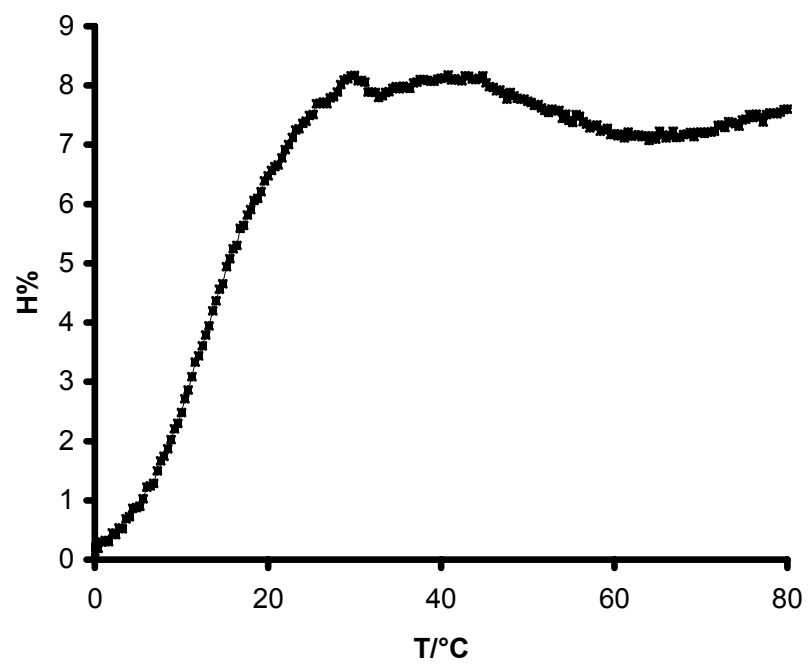

Abb. 24 Oligomer 59 jeweils bei $c=6 \mu \mathrm{M}, \lambda=260 \mathrm{~nm}$, a. im Puffersystem $1\left(10 \mathrm{~mm} \mathrm{Na} \mathrm{HPO}_{4} / \mathrm{H}_{3} \mathrm{PO}_{4}\right.$, $100 \mathrm{mM} \mathrm{NaCl} ; \mathrm{pH}=7.0) \mathrm{T}_{m}={ }^{\circ} \mathrm{C}$; b. im Puffersystem 2 (10 mM AcONH${ }_{4} / \mathrm{AcOH}, 100 \mathrm{mM} \mathrm{NaCl}$; $\mathrm{pH}=7.0) \mathrm{T}_{m}=16^{\circ} \mathrm{C}$.

H-AlaC-AlaC-AlaT-AlaC-AlaG-AlaG-Lys- $\mathrm{NH}_{2}$ Selbstpaarung

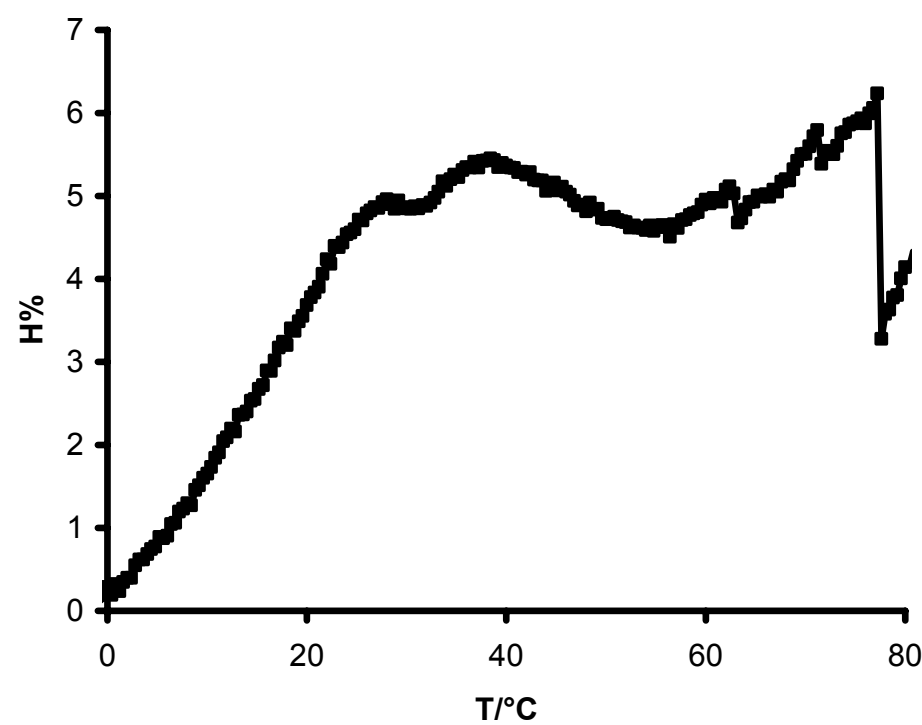

Abb. 25 Oligomer 59 jeweils bei $c=6 \mu \mathrm{M}, \lambda=260 \mathrm{~nm}$, a. im Puffersystem 3 (10 mM Tris/HCl, $100 \mathrm{mM}$ $\mathrm{NaCl} ; \mathrm{pH}=7.5) \mathrm{T}_{m}=16^{\circ} \mathrm{C}$. 
H-AlaC-AlaC-AlaG-AlaT-AlaG-AlaG-Lys- $\mathrm{NH}_{2}$ Selbstpaarung

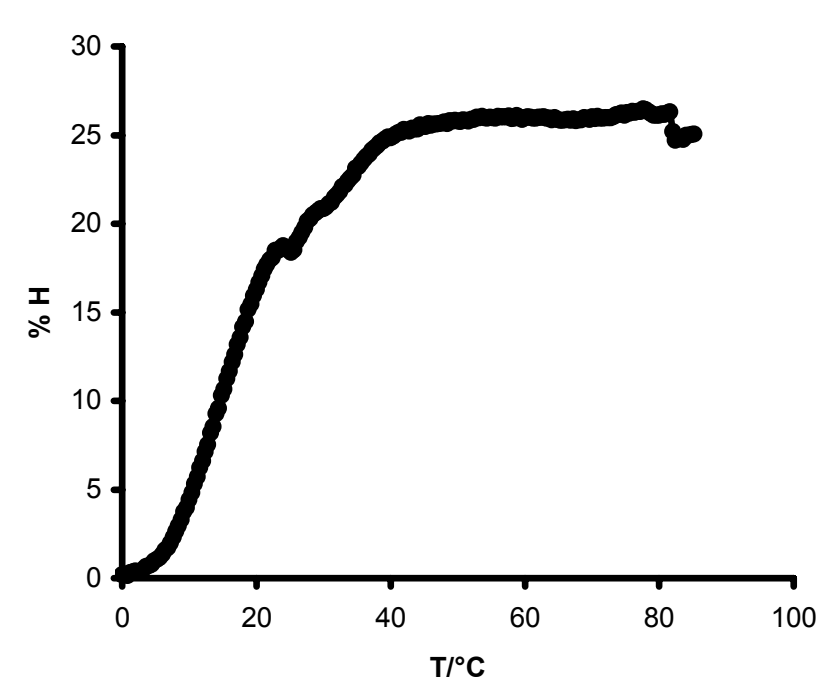

Abb. 26 Oligomer 60 bei c $=6 \mu \mathrm{M}, \lambda=260 \mathrm{~nm}$, im Puffersystem $1\left(\left(10 \mathrm{mM} \mathrm{Na}{ }_{2} \mathrm{HPO}_{4} / \mathrm{H}_{3} \mathrm{PO} 4,100 \mathrm{mM}\right.\right.$ $\mathrm{NaCl} ; \mathrm{pH}=7.0) \mathrm{T}_{m}=15^{\circ} \mathrm{C}$.

Im vergleich zu dem in Puffersystem $1\left(10 \mathrm{~mm} \mathrm{Na} 2 \mathrm{HPO}_{4} / \mathrm{H}_{3} \mathrm{PO}_{4}, 100 \mathrm{~mm} \mathrm{NaCl}\right.$; $\mathrm{pH}=7.0$ ) vermessenen Oligomer H-AlaC-AlaC-AlaG-AlaC-AlaG-AlaG-Lys- $\mathrm{NH}_{2}$ (16) wiesen die modifizierten Oligomere H-AlaC-AlaC-AlaT-AlaC-AlaG-AlaGLys- $\mathrm{NH}_{2}$ (59) und H-AlaC-AlaC-AlaG-AlaT-AlaG-AlaG-Lys- $\mathrm{NH}_{2}$ (60) eine deutlich geringere Stabilität auf. Der Einbau einer Boc-AlaT-OH Basenfehlstelle führte zu einer Destabilisierung auf $16{ }^{\circ} \mathrm{C}$ (Abb. 24 a), so dass Doppelstränge mit herabgesetzter Selbstpaarungstendenz erhalten wurden. Auch die in den Puffersystemen $2\left(10 \mathrm{~mm} \mathrm{AcONH}{ }_{4} / \mathrm{AcOH}, 100 \mathrm{mM} \mathrm{NaCl}\right.$; $\mathrm{pH}=7.0) \mathrm{mit}_{m}=16{ }^{\circ} \mathrm{C}$ und $3(10 \mathrm{~mm}$ Tris $/ \mathrm{HCl}, 100 \mathrm{mM} \mathrm{NaCl} ; \mathrm{pH}=7.5)$ mit $\mathrm{T}_{m}=12{ }^{\circ} \mathrm{C}$ erhaltenen Stabilitäten befinden sich im gleichem Stabilitätsbereich. Die beiden Oligomere 59 und $\mathbf{6 0}$ wurden hinsichtlich der Doppelstrangbildung im Puffersystem 1 (10 mM Na $2 \mathrm{HPO}_{4} / \mathrm{H}_{3} \mathrm{PO}_{4}, 100 \mathrm{~mm} \mathrm{NaCl}$; $\mathrm{pH}=7.0$ ) vermessen. Der Phospat-Puffer wurde verwendet, um Vergleiche mit vorherigen Arbeiten ziehen zu können. 
H-AlaC-AlaC-AlaT-AlaC-AlaG-AlaG-Lys- $\mathrm{NH}_{2}$ mit

H-AlaC-AlaC-AlaG-AlaT-AlaG-AlaG-Lys- $\mathrm{NH}_{2}$

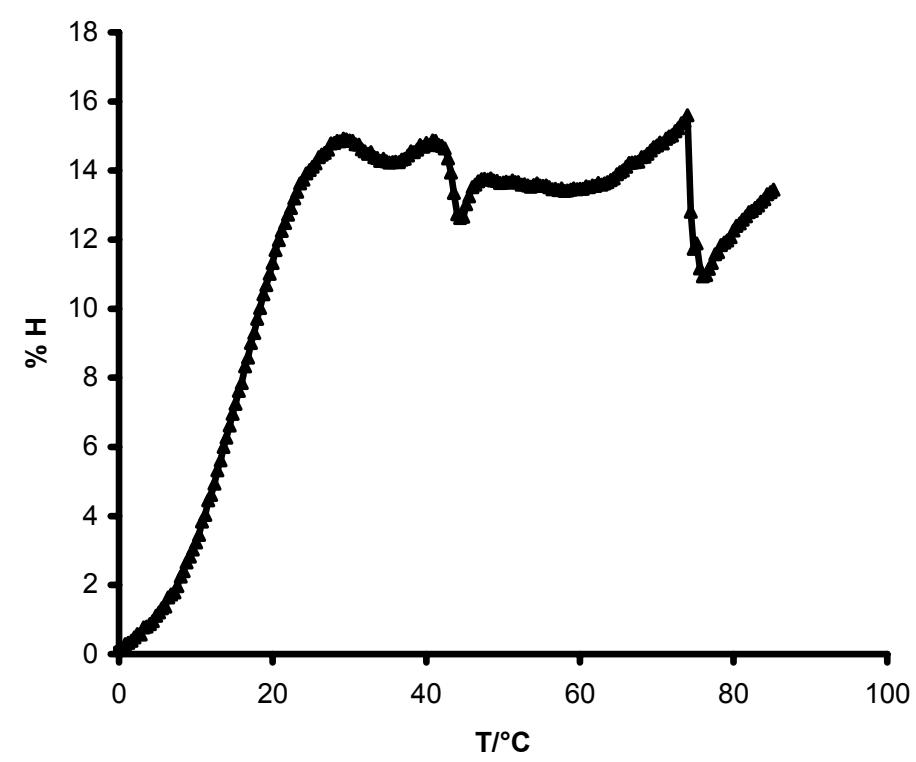

Abb. 27 Mischung der Oligomer 59 und 60 bei je $6 \mu \mathrm{M}, \lambda=260 \mathrm{~nm}$, im Puffersystem 1 (10 mM $\left.\mathrm{Na}_{2} \mathrm{HPO}_{4} / \mathrm{H}_{3} \mathrm{PO}_{4}, 100 \mathrm{mM} \mathrm{NaCl} ; \mathrm{pH}=7.0\right) \mathrm{T}_{m}=15^{\circ} \mathrm{C}$.

Das Ergebnis der UV-Schmelzkurvenbestimmung zeigte eine Schmelztemperatur von $\mathrm{T}_{m}=15^{\circ} \mathrm{C}$ auf, was im Stabilitätsbereich der Selbstpaarung liegt. Es konnte gezeigt werden, dass die eingebauten Basenfehlstellen die Selbstpaarung destabilisieren und die Doppelstrangbildung der enatiomeren Oligomere 59 und 60 nicht fördert. Auch die Oligomere 59und 60 wiesen bei mikromolarer Konzentration eine schlechte Löslichkeit auf, was im Hinblick auf die NMR-Spektroskopie keine Verbesserung darstellte.

So sollten mit den Alanyl-PNA Oligomeren H-AlaC-AlaC-Glu-AlaC-AlaG-AlaGLys-NH2 (61) und H-AlaC-AlaC-AlaG-Lys-AlaG-AlaG-Lys-NH2 (62) Aminosäuren eingeführt werden. Die in die komplementären Oligomere 62 und 61 eingebauten Aminosäuren Lysin und Glutaminsäure tragen zur Verbesserung der Löslichkeit bei und bilden ein komplementäres lonenpaar aus (Abb. 28 a/b und 29). Es wurde erwartet, dass Lysin und Glutaminsäure einen Beitrag zur Stabilität liefern. Bei der Bestimmung der Schmelztemperaturen $T_{m}$ der Einzelstränge wurden für das Oligomer H-AlaC-AlaC-Glu-AlaC-AlaG-AlaG-Lys$\mathrm{NH}_{2}$ (61) Schmelztemperaturen gefunden. Im Puffersystemen 1 (10 mM $\mathrm{Na}_{2} \mathrm{HPO}_{4} / \mathrm{H}_{3} \mathrm{PO}_{4}, 100 \mathrm{mM} \mathrm{NaCl} ; \mathrm{pH}=7.0$ ) wurde eine Stabilität von $\mathrm{T}_{m}=35^{\circ} \mathrm{C}$ 
gefunden. Für die Puffersysteme $2\left(10 \mathrm{nM} \mathrm{AcONH}{ }_{4} / \mathrm{AcOH}, 100 \mathrm{~mm} \mathrm{NaCl}\right.$; $\mathrm{pH}=7.0)$ und $3(10 \mathrm{~mm}$ Tris/ $\mathrm{HCl}, 100 \mathrm{mM} \mathrm{NaCl} ; \mathrm{pH}=7.5)$ wurde keine Stabilität ermittelt. Der Grund für den Hyperchromizitätsanstieg $(\mathrm{H} \%)$ bei einer Temperatur von $60{ }^{\circ} \mathrm{C}$ ist einem Abdampfeffekt zuzuordnen (Abb. 28 b und 29).

H-AlaC-AlaC-Glu-AlaC-AlaG-AlaG-Lys- $\mathrm{NH}_{2}$ Selbstpaarung

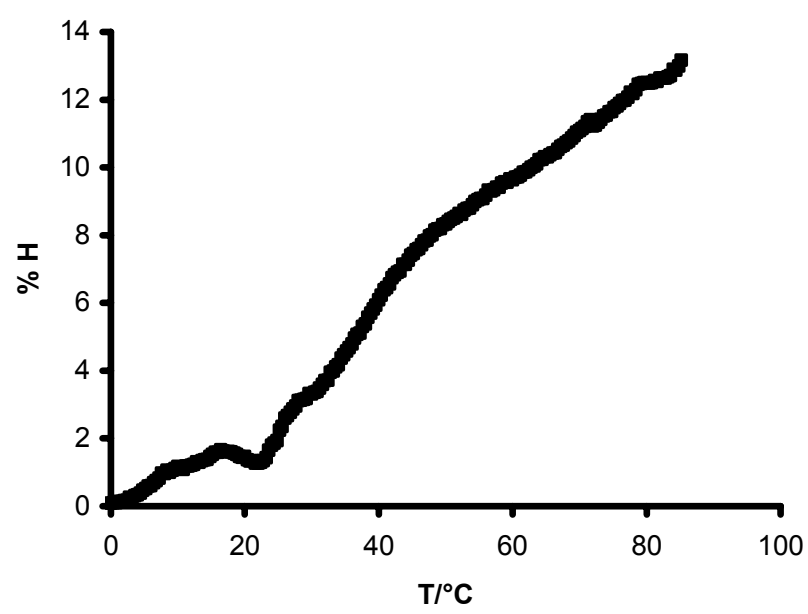

H-AlaC-AlaC-Glu-AlaC-AlaG-AlaG-Lys- $\mathrm{NH}_{2}$ Selbstpaarung

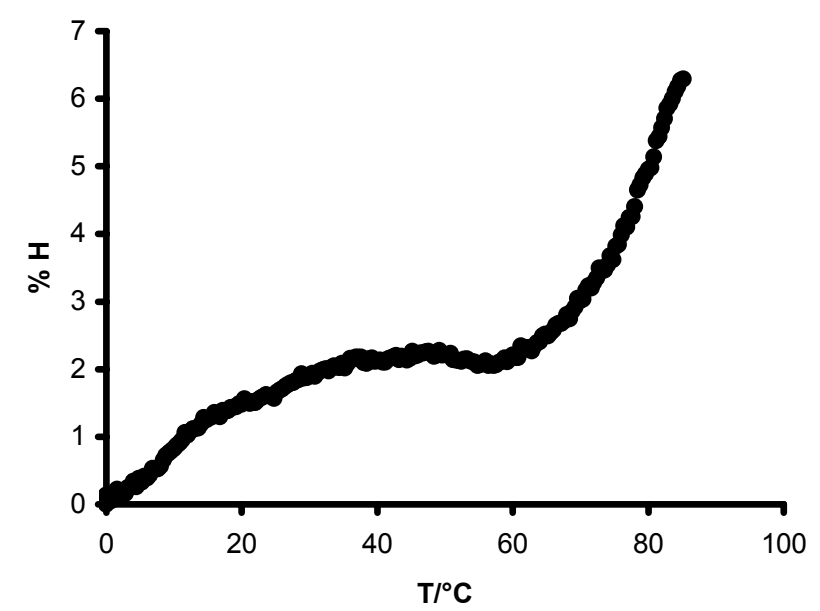

Abb. 28 Oligomer 61 jeweils bei c $=6 \mu \mathrm{M}, \lambda=260 \mathrm{~nm}$, a. im Puffersystem $1\left(10 \mathrm{mM} \mathrm{Na}_{2} \mathrm{HPO}_{4} / \mathrm{H}_{3} \mathrm{PO}_{4}\right.$, $100 \mathrm{~mm} \mathrm{NaCl} ; \mathrm{pH}=7.0) \mathrm{T}_{m}=35^{\circ} \mathrm{C}$; b. im Puffersystem $2(10 \mathrm{nM} \mathrm{AcONH} / \mathrm{AcOH}, 100 \mathrm{~mm} \mathrm{NaCl}$; $\mathrm{pH}=7.0) \mathrm{T}_{m}=<0^{\circ} \mathrm{C}$, Bei der Temperatur $<65^{\circ} \mathrm{C}$ macht sich ein Abdampfen des Lösungsmittels bemerkbar. 
H-AlaC-AlaC-Glu-AlaC-AlaG-AlaG-Lys- $\mathrm{NH}_{2}$

Selbstpaarung

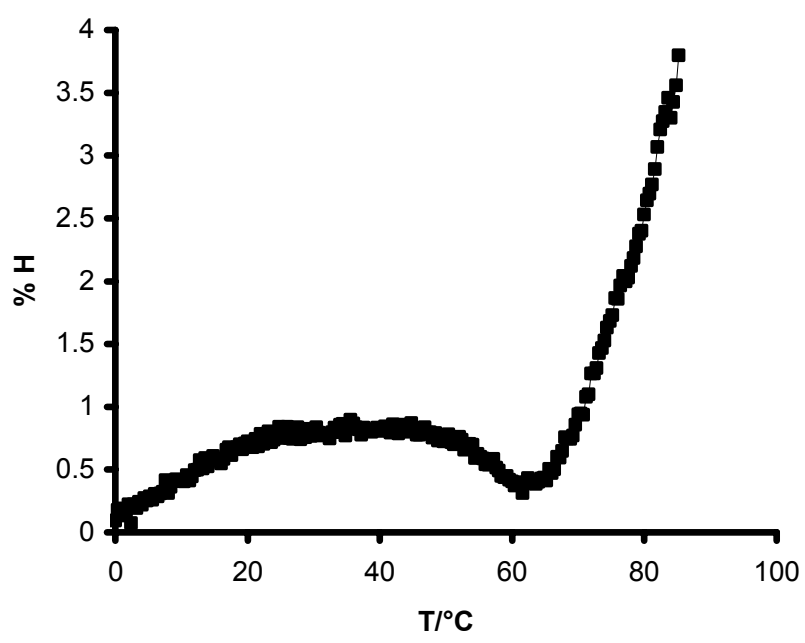

Abb. 29 Oligomer 61 bei c $=6 \mu \mathrm{M}, \lambda=260 \mathrm{~nm}$, im Puffersystem $3(10 \mathrm{~mm}$ Tris/HCl, $100 \mathrm{~mm} \mathrm{NaCl}$; $\mathrm{pH}=7.5) \mathrm{T}_{m}=<0{ }^{\circ} \mathrm{C}$, Bei der Temperatur $<65^{\circ} \mathrm{C}$ macht sich ein Abdampfen des Lösungsmittels bemerkbar.

A

$\mathrm{H}_{2} \mathrm{~N}$-Lys-G-G-Lys- $\underline{-}-\mathrm{C}-\underline{\mathrm{C}}-\mathrm{H}$

H-C-C-C-G-Lys-G-G-Lys $-\mathrm{NH}_{2}$

Selbstpaarung
B

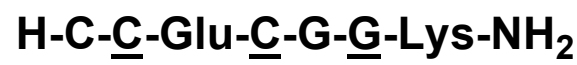

$\mathrm{H}_{2}$ N-Lys-G-G-C-Glu-C-C-C-H

Selbstpaarung

C

$\mathrm{H}_{2} \mathrm{~N}$-Lys-G-G-C-Glu-C-C-C-H

H-C -C- $-\underline{G}-L y s-\underline{G}-G-\underline{L} \underline{\text { s }}-\mathrm{NH}_{2}$

\section{Duplexbildung}

Abb. 30 Selbstpaarungskomplex und Duplexkomplexe der der Sequenz H-AlaC-AlaC-Glu-AlaC-AlaGAlaG-Lys- $\mathrm{NH}_{2}(\mathbf{6 1})$ und H-AlaC-AlaC-AlaG-Lys-AlaG-AlaG-Lys- $\mathrm{NH}_{2}(\mathbf{6 2})$ in der antiparallelen heterochiralen Konformation.

Wahrscheinlich ist die Fehlstelle gebildet durch Glutaminsäure und die dadurch vorhandene Abstoßung der beiden negativen Ladungen für die niedrige Schmelztemperatur verantwortlich (Abb. 30 B). 
H-AlaC-AlaC-AlaG-Lys-AlaG-AlaG-Lys- $\mathrm{NH}_{2}$ Selbstpaarung

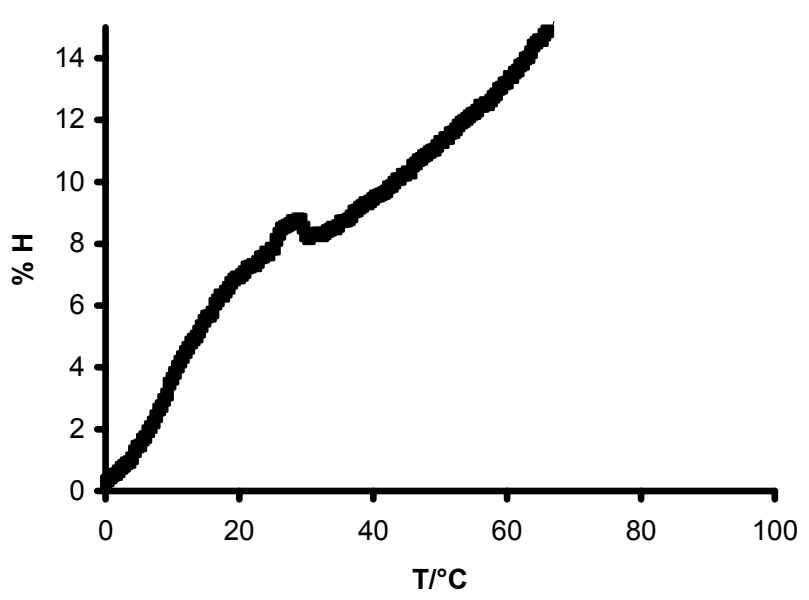

H-AlaC-AlaC-AlaG-Lys-AlaG-AlaG-Lys- $\mathrm{NH}_{2}$ Selbstpaarung

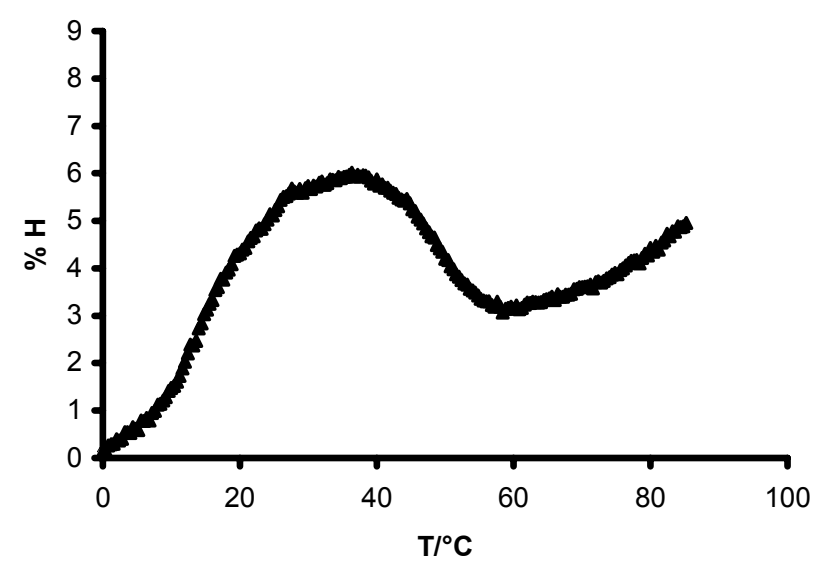

Abb. 31 Oligomer 62 bei je c $=6 \mu \mathrm{M}, \lambda=260 \mathrm{~nm}$, a. im Puffersystem $1\left(10 \mathrm{mM} \mathrm{Na} \mathrm{HPO}_{4} / \mathrm{H}_{3} \mathrm{PO}_{4}\right.$, $100 \mathrm{mM} \mathrm{NaCl} ; \mathrm{pH}=7.0) \mathrm{T}_{m}=12^{\circ} \mathrm{C}$; b. im Puffersystem $2\left(10 \mathrm{nM} \mathrm{AcONH}{ }_{4} / \mathrm{AcOH}, 100 \mathrm{mM} \mathrm{NaCl}\right.$; $\mathrm{pH}=7.0) \mathrm{T}_{m}=12^{\circ} \mathrm{C}$.

H-AlaC-AlaC-AlaG-Lys-AlaG-AlaG-Lys- $-\mathrm{NH}_{2}$ Selbstpaarung

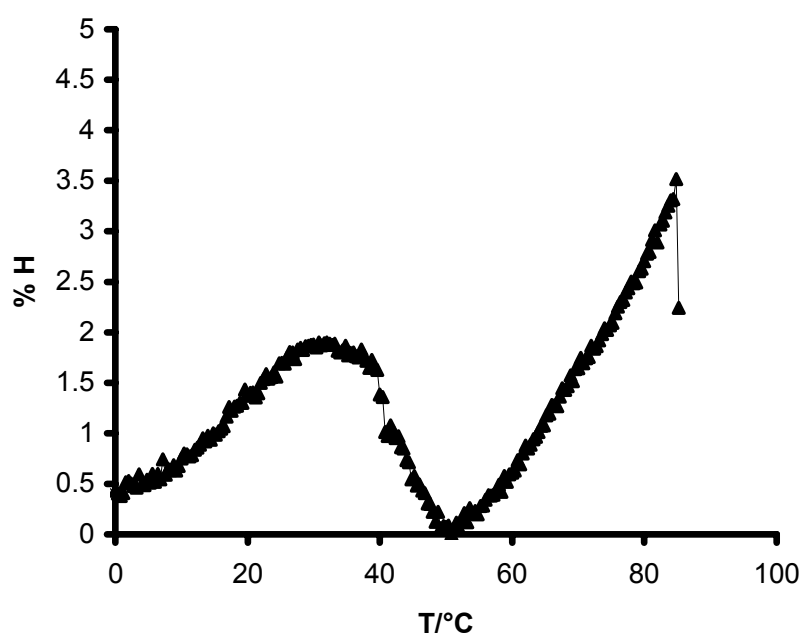

Abb. 32 Oligomer 62 bei c $=6 \mu \mathrm{M}, \lambda=260 \mathrm{~nm}$, im Puffersystem 3 (10 mM Tris/HCl, $100 \mathrm{~mm} \mathrm{NaCl}$; $\mathrm{pH}=$ 7.5) $\mathrm{T}_{m}=$ keinen, Abdampfeffekt.

Bei der Bestimmung der Stabilität des Oligomers H-AlaC-AlaC-AlaG-LysAlaG-AlaG-Lys- $\mathrm{NH} 2$ (62) wurde im Puffersystem $1\left(10 \mathrm{mM} \mathrm{Na} 2 \mathrm{HPO}_{4} / \mathrm{H}_{3} \mathrm{PO}_{4}\right.$, $100 \mathrm{mM} \mathrm{NaCl} ; \mathrm{pH}=7.0$ ) eine Stabilität von $\mathrm{T}_{m}=12{ }^{\circ} \mathrm{C}$ gefunden (Abb. $31 \mathrm{a}$ ). Dies weist, ebenso wie das Oligomer 61 auf eine Abstoßung der beiden 
gleichen Ladungen währen einer Selbstpaarung hin (Abb. 30 A), wobei es zur Erniedrigung der Stabilität kommt. Beide Systeme wiesen eine erhöhte Löslichkeit gegenüber den vorherigen Oligomeren auf. In dem Puffersystem 2 (10 mM AcONH ${ }_{4} / \mathrm{AcOH}, 100 \mathrm{~mm} \mathrm{NaCl} ; \mathrm{pH}=7.0$ ) wurde ebenso eine Stabilität von $\mathrm{T}_{m}=12^{\circ} \mathrm{C}$ gefunden. Im Puffersystem $3(10 \mathrm{~mm}$ Tris $/ \mathrm{HCl}, 100 \mathrm{mM} \mathrm{NaCl}$; $\mathrm{pH}=7.5$ ) wurde keine Ausbildung eines Doppelstranges ermittelt. Die steigende Absorption bei einer Temperatur von $>50^{\circ} \mathrm{C}$ deutet auf ein Abdampfeffekt hin.

H-AlaC-AlaC-Glu-AlaC-AlaG-AlaG-Lys- $\mathrm{NH}_{2}$ mit

H-AlaC-AlaC-AlaG-Lys-AlaG-AlaG-Lys-

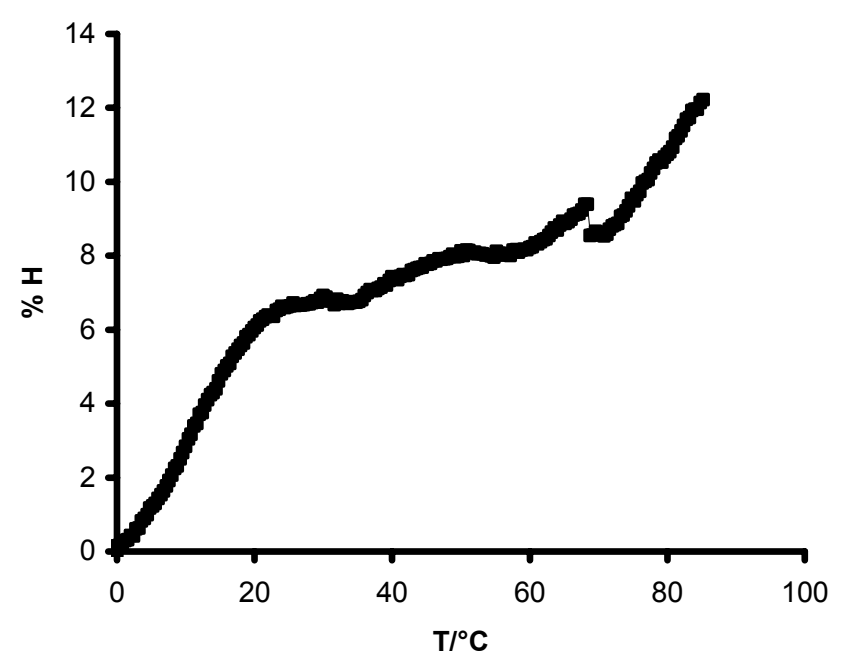

Abb. 33 Mischung der Oligomer 61 und 62 bei je c $=6 \mu \mathrm{M}, \lambda=260 \mathrm{~nm}$, a. im Puffersystem 1 (10 mM $\left.\mathrm{Na}_{2} \mathrm{HPO}_{4} / \mathrm{H}_{3} \mathrm{PO}_{4}, 100 \mathrm{mM} \mathrm{NaCl} ; \mathrm{pH}=7.0\right) \mathrm{T}_{m}=15^{\circ} \mathrm{C}$; b. im Puffersystem 2 (10 nM AcONH$/ \mathrm{AcOH}_{4}$ $100 \mathrm{~mm} \mathrm{NaCl} ; \mathrm{pH}=7.0) \mathrm{T}_{m}=32{ }^{\circ} \mathrm{C}$.
H-AlaC-AlaC-Glu-AlaC-AlaG-AlaG-Lys-NH2 mit

H-AlaC-AlaC-AlaG-Lys-AlaG-AlaG-Lys-NH2

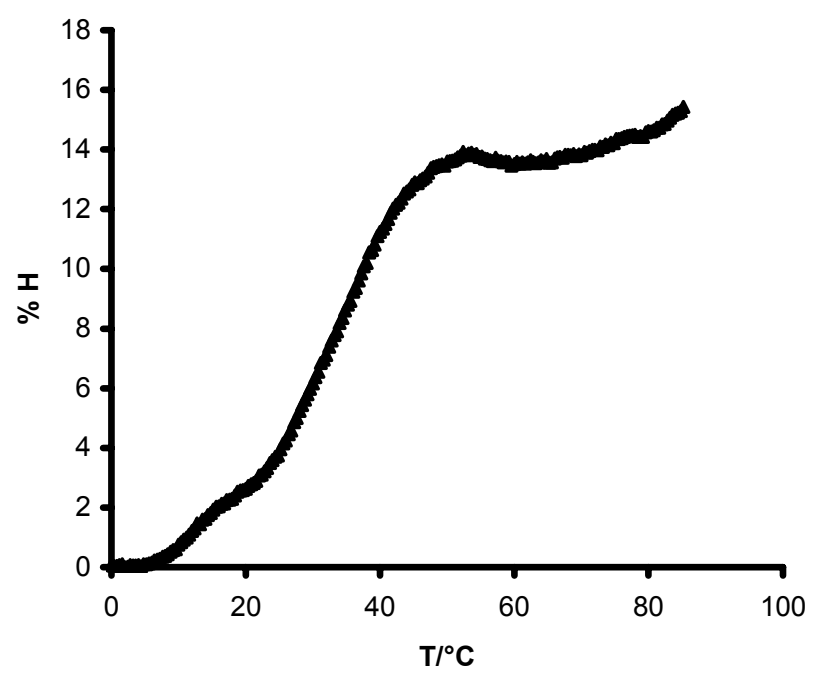


H-AlaC-AlaC-Glu-AlaC-AlaG-AlaG-Lys- $\mathrm{NH}_{2}$ mit H-AlaC-AlaC-AlaG-Lys-AlaG-AlaG-Lys-NH

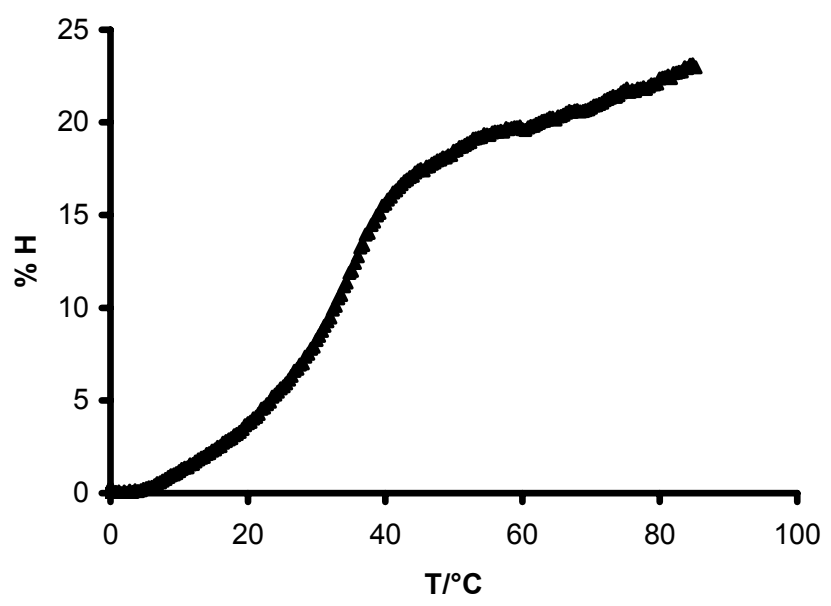

H-AlaC-AlaC-Glu-AlaC-AlaG-AlaG-Lys- $\mathrm{NH}_{2}$ mit H-AlaC-AlaC-AlaG-Lys-AlaG-AlaG-Lys-NH ${ }_{2}$

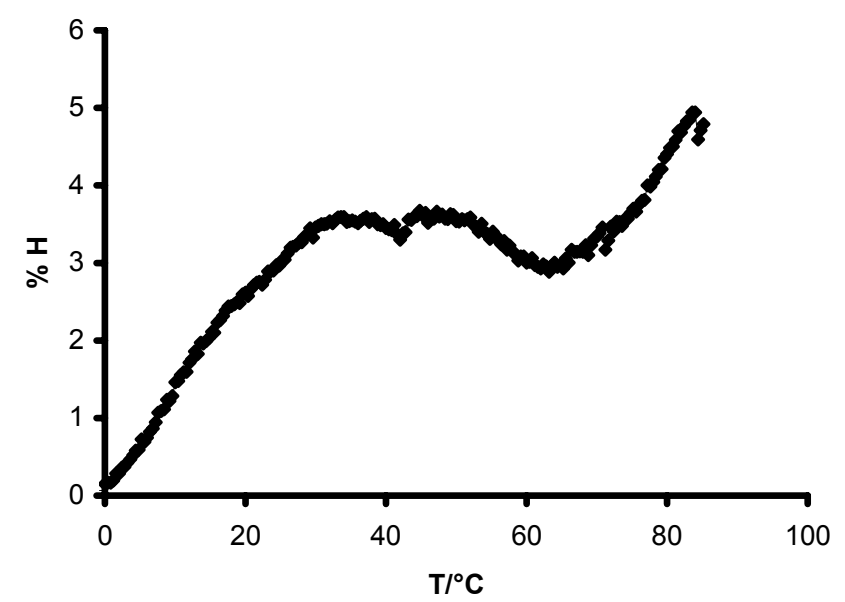

Abb. 34 Mischung der Oligomere61 und 62 bei je $c=6 \mu \mathrm{M}, \lambda=260 \mathrm{~nm}$, a. Puffersystem $3(10 \mathrm{~mm}$ Tris $/ \mathrm{HCl}, 100 \mathrm{mM} \mathrm{NaCl} ; \mathrm{pH}=7.5) \mathrm{T}_{m}=32^{\circ} \mathrm{C}$, b. in Wasser, $100 \mathrm{~mm} \mathrm{NaCl} \mathrm{T} m=15^{\circ} \mathrm{C}$.

Die Mischung der beiden Oligomere H-AlaC-AlaC-Glu-AlaC-AlaG-AlaG-Lys$\mathrm{NH}_{2}$ (61) und $\mathrm{H}$-AlaC-AlaC-AlaG-Lys-AlaG-AlaG-Lys- $\mathrm{NH}_{2}(62)$ wurden in allen drei Puffersystemen und zusätzlich in Wasser $/ \mathrm{NaCl}$ hinsichtlich der Doppelstrangstabilität untersucht (Abb. 33 a/b und 34 a/b). Die Doppelstrangbildung wies im Puffersystem $1\left(10 \mathrm{~mm} \mathrm{Na} \mathrm{HPO}_{4} / \mathrm{H}_{3} \mathrm{PO}_{4}, 100 \mathrm{mM} \mathrm{NaCl}\right.$; $\mathrm{pH}=7.0$ ) einen Stabilitätswert von $\mathrm{T}_{m}=15^{\circ} \mathrm{C}$ auf (Abb. 33 a) auf. Im Puffersystem 2 (10 mM AcONH $4 / A c O H, 100 \mathrm{mM} \mathrm{NaCl}$; $\mathrm{pH}=7.0)$ fand man eine Stabilität von $\mathrm{T}_{m}=32{ }^{\circ} \mathrm{C}$ (Abb. $33 \mathrm{~b}$ ). Eine ähnliche Stabilität ergab die Doppelstrangbildung der beiden Oligomere 61 und 62 im Puffersystem 3 (10 mM Tris/HCl, $100 \mathrm{mM} \mathrm{NaCl} ; \mathrm{pH}=7.5$ ), wo eine Schmelztemperatur von $\mathrm{T}_{m}=34^{\circ} \mathrm{C}$ nachgewiesen werden konnte (Abb. $34 \mathrm{a}$ ). Im System 4 wurde eine erheblich geringere Stabilität von $\mathrm{T}_{m}=15^{\circ} \mathrm{C}$ (Abb. 34 b) nachgewiesen, jedoch ist dieser Stabilitätswert gleich dem des Systems 1. Im Vergleich zu den Stabilitätswerten der Oligomere H-AlaC-AlaC-AlaG-AlaC-AlaG-AlaG-Lys$\mathrm{NH}_{2}$ (15) mit seinem Gegenstrang 16 ist es eine Verringerung in der Stabilität um ca. $20^{\circ} \mathrm{C}$. Dieser Verlust der Stabilität beruht auf den Fehlstellen Lysin und Glutaminsäure. Das Stabilitätsverhalten in den unterschiedlichen Puffersystemen zeigt die Abhängigkeit der Schmelztemperatur von der vorliegenden 
Umgebung auf. Die beiden Aminosäuren Lysin und Glutaminsäure weisen gegensätzliche Ladungen auf und bilden somit ein lonenpaar aus.

Um eine bessere Stabilität bei gleich bleibender Löslichkeit zu erreichen, wurden die Oligomere in einem weiteren Ansatz um jeweils eine Nucleoaminosäure verlängert (Abb. 35 a/b, 36 und 37a/b). Es wurde eine höhere Stabilität des sich bildenden Doppelstranges erwartet, da sich mehr Watson-Crick Wasserstoffbrücken ausbilden können. Bei der Selbstpaarung, wurden beim Oligomer H-AlaC-AlaC-AlaG-Lys-AlaG-AlaG-AlaC-Lys- $\mathrm{NH}_{2}$ (64) in den drei Puffersystemen Stabilitäten $T_{m}$ ermittelt. Im Phosphat-Puffersystem (1) wurde eine Stabilität von $12^{\circ} \mathrm{C} \mathrm{Im}$ Ammoniumacetat-Puffersystem 2 wurde ebenso eine Stabilität von $\mathrm{T}_{m}=12^{\circ} \mathrm{C}$ gemessen, jedoch lag hier eine erheblich niedrigere Hyperchromizität $(\mathrm{H} \%)$ vor. Die Intensität der Hyperchromizität im Tris-Puffersystem 3 liegt im gleichen Bereich wie im Puffersystem 2 auch die ermittelte Stabilität ist mit $\mathrm{T}_{m}=13^{\circ} \mathrm{C}$ identisch. Dies zeigt im Vergleich zu den kurzen Sequenzen, dass eine Stabilisierung um ca. $5{ }^{\circ} \mathrm{C}$ durch die weiteren Nucleobasen erreicht werden konnte.

H-AlaC-AlaC-AlaG-Lys-AlaG-AlaG-AlaC-Lys- $\mathrm{NH}_{2}$ Selbstpaarung

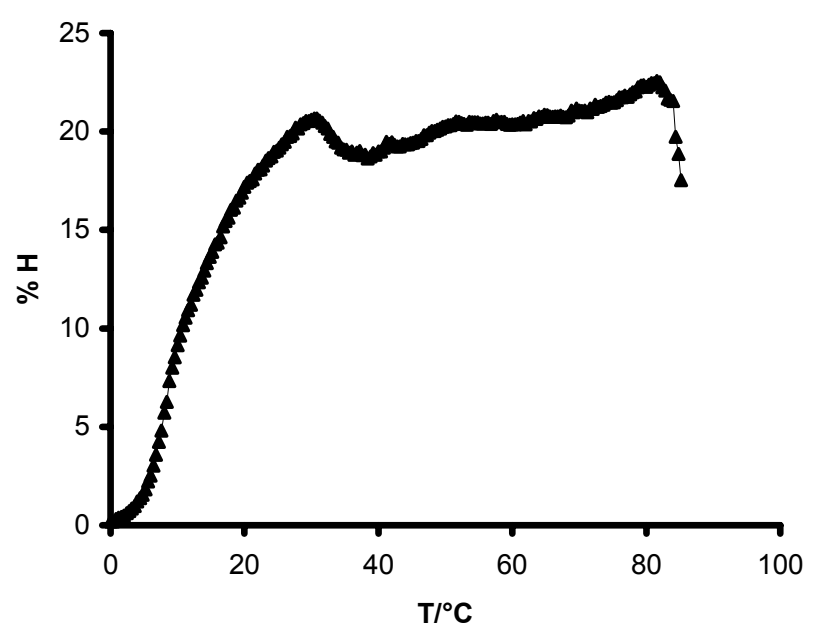

H-AlaC-AlaC-AlaG-Lys-AlaG-AlaG-AlaC-Lys- $\mathrm{NH}_{2}$ Selbstpaarung

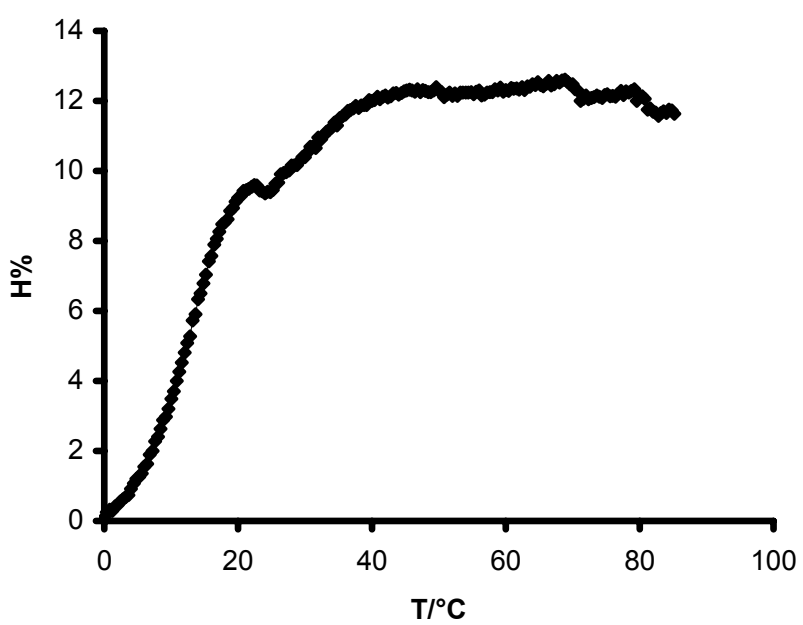

Abb. 35 Oligomer 64 jeweils bei $c=6 \mu \mathrm{M}, \lambda=260 \mathrm{~nm}$, a. im Puffersystem $1\left(10 \mathrm{mM} \mathrm{Na}{ }_{2} \mathrm{HPO}_{4} / \mathrm{H}_{3} \mathrm{PO}_{4}\right.$, $100 \mathrm{~mm} \mathrm{NaCl} ; \mathrm{pH}=7.0) \mathrm{T}_{m}=12^{\circ} \mathrm{C}$; b. im Puffersystem 2 (10 nM AcONH${ }_{4} / \mathrm{AcOH}, 100 \mathrm{~mm} \mathrm{NaCl}$; $\mathrm{pH}=7.0) \mathrm{T}_{m}=12 \mathrm{C}$. 
H-AlaC-AlaC-AlaG-Lys-AlaG-AlaG-AlaC-Lys- $\mathrm{NH}_{2}$ Selbstpaarung

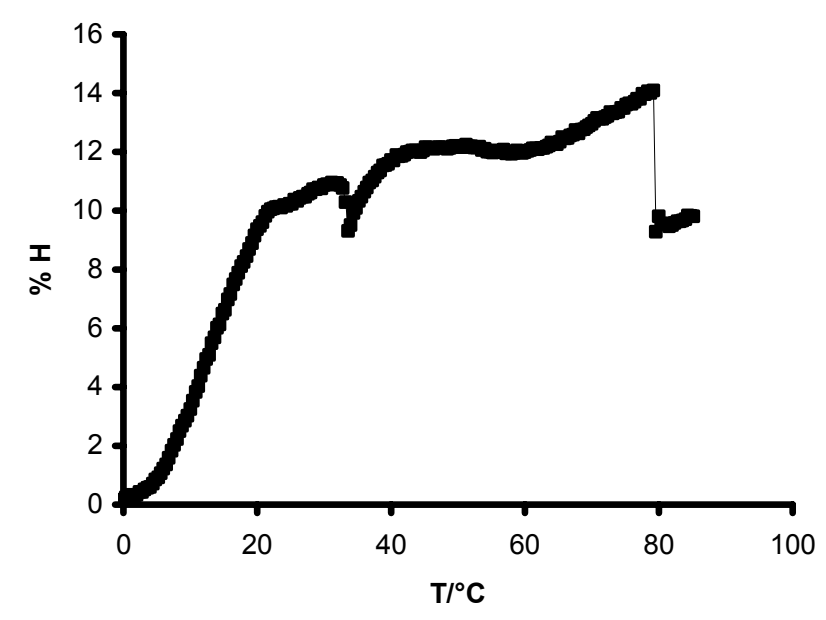

Abb. 36 Oligomer 64 bei c $=6 \mu \mathrm{M}, \lambda=260 \mathrm{~nm}$, im Puffersystem $3(10 \mathrm{mM} \mathrm{Tris} / \mathrm{HCl}, 100 \mathrm{mM} \mathrm{NaCl}$; $\mathrm{pH}=7.5) \mathrm{T}_{m}=13^{\circ} \mathrm{C}$.

Beim Alanyl-PNA Gegenoligomer H-Lys-AlaG-AlaC-AlaC-Glu-AlaC-AlaGAlaG-Lys- $\mathrm{NH}_{2}(65)$ wurde im Puffersystem 1 eine Stabilität von $\mathrm{T}_{m}=17^{\circ} \mathrm{C}$ ermittelt (Abb. 38 a). Im Puffersysteme 3 fand man eine Stabilität von $\mathrm{T}_{m}=11^{\circ} \mathrm{C}$ (Abb. $38 \mathrm{~b}$ ). Im Puffersystem 2 wurde keine Stabilität ermittelt. Auch bei den Hyperchromizitäten wurden unterschiede gefunden. So weißt die Selbstpaarung im Puffersystem 1 (Abb. 37 a) eine erheblich höhere Hyperchromizität auf als im Puffersystem 3 (Abb. 37 b). 
H-Lys-AlaG-AlaC-AlaC-Glu-AlaC-AlaG-AlaG-Lys- $\mathrm{NH}_{2}$ Selbstpaarung

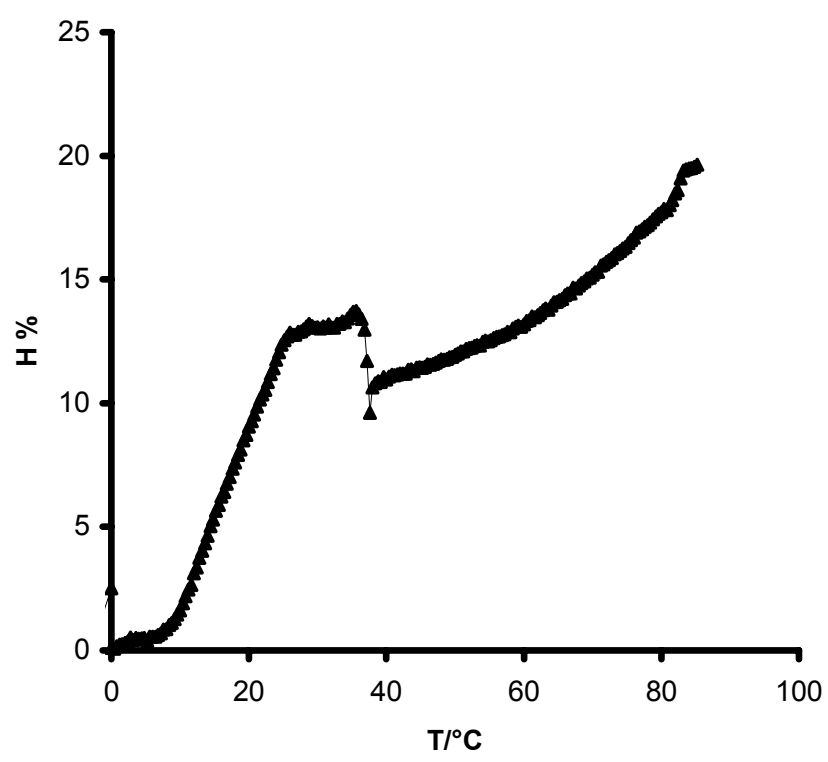

H-Lys-AlaG-AlaC-AlaC-Glu-AlaC-AlaG-AlaG-Lys$\mathrm{NH}_{2}$

Selbstpaarung

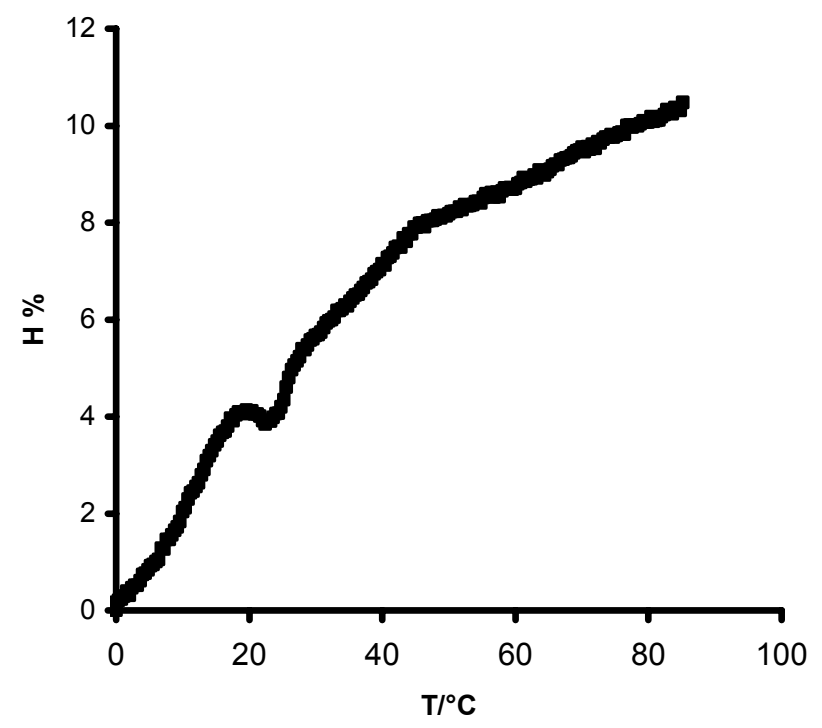

Abb. 37 Oligomer 65 jeweils bei c $=6 \mu \mathrm{M}, \lambda=260 \mathrm{~nm}$, a. im Puffersystem $1\left(10 \mathrm{mM} \mathrm{Na}_{2} \mathrm{HPO}_{4} / \mathrm{H}_{3} \mathrm{PO}_{4}\right.$, $100 \mathrm{~mm} \mathrm{NaCl} ; \mathrm{pH}=7.0) \mathrm{T}_{m}=17^{\circ} \mathrm{C}$; b. im Puffersystem $3(10 \mathrm{~mm}$ Tris/HCl, $100 \mathrm{mM} \mathrm{NaCl} ; \mathrm{pH}=7.5)$ $\mathrm{T}_{m}=11^{\circ} \mathrm{C}$.

Das Ergebnis der Schmelzkurve des Gemisches beider Oligomere 64 und 65 im Tris-Puffer System wies eine leichte Stabilisierung in Bezug auf die Einzelstränge auf. Vergleicht man dieses Ergebnis jedoch mit den vorherigen Messungen, so konnte durch das Einbringen der zusätzlichen Aminosäure keine deutliche Verbesserung des Systems erreicht werden. Die Ausbildung von Doppelsträngen durch die Alanyl-PNA Oligomere 64 und 65 führte offensichtlich zu einem Spezies-Gemisch mit $\mathrm{T}_{m}=18{ }^{\circ} \mathrm{C}$ und möglicherweise auch mit $\mathrm{T}_{m}=45^{\circ} \mathrm{C}$ (Abb. 38). 


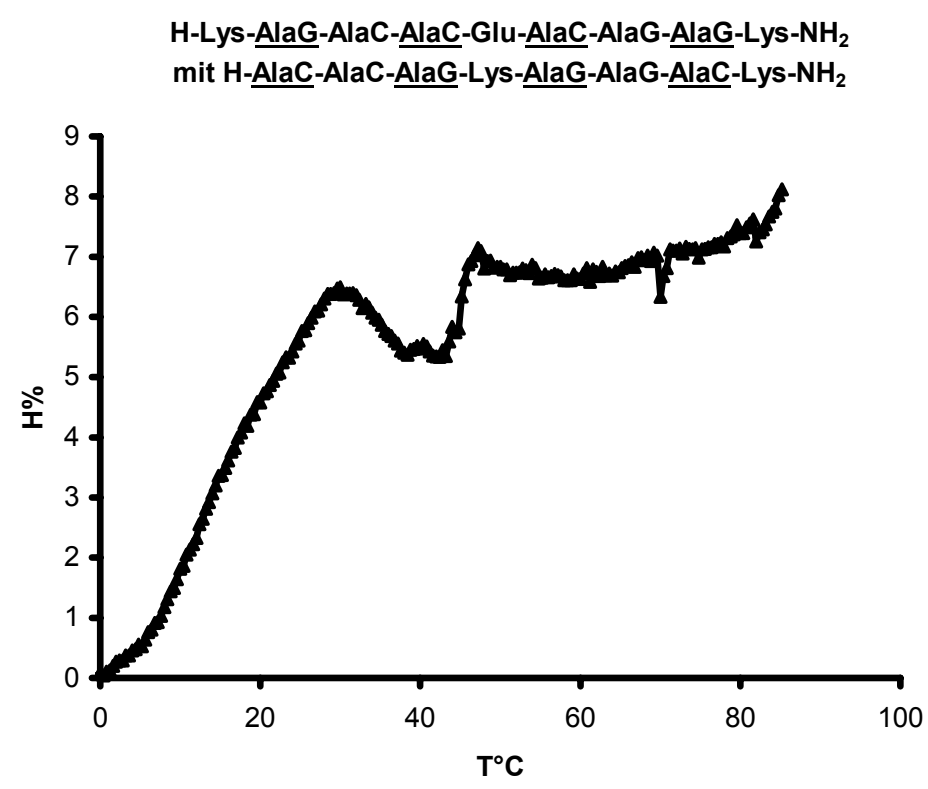

Abb. 38 Doppelstrangbildung einer 1:1 Mischung der Oligomer 64 und 65 bei je $6 \mu \mathrm{M}, \lambda=260 \mathrm{~nm}$, im Puffersystem $3(10 \mathrm{mM}$ Tris $/ \mathrm{HCl}, 100 \mathrm{mM} \mathrm{NaCl} ; \mathrm{pH}=7.5) \mathrm{T}_{m}=18^{\circ} \mathrm{C}$ und möglicherweise $\mathrm{T}_{m}=45^{\circ} \mathrm{C}$.

Durch den Vergleich der vermessenen Schmelzkurven und den erhaltenen Ergebnissen der Stabilität wurden Oligomere zur NMR-spektroskopischen Untersuchung ausgewählt. Auch der Puffer wurde durch den Vergleich der Temperaturen neu bestimmt, so dass das Oligomer H-AlaC-AlaC-AlaG-LysAlaG-AlaG-Lys-OH (62) ebenso wie das Oligomer H-Lys-AlaC-AlaC-AlaGAlaC-AlaG-AlaG-Lys-OH (58) für die NMR-Spektroskopie vorbereitet wurde. Es wurde eine Konzentration von $3 \mathrm{~mm}$ im Phosphat Puffer (siehe oben) gewählt. Bei der Messung des Oligomers 62, bildeten sich bei $278 \mathrm{~K}$ die Aggregate aus und über $278 \mathrm{~K}$ erhielt man scharfe Signale (Abb. 39), welche auf den Einzelstrang hinwiesen. Die in Wasser ergab bei einer Temperatur von $278 \mathrm{~K}$ ebenso eine geringe Signalintensität, die auf Aggregation hindeutete (Abb. 40). 


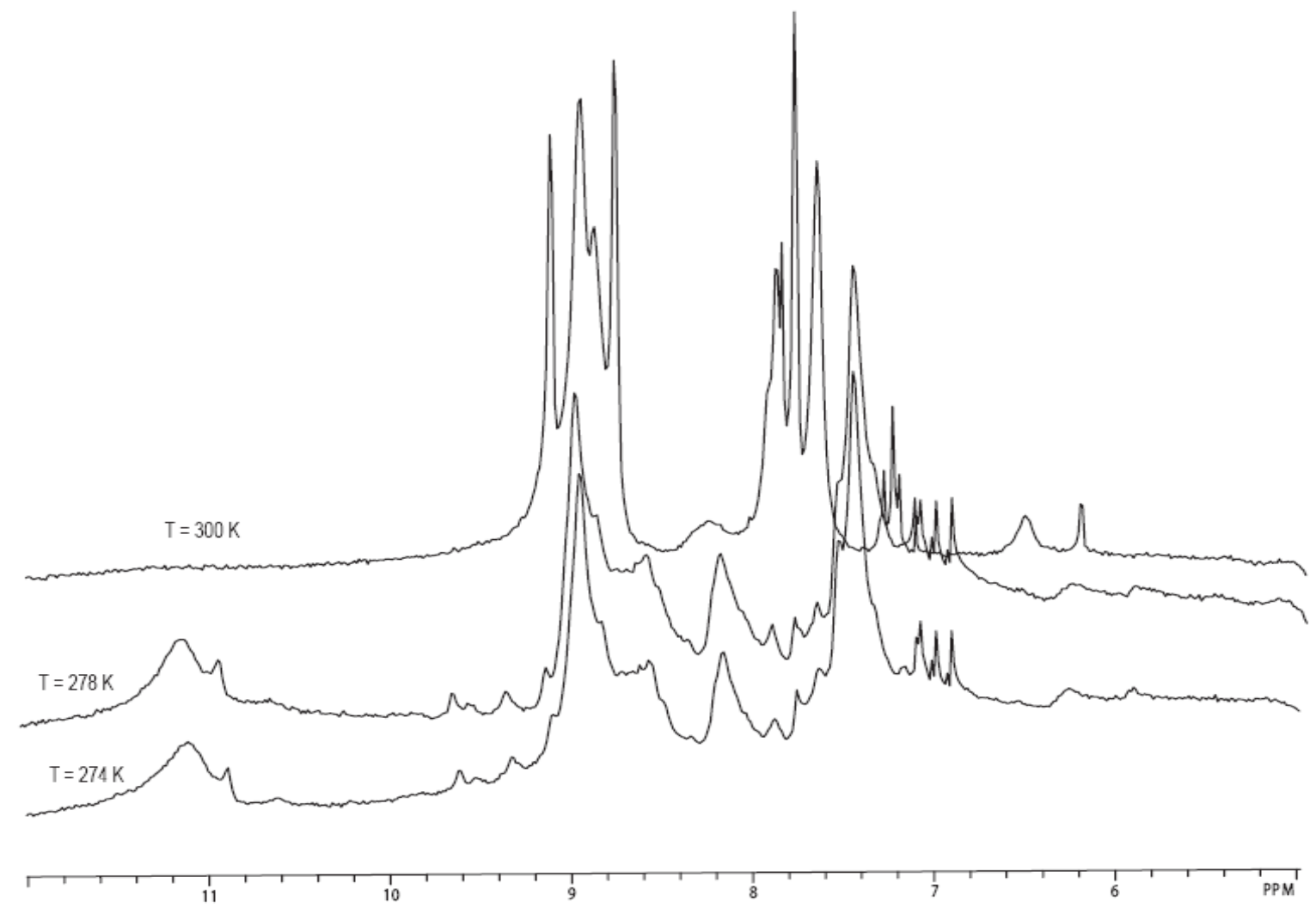

Abb. 39 1D NMR-Spektrum des H-Lys-AlaC-AlaC-AlaG-Lys-AlaG-AlaG-Lys-OH (62) in Puffer 1 bei $274 \mathrm{~K}$ bei $278 \mathrm{~K}$ und $300 \mathrm{~K}$.

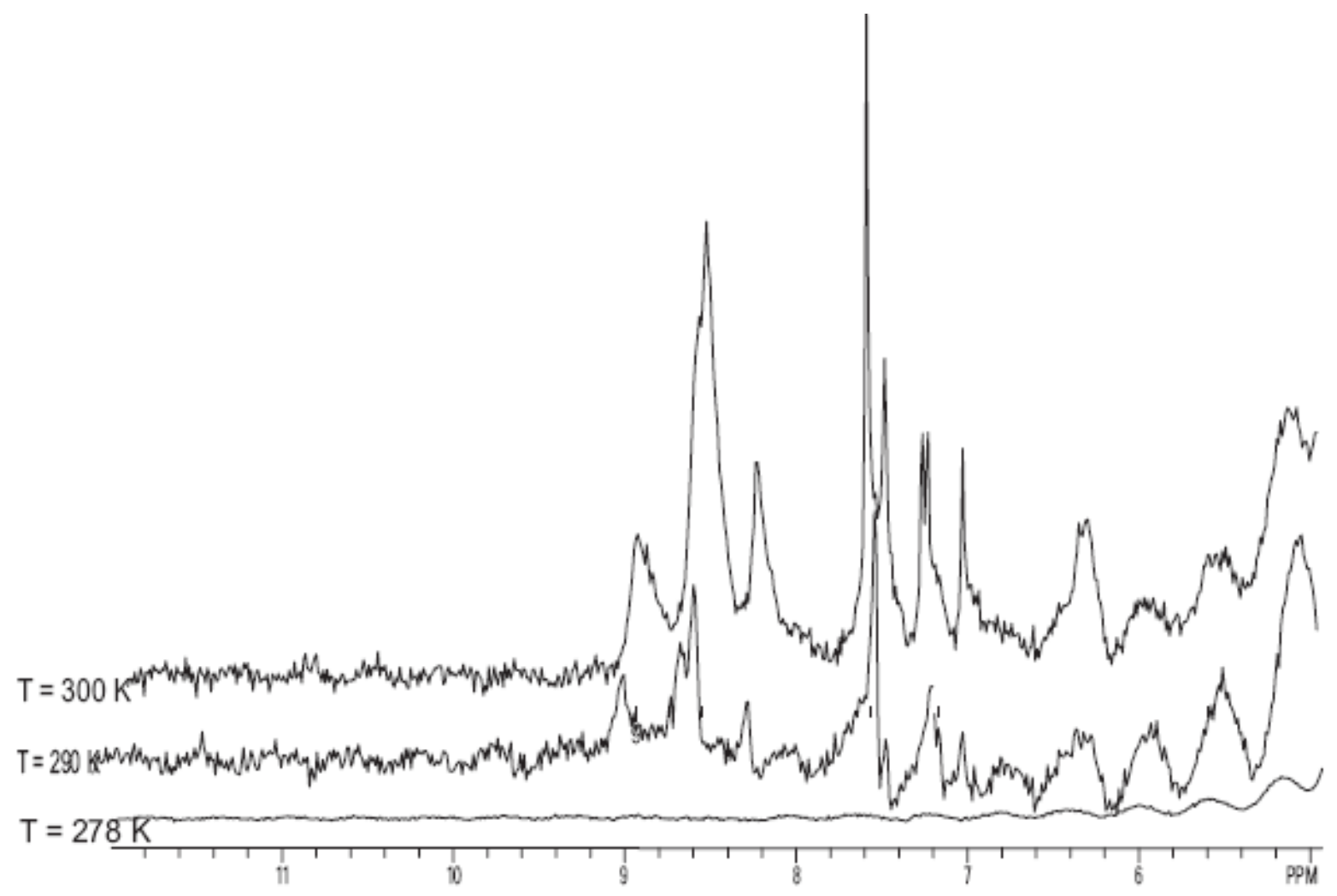

Abb. 40 1D NMR-Spektrum des H-Lys-AlaC-AlaC-AlaG-Lys-AlaG-AlaG-Lys-OH (62) in Wasser bei $278 \mathrm{~K}$ bei $290 \mathrm{~K}$ und $300 \mathrm{~K}$. 
Oberhalb von $278 \mathrm{~K}$ wurden Signale im gewünschten Bereich erhalten, jedoch die der Einzelstrangaggregation. Die Vermessung der Selbstpaarung war hier nicht erfolgreich. Weiter wurde das Oligomer H-AlaC-AlaC-AlaG-Lys-AlaGAlaG-Lys-OH (62) mit dem Gegenstrang H-AlaC-AlaC-Glu-AlaC-AlaG-AlaGLys-OH (61) (3 mM) im Ammoniumacetat Puffer 2 (10 mM Ammoniumacetat $/ 100 \mathrm{mM} \mathrm{NaCl}, \mathrm{pH}=6.5$ ) vermessen. Auch hier wurden Aggregationen beobachtet, jedoch bei einer Temperatur von $305 \mathrm{~K}$. Da die Aggregationen im $\mu \mathrm{M}$-Bereich nicht auftraten, wurde die NMR-Probe einer Verdünnungsreihe unterzogen. Die Probe wurde auf $1.5 \mathrm{~mm}, 1 \mathrm{mM}$ und $0.75 \mathrm{~mm}$ verdünnt, wobei man bei Verringerung der Konzentration eine bessere Löslichkeit erkannte. Nach einigen Stunden wurde ein Niederschlag nachgewiesen, welcher auf eine erneute Aggregation hinwies. Die Vermessung des Doppelstranges der Alanyl-PNA in noch niedrigeren Konzentrationsbereichen erwies sich nicht als aussagekräftig. Ein weiterer Versuch, lag darin den $\mathrm{pH}-$ Wertes auf $\mathrm{pH}=5 \mathrm{zu}$ senken, da die Iminoproteine in diesem Bereich langsamer austauschen und sie besser zu sehen sind und weiterhin die Löslichkeit der Alanyl-PNA dadurch deutlich erhöht wurde. Jedoch wurde auch bei dieser Versuchsreihe Aggregation beobachtet und somit der Doppelstrang nicht bestätigt. 


\subsection{Modifikationen im Rückgrat: $N$-methylierte Alanyl-PNA Oligomere}

Um eine eventuell vorliegende Rückgrataggregation zu unterbinden, wurden $\mathrm{N}$-methylierte Nucleoaminosäuren synthetisiert und diese in Oligomere eingebaut. Das Einbauen der $\mathrm{N}$-methylierten Nucleoaminosäuren in Oligomere erwies sich als problematisch, da die $\mathrm{N}$-methylierten Nucleoaminosäuren sowie die auf diesen folgenden Nucleoaminosäuren langsam und in geringer Ausbeute die Amid-Bindung bilden. ${ }^{[51]}$ Weiterhin gibt es bei den $\mathrm{N}$-methylierten Aminosäuren sowie den Alanyl-PNA Nucleoaminosäuren während der Abspaltung vom Harz bekannte Nebenreaktionen (Kapitel 2.1.2). Zur Abhilfe der schlechten Kupplungsausbeute der $\mathrm{N}$-methylierten Nucleoaminosäuren wurden zahlreiche Kupplungsreagenzien getestet. Es wurde das in der Literatur für $\mathrm{N}$-methylierten Aminosäuren bekannte Kupplungsreagenz Chlorotris(pyrrolidino)phophonium hexafluorophosphat (PyCloP) gewählt und die Kupplungsdauer auf $12 \mathrm{~h}$ erhöht. ${ }^{[52 \mathrm{a}-\mathrm{c}]}$ Die vorher getesteten Kupplungsreagenzien $\mathrm{BOP},{ }^{[53]} \mathrm{Cl}-\mathrm{BOP}^{[54]}$ und $\mathrm{PyBOP}^{[52 \text { a] }}$ führten zu keinen positiven Ergebnissen. Die folgenden Nucleoaminosäuren wurde mit dem Kupplungsreagenz 7-Azabenzotriazol-1-yloxytris(pyrrolidino)phosphoniumhexafluorophosphat (PyAOP) ${ }^{[55]}$ zur Reaktion gebracht. Auch hier ergab die Kupplung mittels PyBOP kein entsprechend positives Ergebnis. Diese wurde mittels einer Doppelkupplung von je $12 \mathrm{~h}$ erreicht. Anschließend wurde das Peptid mittels $m$-Cresol/TFA/TFMSA (1:8:1) vom Harz abgespalten. Hierbei kommt es zur Nebenreaktion, da Oligomere mit einer $N$-methylierten Aminosäure nicht säurestabil sind (Kapitel 1.2). ${ }^{[56 \text { a-b] }}$

Die folgenden Sequenzen $\mathrm{H}$-(Me)AlaC-AlaC-AlaG-AlaC-AlaG-AlaG-Lys- $\mathrm{NH}_{2}$ (67) und $\mathrm{H}-\mathrm{AlaC}-\mathrm{AlaC}-(\mathrm{Me}) \mathrm{AlaG}-\mathrm{AlaC}-\mathrm{AlaG}-\mathrm{AlaG}-\mathrm{Lys}-\mathrm{NH}_{2}$ (68) wurden trotz erheblicher Ausbeuteverluste durch die Nebenreaktionen hergestellt. Hierbei war die Synthese des Oligomers 67 am einfachsten, da sich der $N$-methylierte Baustein am $\mathrm{N}$-Terminus befand und somit die Hydrolyse erschwert bzw. gar nicht stattfindet. Bei dem Oligomer 68 wurde die Ausbeute um die Hälfte verringert (Abb. 41). 
a. H-(Me)AlaG-AlaC-AlaG-AlaG-Lys-NH2 und b. H-AlaC-AlaC-(Me)AlaG-AlaC-AlaG-AlaG-LysNH2

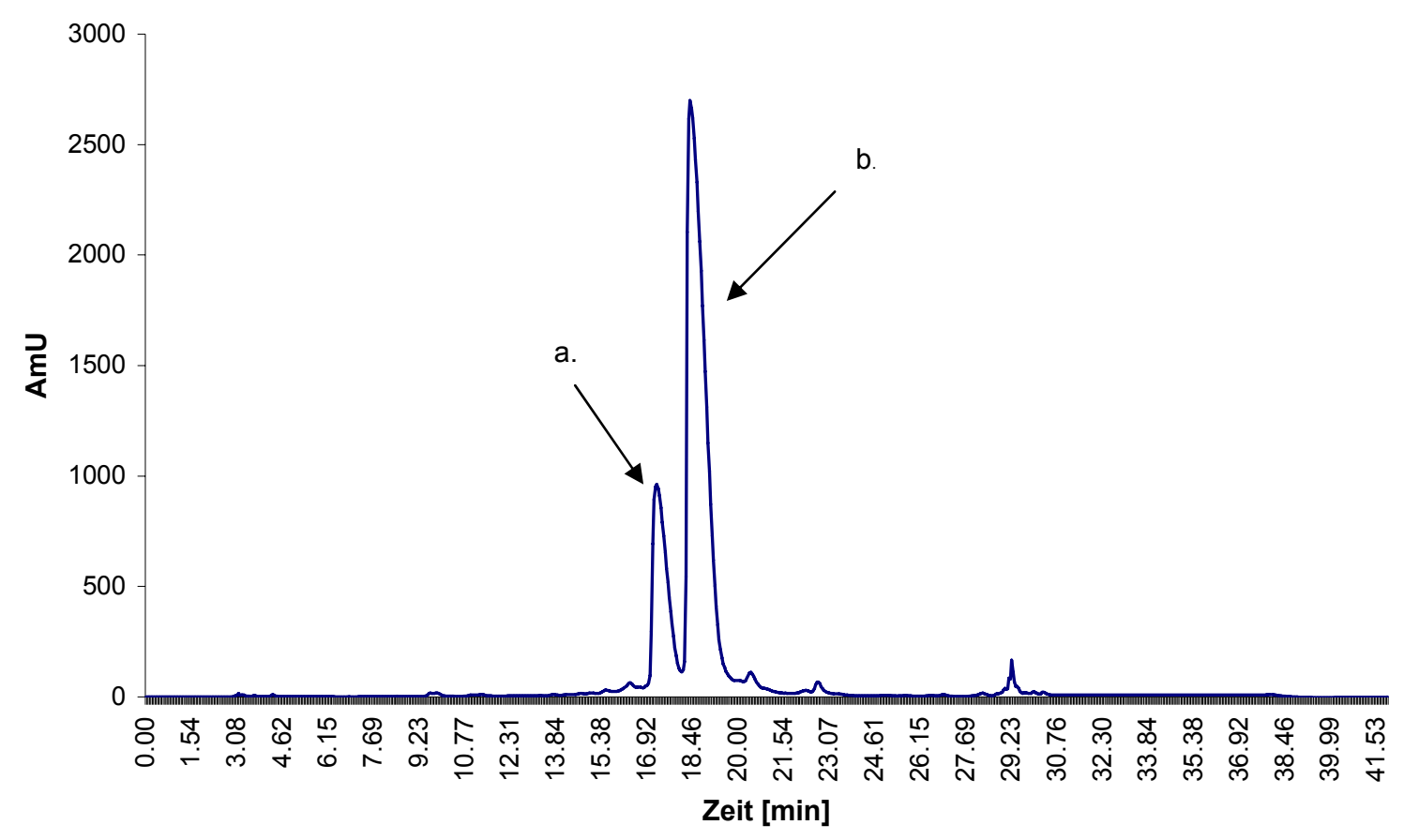

Abb. 41 HPLC-Diagramm des Oligomers H-AlaC-AlaC-(Me)AlaG-AlaC-AlaG-AlaG-Lys- $\mathrm{NH}_{2} 68$ (b) und dessen hydrolysierten Abspaltprodukt (a), Gradient:5 auf $20 \%$ Acetonitril in 30 min.

Die $N$-methylierten Oligomere 67 und 68 wurden UV-spektroskopisch untersucht. Das Oligomer 67 wies bei der Untersuchung der Selbstpaarung eine niedrige Schmelztemperatur von $\mathrm{T}_{m}=18^{\circ} \mathrm{C}$ auf, was auf eine Störung der Paarung hinwies (Abb. 42). Da sich hier die Methylgruppe jedoch $N$-Terminal befindet, wurden trotz der niedrigen Selbstpaarung keine hohen Stabilitätsverluste bei einer Duplexbildung mit einem Gegenstrang erwartet. Das Oligomer 67 wies zwei Schmelztemperaturübergänge von $T_{m}=14{ }^{\circ} \mathrm{C}$ und $\mathrm{T}_{m}=47^{\circ} \mathrm{C}$ auf (Abb. 43). Im Vergleich zum Doppelstrang des nicht methylierten Alanyl-PNA Oligomers 58 mit $\mathrm{T}_{m}=42{ }^{\circ} \mathrm{C}$ ist die geringe Stabilität der beiden methylierten Oligomere $68 \mathrm{~T}_{m}=14{ }^{\circ} \mathrm{C}$ (Abb. 42) und $67 \mathrm{~T}_{m}=18{ }^{\circ} \mathrm{C}$ (Abb. 43) unerwartet. Möglicherweise wirkt sich die Methylierung auf die Rückgratkonformationen und die Kinetik der Duplexbildung aus. Die Stabilität 
von $\mathrm{T}_{m}=47^{\circ} \mathrm{C}$ (Abb. 43) für das methylierte Alanyl-PNA Oligomer 68 entspricht recht genau den Erwartungen, da Methylierung sich auch hinsichtlich der Solvathülle auswirken sollte.

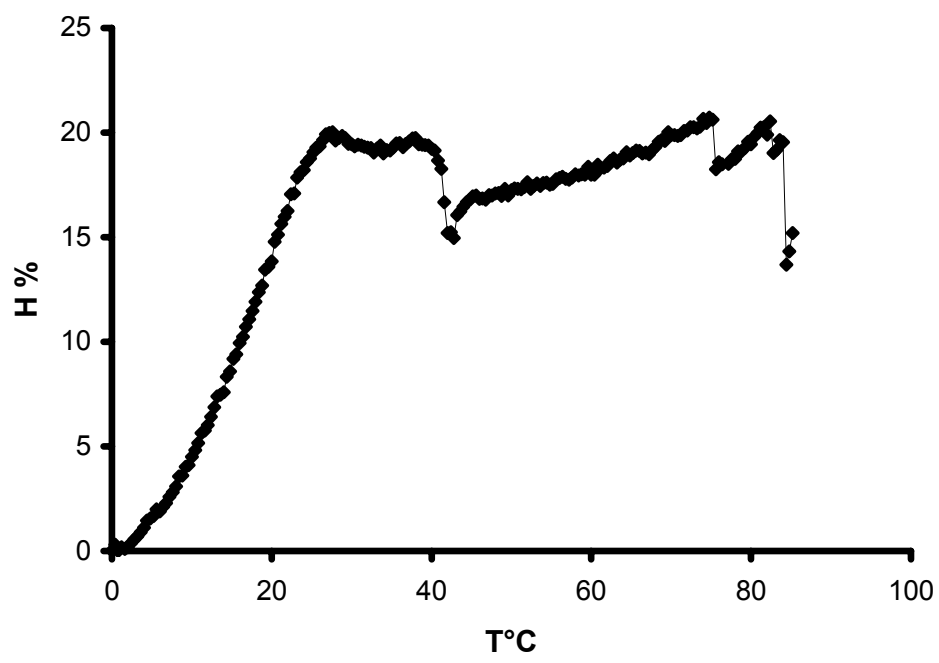

Abb. 42 Oligomer 67 bei c $=6 \mu \mathrm{M}, \lambda=260 \mathrm{~nm}$, im Puffersystem $1\left(10 \mathrm{~mm} \mathrm{Na} \mathrm{HPO}_{4} / \mathrm{H}_{3} \mathrm{PO}_{4}, 100 \mathrm{~mm}\right.$ $\mathrm{NaCl} ; \mathrm{pH}=7.0) \mathrm{T}_{m}=18^{\circ} \mathrm{C}$

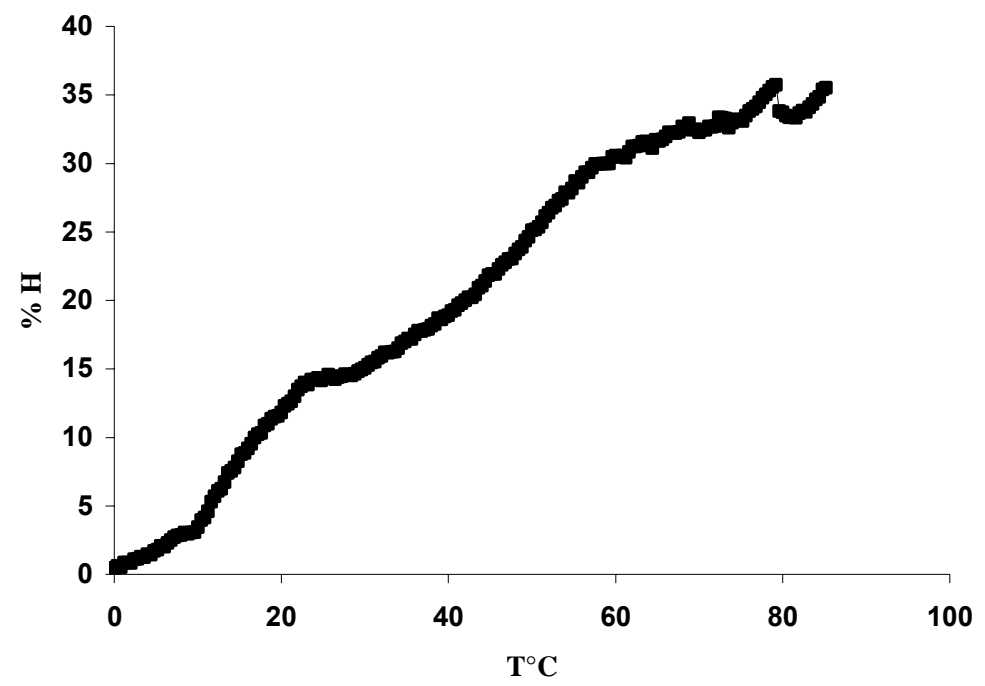

Abb. 43 Oligomer 68 bei c $=6 \mu \mathrm{M}, \lambda=260 \mathrm{~nm}$, im Puffersystem $1\left(10 \mathrm{~mm} \mathrm{Na} 2 \mathrm{HPO}_{4} / \mathrm{H}_{3} \mathrm{PO}, 100 \mathrm{~mm}\right.$ $\mathrm{NaCl} ; \mathrm{pH}=7.0) \mathrm{T}_{m}=14{ }^{\circ} \mathrm{C}$ und $\mathrm{T}_{m}=47^{\circ} \mathrm{C}$. 
Die Alanyl-PNAs 67 und 68 wurden auch NMR-spektroskopisch untersucht, wobei in einem wässrigen System gemessen wurde. Die Untersuchung des Oligomers 67 führte leider ebenfalls zur Aggregation. Diese konnte durch die endständige, $N$-terminale Methylierung nicht unterbunden werden. Der MethylSubstituent verhindert nur geringfügig, die Wechselwirkungen über das Rückgrat. Oligomer 68 sollte zu besseren Ergebnissen führen, da sich die Methylierung in der Mitte der Sequenz befindet und somit ein ausreichender Verlust der Rückgratwechselwirkung erhofft wurde. Diese Ergebnisse stehen noch aus.

Zur Verbesserung der Ausbeute und der Aggregation könnte neben der Methylierung ein Einbau von reversiblen N-Schutzgruppen am Peptidrückgrat in Erwägung gezogen werden. Mit der Entwicklung der N-(2-Hydroxy-4methoxybenzyl)-Schutzgruppe $(\mathrm{Hmb})$ ist es möglich, bisher schwer zugängliche Sequenzen effizienter zu synthetisieren. ${ }^{[57]}$ Die sterische Hinderung, die durch den $N$-Alkylrest verursacht wird, verringert die Acylierungs-geschwindigkeit für die Aminokomponente. Diese Möglichkeiten kann aber nur begrenzt angewendet werden, da sie schon bei der Kupplung von Valin an (Hmb)- Valin versagt. ${ }^{[58]}$ Eine weitere temporäre $N$-Schutzgruppe ist die Dimethoxybenzylschutzgruppe (Dmb). Auch wenn assoziationsbedingte Syntheseschwierigkeiten durch die Einführung temporärer Amidschutzgruppen reduziert werden können, so erwächst daraus das Problem der sterischen Hinderung bei Kupplungen an N-Alkylaminosäurereste.

\section{5 a-Peptid/Alanyl-Peptidnucleinsäure-Chimäre}

\subsection{Synthese und Stabilitätsverhalten der $\alpha$-Peptid/Alanyl-Peptid- nucleinsäuren}

In vorherigen Arbeiten, wurde ein Gramicidin-S Analogon mit einer $\mathrm{N}$ terminalen Alanyl-PNA Sequenz mittels SPPS darstellt. (Abb. 44). ${ }^{[59]} \mathrm{Bei}$ Zugabe eines komplementären Alanyl-PNA Oligomers wurde eine Doppelstrangbildung mit $\beta$-Faltblattstruktur ausgebildet und damit ein Einfluss bzw. 
eine Strukturveränderung hervorgerufen. In diesem Gramicidin-S Analogon dienten die Aminosäuren D-Pro und Phe als turn Bildner. Wie theoretisch erwartet wurde bei UV-Messungen keine Selbstpaarung ermittelt. Erst bei Zugabe des komplementären Gegenstrangs konnte die erwartete Doppelstrangbildung $\left(T_{m}=49^{\circ} \mathrm{C}\right)$ nachgewiesen werden. Dieser ermittelte Wert korreliert gut mit den Werten eines Doppelstranges mit den Alanyl-PNA Oligomeren 15 und 16.

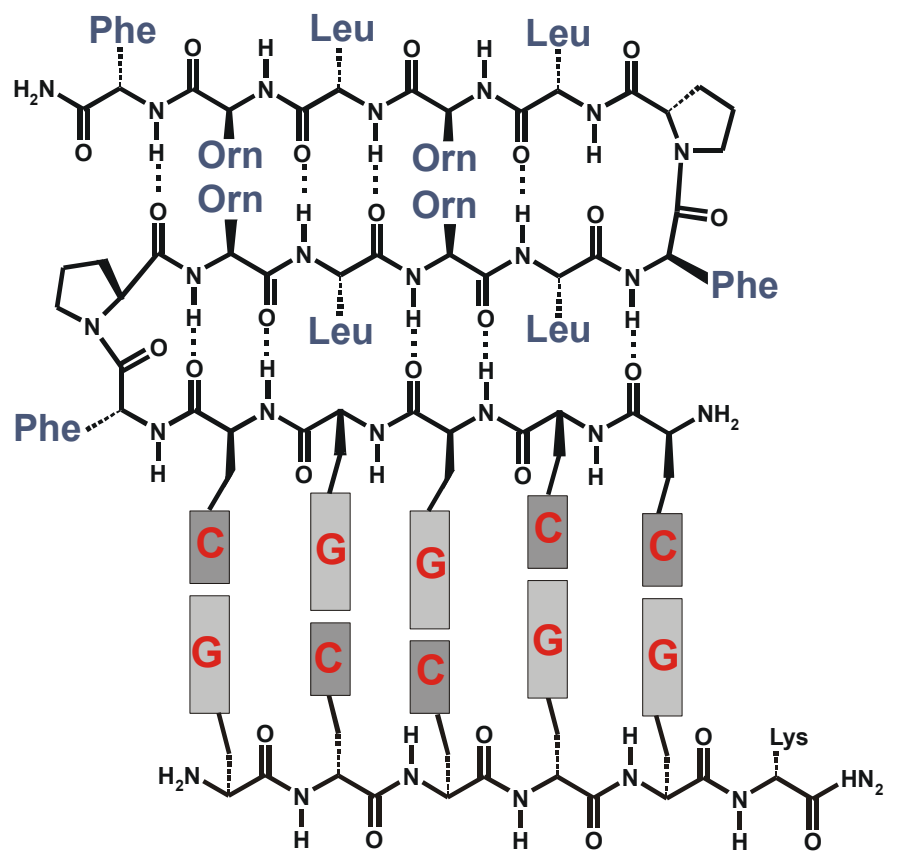

Abb. 44 Alanyl-PNA/Peptid Chimera. Duplexbildung mit dem komplementären Alanyl-PNA Oligomer welches $\beta$-sheet Bildung induzieren kann.

NMR-Studien zeigten jedoch, dass das Gramicidin/Alanyl-PNA Chimäre System als Einzelstrang bereits eine erhebliche Preorganisation des $\beta$-Faltblatts aufwies, so dass dieses Modell-System für die Konformationsänderungsuntersuchungen zu stabil war.

Die Alanyl-PNA sollte in Modellpeptide und Proteine als Teil eines $\beta$-Faltblattes (Doppelstrang) oder eines gestörten $\beta$-Faltblattes (Einzelstrang) eingebaut werden und somit eine Schaltfunktion durch Stabilisierung oder Destabilisierung erreichen. Weiterhin wäre die Möglichkeit gegeben, komplementäre PNAs in zwei oder mehr unterschiedliche Proteine einzubauen und somit eine gegenseitige Erkennung durch die Alanyl-PNA Oligomere zu 
erreichen. Dadurch würde die Möglichkeit gegeben, Proteine zu steuern, sie zu stabilisieren bzw. zu destabilisieren oder gezielt zu schalten (Kapitel 2.1.1). Auf dem Wissen aus Kapitel 2.1.1 gestützt wurde für diese Arbeit eine durch Gellmann et al. NMR-spektroskopisch untersuchte und als $\beta$-Faltblatt ausgewiesene Sequenz 69 ausgewählt (Abb. 45). ${ }^{[60]}$

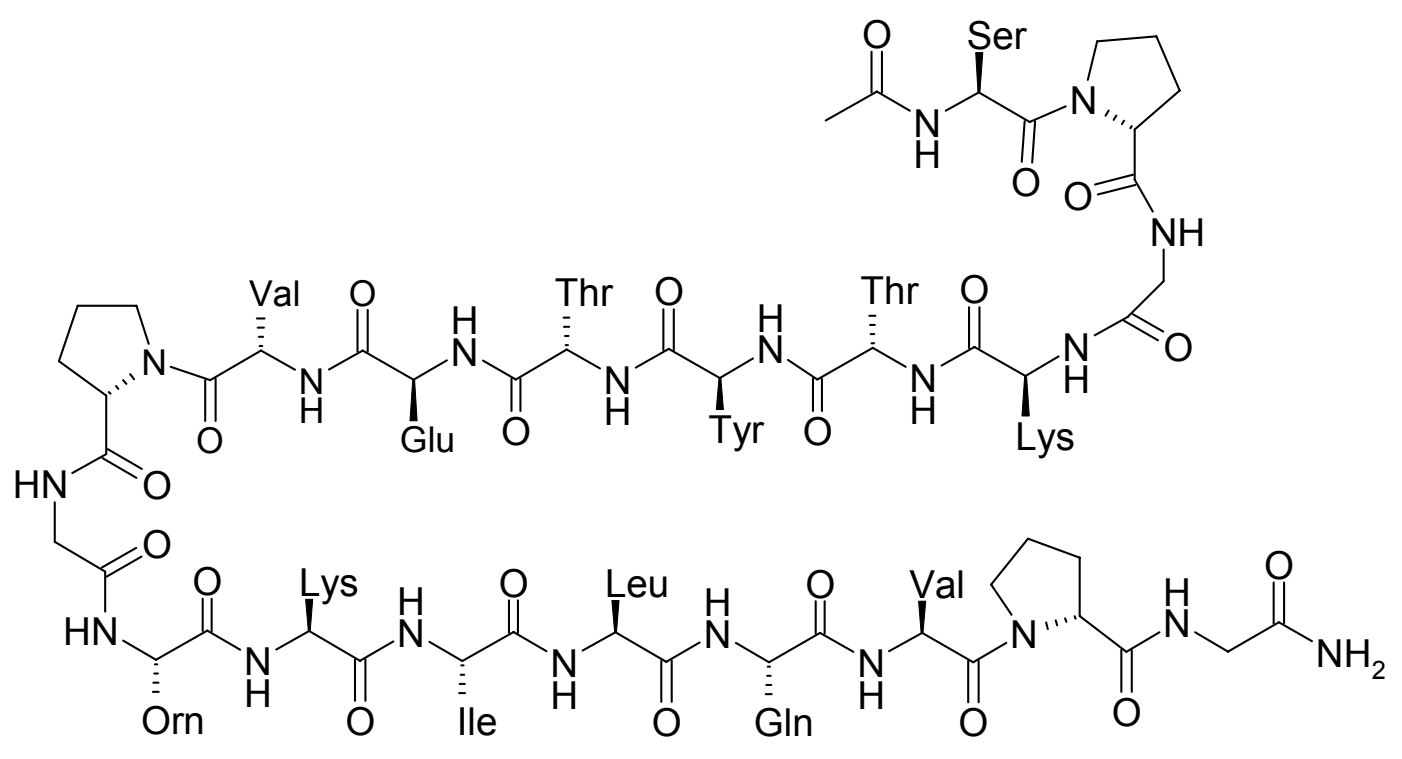

69

Abb. 45 Teilausschnitt des von Gellmann et. al. vorgestellten Peptids 69.

Dieses Modell-Peptid enthält den gut beschriebenen turn-Bildner D-Pro-Gly und weiterhin ein durch Wasserstoffbrücken und Ladungserkennung stabilisiertes $\beta$-Faltblatt. ${ }^{[60]}$ Als Erkennungseinheit wurde ein Alanyl-PNA Hexamer H-AlaC-AlaC-AlaG-AlaC-AlaG-AlaG-Lys- $\mathrm{NH}_{2}$ (16), welches am $C$-Terminus verknüpft wurde, verwendet. Die Verknüpfung der Alanyl-PNA mit dem Peptid erwies sich mittels Boc-Strategie als schwierig. Zur Optimierung wurden zusätzlich zu einer Doppelkupplung der Aminosäuren die Kupplungsreagenzien variiert (Tab. 3). 


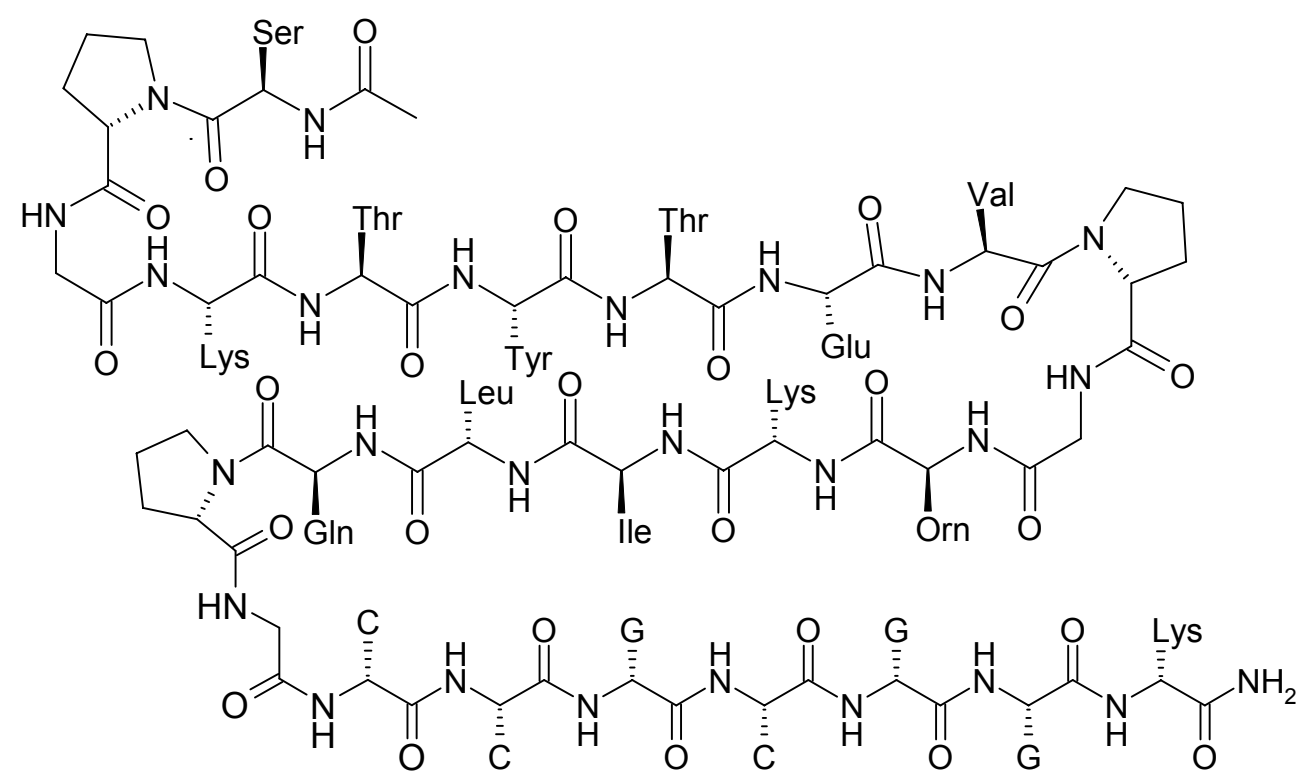

70

Abb. 46 Modellpeptid/Alanyl-PNA Sequenz $\mathbf{7 0 .}$

Neben den verwendeten Aktivatoren HATU und HOAt $(\mathbf{A})$, wurden HCTU und $\mathrm{Cl}-\mathrm{HOBt}(\mathbf{B})$ und HBTU und HOBt (C) als Kupplungsreagenzien getestet, was sich jedoch nicht als erfolgreich herausstellte. Auch der Einsatz einer $0.4 \mathrm{M}$ LiCl-Lösung (D), um den Lithium-Salz Effekt auszunutzen, um somit vorhandene Preorganisationen am Harz zu unterdrücken, brachte keine positiven Ergebnisse. ${ }^{[61 \text { a-b] }}$ Eine weitere Variante (E) war die Darstellung des Alanyl-PNA Oligomers 70 nach der Boc-Strategie und ein Wechsel auf die Fmoc-Strategie ab der Aminosäure Glycin. Auch hier wurden verschiedene Aktivatoren getestet, was jedoch nicht zum gewünschten Produkt führte.

Abhilfe versprachen chemische Ligationsmethoden. Diese wurden entwickelt, um größere Peptidsequenzen aus kleinen Fragmentsequenzen zu

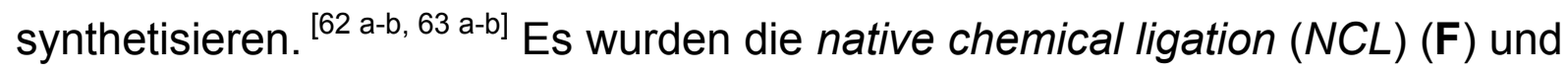
eine neuere Methode, die extendet chemical ligation (ECL) (G) die auf der NCL beruht in Erwägung gezogen. Die ECL beinhaltet die Darstellung einer $N^{\alpha}$-(1-Phenyl-2-mercaptoethyl) Aminosäure. Sie stellt weiterhin eine Ligationsmethode ohne Cystein dar (Kapitel 2.2). ${ }^{[64 \text { a-b] }}$ Die NCL Ligation führte nicht zum gewünschten Ergebnis, da sich das Cystein nicht an das Alanyl-PNA Hexamer und auch nicht zwei Aminosäuren weiter, nach dem D-Prolin, kuppeln ließ. Auch hier wurden verschiedene Lösungsmittel, 
Kupplungsreagenzien und Seitenschutzgruppen des Cysteins, StBu, Trityl (Trt) und Acetamidomethyl (Acm) eingesetzt. Die ECL Ligationsmethode wurde aufgrund der notwendigen Darstellung des $N^{\alpha}$-(1-Phenyl-2mercaptoethyl) Aminosäure-Derivates verworfen (Kapitel 2.2).

\begin{tabular}{|c|c|c|}
\hline Variante & Variation & Ergebnis \\
\hline A & HATU/HOAt & kein Umsatz \\
\hline B & HCTU/Cl-HOBt & kein Umsatz \\
\hline C & HBTU/HOBt & kein Umsatz \\
\hline D & HCTU/Cl-HOBt/LiCl-Lösung & kein Umsatz \\
\hline E & Alanyl-PNA auf Boc-Strategie./Peptid auf Fmoc- \\
Strategie & kein Umsatz \\
\hline F & native chemical ligation & kein Umsatz \\
\hline G & extended chemical ligation & kein Umsatz \\
\hline H & C-terminal Peptid/N-terminal Alanyl-PNA & kein Umsatz \\
\hline I & C-terminal Peptid/N-terminal Alanyl-PNA, Austausch & kein Umsatz \\
von turn Bildner auf Asn & kein Umsatz \\
\hline J & convergent method & kein Umsatz \\
\hline K & zwei Mal Glycin einfügen, Boc-Strategie & Umsatz \\
\hline L & zwei Mal Glycin einfügen, Alanyl-PNA Boc- \\
Strategie/Peptid Fmoc-Strategie & \\
\hline
\end{tabular}

Tab. 2 Variation der Kupplungsbedingungen und verschiedene Synthesestrategien.

Eine weitere Überlegung $(\mathbf{H})$ ging dahin, erst das Peptid (C-terminal) und anschließend das Alanyl-PNA Oligomer $N$-terminal anzuschließen (Abb. 47). Hierzu wurde ein Boc-Glu(OBzl)-MBHA Harz verwendet. Das Polypeptid 72 wurde mittels Boc-Strategie aufgebaut. Dabei wurden die Aktivatoren HATU und HOBt verwendet. 


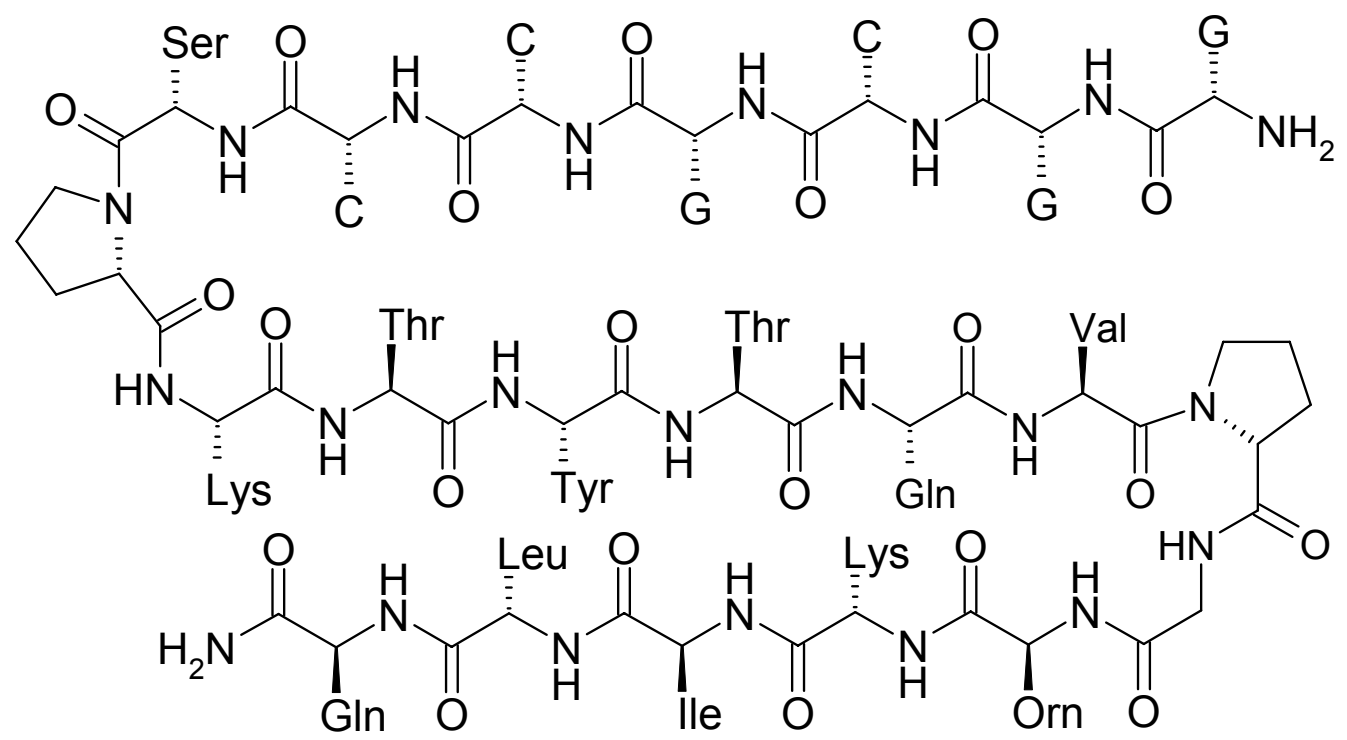

Abb. 47 Modellpeptid/Alanyl-PNA Sequenz 71 ( $G$ = Guanin, C = Cytosin).

Der Versuch führte ebenfalls nicht zum gewünschten Ergebnis. Auch die Variation des turn Bildners von D-Pro auf Asn (I) brachte nicht das gewünschte Produkt. Es wurde angenommen, dass die Voraggregation zu stark war, so dass das Harz nicht mehr ausreichend quellen konnte und eine Anlagerung, auch aus Gründen der geringen Abstände der einzelnen Seitenketten des $\beta$-Faltblatts, verhindert wurde.

Im nächste Ansatz $(\mathbf{J})$ wurden einzelne voll geschützte Peptidfragmente hergestellt, wobei die Problematik entstand, dass die gewählten Schutzgruppen sowohl gegen Fmoc- (da man sie mittels dieser aufbauen wollte und die Fmoc-Strategie am häufigsten und erfolgreichsten ist), als auch Boc-Chemie (jeweils an den $\mathrm{N}$-termini), stabil sein sollten. Das Alanyl-PNA Hexamer wurde, wie schon beschrieben, hergestellt und am Harz belassen. Die Peptidfragmente wurden am H-Gly-2-Cl-Trt-Harz aufgebaut. Ein Fragmentteil war Boc-Lys-Thr-Tyr-Thr-Glu-Val-Pro-Gly-Orn-Lys-Leu-GIn-ValPro-Gly mit den Schutzgruppen 4-Methyltrityl (Mtt) für Ornitin (Orn), Benzyloxycarbonyl (Z) für Lysin (Lys), Benzyloxy (OBzl) für Glutaminsäure (Glu), 2-Bromobenzyloxycarbonyl (2-Br-Z) für Tyrosin (Tyr) sowie Benzyl (Bzl) 
für Threonin (Thr). Die letzte Aminosäure musste Boc-geschützt sein, da die Gesamzsequenz zur Boc-Strategie kompatibel sein sollte

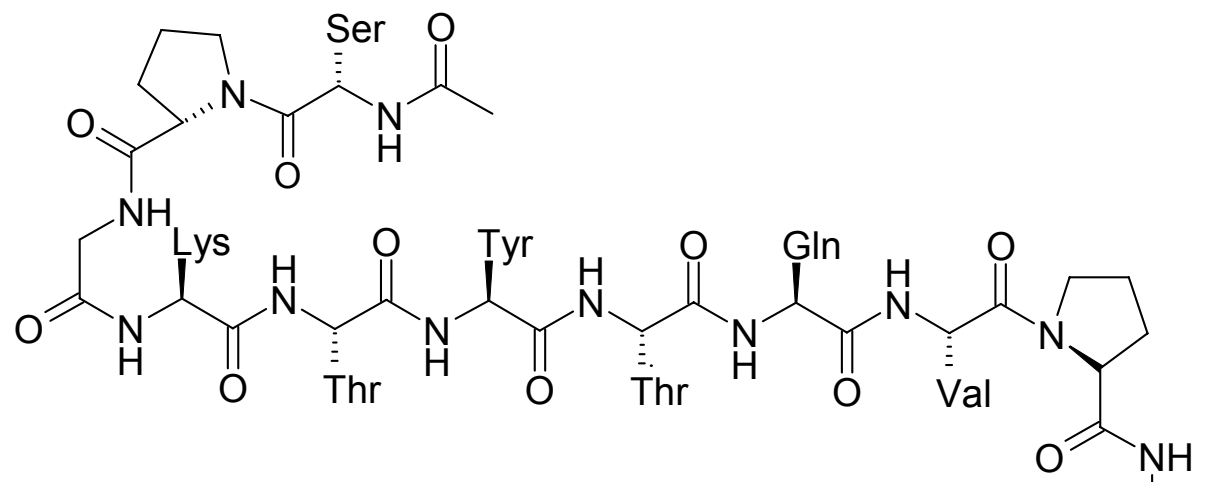

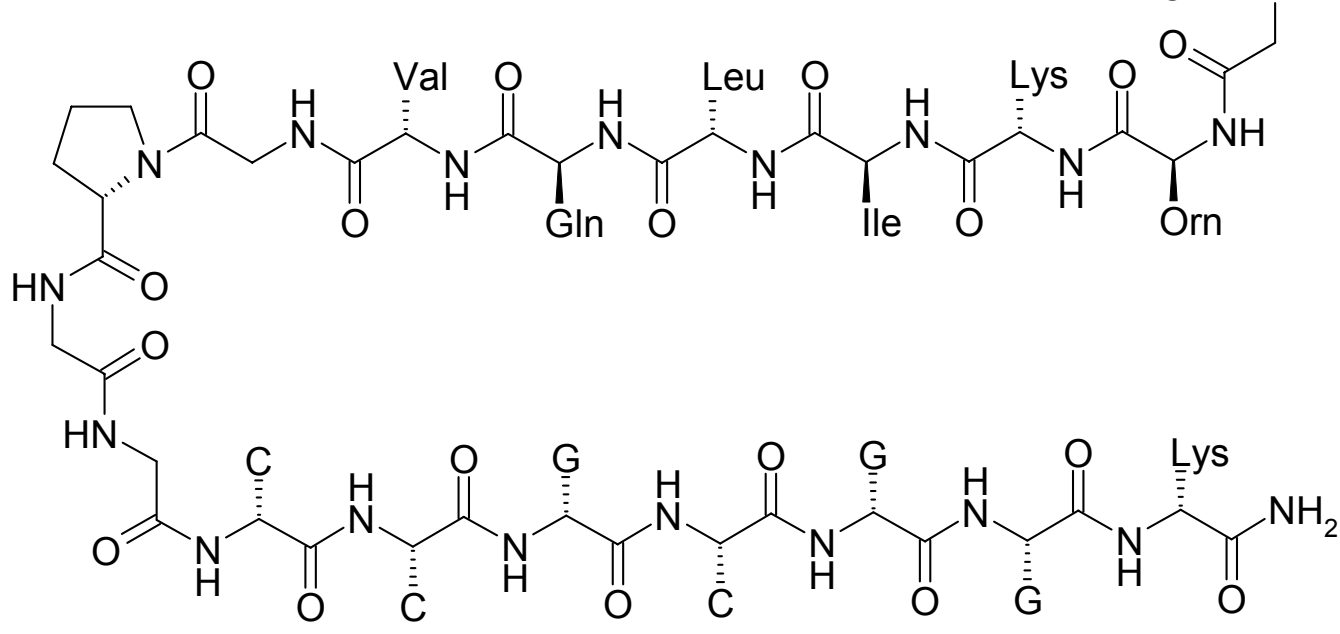

72

Abb. 48 Modellpeptid/Alanyl-PNA Sequenz 72 verlängert durch zwei Aminosäuren Gly.

Die Abspaltung erfolgte mittels Hexafluoroisopropanol (HFIP) in Dichlormethan (DCM). Dieser Versuch ergab nicht die gewünschten Oligomere. Bei Methode J musste $C$-terminal immer ein Glycin vorhanden sein, so dass das Peptid in drei Teile zerlegt wurde: a. C-terminal die Alanyl-PNA am MBHA-Harz; b. die Sequenz Boc-Lys-Thr-Tyr-Thr-Glu-Val-Pro-Gly und c. N-terminal Val-Phe-IleThr-Ser-Pro-Gly (Schutzgruppen: Benzyl (Bzl) für Serin (Ser)). Die Sequenzen b. und c. wurden vollständig geschützt an H-Gly-2-Cl-Trt-Harz aufgebaut. Während die Synthese der Oligomere $\mathbf{a}$ und $\mathbf{b}$ verwirklicht werden konnte, gelang die für Oligomer c nicht, so dass auch diese Strategie verworfen wurde. Näheres Betrachten des vorliegenden turn-Bildners und dessen Umgebung führte zu der Annahme, dass der turn sterisch gehindert sein 
könnte. Daher, wurde der turn weiter nach außen verlegt, indem zwei Aminosäuren (Gly) eingeschoben wurden (Abb. 48) (K). Erst die Zweiteilung der Synthese in a. Boc-Strategie unter Verwendung von HATU und HOAt als Aktivatoren für den Alanyl-PNA Teil und b. Fmoc-Strategie unter Verwendung von HCTU und $\mathrm{Cl}-\mathrm{HOBt}$ als Kupplungsreagenzien für den Peptidteil ab der Aminosäure Gly brachte das gewünschte Produkt (L). Beide Strategien wurden wegen der besseren Löslichkeit der Alanyl-Nucleobasen und der Aminosäuren im Lösungsmittel NMP durchgeführt.

Die darauf folgenden UV-Schmelzkurven ergaben die folgenden Ergebnisse (Abb. 49, 51 a/b). Um das Stabilitätsverhalten der a-Peptidnucleinsäuren noch besser diskutieren zu können, wurde im Phosphat-Puffer die Selbstpaarung der intakten Sequenz H-AlaC-AlaC-AlaG-AlaC-AlaG-AlaG-Lيys- $\mathrm{NH}_{2}$ gemessen. Hierbei wurden Schmelztemperaturen von $\mathrm{T}_{m}=16^{\circ} \mathrm{C}$ und $\mathrm{T}_{m}=35^{\circ} \mathrm{C}$ ermittelt.

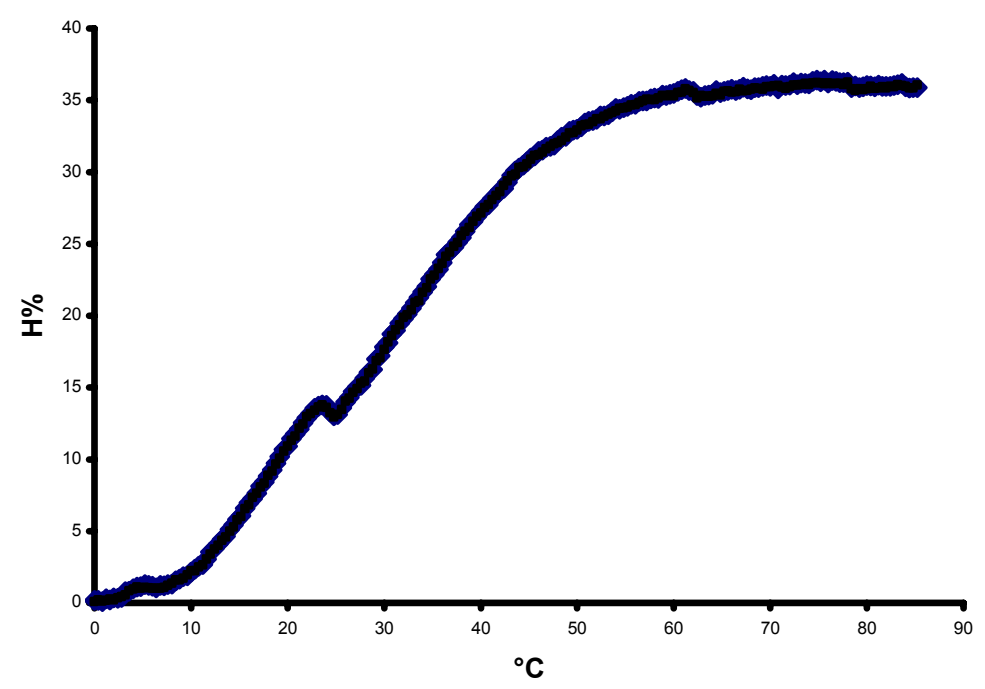

Abb. 49 Oligomer 15 in Phosphat Puffer 1, Selbstpaarung, bei c $=6 \mu \mathrm{M}, \mathrm{T}_{m}=16{ }^{\circ} \mathrm{C}$ und $\mathrm{T}_{m}=35^{\circ} \mathrm{C}$.

Aufgrund früherer Arbeiten war eine Stabilität von $\mathrm{T}_{m}=42^{\circ} \mathrm{C}$ zu erwarten. Für das Auftreten einer Schmelztemperatur bei $T_{m}=16{ }^{\circ} \mathrm{C}$ gibt es keine plausibel Erklährung. In Abbildung 50 sind die möglichen antiparallelen homochirale 
Duplexbildungen der Peptid-Alanyl-PNA/Alanyl-PNA Gegenstrangoligomer (Abb. 50 A) und a-Peptid-Alanyl-PNA/a-Peptid-Alanyl-PNA Selbstpaarung (Abb. 50 B) dargestellt.

A.

$$
\begin{aligned}
& \text { Peptid-C-C- -G- } \underline{\text { C-G-G-Lys }}
\end{aligned}
$$

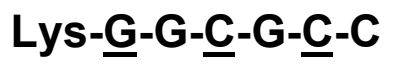

$$
\begin{aligned}
& \text { antiparallel, heterochiral }
\end{aligned}
$$

B.

\section{Peptid-C- $\underline{C}-\mathbf{G}-\underline{C}-$ G-G-Lys}

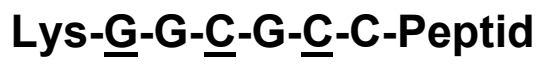

antiparallel, heterochiral

Abb. 50 Paarungsmöglichkeiten des Peptid 72 mit und ohne Gegenstrang 15.

Für die Selbstpaarung der Peptid/PNA Sequenz 72 wurde eine Schmelztemperatur von $\mathrm{T}_{m}=16{ }^{\circ} \mathrm{C}$ und $\mathrm{T}_{m}=35^{\circ} \mathrm{C}$ ermittelt (Abb. $51 \mathrm{~b}$ ). Dies ist vergleichsweise mit einer reverse Watson-Crick Selbstpaarung der AlanylPNA ein erniedrigter Wert. Für das Peptid/Alanyl-PNA Chimära 72 mit dem Gegenstrang H-AlaC-AlaC-AlaG-AlaC-AlaG-AlaG-Lys (15) wurde ein dominanter Übergang von $\mathrm{T}_{m}=24^{\circ} \mathrm{C}$ gefunden (Abb. $51 \mathrm{a}$ ).

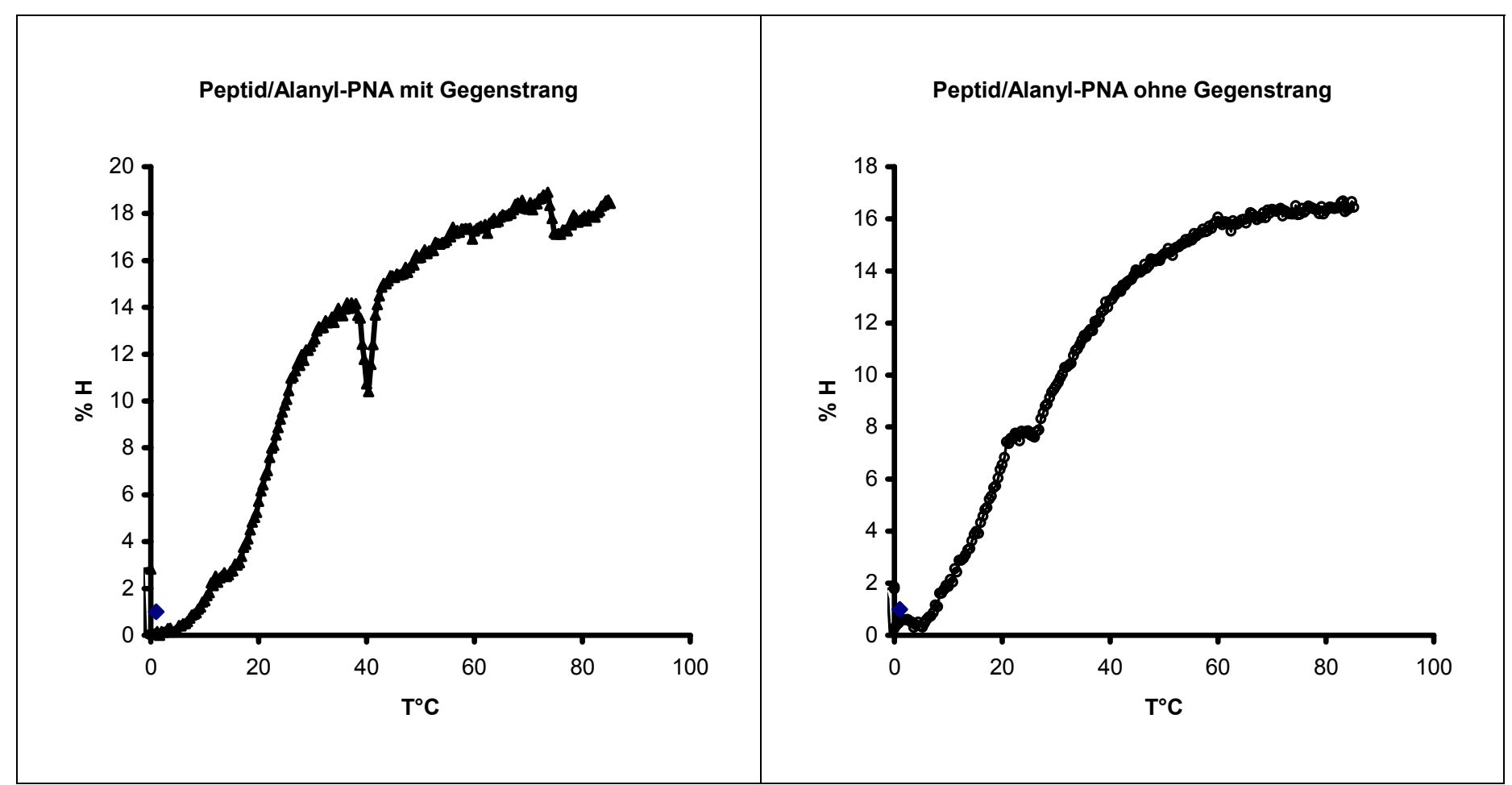

Abb. 51 Peptid/Alanyl-PNA Modellsequenz 72 a. mit Gegenstrang $\mathrm{T}_{m}=12{ }^{\circ} \mathrm{C}$ und $\mathrm{T}_{m}=24^{\circ} \mathrm{C}$ b. ohne Gegenstrang $\mathrm{T}_{m}=16{ }^{\circ} \mathrm{C}$ und $\mathrm{T}_{m}=35^{\circ} \mathrm{C}$ im Puffersystem 1 , Konzentration je $\mathrm{c}=6.0 \mu \mathrm{M}$. 
Es kann nicht mit Sicherheit auf die Ausbildung eines Heteroduplexes geschlossen werden. Aus diesem Grund wurde eine Sequenz untersucht die neben einer Verkürzung der Sequenz einen anderen turn-Bildner aufweist (Asn-Gly), der in der Literatur als nicht so stabil und eindeutig beschrieben wird (Abb. 52). ${ }^{[65]}$ Die Sequenz des Testpeptid/Alanyl-PNA Oligomers weist nur einen turn auf, was eine größere Beeinflussung durch den Alanyl-PNA Gegenstrang vermuten lässt. Es wurden Stabilitätsuntersuchungen durchgeführt. Das Ergebnis der Selbstpaarung des Oligomers 73 wies eine Stabilisierung von $\mathrm{T}_{m}=18^{\circ} \mathrm{C}$ auf (Abb. $53 \mathrm{~b}$ ), was sich mit der Stabilität des Peptides 72deckt und somit nicht von der Länge der Sequenz, sondern nur von dem Alanyl-PNA Oligomer 15 im Modellpeptid 73und 72abhängig ist. Das Experiment mit dem erforderlichen Gegenstrang 15 wies zwei Übergänge von $\mathrm{T}_{m}=20^{\circ} \mathrm{C}$ und $\mathrm{T}_{m}=32^{\circ} \mathrm{C}$ auf. Hierbei wurde die Stabilität $\mathrm{T}_{m}=20^{\circ} \mathrm{C}$ der Selbstpaarung des Peptides 73 zugeordnet (Abb. 53 a). Die Stabilität bei $\mathrm{T}_{m}=32^{\circ} \mathrm{C}$ wurde der Stabilisierung durch den Gegenstrang zugeordnet (Abb. 53 a).

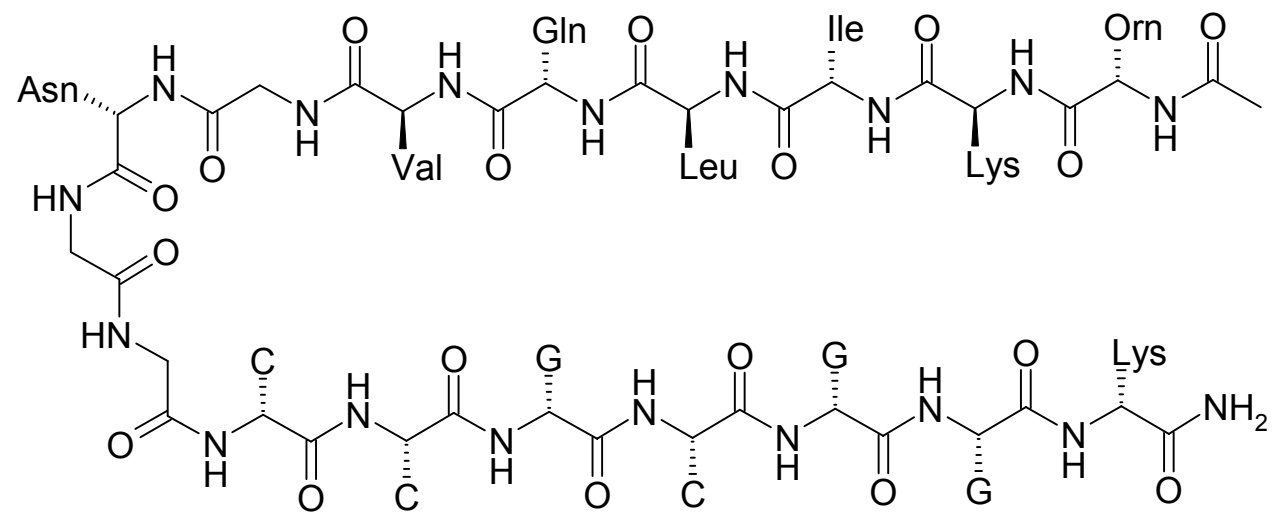

73

Abb. 52 Peptid/Alanyl-PNA Chimära 73 ( $G$ = Guanin, C = Cytosin). 

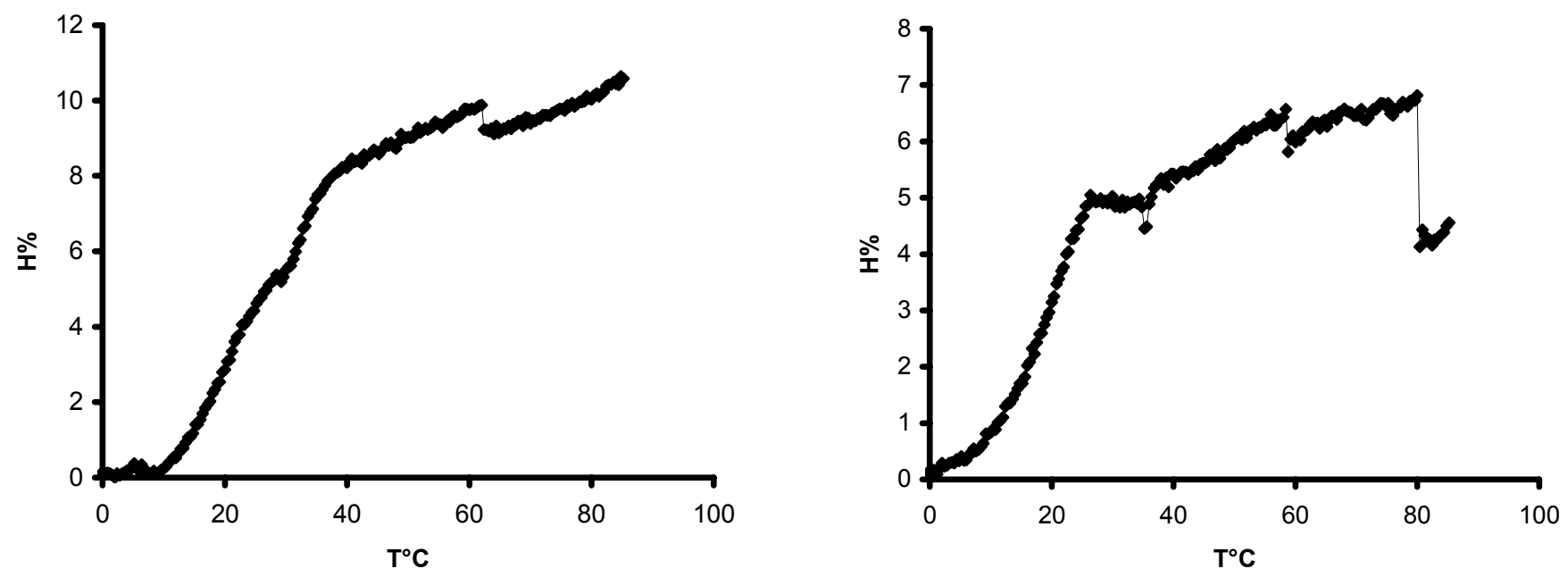

Abb. 53. Peptid/Alanyl-PNA Modellsequenz 73 a. mit Gegenstrang, $T_{m}=20^{\circ} \mathrm{C}$ und $T_{m}=32{ }^{\circ} \mathrm{C} ; \mathrm{b}$. ohne Gegenstrang, $\mathrm{T}_{m}=18^{\circ} \mathrm{C}$ im Puffersystem 1, bei je einer Konzentration von $\mathrm{c}=6.0 \mu \mathrm{M}$. 


\section{Synthese des Interleukin-8 (hIL-8)/Alanyl-PNA Derivats}

Im Rahmen dieser Arbeit sollte das Projekt von M. Hoffmann weitergeführt werden, welches die Synthese von hIL-8 Analoga mit eingebauter Alanyl-PNA beinhaltete. ${ }^{[59]}$ Es wurde versucht die C-terminale Helix des humanen Interleukin-8 (hIL-8) Proteins mit Alanyl-PNA hinsichtlich strukturgebendener Eigenschaften zu imitieren (Abb. 55).

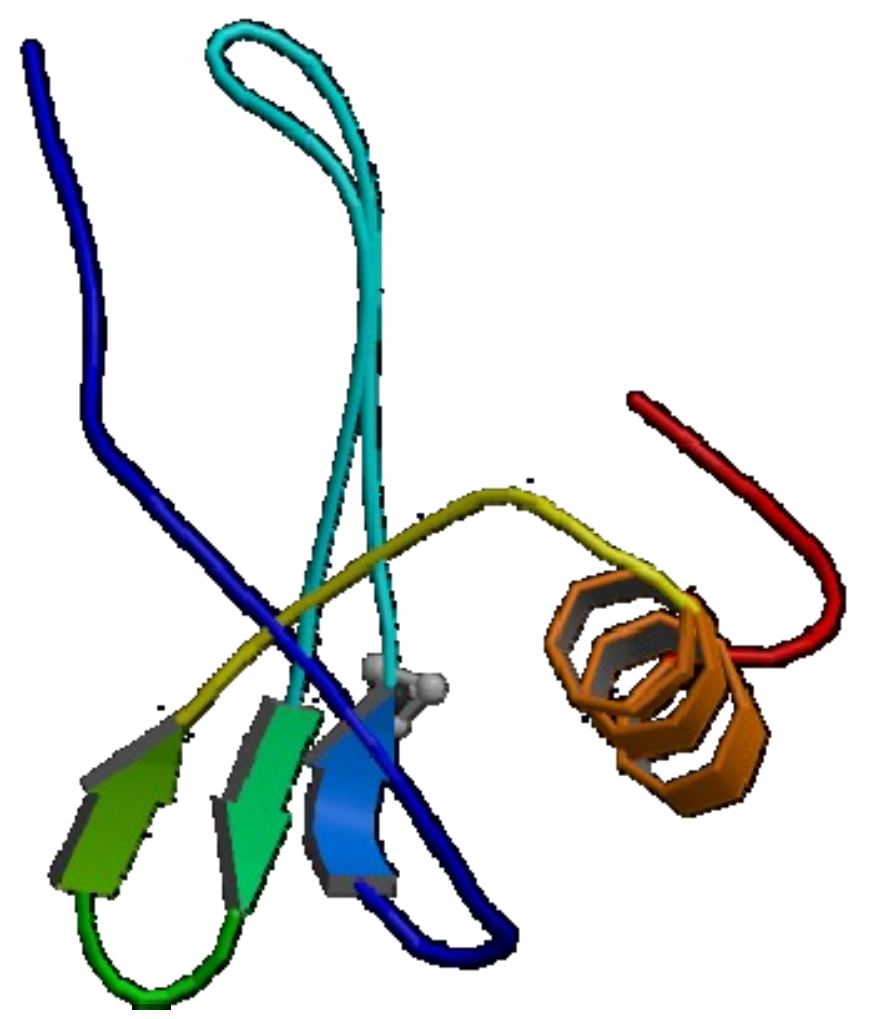

Abb. 54 Gesamtstruktur des humanen Interleukin-8.

Modifiziert wurden die Aminosäuren 56-77 des Interleukin-8 (IL-8) 74 die die $\alpha$-Helix bilden (Abb. 55). Anstelle der $\alpha$-Helix wurde eine Alanyl-PNA Sequenz eingebaut, so dass unter Zugabe des komplementären Gegenstranges Konformationsänderungen des Proteins erzeugt werden sollten, welche Einfluss auf die Aktivität des Proteins haben sollte. 
C-terminale Sequenzbereich 56-77 des humanen Interleukin-8

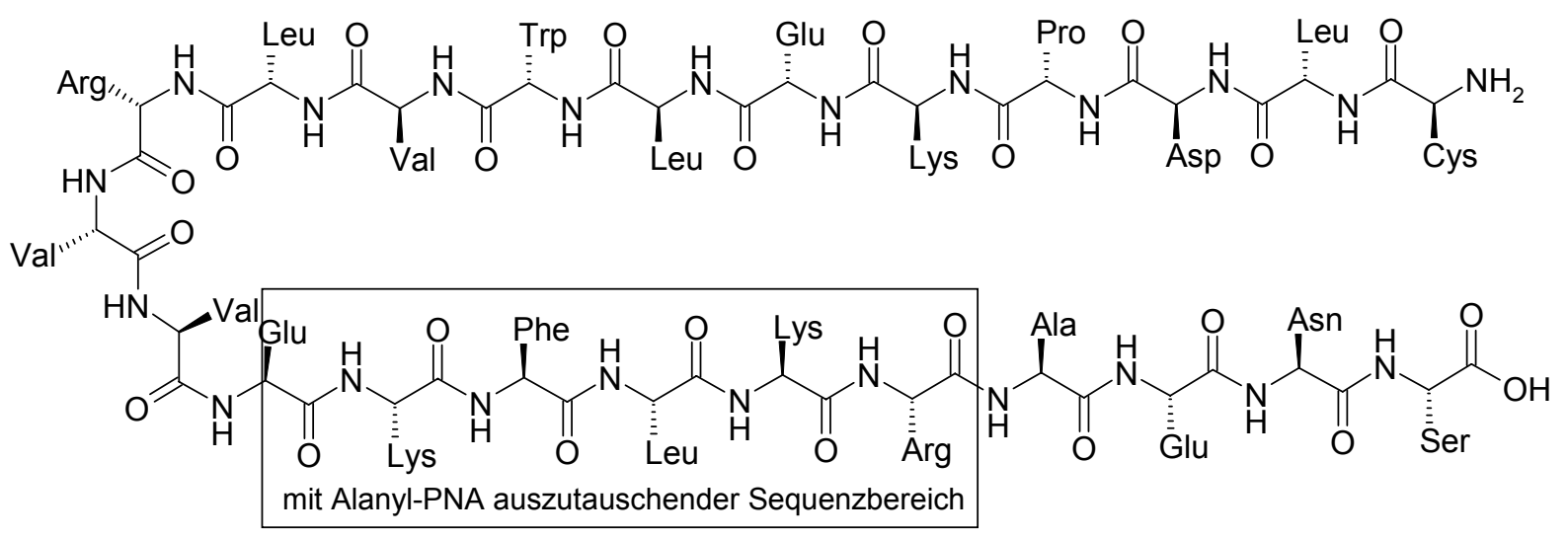

74<smiles>C[C@H](N)C(=O)N[C@@H](C)C(=O)N[C@@H](C)C(=O)N[C@@H](C)C(=O)N[C@@H](C)C(=O)O</smiles>

einzubauende Alanyl-PNA Sequenz

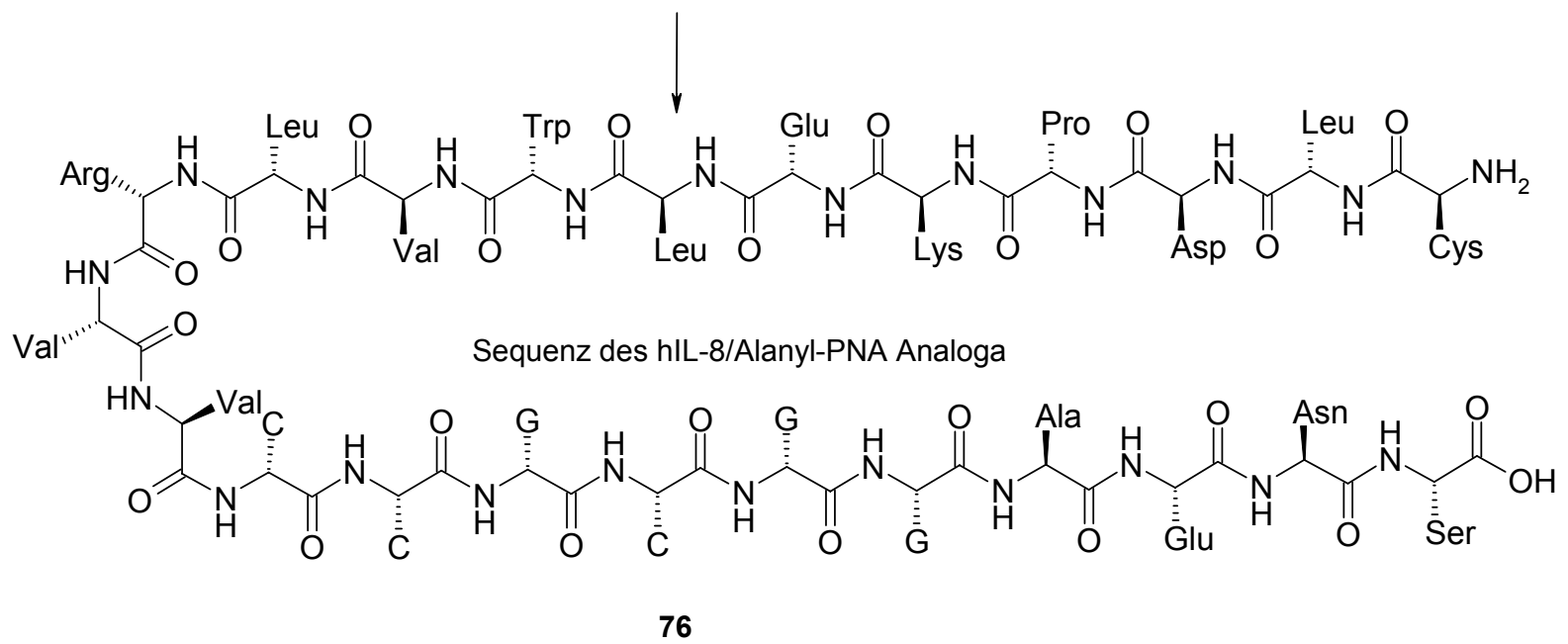

Abb. 55 Darstellung des synthetisierten Sequenzbereiches des Interleukin-8 74, der verwendeten Alanyl-PNA Sequenz $\mathbf{7 5}$ sowie das daraus resultierenden hIL-8/Alanyl-PNA Analogons $\mathbf{7 6 .}$

Die Synthese wurde mittels Boc-Strategie an Ser(OBzI)-PAM-Harz versucht. Hierbei kam es zum Abbruch der Reaktion an der Position 66 (Val), 59 (Lys) und 56 (Cys). Der Peptid/Alanyl-PNA Teil der Sequenz bis Nucleoaminosäure 68 konnte mittels Massenspektrometrie stets nachgewiesen werden. Die Nucleoaminosäuren wurden mittels HATU/HOAt in NMP aktiviert. Die Aminosäuren wurden zu Beginn mittels HBTU/HOBt aktiviert (AA). Da dies nicht zum Erfolg führte, wurden die Kupplungsreagenzien variiert. Es wurden 
noch HCTU/HOBt-Cl (BB) und BOP (CC) getestet, jedoch ohne Erfolg. Weiterhin wurde die Ligationsstrategie in Erwägung gezogen (DD), jedoch wurde auch hier der Aminosäureester des Valins nicht erfolgreich dargestellt. Der Einbau eines Cysteins nach der Aminosäure Valin 67 (EE) gelang nicht, so dass die Anwendung einer native chemical Ligation nicht zum Zuge kommen konnte.

\begin{tabular}{|c|c|c|}
\hline Experiment & Variation & Ergebnis \\
\hline AA & Alanyl-PNA (HATU/HOAt)/Peptid (HBTU/HOBt) & kein Umsatz \\
\hline BB & $\begin{array}{c}\text { Alanyl-PNA (HATU/HOAt)/Peptid (HCTU/Cl- } \\
\text { HOBt) }\end{array}$ & kein Umsatz \\
\hline CC & Alanyl-PNA (HATU/HOAt)/Peptid (BOP) & kein Umsatz \\
\hline DD & native chemical ligation (ab AlaC) & kein Umsatz \\
\hline EE & native chemical ligation (ab Val) & kein Umsatz \\
\hline FF & Alanyl-PNA (Boc-Strat.)/ Peptid (Fmoc-Strat.) & kein Umsatz \\
\hline GG & Austausch Glutamin gegen Leucin & kein Umsatz \\
\hline $\mathbf{H H}$ & expressed protein ligation & kein Umsatz \\
\hline II & Austausch von Glutamin/Aspargin gegen Leu & Umsatz \\
\hline
\end{tabular}

Tab. 3 Synthesestrategien zur Darstellung des Interleukin-8/Alanyl-PNA Derivats 76.

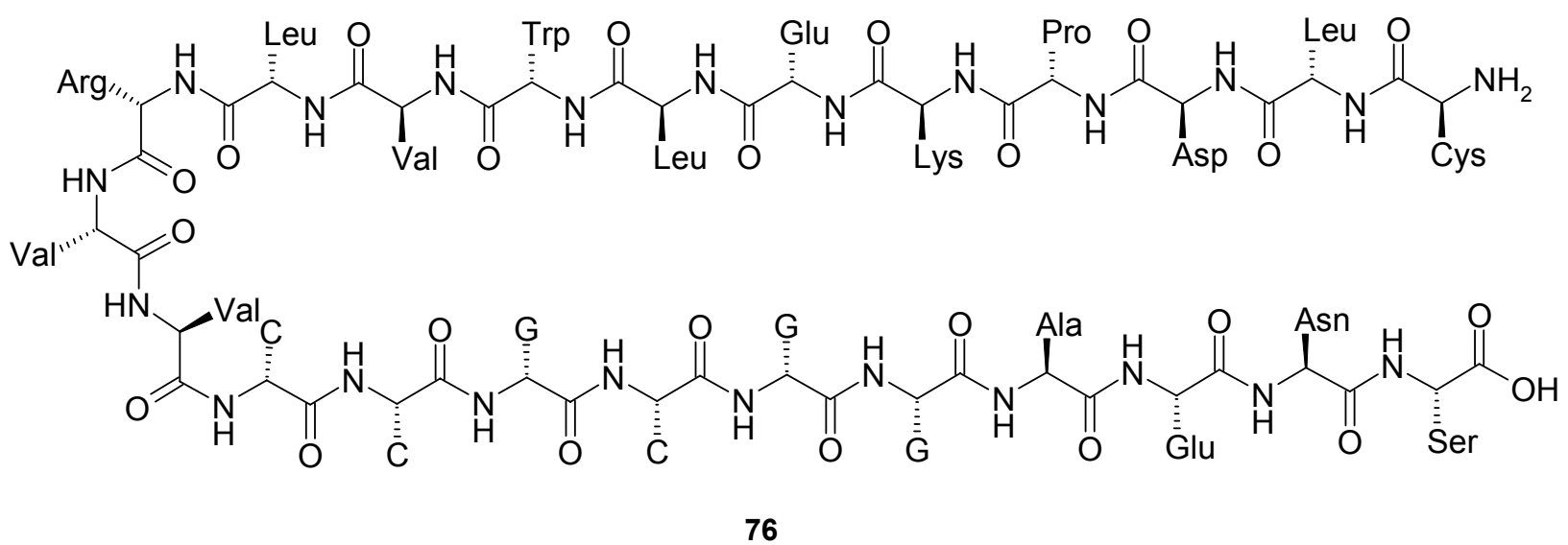

Abb. 56 Sequenz der IL-8/Alanyl-PNA Analoga 76 ( $G$ = Guanin, C = Cytosin). 
Anschließend wurde auch hier der erste Teil des Peptides (Peptid/Alanyl-PNA Teil (56-77)) mittels Boc-Strategie aufgebaut und die restliche Sequenz mittels Fmoc-Strategie verlängert (FF). Hierbei kam es zu ersten Erfolgen. Sequenzbereiche bis zur Aminosäure Valin 66 wurden nicht mehr in der Massenanalyse nachgewiesen. Auch der Austausch der Aminosäure Glutamin (Gln), die zu starken Nebenreaktionen führt, durch die Aminosäure Leucin (Leu) in Kombination mit der Fmoc-Strategie ergab nicht das gewünschte Produkt (GG). Ein weiterer Ansatz ergab sich über die expressed protein ligation (HH) (Kapitel 2.2). Es wurde die Darstellung des $N^{\alpha}$-(1-Phenyl-2mercaptoethyl)-Aminosäure-Derivats angestrebt. Zuerst wurde das Keton 26 hergestellt (Abb. 57). Hierfür wurden das Thiol 25 und das Bromid 24 mittels Hünig-Base (Dipea) in DMF umgesetzt. Das 1-(4-Methoxyphenyl)-2-(4methylbenzylsulfanyl)ethanon (26) wurde in einer Ausbeute von $64 \%$ erhalten.

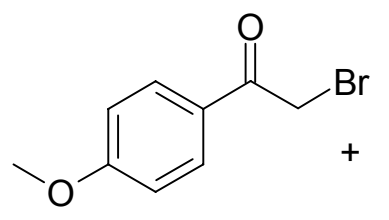

24

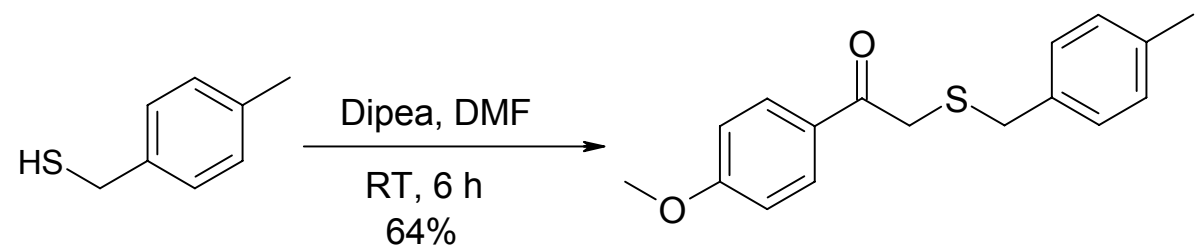

25

26

Abb. 57 Synthese des Ketons 26.

Weiterhin wurde das Keton 26 mit Glycinethylester Hydrochlorid 77 und Valinethylester Hydrochlorid $\mathbf{2 7}$ in einer reduktiven Aminierung umgesetzt. Die Synthese (eine Eintopfreaktion) wurde, wie von Botti et al. beschrieben, durchgeführt. ${ }^{[64 \text { a] }}$ Dabei wurde das 1-(4-Methoxyphenyl)-2-(4-methylbenzylsulfanyl)ethanon (26) mit dem entsprechenden Aminosäureester und Bortrifluoriddiethylerat (BFEE) unter Wasserabscheidung in einer Dean-Stark Apparatur umgesetzt. Das zu erwartende Produkt konnte nicht erhalten werden. 


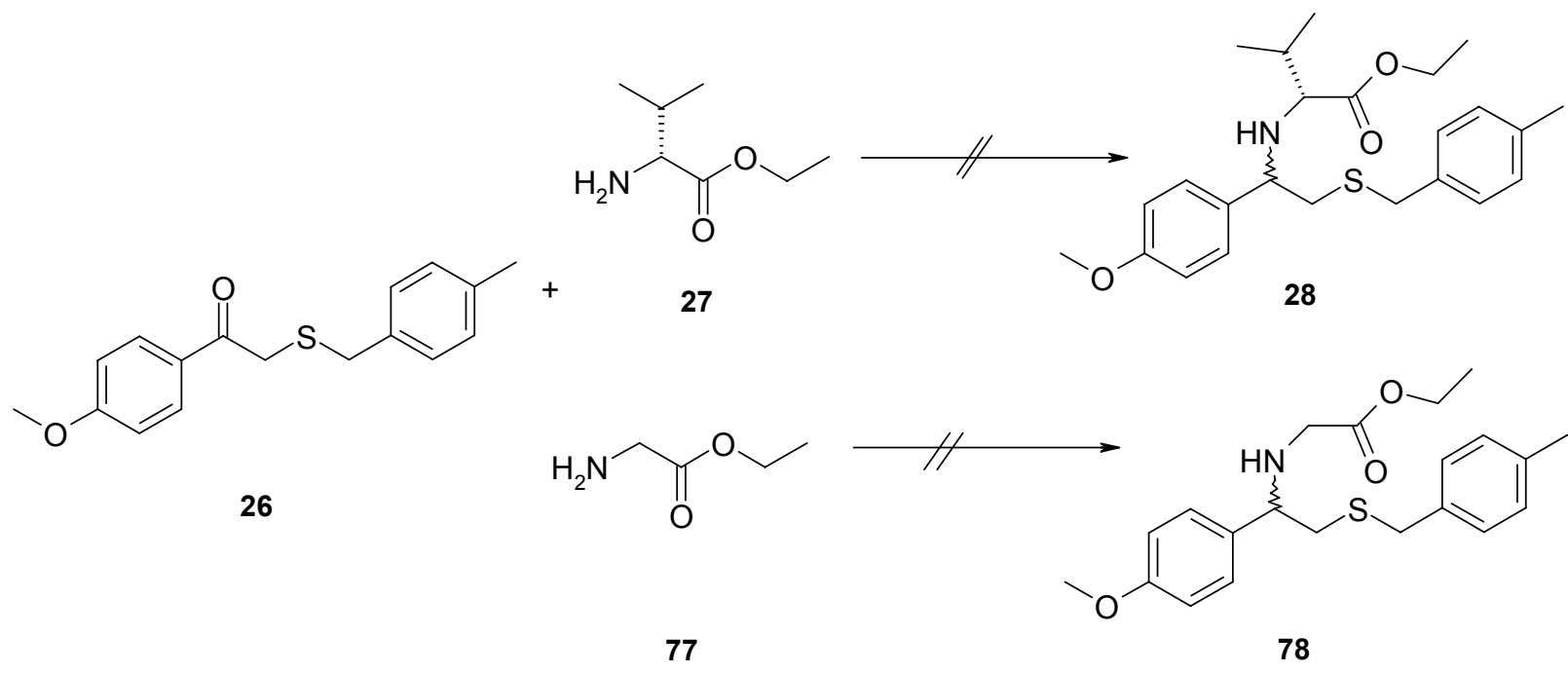

Abb. 58 Synthesestrategie zur Komponente 28 und $\mathbf{7 8 .}$

Erst der Austausch der Aminosäure Glutamin (Gln) und zusätzlich Asparagin (Asn) ermöglichte es, eine sehr geringe Menge des gewünschten Produktes $74 \mathrm{zu}$ isolieren (II). Jedoch war die isolierte Menge nicht ausreichend, um weitere Versuche (außer dem ESI-MS) durchzuführen (Abb. 59).

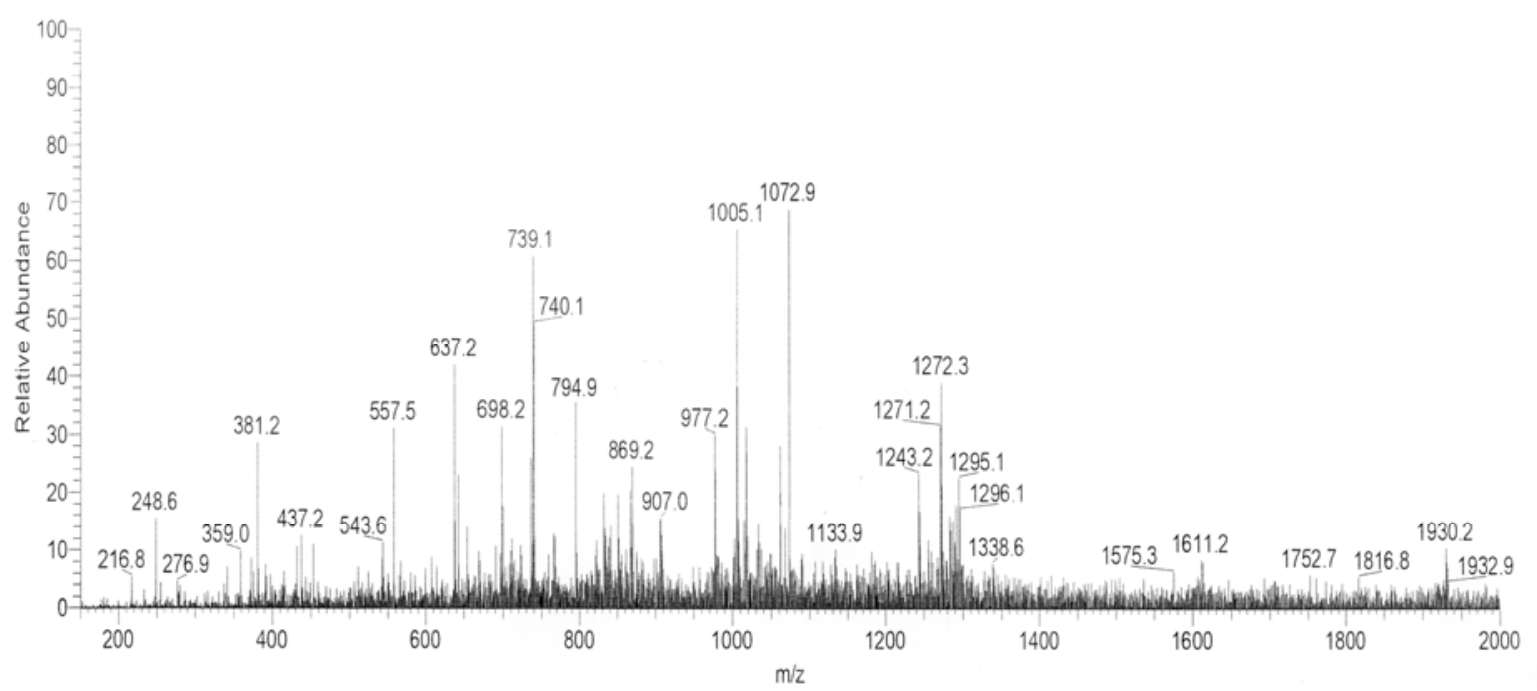

Abb. 59 Massenspektrum des synthetisierten IL-8-Derivats.

Für die Aminosäure Cystein wurde DIC als Aktivator und die Schutzgruppe Trityl (Trt) verwendet. Gründe für das Misslingen dieser Festphasensynthese können an den voluminösen Schutzgruppen, Seitenketten oder der Lage der geladenen Aminosäuren (siehe Lysin (Lys) und Glutaminsäure (Glu)) liegen. Aufgrund sterischer Hinderung der Amino- bzw. der angreifenden 
Carboxylkomponente waren die Reaktanden möglicherweise zu unaktiv und damit einer unvollständigen Acylierungen unterworfen. Andererseits kann es bei Verlängerung der Peptidkette durch Ausbildung intra- und/oder intermolekularer Wasserstoffbrückenbindungen zu einem Übergang von randomcoil-Strukturen zu $\beta$-Faltblatt- und $\alpha$-helikalen Strukturen kommen. Infolge der Ausbildung von übergeordneten Strukturen kommt es zu einer Aggregation des Harzes verbunden mit verschlechterter Solvatation wodurch die Quellung des Harzes nicht mehr in ausreichendem Maße gegeben ist. Dadurch wird auch die Diffusion der reaktiven Komponenten in die Harzmatrix erschwert. Dies führt zu Problemen bei der Kupplung und beim Nachweis nicht umgesetzter Aminogruppen. Nach Abspaltung vom Harz kann es bei derartigen Peptiden durch die Assoziation der Peptidketten zu Problemen bei der Charakterisierung und Reinigung kommen.

\section{Ligationsverfahren nach Bordusa mit Alanyl-PNA}

In Kooperation mit der Arbeitsgruppe Bordusa (Halle) wurden Alanyl-PNA Oligomere mit Peptiden ligiert (Abb. 60). Das Verfahren dieser Ligation wurde in Kapitel 2.2 näher erläutert.

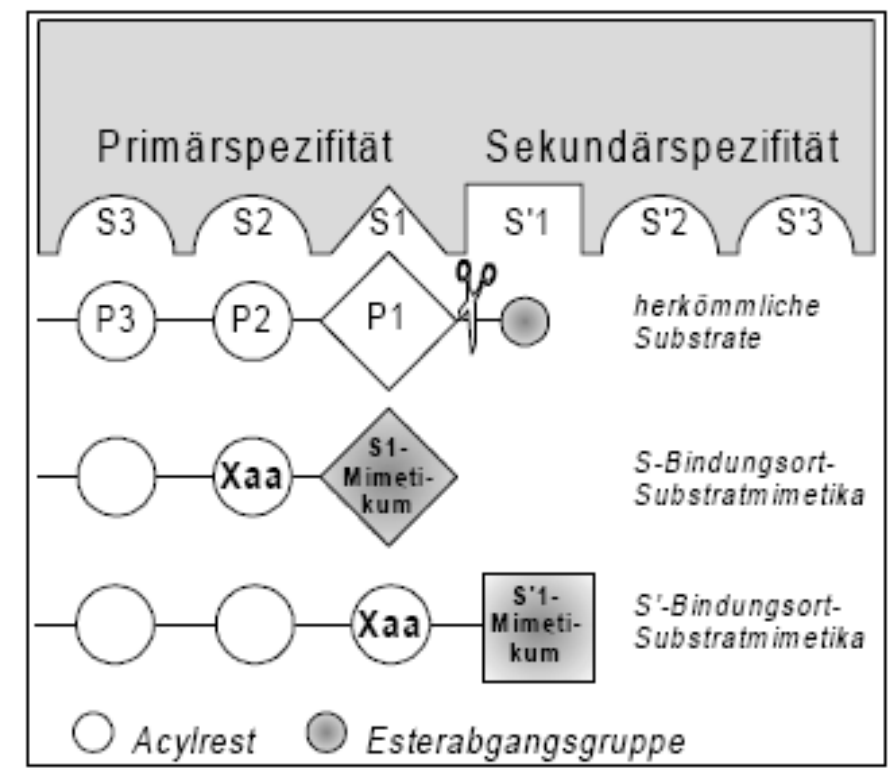

Abb. 60 Prinzip der substratvermittelten Einbindung von Donorestern in die Bindungsregion einer Protease. 
Substratmimetika zeigen Wechselwirkungen über Estergruppen mit dem Enzym, wobei je nach Bindungsort der Spezifitätsdeterminanten zwischen Sund S'-Bindungsort-Substratmimetikum unterschieden werden kann. Das allgemeine Prinzip der Substratmimetika-vermittelten Einbindung eines Acyldonoresters in das aktive Zentrum einer Protease ist in Abb. 60 dargestellt. Durch die Wechselwirkung der Esterabgangsgruppe mit der Enzymoberfläche im aktiven Zentrum wird der Acyldonorester so in die Substratbindung eingebunden, dass das Enzym den Acylrest unter Ausbildung eines Acylenzymintermediats übernehmen kann. Die angreifende nucleophile Aminkomponente bildet zunächst mit dem Acylenzymintermediat ein Acylenzym-Nucleophil-Komplex aus, welcher in das Peptidfragment und das Enzym zerfällt.

Es wurden hierzu die Oligomere (AlaA-AlaT) $)_{2}-\mathrm{Lys}-\mathrm{NH}_{2}$ (79), H-AlaC-AlaCAlaG-AlaC-AlaG-AlaG-Lys-OH (80), H-AlaC-AlaC-AlaG-AlaC-AlaG-AlaG-Lys$\mathrm{NH}_{2}$ (16), H-AlaC-AlaC-AlaG-Glu-AlaG-AlaG-Gly-OH (66) und H-AlaG-AlaGAlaC-AlaG-AlaC-AlaC-Gly-OH (81) mittels Boc-SPPS an den belegten Harzen Boc-Lys(2-Cl-Z)-OH-MBHA, Boc-Lys(2-Cl-Z)-OH-Merrifield und Boc-Gly-OHMerrifield synthetisiert. Als Kupplungsreagenzien wurden die Standardreagenzien HATU und HOAt verwendet. Die synthetisierten Oligomere wurden nach der oben beschriebenen Methode an Peptide ligiert, wobei alle Ligationen in wässriger Umgebung in einem HEPES-Puffer und bei $25^{\circ} \mathrm{C}$ durchgeführt wurden. Zum Lösen des Esters wurde DMSO verwendet. Die Reaktionszeiten betrugen 1-2 h. Der erste Versuch beinhaltete eine Ligation mit dem Peptid Ac-Phe-Gly-Gly-OGp (82), Clostripain (Enzym) und H-(AlaAAlaT) ${ }_{2}$-Lys- $\mathrm{NH}_{2}$ (79) (Abb. 60). Es wurden 10-20\% des Produktes Boc-PheGly-Gly-(AlaA-AlaT) $)_{2}$-Lys- $\mathrm{NH}_{2}$ (83) hergestellt. Das Produkt 83 wurde mittels Maldi-ToF, als $[\mathrm{M}+\mathrm{H}]^{+},[\mathrm{M}+\mathrm{Na}]^{+}$und $[\mathrm{M}+\mathrm{K}]^{+}$ermittelt. 
<smiles>Nc1ccn(C[C@H](N)C(=O)N[C@H](Cn2ccc(N)nc2=O)C(=O)N[C@@H](Cn2cnc3c(=O)[nH]c(N)nc32)C(=O)N[C@@H](Cn2cnc3c(=O)[nH]c(N)nc32)C(=O)N[C@@H](Cn2cnc3c(=O)[nH]c(N)nc32)C(=O)N[C@@H](Cn2cnc3c(=O)[nH]c(N)nc32)C(=O)NCC(=O)O)c(=O)n1</smiles><smiles>CC(C)NC(Cc1ccccc1)C(=O)NCC(=O)NCC(=O)N[C@H](Cn1ccc(N)nc1=O)C(=O)NCC(=O)N[C@@H](Cn1ccc(N)nc1=O)C(=O)N[C@@H](CC(=O)N[C@@H](Cn1cnc2c(=O)[nH]c(N)nc21)C(=O)N[C@@H](Cn1cnc2c(=O)[nH]c(N)nc21)C(=O)NCC(=O)O)Cn1cnc2c(=O)[nH]c(N)nc21</smiles>

83

Abb. 61 Enzymatische Ligation nach Bordusa et al..

Ein weitere Umsetzung wurde mit dem Peptid Ac-Lys-Leu-Pro-Gly-Trp-GluLys-Arg-Met-Ser-Arg-Ser-Ser-Gly-OGp 84 und H-(AlaG-AlaT) $)_{2}-$ Lys- $-\mathrm{NH}_{2} \mathbf{7 9}$ unter Katalyse mit dem Enzym Clostripain bei $10-20^{\circ} \mathrm{C}$ zu dem Produkt AcLys-Leu-Pro-Gly-Trp-Glu-Lys-Arg-Met-Ser-Arg-Ser-Ser-Gly-(AlaA-AlaT) ${ }_{2}$-Lys$\mathrm{NH}_{2}(85)$ durchgeführt. Das Produkt 85 wurde mittels MALDI-ToF als $[\mathrm{M}+\mathrm{H}]^{+}$ identifiziert. Der dritte Versuch erfolgte mit Oligomer H-AlaC-AlaC-AlaG-AlaCAlaG-AlaG-Lys-OH 80. Um eine bessere Selektivität für die Ligation zu erreichen, wurde hierbei die $C$-terminale Aminogruppe durch eine Carboxylgruppe ersetzt. Das Testpeptid wurde nach einer Sequenz von Gellmann et al. gewählt Ac-Val-Phe-Ile-Thr-Ser-Pro-Gly-Lys(Z)-Thr-Tyr-ThrGlu-Val-Pro-Gly-Orn-Lys(Z)-Ile-Leu-GIn-Val-Pro-Gly-OGp (86). Das Produkt bekam man zu $9 \%$ als Ac-Val-Phe-Ile-Thr-Ser-Pro-Gly-Lys(Z)-Thr-Tyr-Thr- 
Glu-Val-Pro-Gly-Orn-Lys(Z)-Ile-Leu-GIn-Val-Pro-Gly-AlaC-AlaC-AlaG-AlaCAlaG-AlaG-Lys-OH (87) (MALDI-ToF ergab $[\mathrm{M}+\mathrm{H}]^{+}$). Im Gegensatz zu Kapitel 5 mussten hier keine weiteren Glycine eingebunden werden, um die gewünschten Alanyl-PNA Oligomere an das Peptid zu ligieren, was einen erheblichen Vorteil darstellt.

Die unerwartet niedrige Ausbeute der Sequenz $\mathbf{8 0}$ gegenüber den Sequenzen mit einer $\mathrm{C}$-terminalen $\mathrm{NH}_{2}$-Gruppe könnte darin begründet liegen, dass Aminogruppen den Fortgang der Peptidketten imitieren und somit eine bessere Einpassung des Substrates in die Substratbindungstasche des Enzyms bewirken. Ferner kann es zu einer Veränderung des pK-Wertes der Substanz kommen, die sich auf die Synthese auswirkt. 


\section{Zusammenfassung und Ausblick}

Die Funktion und Aktivität von Proteinen hängt im wesentlichem von der dreidimensionalen Struktur und der Konformation des Proteins ab. Die Konformationswechsel sowie die Wechselwirkung zwischen Proteinen, beeinflusst durch einen molekularen Schalter, würden maßgeblich zur biologischen Aktivitätsänderung und sowie deren Funktion beitragen. Die als Schalter verwendeten Alanyl-PNA Oligomere sind Oligopeptide mit alternierender Konfiguration und mit Nucleobasen, die an der $\beta$-Position der Alanyl-Aminosäure kovalent gebunden sind

Im Rahmen dieser Arbeit wurden Interaktionen und damit die Stabilität von verschiedenen komplementärer Alanyl-PNA Oligomere mit Hinblick auf eine mögliche „Schalter"-Funktion mittels UV- und NMR-spektroskopie untersucht. Die untersuchten Alanyl-PNA Oligomere unterschieden sich in den Längen und durch die eingebauten Fehlstellen. Weiterhin wurden verschiedene Puffersysteme für die Untersuchungn gewählt. Ein zweiter Punkt dieser Arbeit war der Einbau eines Alanyl-PNA Stranges in ein Peptid oder Protein. Durch Zugabe eines komplementären Alanyl-PNA-Gegenstranges sollte sich ein $\beta$ Faltblatt stabilisieren lassen. Weiterhin wurde nach einer effizienten Methode gesucht, um $\mathrm{N}$-methylierte Aminosäurederivate ausgehend von $\mathrm{N}$-MethylSerinlacton 42 zu entwickeln und diese in alanyl-PNA Oligomere einbauen zu können. Durch das Ersetzen der C-Terminalen Helix des humanen Interleukin 8 (hIL-8) (Aminosäure 56-77) durch ein alanyl-PNA Hexamer wollten wir eine Schaltung des helicalen C-Terminus zu einer anderen stabilen Konformation erreichen. Der Einbau von alanyl-PNA Oligomere in Peptide und Proteine erweißt sich als schwierig, so dass wir am Ende dieser Arbeit in Kooperation mit dem Arbeitskreis Bordusa eine enzymatische Ligation zum Einbau durchgeführt haben.

Der Erste Teil dieser Arbeit, wurden verschiedene Alanyl-PNA Oligomere unterschiedlicher Länge dargestellt, wobei um Aggregationen zu vermeiden auch die nicht komplementäre Nucleoaminosäure Boc-AlaT-OH, sowie die Aminosäuren Lysin und Glutaminsäure eingebaut wurden. Anhand dieser 
Sequenzen wurden neben der temperaturabhängigen UV-Spektroskopie in Kooperation mit der Abteilung Griesinger auch NMR-spektroskopische Untersuchungen durchgeführt. Hierbei zeigte sich deutlich, dass die Modifikationen einen Einfluss auf die Selbstpaarung hatten. Der Einbau der geladenen Aminosäuren Lysin und Glutamin führte zu einer Verbesserung der Löslichkeit. Die NMR-spektroskopischen Messungen zeigten, dass die Aggregation in reinen G/C-Alanyl-PNA Oligomeren höher ist als die der Oligomere mit Modifikationen. Eine Rückgratmethylierung versprach Abhilfe hinsichtlich Aggregation im für die NMR-Spektroskopie erforderlichen Konzentrationsbereich. Eine $N$-terminale $N$-methylierte Nucleoaminosäure im Oligomer 67 brachte keine Abhilfe bei der Vermeidung der Aggregation. Die Messung zentral eingebauter $\mathrm{N}$-methylierter Nucleoaminosäure im Oligomer 68 wird noch NMR-spektroskopisch ermittelt.

Viertens, befassten wir uns mit den „Schalter Funktionen“ und somit den Wechselwirkungender alternierenden alanly-PNA Oligomere. Beim Einbau von Alanyl-PNA Oligomeren in $\beta$-Faltblatt bildende Peptide, sollte der Einfluss der Alanyl-PNAs und damit die Schaltfähigkeit der Sekundärstruktur untersucht werden. Die Peptid/PNA Sequenz Ac-Ser-Pro-Gly-Lys-Thr-Tyr-Thr-Glu-ValPro-Gly-Orn-Lys-Ile-Leu-Gln-Val-Gly-Pro-Gly-Gly-AlaC-AlaC-AlaG-AlaC-AlaGAlaG-Lys- $\mathrm{NH}_{2}$ (85) konnte hergestellt werden, jedoch nicht mit seinem Gegenstrang zur Paarung gebracht werden. Dies kann auf sterische Faktoren sowie Wechselwirkungen der Nucleoaminosäuren der Alanyl-PNA mit den Aminosäuren aus dem Peptid hinweisen. Um eine bessere Wechselwirkung mit komplämemtären Alanyl-PNA Oligomeren zu erreichen, wurde ein kürzeres, weniger rigides Peptid Ac-Orn-Lys-Ile-Leu-Gln-Val-Gly-Asn-Gly-GlyAlaC-AlaC-AlaG-AlaC-AlaG-AlaG-Lys- $\mathrm{NH}_{2}$ (87) mit schwächerem turn-Bildner hergestellt. Erwartungsgemäß wurde hierbei ein viel größerer Einfluss des Gegenstranges auf die Peptid/PNA Sequenz beobachtet.

Ein weiterer Teil dieser Arbeit befasste sich mit dem Einbau eines PNAHexamers in ein menschliches Interleukin 8 (hIL-8) bzw. in einen Teil dieser Sequenz (Aminosäure 56 bis 77). Es sollte gezeigt werden, dass auch ein Hexamer durch die Technik der native chemical ligation in größere Peptide 
eingebaut werden kann. Weiterhin, sollte gezeigt werden, dass die Struktur des C-terminalen Endes durch zugabe eines komplementären Gegenstranges in eine stabiele Sekundärstruktur überführt werden kann. Hierfür wurde im Arbeitskreis Beck-Sickinger ein Teil des humanen Interleukin-8 hIL-8 (1-55), als $C$-terminaler Thioester durch Expression des Fusionsproteins in E. coli und expressed protein ligation.

Der letzte Punkt dieser Arbeit war eine enzymatische Ligation in Kooperation mit dem Arbeitskreis Bordusa. Hierbei sollten Alanyl-PNA Oligomere verschiedener Länge sowie $\mathrm{N}$-terminale Nucleoaminosäuren mittels Enzym Clostripain an verschiedene Sequenzen ligiert werden.

Die Bordusa Ligationen stellten sich als eine erfolgreiche und gute Methode zum Einbau von Alanyl-PNA in größere Peptide dar. Die manuelle Synthese war nur durch Verlängerung der Sequenz um zwei Glycine möglich. Insgesamt konnte in dieser Arbeit eine viel versprechende neue Synthese zur Darstellung von $\mathrm{N}$-methylierten Aminosäuren sowie Nucleoaminosäuren entwickelt und deren Einbau in Oligomere gezeigt werden. Die Ligationsmethode von Bordusa stellt eine sehr effiziente Methode dar, um die Alanyl-PNA Oligomere in große Systeme einzubauen und wird aufgrund dieses Erfolges sicherlich eine gute Option auch zur Darstellung des Interleukin-8 Derivates und weiterer größerer Peptid/PNASequenzen sein. Zur Optimierung dieser Schalffunktion wäre es denkbar, eine $N$-metylierte Alanyl-PNA in den Komplementärstrang einzubauen. Eine weitere Möglichkeit zur Optimierung wäre ein Einbau von Aminosäuren gegensätzlicher Ladung in die Oligomere. 


\section{Summary and Outlook}

The activity and properties of proteins mainly depend on the three-dimensional arrangment of their secondary structure elements and their conformation. Conformational changes as well as protein-protein interactions, be influenced by molecular switches, contribute to changes in biological activity and the function of peptide.The molecular switches used are alanyl peptide nucleic acids (alanyl-PNA), alternating oligopeptides based on amino acid alanyl with nucleobases attached to the $\beta$-postition.

In the present work we studied the interaction and so the stability of diffrent complementary alanyl-PNA oligomers with varying mismatches,lengths and buffers by using UV- and NMR-spectroscopy. Further on, alanyl-PNA was be incorporated in $\beta$-sheet forming peptides. In addition, we aimed to develop an efficient method to synthesize $\mathrm{N}$-methylated amino acid derivatives from $\mathrm{N}$ methyl-serinelactone 42 (Figure 61) and incorporate $N$-methylated nucleoamino acids in alanyl-PNAs. By replacing C-terminal helix of humane interleukine 8 (hIL-8) (amino acids 56-77) with an alanyl-PNA hexamer we wanted to switch from a helical-structured C-terminus to nother stable secondary structure. It is very difficult to incorporate alanyl-PNA in peptides or proteins, so that we decided at end our study to performed the enzymatic ligation in cooperation with the Bordusa group.

The first aim part of this work was to understand the interaction and so the stability of diffrent complementary alanyl-PNA oligomers with varying mismatches and buffers by using UV- and NMR-spectroscopy. The stability of duplex was investigated by varying the lengths of different alanyl-PNA oligomers. To avoid aggregation problems, we incorporated Boc-AlaT-OH or amino acids lysine and glutamine as a mismatch. The structure and the conformational changes of this sequences were investigated by temperaturedependent UV- and NMR-spectroscopy. We found that a modification increased/reduced the selfpairing. In order to increase the solubility of alanylPNA oligomers, amino acids lysine and glutamine were incorporated. NMR- 
spectroscopy revealed higher aggregation in pure G/C-alanyl-PNA than in the modified oligomers.

To avoid aggregation the oligomere 68 with a central incorporated $\mathrm{N}$ methylated nucleoamino acid was prepared. In addition, the complementary alanyl-PNA with charged $\mathrm{N}$-alkyl chains was prepared to enable NMRspectroscopy measurements blocking one aggregation side.

The fourth goal of this work was to investigat interactions of alternating alanylPNA oligomeres as molecular switches. Based on the specific nucleobase recognition, the two complementary alanyl-PNA hexamers provide a stable double strand with linear topology. Considering this, one alanyl-PNA hexamer was inserted in a peptide or protein to stabilize a $\beta$-sheet conformation. AlanylPNAs randomly brought together from a single strand. Two complementary strands are able to form duplex, resulting in the $\beta$-strand conformation. Next, alanyl-PNA was incorporated eigther in the model peptide or in proteins to function as a distrurbed $\beta$-sheet (PNA double strand). As sutch the duplex formed a switchable de-/stabilizing element of protein conformation.

Further on, alanyl-PNA was incorporated in $\beta$-sheet forming peptides as well as in proteins in order to function either as a part of a $\beta$-sheet (PNA double strand) or a disturbed $\beta$-sheet (PNA single strand). The peptide/PNA sequence Ac-Ser-Pro-Gly-Lys-Thr-Tyr-Thr-Glu-Val-Pro-Gly-Orn-Lys-Ile-Leu-GIn-Val-GlyPro-Gly-Gly-AlaC-AlaC-AlaG-AlaC-AlaG-AlaG-Lys- $\mathrm{NH}_{2}$ (85) was synthesized, but the recognition of the complementary alanyl-PNAs failed. This could be due to the sterical or electronical interactions between the nucleoamino acids (alanyl-PNA) and the amino acids of peptide.

Becuse of this, and a shorter and less rigid peptide containing a weaker $\beta$-turn Ac-Orn-Lys-Ile-Leu-GIn-Val-Gly-Asn-Gly-Gly-AlaC-AlaC-AlaG-AlaC-AlaG-

AlaG-Lys- $\mathrm{NH}_{2}$ (87) (Figure 60) was synthesized. A much more intensive influence was measured between complementary alanyl-PNA and peptide/ PNA sequence, confirming our hypotheses.

As fifth part of this work, the C-terminal helix of humane interleukine 8 (hIL-8) (amino acids 56-77) was replaced with a peptide sequence that contained an alanyl-PNA hexamer with the intention to switch from a structured C-terminus 
to a stable secondary structure. In the present approach the native chemival ligation was applied to obtain protein/alanyl-PNA-chimera that allows to switch the protein conformation and to modify the protein interaction by the base pairing. Interleukin 8 is the first example we already obtained the preliminary data from. The fragment hIL-8 (1-55) was expressed in E. coli by the IMPACT system and purified by the Beck-Sickinger group.

A last aim, was an enzymatic ligation in coorperation with the Bordusa group. For this reason, it was necessary to synthesize alanyl-PNA oligomeres of different lenghts and $\mathrm{N}$-terminal nucleo amino acids. The ligation step was done by using different sequences and clostripain as an enzyme (Figure 61 ). Bordusa ligation formed out to be a promising method to incorporate alanylPNA in peptides or proteins. The existence of $\mathbf{7 0}$ with SPPS (solid phase peptide synthesize), was made possible by extending it's sequence with two glycines.

In conclusion, this work describes a novel method to synthesize $\mathrm{N}$-methylated amino and nucleo amino acids and incorporated them in alanyl-PNA oligomers. We suggest that the Bordusa ligation methode is an efficient strategy to incorporate into alanyl-PNA in peptides and proteins. Furthermore, to optimize/prevent the switching attachement and aggregation problems a $\mathrm{N}$ methylation over this peptide backbone to one or more central nucleo amino acids of the strand would be done. 


\section{Experimenteller Teil}

\section{Allgemeine Arbeitstechniken}

\subsection{Allgemeine Methoden}

\section{Reagenzien}

Die verwendeten Harze wurden von der Firma Novabiochem bezogen. Die Peptidkupplungsreagenzien stammen von Applied Biosystems, IRIS Biotech und Novabiochem. Die Aminosäurederivate wurden von Novabiochem, Fluka, MultiSyntech und Bachem erhalten. Alle anderen Reagenzien stammen von Fluka, Sigma-Aldrich, Lancaster und Acros und entsprachen der Qualität ,zur Synthese’.

\section{Lyophilisieren}

Die wässrigen Lösungen wurden mittels flüssigen Stickstoffs eingefroren und an einem Christ-Alpha-2-4-Lyophilisator gefriergetrocknet. Bei kleineren Mengen wurden die Substanzen an einer Speed-Vac RC 10.22. der Firma Joan lyophilisiert.

\section{Lösungsmittel}

Alle technischen Lösungsmittel wurden vor Gebrauch destilliert. DMF abs. und THF abs. wurden von Fluka in der Qualität puriss. absolut bezogen. Pyridin und Dichlormethan wurden über $\mathrm{CaH}_{2}$ getrocknet und destilliert. Lösungsmittel für die HPLC wurden vor Verwendung durch Rühren im Vakuum entgast. Acetonitril (,HPLC-Qualität') stammte von Acros Organics und Wasser wurde mittels einer Wasseraufbereitungsanlage ,Simplicity' der Firma Milipore aufbereitet.

\section{Schmelzpunkte}

Die Schmelzpunkte wurden mit einer Büchi-510 Schmelzpunktapparatur bestimmt und sind nicht korrigiert. 


\section{Reaktionen}

Für Reaktionen unter Luft- und Feuchtigkeitsausschluss diente das Gas Argon (99.996\%) als Inertgas.

\subsection{Chromatographie}

\section{Dünnschichtchromatographie (DC)}

Es wurden Dünnschichtfertigplatten mit Aluminiumfolie als Trägermaterial der Firma Merck verwendet (Kieselgel 60 F254, Schichtdicke $0.25 \mathrm{~mm}$ ). Zum Nachweis der Substanzen diente die Fluoreszenzlöschung bei einer Wellenlänge von $254 \mathrm{~nm}$ sowie die Tauchfärbung mit Ninhydrin-Lösung $(500 \mathrm{~mL}$ Ethanol, $3.00 \mathrm{~mL}$ Essigsäure, $1.00 \mathrm{~g}$ Ninhydrin).

\section{Flash-Säulenchromatographie (FC)}

Als Säulenmaterial wurde Kieselgel 60 der Firma Merck mit einer Korngröße von $40-62 \mu \mathrm{m}$ verwendet. Die Säulen wurden nass mit 50$100 f a c h e m$ Überschuss an Kieselgel befüllt und das Substanzgemisch als konzentrierte Lösung (im Laufmittel) aufgetragen.

\section{Hochleistungsflüssigkeitschromatographie (HPLC)}

Analytische und präparative HPLC wurden an Geräten der Firma Pharmacia (Äkta Basic, P900, UV 900) und JASCO (semipräparative HPLC Anlage mit 2 Pumpen 2080-20-PU sowie einem programmierbaren 875-UV-Detektor) durchgeführt.

Analytik

YMC-Säulen (J'sphere ODS-H80, $250 \times 4.6 \mathrm{~mm}$, $4 \mu \mathrm{m}, \quad 80 \AA, \quad \mathrm{C}-18$ und Jsphere ODS - H80, $150 \times 4.6 \mathrm{~mm}, 4 \mu \mathrm{m}, 80 \AA, \mathrm{C}-18$, Fluss: $1 \mathrm{~mL} / \mathrm{min}$ ) .Sephasil Peptide Säule $(250 \times 4.6 \mathrm{~mm}, 5 \mu \mathrm{m}, 100 \AA$, C-18, Fluss: $1 \mathrm{~mL} / \mathrm{min}$ ) 
Semipräparativ 'YMC-Säulen (J'sphere ODS-H80, $150 \times 10 \mathrm{~mm}$, $4 \mu \mathrm{m}, 80 \AA$, C-18, Fluss: $3 \mathrm{~mL} / \mathrm{min}$ und J'sphere ODS-H80, $250 \times 20 \mathrm{~mm}, 4 \mu \mathrm{m}, 80 \AA, \mathrm{C}-18$, Fluss: $10 \mathrm{~mL} / \mathrm{min})$.

Die Gradienten der Laufmittel A $\left(\mathrm{H}_{2} \mathrm{O}+0.1 \%\right.$ TFA $)$ und $\mathbf{B}(\mathrm{ACN}+$ $0.1 \%$ TFA), B' $\left(\mathrm{ACN} / \mathrm{H}_{2} \mathrm{O}(9: 1)+0.1 \%\right.$ TFA) bzw. B' $\left(\mathrm{ACN} / \mathrm{H}_{2} \mathrm{O}(8: 2)+\right.$ $0.1 \%$ TFA) sind jeweils angegeben. Die UV-Detektion erfolgte bei den Wellenlängen $218 \mathrm{~nm}, 254 \mathrm{~nm}$ und $280 \mathrm{~nm}$.

\section{Reverse Phase Chromatographie (RP)}

Es wurde RP-Kieselgel der Firma YMC (ODS-A, AA06S50, $60 \AA$, S-50 $\mu \mathrm{m}, \mathrm{C}-18)$ verwendet. Die Substanzen wurden in wenig Wasser suspendiert und auf die mit Wasser äquilibrierte Säulenpackung gegeben. Der Gehalt an Methanol wurde stufenweise erhöht.

\subsection{Spektroskopie}

\section{Circulardichroismus-Spektroskopie (CD)}

Die Messungen wurden an einem JASCO J-810A Spektropolarimeter, ausgerüstet mit einer JASCO PTC423S Temperiereinheit, durchgeführt. Der Probenraum wurde kontinuierlich mit Stickstoff gespült. Die Temperatur wurde im Temperierblock in Nachbarschaft zur Küvette gemessen. Alle Messungen wurden mit 5 Akkumulationen, $1.0 \mathrm{~nm}$ bandwidth, $1.0 \mathrm{~s}$ response und, wenn nicht anders angegeben, mit einem scan speed von $50 \mathrm{~nm} / \mathrm{min}$ durchgeführt. Messungen in Lösung wurden in Quarzglasküvetten $(0.25 \mathrm{~cm}$ oder $1.0 \mathrm{~cm})$ durchgeführt.

\section{UV-Spektroskopie (UV)}

Die UV-Spektren wurden in einer Quarzglasküvette $(1.0 \mathrm{~cm})$ mit einem JASCO V-550 oder einem Perkin Elmer Lambda 10 UV/VIS Spektrometer aufgenommen. 
Die Schmelzkurven wurden mit einem JASCO V-550 Spektrometer, ausgerüstet mit einer programmierbaren JASCO ETC-505S/ETC-505T Peltier-Temperiereinheit, aufgenommen. Falls nicht anders vermerkt, wurden die Spektren in einer Quarzglasküvette $(1.0 \mathrm{~cm})$ bei $260 \mathrm{~nm}$ aufgenommen. Die Konzentrationen der Oligomere wurden bei $80^{\circ} \mathrm{C}$ aus der UV-Absorption berechnet. Es wurde folgendes Temperaturprogramm für die temperaturabhängigen UV-Messungen verwendet:

$28^{\circ} \mathrm{C} \rightarrow 80^{\circ} \mathrm{C}\left(6{ }^{\circ} \mathrm{C} / \mathrm{min}\right) \rightarrow 85^{\circ} \mathrm{C}(3 \mathrm{~min}) \rightarrow-2{ }^{\circ} \mathrm{C}\left(3{ }^{\circ} \mathrm{C} / \mathrm{min}\right)$

$\rightarrow-2{ }^{\circ} \mathrm{C}(5 \mathrm{~min}) \rightarrow 85^{\circ} \mathrm{C}(180 \mathrm{~min}) \rightarrow-2^{\circ} \mathrm{C}(180 \mathrm{~min}) \rightarrow$ $28^{\circ} \mathrm{C}(5 \mathrm{~min})$.

Die Hyperchromizität $(\mathrm{H} \%)$ ist definiert als

$$
H \%=\frac{\left(A_{T}-A_{0}\right) \cdot 100}{A_{0}},
$$

wobei $A_{0}$ den kleinsten Absorptionswert entspricht.

\section{Massenspektrometrie (MS)}

Die ESI-Massenspektren wurden an einem Gerät der Firma Finnigan (Typ LCQ oder TSQ 7000) aufgenommen. Die Aufnahme der ElMassenspektren erfolgte an einem Instrument der Firma Varian (Typ MAT 731). Die Aufnahme der hochaufgelösten ESI-Massenspektren (HR-MS) erfolgte an einem APEX-Q IV 7T-Spektrometer der Firma Bruker.

\section{Infrarot-Spektroskopie (IR)}

Die Aufnahme der IR-Spektren erfolgte an einem Gerät der Firma Perkin Elmer Typ 1600 Series FT-IR unter Benutzung von KBr-Presslingen. 


\section{Kernspinresonanzspektroskopie (NMR)}

Die NMR-Spektren wurden an Varian Unity 300 oder Varian INOVA 600 Spektrometern aufgenommen. Die Probentemperatur betrug im Fall von $\mathrm{CDCl}_{3} 27^{\circ} \mathrm{C}$ und für $\left[D_{6}\right] \mathrm{DMSO}$, falls nicht anders angegeben, $35^{\circ} \mathrm{C}$. Die chemische Verschiebung der Signale sind in Einheiten der $\delta$-Skala registriert (TMS $=0 \mathrm{ppm})$. Als interner Standard dienten die Resonanzsignale der Restprotonen der verwendeten deuterierten Lösungsmittel $\mathrm{CDCl}_{3}: 7.24 \mathrm{ppm}\left({ }^{1} \mathrm{H}\right.$-NMR) und $77.0 \mathrm{ppm}\left({ }^{13} \mathrm{C}\right.$-NMR), [ $\left.D_{6}\right]$ DMSO: 2.49 ppm ( ${ }^{1} H$-NMR), 39.5 ppm $\left({ }^{13} \mathrm{C}\right.$-NMR). Die Multiplizitäten der Signale werden durch die Abkürzungen $s=$ Singulett, $d=$ Dublett, $\mathrm{dd}=$ Dublett vom Dublett, $\mathrm{t}=$ Triplett, $\mathrm{q}=$ Quartett, $\mathrm{m}=$ Multiplett, $\mathrm{br}$. $s=$ breites Singulett charakterisiert. Die Kopplungskonstanten $J$ sind in Hertz $(\mathrm{Hz})$ angegeben. ${ }^{13} \mathrm{C}$-NMR-Spektren wurden als ${ }^{1} \mathrm{H}$-Breitbandentkoppelte oder als ATP-Spektren aufgenommen. Die Signalzuordnung erfolgte mit Hilfe von $\left[{ }^{1} \mathrm{H},{ }^{1} \mathrm{H}\right]$-COSY, HMQC- und HMBC-Experimenten. Für die Auswertung der Peptidspektren wurden TOCSY, NOESY und DQF-COSY als 2D-Spektren mit einbezogen. Die NMR-Spektren der methylierten-Alanyl-PNA wurden an $400-800 \mathrm{MHz}$ Bruker Spektrometern aufgenommen. Die Proben wurden in einem Shigemi $D_{2} \mathrm{O}$ Röhrchen $(200 \mu \mathrm{m})$ gelöst und WATERGATE oder jump and return Pulssequenzen verwendet.

\section{Optische Drehung}

Die Drehwerte wurden mit dem Polarimeter 241 MC der Firma PerkinElmer gemessen. Der spezifische Drehwert errechnet sich wie folgt:

$$
[\alpha]_{D}^{20}=\frac{\alpha \cdot 100}{c \cdot l}
$$

Hierbei sind $\alpha$ der gemessene Drehwert bei $20^{\circ} \mathrm{C}$ und der Wellenlänge $D$ (Natriumlinie $589 \mathrm{~nm}$ ), $c$ die Konzentration in $\mathrm{g} / 100 \mathrm{~mL}$ und $/$ die Küvettenlänge in $\mathrm{dm}$. 


\section{Synthesen}

\subsection{Allgemeine Arbeitsvorschriften(AAV)}

\subsubsection{AAV1: Bestimmung der Enantiomerenreinheit in Anlehnung an} Lohse $^{[41 \mathrm{a}]}$

Zu der jeweiligen $5 \mu \mathrm{mol}$ (1.0 eq) Alanyl-Nucleoaminosäure wurde $120 \mu \mathrm{L}$ TFA gegeben und die Lösung für $10 \mathrm{~min}$ bei RT geschüttelt. Nach entfernen der TFA im Hochvakuum entfernt wurde, wurde der Rückstand mit $175 \mu \mathrm{L}$ bidest. Wasser sowie $175 \mu \mathrm{L} \quad(\mathrm{pH} \mathrm{9,} \quad c=1.20 \mathrm{~mol} / \mathrm{L})$ $\mathrm{NaHCO}_{3}$-Puffer aufgenommen und hierzu eine Lösung von $8.68 \mathrm{mg}$ (30.0 $\mu \mathrm{mol}, 6.0$ eq.) $\mathrm{N}$-Boc-L-Ala-OSu in $350 \mu \mathrm{L}$ THF gegeben. Die Reaktionsmischung wurde für $5 \mathrm{~h}$ bei RT geschüttelt, mit $10 \%$ iger TFA auf $\mathrm{pH} 2.5$ angesäuert, der Feststoff filtriert. $5 \mu \mathrm{L}$ wurden für die HPLCAnalytik entnommen und die Diastereomere an einer RP-C-18 Säule getrennt. Die Integration der Absorptionsbanden bei $\lambda=254 \mathrm{~nm}$ ergab das jeweilige Enantiomerenverhältnis.

\subsubsection{AAV2: Kupplung der ersten Aminosäure an das Harz}

In einer kleinen Säule wurden $1.0 \mathrm{~g}$ MBHA-Polystyrolharz (Belegungsdichte $0.66 \mathrm{mmol} / \mathrm{g}$ ) eingewogen und $2 \mathrm{~h}$ in DCM quellen lassen. Anschließend wurde eine Lösung aus $2.0 \mathrm{mmol}$ (1.0 eq.) einer $N$-terminalen Boc-geschützten Aminosäure, $0.62 \mathrm{~g}(2.0 \mathrm{mmol})$ TBTU

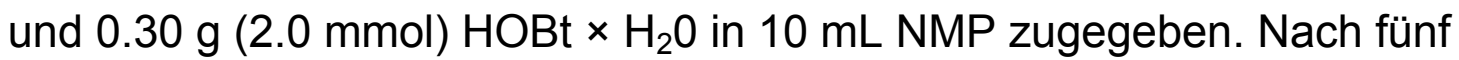
Minuten wurde $0.68 \mathrm{~mL}(4.0 \mathrm{mmol})$ DIPEA zur Reaktionsmischung gegeben und die Lösung $2 \mathrm{~h}$ bei RT rotiert. Der $\mathrm{pH}-$ Wert wurde durch Zugabe von DIPEA wiederholt auf einen Wert von 8 - 8.5 eingestellt. Das Reaktionsende zeichnet sich durch einen konstanten pH-Wert aus. Das Harz wurde mehrmals mit NMP und DCM gewaschen und die Reaktion am Harz in der gleichen Ansatzgröße wiederholt. Nach der Doppelkupplung wurde das belegte Harz im Hochvakuum getrocknet 
und die Belegungsdichte mit der folgenden Formel gravimetrisch bestimmt:

$$
n=\frac{m_{\text {ges }}-m_{\text {Harz }}}{\left(M G_{X_{\text {aа }}}-M G_{\text {Wasser }}\right) \cdot m_{\text {Harz }}} \cdot 1000
$$

Hierbei steht $n$ für die Belegungsdichte bezogen auf das verwendete Harz in mmol/g; $m_{\text {ges }}$ für die Gesamtmasse des Polymers nach der Doppelkupplung in $\mathrm{g}, \mathrm{m}_{\text {Harz }}$ für die Masse des eingesetzten Harzes in $\mathrm{g}$ und $\mathrm{MG}_{\text {Xaa }}$ bzw. $M \mathrm{G}_{\text {Wasser }}$ für die Molmassen der Boc-geschützten Aminosäure bzw. von Wasser.

\subsubsection{AAV3: Manuelle Synthese der Peptidnucleinsäure-Oligomere mittels Boc-Festphasenstrategie ${ }^{[66 a-c]}$}

\subsubsection{AAV3.1: Allgemeines Kupplungsprotokoll}

Die Peptidnucleinsäuren wurden über Boc-Festphasensynthese nach folgendem Synthesezyklus an N-Boc-D-Lys(Z)-MBHA-Harz, N-Boc-LLys(Z)-MBHA-Harz, N-Boc-D-Lys(2-Cl-Z)-Merrifield-Harz oder N-BocGly-Merrifield-Harz (Belegungsdichte $n=0.43-0.70 \mathrm{mmol} / \mathrm{g}$ ) aufgebaut. Die Festphasensynthese wurde in einer kleinen Säule durchgeführt, welche zur Reaktion langsam rotiert wurde.

A1: Quellen:

Das Harz wurde $3 \mathrm{~h}$ in DCM/NMP (1:1) gequollen.

B1: Entschützen:

Das harzgebundene Peptid wurde mit einer Lösung aus $5 \% \mathrm{~m}$-Cresol in TFA ( $3 \times 5 \mathrm{~min}, 1 \mathrm{~mL}$ ) bei RT behandelt. 
C1: Waschen:

Das Harz wurde zunächst mit DCM $(5 \times 1 \mathrm{~mL})$ und anschließend mit DCM/NMP $(1: 1,5 \times 1 \mathrm{~mL})$ gewaschen.

D1: Entstapeln:

Es wurde sowohl zum Neutralisieren, als auch zum Entstapeln mit Pyridin $(5 \times 1 \mathrm{~mL}, 1 \times 3 \mathrm{~min})$ gewaschen und das Harz im Stickstoffstrom für 3 min getrocknet.

E1: Kuppeln:

Es wurden 5.0 eq. der jeweiligen Boc-geschützten Nucleoaminosäure mit 4.5 eq. HATU und 5.0 eq. HOAt (bei den $N$-methylierten Nucleoaminosäuren wurden 4.5 eq. PyCloP und PyAOP verwendet) zu dem Harz gegeben und in NMP gelöst. Nach 3 min wurden 12 eq. DIPEA zugegeben und die Reaktionsmischung für die jeweils angegebene Zeit rotiert.

F1: Waschen:

Die überschüssigen Kupplungsreagenzien wurden nach der Kupplung vom Harz gewaschen. Dazu wurde mit NMP $(5 \times 1 \mathrm{~mL})$, DCM/NMP $(1: 1,5 \times 1 \mathrm{~mL})$, Piperidin/NMP $(1: 9,3 \times 1 \mathrm{~mL})$ und mit DCM/NMP (1:1, $5 \times 1 \mathrm{~mL}$ ) gewaschen.

G1: Cappen:

Um die Bildung unerwünschter Peptidsequenzen zu vermeiden, wurden mögliche freie Aminofunktionen des harzgebundenen Peptides mit einer Lösung aus $\mathrm{Ac}_{2} \mathrm{O} / \mathrm{DIPEA} / \mathrm{NMP}(1: 1: 8,2 \times 5 \mathrm{~min}, 1 \mathrm{~mL})$ acetyliert.

H1: Waschen:

Das Harz wurde mit DCM/NMP (1:1, $5 \times 1 \mathrm{~mL})$, mit Piperidin/NMP (1:9, $3 \times 1 \mathrm{~mL})$ und mit DCM/NMP $(1: 1,5 \times 1 \mathrm{~mL})$ gewaschen. 
Die Schritte $\mathrm{B} 1$ bis $\mathrm{H} 1$ wurden unter Verwendung der jeweiligen Nucleoaminosäuren bis zum Ende der gewünschten Sequenz wiederholt. Nach der letzten Kupplung wurde das Cappen (G1) ausgelassen. Stattdessen wurde das Harz mit DCM/NMP $(1: 1,5 \times 1 \mathrm{~mL})$, DCM $(5 \times 1 \mathrm{~mL})$ und Methanol $(5 \times 1 \mathrm{~mL})$ gewaschen. Nachdem das Harz im Vakuum über $\mathrm{KOH}$ über Nacht getrocknet wurde, wurde das gewünschte Peptid mit TFMSA/m-Cresol/TFA (1:1:8, $2 \mathrm{~mL}, 120 \mathrm{~min})$ vom Harz abgespalten. Das erhaltene Filtrat wurde evaporiert und der Rückstand mit gekühltem tert - Butylmethylether (( \pm$)$-Ether) prezipitiert. Der so erhaltene Feststoff wurde zentrifugiert und der $( \pm)$-Ether abpipettiert. Zur Reinigung wurde dieser Vorgang zwei bis drei Mal wiederholt und der erhaltene Feststoff aus Wasser lyophilisiert.

\subsubsection{AAV3.2: Kupplungsprotokoll beim Einsatz von Aminosäuren mit Fehlstellungen:}

Eine Abweichung von dem angegebenen Protokoll wurde beim Verwenden von Aminosäuren als Fehlstellen ab dem Punkt D1 notwendig, da es verstärkt zur Bildung von Nebenprodukten kam. Es wurde nicht mehr entstapelt, sondern nur neutralisiert. Es wurden folgende Veränderungen am Protokoll vorgenommen:

D2: Neutralisieren:

Es wurde zum Neutralisieren TEA $(2 \times 1 \mathrm{~mL}, 2 \times 5 \mathrm{~min})$ verwendet.

E2: Waschen:

Das Harz wurde mit DCM/NMP (1:1, $5 \times 1 \mathrm{~mL})$, mit Piperidin/NMP (1:9, $3 \times 1 \mathrm{~mL})$ und mit DCM/NMP $(1: 1,5 \times 1 \mathrm{~mL})$ gewaschen .

F2: Kuppeln:

Es wurden 5.0 eq. der jeweiligen Boc-geschützten Aminosäure mit 4.5 eq. HCTU und 5.0 eq. Cl-HOBt zu dem Harz gegeben und in NMP 
gelöst. Nach 3 min wurden 12 eq. DIPEA zugegeben und die Reaktionsmischung für die jeweils angegebene Zeit rotiert.

\subsubsection{AAV3.3: Manuelle Synthese des Peptides mittels}

\section{Fmoc-Festphasen-strategie ${ }^{[66 \text { a] }}$}

Die Peptide 72, 73 und das IL-8-Analoga 76 wurden mittels Festphasensynthese (SPPS) dargestellt. Der Alanyl-PNA Teil wurde nach der oben beschriebenen Boc - Strategie AV3.1 und der Peptid Teil nach dem nachfolgenden Synthesezyklus an Alanyl-PNA-N-Boc-D-Lys(Z)MBHA-Harz oder Alanyl-PNA-N-Boc-L-Lys(Z)-MBHA-Harz (Belegungsdichte $n=0.43-0.66 \mathrm{mmol} / \mathrm{g}$ ) und an Alanyl-PNA-N-Boc-L-Ser(Bzl)-

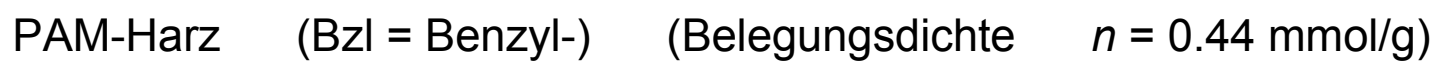
aufgebaut. Die Festphasensynthese fand in einer kleinen Säule statt, welche zur Reaktion langsam rotiert wurde.

A3: Quellen:

Das Harz wurde $3 \mathrm{~h}$ in DCM/NMP (1:1) quellen gelassen.

B3: Entschützen:

Das harzgebundene Peptid wurde mit einer Lösung von $20 \%$ Piperidin in NMP $(1 \times 5 \mathrm{~min}, 1 \times 15 \mathrm{~min}, 1 \mathrm{~mL})$ bei RT rotiert.

C3: Waschen:

Anschließend wurde das Harz mit NMP $(5 \times 1 \mathrm{~mL})$ und DCM/NMP $(1: 1$, $5 \times 1 \mathrm{~mL}$ ) gespült.

D3: Kuppeln:

Es wurden 5.0 eq. der jeweiligen Fmoc-geschützten Aminosäure mit 4.5 eq. HCTU und 5.0 eq. HOBt-Cl in NMP gelöst und 12 eq. DIPEA (20 min preaktiviert) zum Harz gegeben und die Reaktionsmischung wurde für die jeweils angegebene Zeit rotiert. Die Kupplungen wurden, 
wenn nicht anders vermerkt, als Doppelkupplung $(2 \times 50 \mathrm{~min})$ durchgeführt.

E3: Waschen:

Die überschüssigen Kupplungsreagenzien wurden nach der Kupplung vom Harz gewaschen. Dazu wurde mit NMP $(5 \times 1 \mathrm{~mL})$, DCM/NMP $(1: 1,5 \times 1 \mathrm{~mL})$, mit Isopropylamin $(2 \times 1 \mathrm{~mL})$ und mit DCM/NMP $(1: 1$, $5 \times 1 \mathrm{~mL})$ gespült.

F3: Cappen:

Um die Bildung unerwünschter Peptidsequenzen zu vermeiden, wurden mögliche freie Aminofunktionen des harzgebundenen Peptides mit einer Lösung aus $A_{2}$ O/DIPEA/NMP $(1: 1: 8,2 \times 5 \mathrm{~min}, 2 \mathrm{~mL})$ acetyliert.

G3: Waschen:

Das Harz wurde mit NMP $(5 \times 1 \mathrm{~mL}), \mathrm{DCM} / \mathrm{NMP}(1: 1,5 \times 1 \mathrm{~mL})$, mit Isopropylamin $(2 \times 1 \mathrm{~mL})$ und mit DCM/NMP $(1: 1, \quad 5 \times 1 \mathrm{~mL})$ gewaschen.

Die Schritte B3 bis G3 wurden unter Verwendung der jeweiligen Aminosäure bis zum Ende der gewünschten Sequenz wiederholt. Nach der letzten Kupplung wurden die Schritte B3 und C3 wiederholt und das Harz zusätzlich mit DCM $(5 \times 1 \mathrm{~mL})$ gewaschen. Nachdem das Harz im Vakuum über $\mathrm{KOH}$ über Nacht $(12 \mathrm{~h})$ getrocknet wurde, wurde es mit der jeweiligen Abspaltlösung für $2 \mathrm{~h}$ versetzt. Das am MBHA-Harz gebundene Peptid wurde mit der Abspaltlösung TFMSA/m-Cresol/TFA (1:1:8, $2 \mathrm{~mL})$ und das am PAMHarz gebundene Peptid mit EDT/Thioanisol/TFA/TFMSA $(0.3,0.6,1: 1: 8$, $2 \mathrm{~mL}$ ) behandelt. Die erhaltenen Filtrate wurden evaporiert und der Rückstand mit gekühltem tert-Butylmethylether prezipitiert. Die Mischung wurde zentrifugiert, der tert - Butylmethylether dekantiert, dieser Vorgang wurde zwei bis drei Mal wiederholt. Der Feststoff wurde aus Wasser lyophilisiert. 


\subsection{Synthese von Alanyl-Nucleoaminosäuren ${ }^{[47]}$}

\subsection{1 (S)-N-tert-Butoxycarbonyl- $\beta$-(N-4-benzyloxycarbonyl-1-cytosinyl)-} alanin (39)

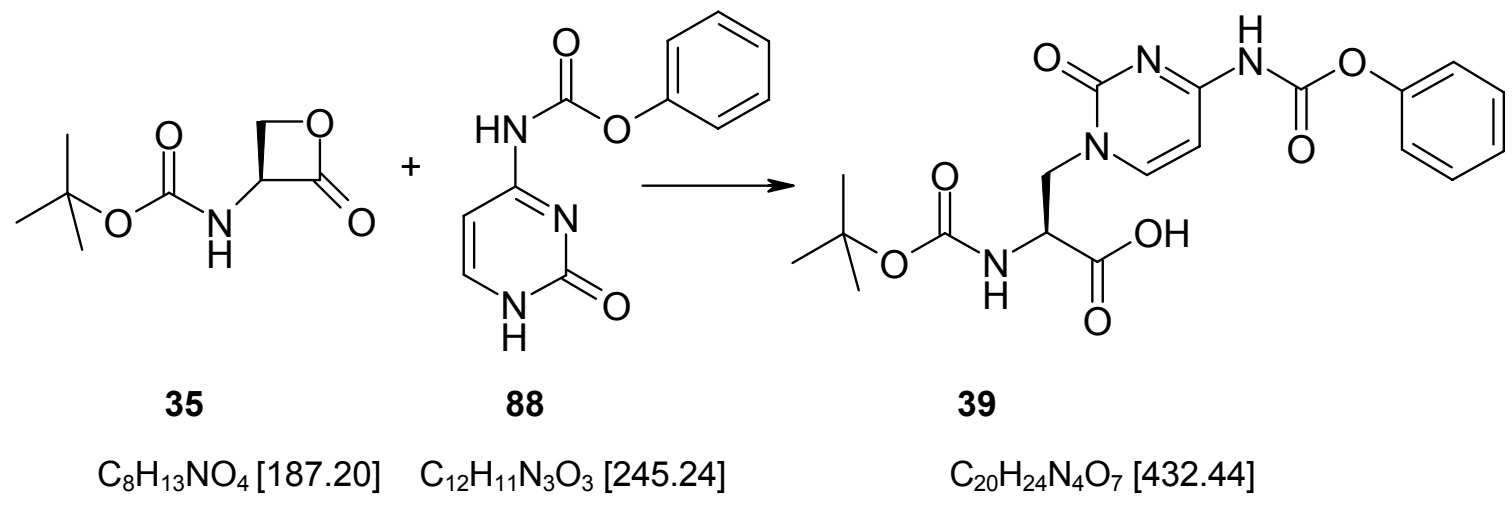

Zu einer Suspension von $4.56 \mathrm{~g}$ (18.6 mmol, 2.0 eq.) N-4-Benzyloxycarbonyl1-cytosin (88) in $15 \mathrm{~mL}$ trockenem DMSO wurden unter Argonatmosphäre $2.08 \mathrm{~mL}$ (2.12 g, $13.9 \mathrm{mmol}, 1.50$ eq.) DBU zugetropft. Anschließend wurde innerhalb von $15 \mathrm{~min}$ eine Lösung aus $1.74 \mathrm{~g}$ (9.31 mmol, 1.0 eq.) (S)-N-tertButoxycarbonyl-serinlacton (35) in $5.0 \mathrm{~mL}$ trockenem DMSO zugetropft und weitere $3 \mathrm{~h}$ gerührt. Die Reaktion wurde mittels Zugabe von $837 \mu \mathrm{L}$ (13.9 mmol, 1.5 eq.) Essigsäure beendet. Aus dem Reaktionsgemisch wurde das Produkt mittels FC an Kieselgel $(10 \mathrm{~cm}, \varnothing 6 \mathrm{~cm}$; Essigester/Methanol 9:1, Gradient $0.2-1 \%$ Essigsäure pro $500 \mathrm{~mL}$ ) isoliert. Es wurden $2.94 \mathrm{~g}$ $(6.73 \mathrm{mmol}, 74 \%, 39, e e=98 \%)$ des Produkts als gelber Feststoff erhalten.

DC (Essigester/Methanol/Wasser/Essigsäure (10:1:1:0.5, NaCl ges.) $R_{\mathrm{f}}=0.31$.

\section{${ }^{1} \mathrm{H}-\mathrm{NMR}\left(300 \mathrm{MHz},\left[D_{6}\right] \mathrm{DMSO}\right)$}

$\delta=1.27(\mathrm{~s}, 9 \mathrm{H}, t-\mathrm{Bu}), 3.39-3.47(\mathrm{~m}, 1 \mathrm{H}, \beta-\mathrm{H}), 4.00-4.13(\mathrm{~m}, 1 \mathrm{H}, \alpha-\mathrm{H}), 4.45$ (dd, $1 \mathrm{H}, J=12.7,3.5 \mathrm{~Hz}, \beta-\mathrm{H}), 5.17$ (s, $2 \mathrm{H}, \mathrm{CH}_{2} \mathrm{Ph}$ ), $6.21(\mathrm{~s}, 1 \mathrm{H}, \mathrm{NHBoc}$ ), $6.86(\mathrm{~d}, 1 \mathrm{H}, J=7.2 \mathrm{~Hz}, \mathrm{H}-5), 7.34-7.41(\mathrm{~m}, 5 \mathrm{H}, \mathrm{Ph}), 7.86(\mathrm{~d}, J=7.2 \mathrm{~Hz}, 1 \mathrm{H}$, $\mathrm{H}-6), 10.6$ (br. s, $1 \mathrm{H}, \mathrm{COOH}$ ) ppm. 
${ }^{13} \mathrm{C}-\mathrm{NMR}\left(75 \mathrm{MHz},\left[D_{6}\right] \mathrm{DMSO}\right)$

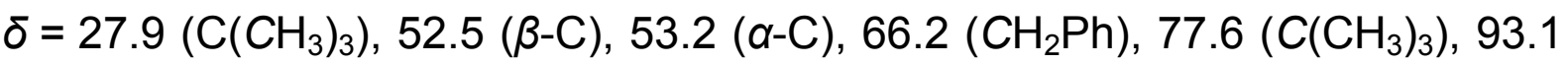
(C-5), 127.7 (m-C, Ph), 127.9 (p-C, Ph), 128.3 (o-C, Ph), 135.9 (C-4), 150.1 (C-6), 153.2 (C-2), $154.9(\mathrm{CONH}), 162.4(\mathrm{CONH}), 171.2(\mathrm{COOH}) \mathrm{ppm}$.

HPLC für (S)- $N$-tert-Butoxycarbonyl- $\beta$-( $N$-4-benzyloxycarbonyl-1-cytosinyl)alanin (39) (AAV1; Gradient 30\% auf 60\% B' (Acetonitril + $0.1 \%$ TFA) in $30 \mathrm{~min}, \lambda=254 \mathrm{~nm}) t_{\mathrm{R}}=21.9 \mathrm{~min}$.

\subsection{2 (R)-N-tert-Butoxycarbonyl- $\beta$-( $N$-4-benzyloxycarbonyl-1-cytosinyl)- alanin (39a)}

Die Synthesevorschrift und die analytische Daten entsprechen mit Ausnahme der HPLC-Analytik jenen des (S)-Enantiomers.

\subsection{3 (S)-N-tert-Butoxycarbonyl- $\beta$-(2-amino-6-chlor-9-purinyl)-alanin $(36)^{[47]}$}<smiles>CC(C)(C)OC(=O)NC1COC1=O</smiles>

35

$\mathrm{C}_{8} \mathrm{H}_{13} \mathrm{NO}_{4}[187.20]$<smiles>Nc1nc(Cl)c2nc[nH]c2n1</smiles>

89<smiles>CC(C)(C)OC(=O)NC(Cn1cnc2c(Cl)nc(N)nc21)C(=O)O</smiles>

36

$\mathrm{Zu}$ einer Suspension bestehend aus $2.05 \mathrm{~g}$ (12.1 mmol, 1.3 eq.) 2-Amino-6chlorpurin (89) in $5 \mathrm{~mL}$ Dimethylsulfoxid wurden innerhalb von $15 \mathrm{~min} 1.53 \mathrm{~mL}$ (1.56 g, $10.2 \mathrm{mmol}, 1.1$ eq.) DBU zugetropft und $15 \mathrm{~min}$ bei RT gerührt. Anschließend wurde innerhalb weiterer 15 min eine Lösung bestehend aus $1.74 \mathrm{~g}$ (9.31 mmol, 1.0 eq.) (S)-N-tert-Butoxycarbonyl-serinlacton (35) in $5 \mathrm{~mL}$ 
Dimethylsulfoxid zugegeben. Es wurde $3 \mathrm{~h}$ bei RT gerührt und die Reaktion durch Zugabe von $584 \mu \mathrm{L}(0.52 \mathrm{~g}, 8.74 \mathrm{mmol}, 1.1$ eq.) Essigsäure beendet. Die Reinigung erfolgte mittels $\mathrm{FC}$ an Kieselgel $(12 \mathrm{~cm}, \varnothing 6 \mathrm{~cm}$, Essigester/Methanol (8:2), Gradient 0.2-1\% Essigsäure pro $1000 \mathrm{~mL}$ ). Es wurden $1.73 \mathrm{~g}(4.83 \mathrm{mmol}, 52 \%, 36)$ des Produktes als weißer Feststoff isoliert.

DC (Chloroform/Methanol/Wasser/Essigsäure 70:30:3:0.3) $R_{\mathrm{f}}=0.24$.

${ }^{1} \mathrm{H}-\mathrm{NMR}\left(300 \mathrm{MHz},\left[D_{6}\right] \mathrm{DMSO}\right)$

$\delta=1.07(\mathrm{~s}, 1.5 \mathrm{H}, t-\mathrm{Bu}), 1.26(\mathrm{~s}, 7.5 \mathrm{H}, t-\mathrm{Bu}), 4.15(\mathrm{dd}, J=10, J=14 \mathrm{~Hz}, 1 \mathrm{H}$, $\beta-\mathrm{H}), 4.30-4.41(\mathrm{~m}, 1 \mathrm{H}, \alpha-\mathrm{H}), 4.39-4.46(\mathrm{~m}, 1 \mathrm{H} ; \beta-\mathrm{H}), 6.85\left(\mathrm{~s}, 2 \mathrm{H}, \mathrm{NH}_{2}\right), 6.94$ (d, $J=8 \mathrm{~Hz}, 1 \mathrm{H}, \mathrm{NHBoc}), 7.92(\mathrm{~s}, 1 \mathrm{H}, \mathrm{H}-8) \mathrm{ppm}$.

${ }^{13}$ C-NMR $\left(75 \mathrm{MHz},\left[D_{6}\right] \mathrm{DMSO}\right)$

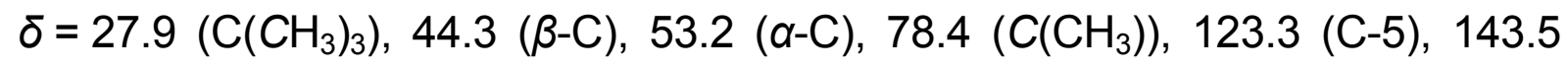
(C-8), 149.1 (C-6), 154.1 (C-2), $155.0(\mathrm{CONH}), 159.6(\mathrm{C}-4), 171.1(\mathrm{COOH})$ ppm.

\subsection{4 (R)-N-tert-Butoxycarbonyl- $\beta$-(2-amino-6-chlor-9-purinyl)-alanin (36a)}

Die Synthesevorschrift und die analytischen Daten entsprechen jenen der (S)Enantiomeren. 


\subsection{5 $\beta$-(9-Guaninyl)-alanin (90)}<smiles>CC(C)(C)OC(=O)NC(Cn1cnc2c(Cl)nc(N)nc21)C(=O)O</smiles>

36

$$
\mathrm{C}_{13} \mathrm{H}_{17} \mathrm{CIN}_{6} \mathrm{O}_{4}[356.77]
$$<smiles>Nc1nc2c(ncn2CC(N)C(=O)O)c(=O)[nH]1</smiles>

90

Eine Lösung aus $2.68 \mathrm{~g}$ (7.51 mmol, 1.0 eq.) (S)- N-tert-Butoxycarbonyl- $\beta$-(2amino-6-chlor-9-purinyl)-alanin (36) und $33 \mathrm{~mL}$ TFA/Wasser 3:1 wurde $5 \mathrm{~d}$ bei RT gerührt. Anschließend wurde die Reaktionsmischung unter Zugabe von Toluol bis zur Trockene eingeengt. Das Rohprodukt wurde ohne weitere Aufreinigung direkt weiter umgesetzt.

DC (iso-Propanol/Wasser/Essigsäure 5:2:1, NaCl ges.): $R_{\mathrm{f}}=0.37$. 


\subsection{6 (S)-N-tert-Butoxycarbonyl- $\beta$-(9-guaninyl)-alanin (37)}<smiles>Nc1nc2c(ncn2CC(N)C(=O)O)c(=O)[nH]1</smiles>

90<smiles>CC(C)(C)OC(=O)NC(Cn1cnc2c(=O)[nH]c(N)nc21)C(=O)O</smiles>

37

$\mathrm{C}_{8} \mathrm{H}_{10} \mathrm{~N}_{6} \mathrm{O}_{3}[238.24]$

$\mathrm{C}_{13} \mathrm{H}_{18} \mathrm{~N}_{6} \mathrm{O}_{5}$ [338.33]

Es wurden $1.79 \mathrm{~g}$ (7.51 mmol, 1.0 eq.) des Rohprodukts (S)- $N$-tertButoxycarbonyl- $\beta$-(9-guaninyl)-alanin (91) in $48 \mathrm{~mL}$ Wasser/1 $\mathrm{N} \mathrm{NaOH/Dioxan}$ (1:1:2) suspendiert und mit $1 \mathrm{~N} \mathrm{NaOH}$ ein $\mathrm{pH}$-Wert von 9-9.5 eingestellt. Anschließend wurde zur Suspension bei $0{ }^{\circ} \mathrm{C} 1.8 \mathrm{~g}$ (8.26 mmol, 1.1 eq.) $\mathrm{N}$-Ditert-Butyldicarboxylat gegeben. Es wurde $45 \mathrm{~min}$ bei $0{ }^{\circ} \mathrm{C}$ gerührt und weitere $60 \mathrm{~h}$ bei RT. Das Gemisch wurde mit $1 \mathrm{~N} \mathrm{HCl}$ auf einen pH-Wert von 6.0-6.5 gebracht und bis zur Trockene eingeengt. Das Rohprodukt wurde mittels FC an RP-Kieselgel (10 cm, Ø $2 \mathrm{~cm}$, Wasser, Gradient $8 \%$ Methanol pro $500 \mathrm{~mL}$ ) gereinigt. Es wurden $2.34 \mathrm{~g}(6.91 \mathrm{mmol}, 92 \%, 37$, ee $=91 \%)$ des Produktes als Feststoff isoliert.

DC (iso-Propanol/Wasser/Essigsäure 5:2:1: $\mathrm{NaCl}$ ges.) $R_{\mathrm{f}}=0.53$.

${ }^{1} \mathrm{H}-\mathrm{NMR}\left(300 \mathrm{MHz},\left[D_{6}\right] \mathrm{DMSO}\right)$

$\delta=1.07$ (s, $9 \mathrm{H}, t$-Bu Rotamer), 3.84-4.03 (m, $2 \mathrm{H}, \beta-\mathrm{H}, \alpha-\mathrm{H}), 4.43(\mathrm{~d}$, $J=10.9 \mathrm{~Hz}, 1 \mathrm{H}, \beta-\mathrm{H}), 6.09-6.22(\mathrm{~m}, 1 \mathrm{H}, \mathrm{NHBoc}), 6.75\left(\mathrm{~s}, 2 \mathrm{H}, \mathrm{NH}_{2}\right), 7.50$ (s, $1 \mathrm{H}, \mathrm{H}-8), 11.1$ (br. s, $1 \mathrm{H}, \mathrm{NH}$ ) ppm. 
${ }^{13} \mathrm{C}-\mathrm{NMR}\left(75 \mathrm{MHz},\left[D_{6}\right] \mathrm{DMSO}\right)$

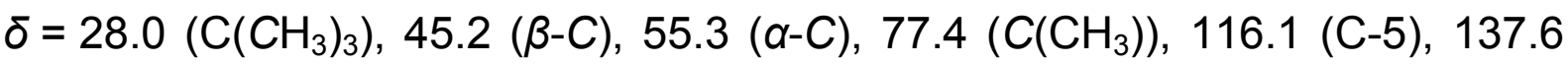
(C-8), 151.5 (C-6), 153.6 (C-2), $154.8(\mathrm{CONH}), 157.1(\mathrm{C}-4), 172.1(\mathrm{COOH})$ ppm.

HPLC für (S)-N-tert-Butoxycarbonyl- $\beta$-(9-guaninyl)-alanin (37) (AAV1; Gradient $5 \%$ auf $20 \%$ B' (Acetonitril $+0.1 \%$ TFA) in $30 \mathrm{~min}, \lambda=254 \mathrm{~nm}$ ) $t_{\mathrm{R}}=26.1 \mathrm{~min}$.

\subsection{7 (R)-N-tert-Butoxycarbonyl- $\beta$-(9-guaninyl)-alanin (37a)}

Die Synthesevorschrift und die analytische Daten entsprechen mit Ausnahme der HPLC-Analytik jenen der (S)-Enantiomeren. Das Produkt wies eine Enantiomerenreinheit von ee $=97 \%$ auf.

HPLC für (R)-N-tert-Butoxycarbonyl- $\beta$-(9-guaninyl)-alanin (37a) (AAV1; Gradient $5 \%$ auf $20 \%$ Acetonitril in $30 \mathrm{~min}, \lambda=254 \mathrm{~nm}) t_{\mathrm{R}}=29.3 \mathrm{~min}$.

\subsection{8 (S)-N-Butoxycarbonyl- $\beta$-(1-thyminyl)-L-alanin (38)}

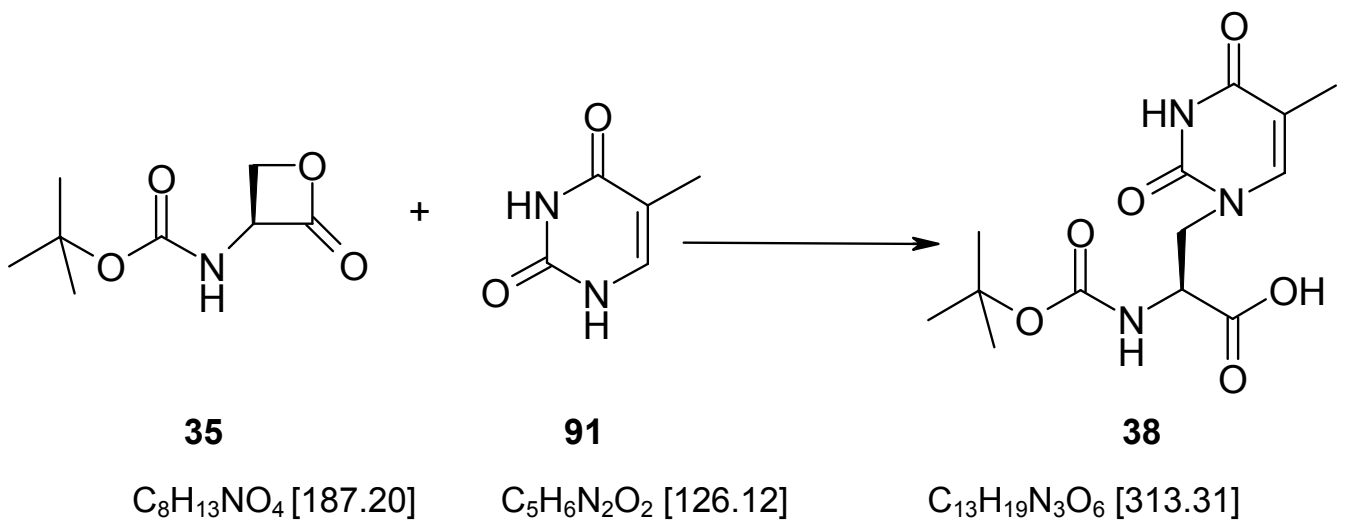

Unter Argon wurden $1.35 \mathrm{~g}$ (10.6 mmol, 2.1 eq.) Thymin 91 in $5 \mathrm{~mL}$ absolutem Dimethylsulfoxid suspendiert. Es wurden $1.93 \mathrm{~mL}$ (8.01 mmol, 1.5 eq.) DBU zugegeben und 10 min gerührt. Anschließend wurde innerhalb von 35 min 
eine Lösung aus $1.00 \mathrm{~g}$ (5.34 mmol, 1.0 eq.) (S)-N-tert-Butoxycarbonylserinlacton (35) in $8 \mathrm{~mL}$ Dimethylsulfoxid zu der Vorlage getropft, wobei Temperatur auf $35^{\circ} \mathrm{C}$ anstieg. Es wurde $12 \mathrm{~h}$ bei RT gerührt und die Reaktion durch $460 \mu \mathrm{L}$ (8.01 mmol, 1.5 eq.) Essigsäure beendet. Das Lösungsmittel wurde entfernt und das Rohprodukt mittels $F C$ an Kieselgel $(10 \mathrm{~cm}, \varnothing 4 \mathrm{~cm}$, Essigester/Methanol 8:2, Gradient: Essigsäure 0-0.5\% pro $1000 \mathrm{~mL}$ ) gereinigt. Es wurden $936 \mathrm{mg}(2.93 \mathrm{mmol}, 56 \%)(S)-N$-Butoxycarbonyl- $\beta$-(1thyminyl)-L-alanin (38) isoliert.

DC (Essigester/Methanol 8:2, $254 \mathrm{~nm}) R_{\mathrm{f}}=0.32$

${ }^{1} \mathrm{H}-\mathrm{NMR}\left(300 \mathrm{MHz},\left[D_{6}\right] \mathrm{DMSO}\right)$

$\delta=1.24(\mathrm{~s}, 9 \mathrm{H}, t-\mathrm{Bu}), 1.72\left(\mathrm{~d}, J=0.9 \mathrm{~Hz}, 3 \mathrm{H}, \mathrm{CH}_{3}-\mathrm{C}\right), 3.43-3.51(\mathrm{~m}, 1 \mathrm{H}, \beta-$ $\mathrm{H})$, 4.17-4.23 (m, $1 \mathrm{H}, \beta-\mathrm{H}), 4.31-4.39(\mathrm{~m}, 1 \mathrm{H}, \alpha-\mathrm{H}), 6.71$ (br. s, $1 \mathrm{H}, \mathrm{NHBoc})$, 7.32 (d, $J=0.8 \mathrm{~Hz}, 1 \mathrm{H}, \mathrm{H}-6), 11.3(\mathrm{~s}, 1 \mathrm{H}, \mathrm{NH}-3) \mathrm{ppm}$.

${ }^{13}$ C-NMR (75 MHz, [ $\left.\left.D_{6}\right] \mathrm{DMSO}\right)$

$\delta=12.0\left(\mathrm{CCH}_{3}\right), 27.6\left(\mathrm{C}\left(\mathrm{CH}_{3}\right)_{3}\right), 48.7(\beta-\mathrm{C}), 51.4(\alpha-\mathrm{C}), 78,8\left(\mathrm{C}_{\left(\mathrm{CH}_{3}\right)_{3}, 107.7}\right.$ (C-5), 141.9 (C-6), 150.0 (C-2), $155.2(\mathrm{CONH}), 164.2(\mathrm{C}-2), 171.2(\mathrm{COOH})$ ppm. 


\subsection{9 (S)-N-Butoxycarbonyl- $\beta-(9-a d e n i n y l)-L-a l a n i n ~(40)^{[47]}$}<smiles>CC(C)(C)OC(=O)NC1COC1=O</smiles>

35<smiles>Nc1ncnc2[nH]cnc12</smiles>

92<smiles>CC(C)(C)OC(=O)NC(Cn1cnc2c(N)ncnc21)C(=O)O</smiles>

40

Unter einer Argonatmosphäre wurden zu $1.10 \mathrm{~g} \mathrm{(8.10} \mathrm{mmol,} 1.5$ eq.) Adenin, $1.01 \mathrm{~g}$ (5.33 mmol, 1.0 eq.) (S)-N-tert-Butoxycarbonyl-serinlacton (35) und $741 \mathrm{mg}$ (5.33 mmol, 1.1 eq.) $\mathrm{K}_{2} \mathrm{CO}_{3} 5 \mathrm{~mL}$ absolutes Dimethylsulfoxid gegeben. Die entstandene Suspension wurde $3 \mathrm{~h}$ bei RT gerührt. Zur Beendigung der Reaktion wurden $0.61 \mathrm{~mL}$ (10.6 mmol, 2.0 eq.) Essigsäure zugegeben und das Reaktionsgemisch im Hochvakuum $\left(40^{\circ} \mathrm{C}\right)$ eingeengt. Der hellgelbe Feststoff wurde in Methanol gelöst und mittels FC an Kieselgel (Essigester/ Methanol/Wasser 80:14:6, Gradient: 0-1\% Essigsäure auf $1000 \mathrm{~mL}$ ) gereinigt. Das gewünschte Produkt wurde in einer Ausbeute von $0.53 \mathrm{~g}(1.65 \mathrm{mmol}$, $31 \%, 40)$ erhalten.

DC (Essigester/Methanol/Wasser 80:14:6, $\lambda=254 \mathrm{~nm}) R_{\mathrm{f}}=0.41$.

${ }^{1} \mathrm{H}-\mathrm{NMR}$ (300 MHz, [ $\left.\left.D_{6}\right] \mathrm{DMSO}\right)$

$\delta=1.12(\mathrm{~s}, 9 \mathrm{H}, t-\mathrm{Bu}) 6.86(\mathrm{~s}, 1 \mathrm{H}, \mathrm{N} H(\mathrm{BOC})), 7.20\left(\mathrm{~s}, 2 \mathrm{H}, \mathrm{NH}_{2}\right), 7.96(\mathrm{~s}, 1 \mathrm{H}$, $\mathrm{H}-8), 8.14$ (s,1 H, H-2), 13.0 (br. s, $1 \mathrm{H}, \mathrm{COOH}$ ) ppm.

\section{${ }^{13}$ C-NMR (75 MHz, $\left.\left[D_{6}\right] \mathrm{DMSO}\right)$}

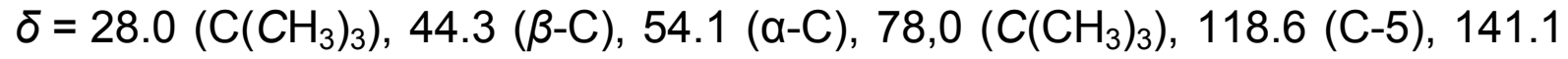
(C-6), 149.6 (C-4), $152.4(\mathrm{CONH}), 155.2(\mathrm{C}-6), 171.2(\mathrm{COOH}) \mathrm{ppm}$. 


\subsection{Synthese von $\mathbf{N}$-methylierten Alanyl-Nucleoaminosäuren}

\subsection{1 (S)-N-Butoxycarbonyl-N-methyl-L-serinlacton (42)}<smiles>CN(C(=O)OC(C)(C)C)C(CO)C(=O)O</smiles>

41

$\mathrm{C}_{9} \mathrm{H}_{17} \mathrm{NO}_{5}[219.24]$

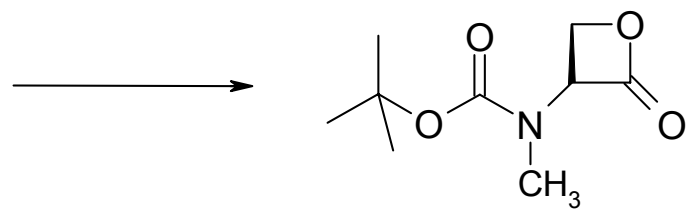

42

$\mathrm{C}_{9} \mathrm{H}_{14} \mathrm{NO}_{4}[201.22]$

Unter einer Argonatmosphäre wurden $6.04 \mathrm{~g}$ (23.1 mmol, 1.0 eq.) Triphenylphosphin in $100 \mathrm{~mL}$ absolutem Acetonitril gelöst und auf $-40^{\circ} \mathrm{C}$ abgekühlt. In der Kälte wurden innerhalb von $15 \mathrm{~min} 3.58 \mathrm{~mL}$ (22.1 mmol, 1.0 eq.) DEAD zugetropft und $15 \mathrm{~min}$ gerührt. Anschließend wurden $6.04 \mathrm{~g}(22.8 \mathrm{mmol}$, 1.0 eq.) (S)-N-Butoxycarbonyl- $N$-methyl-L-serin (41) in $50 \mathrm{~mL}$ absolutem Acetonitril gelöst und langsam zur Reaktionsmischung getropft. Die Reaktion wurde $2 \mathrm{~h}$ bei $-35^{\circ} \mathrm{C}$ gerührt und weitere $5 \mathrm{~h}$ bei $\mathrm{RT}$ gerührt. Das Lösungsmittel wurde im Hochvakuum bei $45^{\circ} \mathrm{C}$ entfernt, das Rohprodukt in $50 \mathrm{~mL}$ Hexan/Essigester (3:1) aufgenommen und $10 \mathrm{~min}$ im Ultraschallbad behandelt. Die entstandene Suspension wurde mittels FC an Kieselgel $(20 \mathrm{~cm}$, $\varnothing 7 \mathrm{~cm}$, Hexan/Essigester 3:1) gereinigt. Nach Trocknung wurden $3.37 \mathrm{~g}$ (16.75 mmol, $73.5 \%, 42)$ des gewünschten Produkts isoliert.

Drehwert $[\alpha]_{D}^{20}=-44(\mathrm{c}=0.75$ in Methanol).

DC (Hexan/Essigester 3:1, $254 \mathrm{~nm}) R_{\mathrm{f}}=0.37$.

${ }^{1} \mathrm{H}-\mathrm{NMR}\left(300 \mathrm{MHz},\left[D_{6}\right] \mathrm{DMSO}\right)$

$\delta=1.47(\mathrm{~s}, 9 \mathrm{H}, \mathrm{t}-\mathrm{Bu}), 2.98\left(\mathrm{~s}, 3 \mathrm{H}, \mathrm{CH}_{3}\right), 4.43\left(\mathrm{~d}, 2 \mathrm{H}, \mathrm{CH}_{2}\right), 5.00-5.50(\mathrm{~m}$, $1 \mathrm{H}, \mathrm{CH}) \mathrm{ppm}$. 
${ }^{13}$ C-NMR (75 MHz, [ $\left.\left.D_{6}\right] \mathrm{DMSO}\right)$

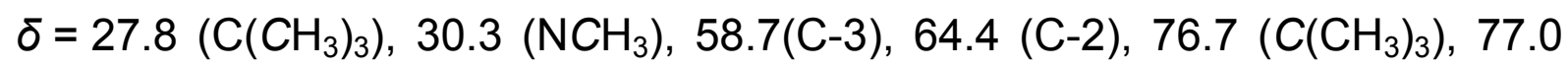
(CO), 77.2 (CO-Lacton) ppm.

HPLC für (S)-N-Butoxycarbonyl-N-methyl-L-serinlacton (42) (AAV1; Gradient $10 \%$ auf $18 \%$ Acetonitril in $30 \mathrm{~min}, \lambda=254 \mathrm{~nm}$ ) $t_{\mathrm{R}}=22.1 \mathrm{~min}$.

IR (Film) $\tilde{v}=2980,2935,1833,1762,1697,1482,1455,1401,1370,1352$, $1329,1302,1254,1111,1051,968,941 \mathrm{~cm}^{-1}$.

MS (HRMS) m/z 224.08938 [M+Na] berechnet für $224.08933[\mathrm{M}+\mathrm{Na}]^{+}$.

\subsection{2 (S)-N-tert-Butoxycarbonyl- $N$-methyl- $\beta$-( $N$-4-benzyloxycarbonyl-1- cytosinyl)-alanin (45)}

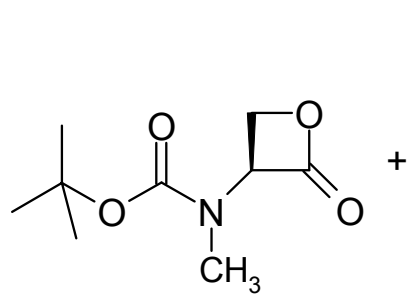

42

$\mathrm{C}_{9} \mathrm{H}_{15} \mathrm{NO}_{4}[201.22]$<smiles>O=C(Nc1cc[nH]c(=O)n1)Oc1ccccc1</smiles>

88<smiles>CN(C(=O)OC(C)(C)C)C(Cn1ccc(NC(=O)Oc2ccccc2)nc1=O)C(=O)O</smiles>

45

Bei RT wurde zu einer Suspension von $753 \mathrm{mg}$ (2.43 mmol, 1.0 eq.) N-4Benzyloxycarbonyl-1-cytosin (88) in $3 \mathrm{~mL}$ absolutem Dimethylsulfoxid langsam $332 \mu \mathrm{L}$ (2.20 mmol, 1.5 eq.) DBU getropft und die Reaktions-mischung für $15 \mathrm{~min}$ gerührt. Anschließend wurden $293 \mathrm{mg}$ (1.53 mmol, 1.0 eq.) (S)-NButoxycarbonyl- $N$-methyl-L-serinlacton (42), gelöst in $2 \mathrm{~mL}$ absolutem Dimethylsulfoxid, zur Reaktion getropft und $3 \mathrm{~h}$ gerührt. Die Reaktion wurde durch $127 \mu \mathrm{L}(2.20 \mathrm{mmol}, 1.5$ eq.) Essigsäure beendet. Das Lösungsmittel 
wurde im Hochvakuum entfernt, der Rückstand in $5 \mathrm{~mL}$ Methanol suspendiert und zentrifugiert. Das Methanol wurde im Vakuum entfernt und das Rohprodukt mittels FC an Kieselgel $(20 \mathrm{~cm}, \varnothing 3 \mathrm{~cm}$, /Methanol 9:1, Gradient: Essigsäure $0.2-1.0 \%$ auf $1000 \mathrm{~mL}$ ) gereinigt. Das Produkt 45 wurde zu $409.2 \mathrm{mg}(0.95 \mathrm{mmol}, 63 \%$, ee $=99 \%$.) erhalten

Drehwert $[\alpha]_{D}^{20}=-143(\mathrm{c}=0.5 \mathrm{~g} / 100 \mathrm{~mL}$ in DMSO $)$.

DC (Essigester/Methanol/Essigsäure 9:1:0.1, $\lambda=254 \mathrm{~nm}) R_{\mathrm{f}}=0.53$.

${ }^{1} \mathrm{H}-\mathrm{NMR}\left(300 \mathrm{MHz},\left[D_{6}\right] \mathrm{DMSO}\right)$

$\delta=1.29(\mathrm{~s}, 9 \mathrm{H}, t-\mathrm{Bu}), 2.69\left(\mathrm{NCH}_{3}\right), 4.06-4.13(\mathrm{~m}, 1 \mathrm{H}, \beta-\mathrm{H}), 4.35-4.48(\mathrm{~m}$, $1 \mathrm{H}, \alpha-\mathrm{H}), 4.76-4.82(\mathrm{~m}, 1 \mathrm{H}, \beta-\mathrm{H}), 5.17\left(\mathrm{~s}, 2 \mathrm{H}, \mathrm{CH}_{2} \mathrm{Ph}\right), 6.94(\mathrm{~d}, 1 \mathrm{H}$, $J=7.2 \mathrm{~Hz}, \mathrm{H}-5), 7.38-7.40$ (m, $5 \mathrm{H}, \mathrm{Ph}), 7.86(\mathrm{~d}, 1 \mathrm{H}, J=7.3 \mathrm{~Hz}, \mathrm{H}-6) \mathrm{ppm}$.

${ }^{13}$ C-NMR $\left(75 \mathrm{MHz},\left[D_{6}\right] \mathrm{DMSO}\right)$

$\delta=27.5\left(\mathrm{C}\left(\mathrm{CH}_{3}\right)_{3}\right), 27.8\left(\mathrm{NCH}_{3}\right), 57.0(\beta-\mathrm{C}), 57.7(\alpha-\mathrm{C}), 66.3\left(\mathrm{CH}_{2} \mathrm{Ph}\right), 78.6$ $\left(\mathrm{C}\left(\mathrm{CH}_{3}\right)_{3}\right), 93.6$ (C-5), $127.6(m-\mathrm{C}, \mathrm{Ph}), 127.7$ (p-C, $\left.\mathrm{Ph}\right), 127.9$ (o-C, $\left.\mathrm{Ph}\right), 135.8$ (C-4), 150.0 (C-6), 154.3 (C-2), $155.2(\mathrm{CONH}), 162.7(\mathrm{CONH}), 164.9(\mathrm{COOH})$ ppm.

HPLC für (S)-N-tert-Butoxycarbonyl- $N$-methyl- $\beta$-( $N$-4-benzyloxycarbonyl-1cytosinyl)-alanin (45) (AAV1; Gradient $20 \%$ auf $48 \%$ B' (Acetonitril + $0.1 \% \mathrm{TFA}$ ) in $30 \mathrm{~min}, \lambda=254 \mathrm{~nm}$ ) $t_{\mathrm{R}}=14.3 \mathrm{~min}$.

IR $(\mathrm{KBr}) \tilde{v}=3429,2977,1686,1560,1499,1369,1322,1214,1153,1064$, $788,698 \mathrm{~cm}^{-1}$.

UV/VIS (Methanol) $\lambda_{\max }(\varepsilon)=201,240,297 \mathrm{~nm}$. 
MS (HRMS) $\mathrm{m} / \mathrm{z} \quad 447.18760[\mathrm{M}+\mathrm{H}]^{+}, 883.36818[2 \mathrm{M}+\mathrm{H}]^{+}$berechnet für $447.18743[\mathrm{M}+\mathrm{H}]^{+}$.

\subsection{3 (S)-N-tert-Butoxycarbonyl-N-methyl- $\beta$-(2-amino-6-chlor-9-purinyl)- alanin (93)}

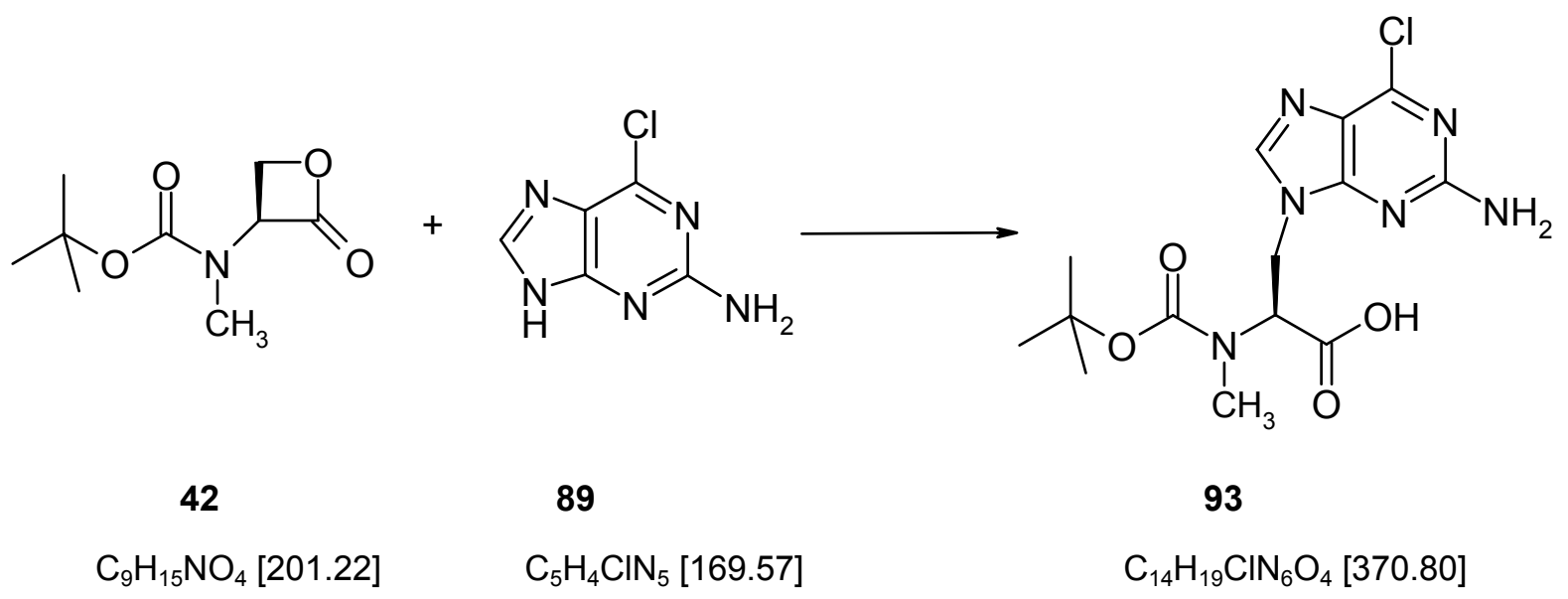

Es wurden $688 \mathrm{mg}$ (4.11 mmol, 1.3 eq.) 2-Amino-6-chlorpurin (89) in $2 \mathrm{~mL}$ absolutem Dimethylsulfoxid suspendiert und unter Argonatmosphäre gerührt. Anschließend wurde bei RT $513 \mu \mathrm{L}$ (3.44 mmol, 1.1 eq.) DBU langsam zugetropft und die Reaktionsmischung 15 min weitergerührt. Eine Lösung aus $628 \mathrm{mg}$ (3.10 mmol, 1.0 eq.) (S)-N-Butoxycarbonyl- $N$-methyl-L-serinlacton (42) in $2 \mathrm{~mL}$ absolutem Dimethylsulfoxid wurde zur Reaktion getropft und $4 \mathrm{~h}$ gerührt. Die Reaktion wurde durch Zugabe von $196 \mu \mathrm{L}$ (3.42 mmol, 1.1 eq.) Essigsäure beendet. Das Lösungsmittel wurde im Hochvakuum aus dem System entfernt. Der ölige Rückstand wurde mittels FC an Kieselgel $(20 \mathrm{~cm}$, $\varnothing 3 \mathrm{~cm}$, Essigester/Methanol 8:2, Gradient: Essigsäure $0.2-1.0 \%$ auf $1000 \mathrm{~mL}$ ) gereinigt. Das Produkt 93 wurde zu $77 \%$ (2.39 mmol, $889 \mathrm{mg}$ ) isoliert.

Drehwert $[\alpha]_{D}^{20}=-109.3(\mathrm{c}=0.3 \mathrm{~g} / 100 \mathrm{~mL}$ in DMSO).

DC (Essigester/Methanol/Essigsäure 8:2:0.1, $\lambda=254 \mathrm{~nm}): R_{\mathrm{f}}=0.52$. 
${ }^{1} \mathrm{H}-\mathrm{NMR}\left(300 \mathrm{MHz},\left[D_{6}\right] \mathrm{DMSO}\right)$

$\delta=1.06(\mathrm{~s}, 7.5 \mathrm{H}, t-\mathrm{Bu}), 1.20(\mathrm{~s}, 1.5 \mathrm{H}, t-\mathrm{Bu}), 2.70\left(\mathrm{~s}, 2.5 \mathrm{H}, \mathrm{N}-\mathrm{CH}_{3}\right) 2.74(\mathrm{~s}$, $\left.0.5 \mathrm{H}, \mathrm{N}-\mathrm{CH}_{3}\right), 4.45-4.51(\mathrm{~m}, 1 \mathrm{H}, \beta-\mathrm{H}), 4.80-4.89(\mathrm{~m}, 2 \mathrm{H}, \alpha-\mathrm{H}, \beta-\mathrm{H}), 6.85(\mathrm{~s}$, $\left.2 \mathrm{H}, \mathrm{NH}_{2}\right), 8.01(\mathrm{~s}, 1 \mathrm{H}, \mathrm{H}-8) \mathrm{ppm}$.

${ }^{13}$ C-NMR $\left(75 \mathrm{MHz},\left[D_{6}\right] \mathrm{DMSO}\right)$

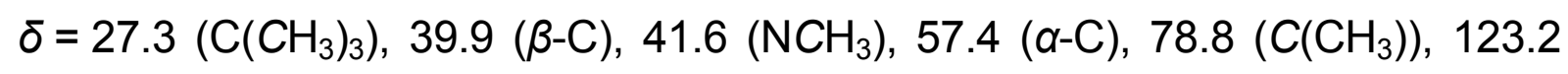
(C-5), 142.3 (C-8), 149.5 (C-6), 154.2 (C-2), 155.0 (CONH), 160.0 (C-4), 170.2 $(\mathrm{COOH}) \mathrm{ppm}$.

IR $(\mathrm{KBr}) \tilde{v}=3347,2977,1693,1616,1565,1520,1469,1393,1368,1155$, $916,785,643 \mathrm{~cm}^{-1}$.

UV/VIS (Methanol) $\lambda_{\max }=201,222,310 \mathrm{~nm}$.

MS (HRMS) m/z 371.12309 [M+H] berechnet für 371.12291 [M+H] .

\subsubsection{N-Methyl- $\beta$-(9-guaninyl)-alanin (94)}<smiles>CN(C(=O)OC(C)(C)C)C(Cn1cnc2c(Cl)nc(N)nc21)C(=O)O</smiles>

93<smiles>CNC(Cn1cnc2c(=O)[nH]c(N)nc21)C(=O)O</smiles>

94 
Eine Lösung aus $869 \mathrm{mg}$ (2.34 mmol, 1.0 eq.) (S)-N-tert-Butoxycarbonyl$N$-methyl- $\beta$-(2-amino-6-chlor-9-purinyl)-alanin (93) und $12 \mathrm{~mL}$ TFA/ $\mathrm{H}_{2} \mathrm{O}$ 3:1 wurde über Nacht bei RT gerührt. Anschließend wurde die Reaktionsmischung unter Zugabe von Toluol bis zur Trockene eingeengt. Das Rohprodukt wurde zweimal in $10 \mathrm{~mL} 1 \mathrm{~N} \mathrm{HCl}$ aufgenommen und wiederholt eingeengt. Der Feststoff wurde ohne weitere Aufarbeitung im Folgeschritt eingesetzt.

Drehwert $[\alpha]_{D}^{20}=-10.8(\mathrm{c}=0.5 \mathrm{~g} / 100 \mathrm{~mL}$ in DMSO).

UV/VIS (Methanol) $\lambda_{\max }=202,554 \mathrm{~nm}$

\subsection{5 (S)-N-tert-Butoxycarbonyl-N-methyl- $\beta$-(9-guaninyl)-alanin (43)}<smiles>CNC(Cn1cnc2c(=O)[nH]c(N)nc21)C(=O)O</smiles>

94

$\mathrm{C}_{9} \mathrm{H}_{12} \mathrm{~N}_{6} \mathrm{O}_{3}[252.23]$<smiles>CN(C(=O)OC(C)(C)C)C(Cn1cnc2c(=O)[nH]c(N)nc21)C(=O)O</smiles>

43

$\mathrm{C}_{14} \mathrm{H}_{20} \mathrm{~N}_{6} \mathrm{O}_{5}$ [352.35]

Bei RT wurde das Rohprodukt 94 in $10 \mathrm{~mL}$ Wasser/NaOH/Dioxan 1:1:2 suspendiert. Der pH-Wert wurde mit $1 \mathrm{~N} \mathrm{NaOH}$ auf einen Wert von $\mathrm{pH}=9.5$ eingestellt. Die Suspension wurde im Eisbad auf $0{ }^{\circ} \mathrm{C}$ gekühlt, mit $563 \mathrm{mg}$ (2.61 mmol, 1.1 eq.) N-Di-tert-Butyldicarboxylat versetzt. Die Lösung wurde auf RT erwärmt Es wurde über $2 \mathrm{~h}$ kontrolliert und gegebenenfalls erneut auf 9.5 eingestellt. Nachdem die Lösung über Nacht gerührt wurde, wurden weitere $60.0 \mathrm{mg}(0.27 \mathrm{mmol}, 0.1 \mathrm{eq}$.) $\mathrm{N}$-Di-tert-Butyldicarboxylat zugegeben. 
Der pH-Wert wurde mit $1 \mathrm{~N} \mathrm{NaOH}$ auf 9.5 eingestellt und erneut kontrolliert. Anschließend wurde mit $1 \mathrm{~N} \mathrm{HCl}$ auf einen $\mathrm{pH}$-Wert von $\mathrm{pH}=6$ eingestellt und das Lösungsmittelgemisch im Hochvakuum entfernt. Der Feststoff wurde anschließend mittels FC an RP-Kieselgel $\left(20 \mathrm{~cm}, \varnothing 3 \mathrm{~cm}, \mathrm{H}_{2} \mathrm{O}\right.$, Gradient $8 \%$ Methanol pro $500 \mathrm{~mL}$ ) gereinigt. Die Ausbeute betrug $79 \%$ (522.6 mg, $1.48 \mathrm{mmol}, 43$, ee $=93 \%$ ).

Drehwert $[\alpha]_{D}^{20}=-73.4(\mathrm{c}=0.3 \mathrm{~g} / 100 \mathrm{~mL}$ in DMSO).

DC (Essigester/Methanol 8:2, Gradient: Essigsäure 0.2-1.0 \% auf $1000 \mathrm{~mL}$, $254 \mathrm{~nm}) R_{\mathrm{f}}=0.69$.

${ }^{1} \mathrm{H}-\mathrm{NMR}\left(300 \mathrm{MHz},\left[D_{6}\right] \mathrm{DMSO}\right)$

$\delta=1.11\left(\mathrm{~s}, 9 \mathrm{H}, t\right.$-Bu-Rotamer), $2.71\left(\mathrm{~s}, 3 \mathrm{H}, \mathrm{CH}_{3}-\mathrm{N}\right), 4.95(\mathrm{~m}, 1 \mathrm{H}, \beta-\mathrm{H}), 4.42$ $\left(\mathrm{dd}, J_{1}=-14.5, J_{2}=-3.5,1 \mathrm{H}, \beta-\mathrm{H}\right), 4.59\left(\mathrm{dd}, J_{1}=-11.3, J_{2}=-3.9,1 \mathrm{H}, \alpha-\mathrm{H}\right)$, 6.47 (br. s, $1 \mathrm{H}, \mathrm{NHBoc}), 7.38$ (s, $1 \mathrm{H}, \mathrm{H}-6)$ ppm.

${ }^{13}$ C-NMR (75 MHz, [ $\left.\left.D_{6}\right] \mathrm{DMSO}\right)$

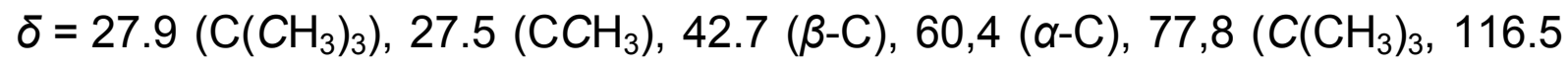
(C-5), 137.2 (C-6), $151.2(\mathrm{C}-2), 154.2(\mathrm{CONH}), 155.2(\mathrm{C}-2), 171.2(\mathrm{COOH})$ ppm.

HPLC für (S)-N-tert-Butoxycarbonyl-N-methyl- $\beta$-(9-guaninyl)-alanin (43)

(AAV1; Gradient $0 \%$ auf $15 \%$ B' (Acetonitril + $0.1 \%$ TFA) in $30 \mathrm{~min}$, $\lambda=280 \mathrm{~nm}) t_{\mathrm{R}}=6.3 \mathrm{~min}$.

IR $(\mathrm{KBr}) \tilde{v}=3430,1684,1541,1483,1444,1387,1252,1161,961,861,781$, $690,643 \mathrm{~cm}^{-1}$.

UV/VIS (Methanol) $\lambda_{\max }=255 \mathrm{~nm}$. 
MS (ESI) m/z (\%) $353.1[\mathrm{M}+\mathrm{H}]^{+}(100), 704.8[2 \mathrm{M}+\mathrm{H}]^{+}(20)$.

\subsection{6 (S)-N-Butoxycarbonyl-N-methyl- $\beta$-(1-thyminyl)-L-alanin (44)}

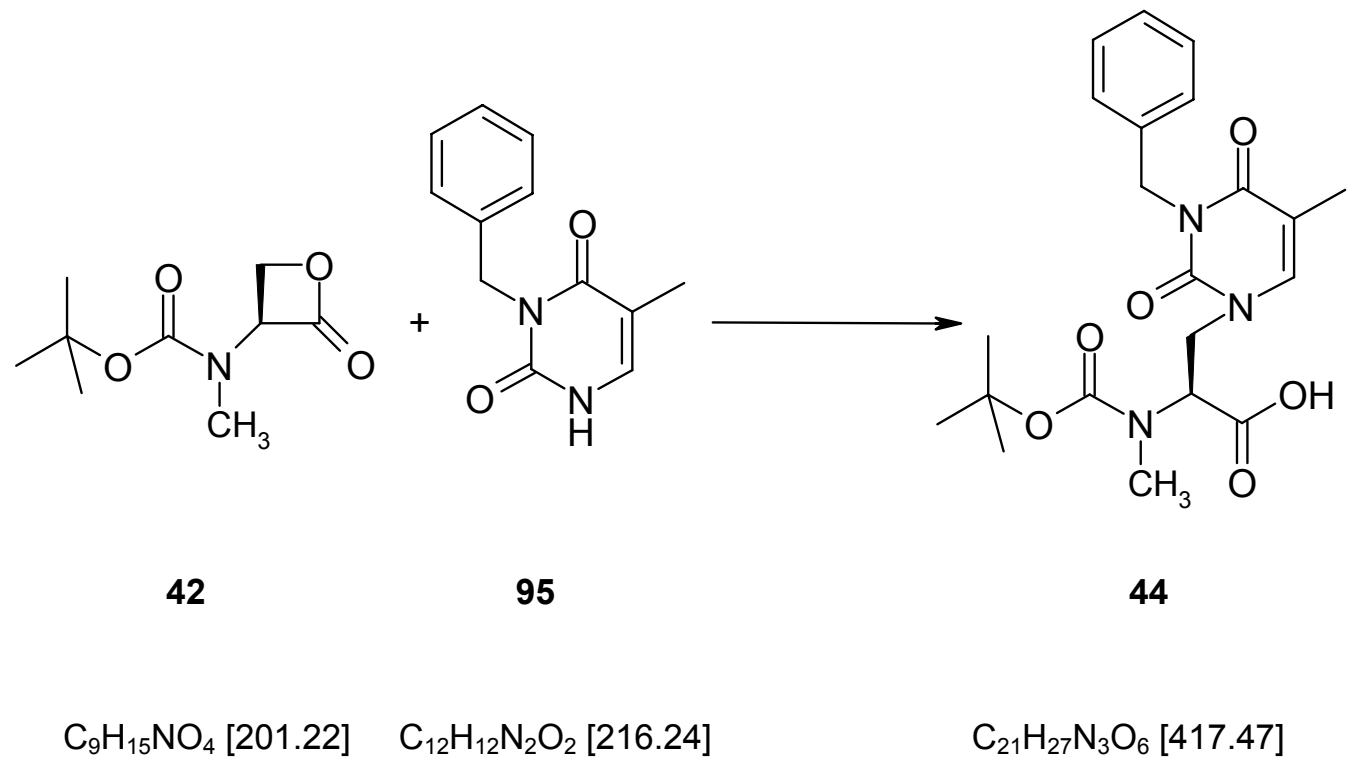

Unter Argon wurden $215 \mathrm{mg}$ (1.01 mmol, 1.0 eq.) N-3-Benzylcarbonyl-1thymin (95) in $3 \mathrm{~mL}$ Dimethylsulfoxid suspendiert. Zur Suspension wurden $111 \mu \mathrm{L}$ ( $0.78 \mathrm{mmol}, 1.5$ eq.) $\mathrm{DBU}$ zugegeben und $15 \mathrm{~min}$ bei RT gerührt. Innerhalb weiterer $15 \mathrm{~min}$ wurden zur Reaktionsmischung $100 \mathrm{mg}(0.51 \mathrm{mmol}$, 1.0 eq.) (S)-N-tert-Butoxycarbonyl- $N$-methyl-L-serinlacton (42) gelöst in $1 \mathrm{~mL}$ Dimethylsulfoxid getropft. Die Reaktion wurde bei RT $3 \mathrm{~h}$ gerührt. Anschließend wurde mit $43.0 \mu \mathrm{L}(0.82 \mathrm{mmol}, 1.1$ eq. $)$ Essigsäure die Reaktion beendet und das Lösungsmittel entfernt. Die Reinigung erfolgte mittels FC an Kieselgel (Essigester/Methanol 8:2, Gradient: 0.1\%-0.3\% Essigsäure pro $1000 \mathrm{~mL}$ ). Die Ausbeute des Produkts 44 betrug $31 \%$ (0.12 mmol, $50.1 \mathrm{mg}$, $e e=98 \%)$.

Drehwert $[\alpha]_{D}^{20}=-92(\mathrm{c}=0.5 \mathrm{~g} / 100 \mathrm{~mL}$ in DMSO).

DC (Essigester/Methanol/Essigsäure 8:2:0.05, $\lambda=254 \mathrm{~nm}) R_{\mathrm{f}}=0.69$. 
${ }^{1} \mathrm{H}-\mathrm{NMR}\left(300 \mathrm{MHz},\left[D_{6}\right] \mathrm{DMSO}\right)$

$\delta=1.38$ (s, $9 \mathrm{H}, t-\mathrm{Bu}$ ), 1.40 (s, $3 \mathrm{H}, \mathrm{CH}_{3}-\mathrm{C}$ ), 1.82 (br. s, $2 \mathrm{H}, 3-\mathrm{NCH}_{2}$ ), 2.77 (br.

$\left.\mathrm{s}, 3 \mathrm{H}, \mathrm{N}-\mathrm{CH}_{3}\right), 3.86-3.91(\mathrm{~m}, 1 \mathrm{H}, \beta-\mathrm{H}), 4.14-4.24(\mathrm{~m}, 1 \mathrm{H}, \beta-\mathrm{H}), 4.72-4.83(\mathrm{~m}$, $1 \mathrm{H}, \alpha-\mathrm{H})$, 7.51-7.63 (m, $1 \mathrm{H},), 7.72-7.77(\mathrm{~m}, 5 \mathrm{H}, \mathrm{Ph})$ 7.93-7.06 (m, $1 \mathrm{H}, \mathrm{H}-6)$ ppm.

${ }^{13}$ C-NMR (75 MHz, [D 6 DMSO)

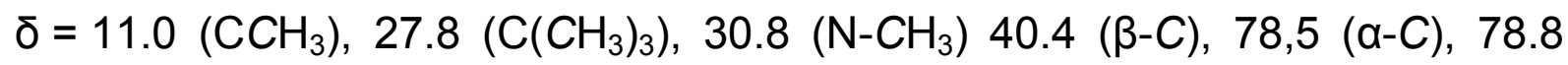
$\left(\mathrm{C}\left(\mathrm{CH}_{3}\right)_{3}, 107.7\right.$ (s, C-5), $127.7(\mathrm{C}-\mathrm{Ph}), 127.8(\mathrm{C}-\mathrm{Ph}), 127.9(\mathrm{C}-6), 128.8(\mathrm{C}-2)$, $131.8(\mathrm{Ph}, \mathrm{q}-\mathrm{C}), 134.6(\mathrm{CONH}), 142.0(\mathrm{C}-2), 171.2(\mathrm{COOH}) \mathrm{ppm}$.

HPLC für (S)-N-Butoxycarbonyl-N-methyl- $\beta$-(1-thyminyl)-L-alanin (44) (AAV1; Gradient $0 \%$ auf $15 \% B^{\prime}$ (Acetonitril $+0.1 \%$ TFA) in $30 \mathrm{~min}, \lambda=280 \mathrm{~nm}$ ) $t_{\mathrm{R}}=6.8 \mathrm{~min}$.

IR $(\mathrm{KBr}) \tilde{v}=2978,1749,1699,1659,1442,1387,1321,1354,1157,988,763$ $\mathrm{cm}^{-1}$.

UV/VIS (Methanol) $\lambda_{\max }=202,272 \mathrm{~nm}$.

MS (ESI) m/z (\%) $350.0[\mathrm{M}+\mathrm{Na}]$ (86), $326.1[\mathrm{M}-\mathrm{H}]^{-}, 653.0[2 \mathrm{M}-\mathrm{H}]^{-}(98)$. 


\subsection{7 (S)-N-Butoxycarbonyl-N-methyl- $\beta$-(9-adeninyl)-L-alanin (46)}<smiles>CN(C(=O)OC(C)(C)C)C1COC1=O</smiles>

42<smiles>Nc1ncnc2[nH]cnc12</smiles>

92<smiles>CN(C(=O)OC(C)(C)C)C(Cn1cnc2c(N)ncnc21)C(=O)O</smiles>

46

$$
\mathrm{C}_{9} \mathrm{H}_{15} \mathrm{NO}_{4} \text { [201.22] } \quad \mathrm{C}_{5} \mathrm{H}_{5} \mathrm{~N}_{5}[135.13] \quad \mathrm{C}_{14} \mathrm{H}_{20} \mathrm{~N}_{6} \mathrm{O}_{4}[336.35]
$$

Unter Argon wurden $80 \mathrm{mg}$ ( $0.43 \mathrm{mmol}, 1.0$ eq.) (S)-N-Butoxycarbonyl- $N$ methyl-L-serinlacton (42) $81 \mathrm{mg} \quad(0.67 \mathrm{mmol}, 1.5$ eq.) Adenin und $55 \mathrm{mg}$ ( $0.43 \mathrm{mmol}, 1.0$ eq.) $\mathrm{K}_{2} \mathrm{CO}_{3}$ in $2 \mathrm{~mL}$ absolutem Dimethylsulfoxid suspendiert und bei $10^{\circ} \mathrm{C}$ gerührt. Die Reaktionsmischung wurde anschließend über Nacht bei RT gerührt. Die Reaktion wurde durch Zugabe von $45.6 \mu \mathrm{L}$ ( $0.85 \mathrm{mmol}, 2.0$ eq.) Essigsäure abgebrochen und das Lösungsmittel im Vakuum entfernt. Die Reinigung erfolgte mittels FC an Kieselgel (Essigester/Methanol/Wasser 8:1.4:0.6, Gradient: 0.2-0.5 \% Essigsäure auf $1000 \mathrm{~mL})$. Es wurden $48.5 \mathrm{mg}(0.14 \mathrm{mmol}, 36 \%, 46)$ erhalten.

Drehwert $[\alpha]_{D}^{20}=-34(\mathrm{c}=0.4 \mathrm{~g} / 100 \mathrm{~mL}$ in DMSO).

DC (Essigester/Methanol 8:2, $\lambda=254 \mathrm{~nm}) R_{\mathrm{f}}=0.35$.

\section{${ }^{1} \mathrm{H}-\mathrm{NMR}\left(300 \mathrm{MHz},\left[\mathrm{D}_{6}\right] \mathrm{DMSO}\right)$}

$\delta=1.72(\mathrm{~s}, 9 \mathrm{H}, t-\mathrm{Bu}) 2.71\left(\mathrm{~s}, 3 \mathrm{H}, \mathrm{N}-\mathrm{CH}_{3}\right), 3.80-3.86(\mathrm{~m}, 1 \mathrm{H}, \beta-\mathrm{H}), 4.05-4-10$ $\left.(\mathrm{m}, 1 \mathrm{H}, \beta-\mathrm{H}), 4.32 .4 .36(\mathrm{~m}, 1 \mathrm{H}, \alpha-\mathrm{H}), 7.01(\mathrm{~s}, 2 \mathrm{H}, \mathrm{NH})_{2}\right), 7.94(\mathrm{~s}, 1 \mathrm{H}, \mathrm{H}-8)$, $8.11(\mathrm{~s}, 1 \mathrm{H}, \mathrm{H}-2) \mathrm{ppm}$. 
${ }^{13}$ C-NMR (75 MHz, [D 6 ]DMSO)

$\delta=27.1\left(\mathrm{C}\left(\mathrm{CH}_{3}\right)_{3}\right), 29.7\left(\mathrm{~N}-\mathrm{CH}_{3}\right), 40.0(\beta-\mathrm{C}), 60.1(\alpha-\mathrm{C}), 77.5\left(\mathrm{C}_{\left(\mathrm{CH}_{3}\right)_{3}, 118.8}\right.$ (C-5), $141.0(C-6), 149.7(C-4), 152.0(\mathrm{CONH}), 155.8(C-6), 175.9(\mathrm{COOH})$ ppm.

IR $(\mathrm{KBr}): \tilde{v}=3350,1746,1602,1482,1416,1327,1246,1159,1048$, $765 \mathrm{~cm}^{-1}$.

UV/VIS (Methanol) $\lambda_{\max }=204,260 \mathrm{~nm}$.

MS (ESI) m/z (\%) $335.1[\mathrm{M}-\mathrm{H}]^{-}(100), 381.1\left[\mathrm{M}-\mathrm{H}+2 \mathrm{Na}^{+}\right.$(100) , $670.9[2 \mathrm{M}-\mathrm{H}]^{-}$ (14), $739.1[2 \mathrm{M}-2 \mathrm{H}+3 \mathrm{Na}]^{+}(22), 693.2[2 \mathrm{M}-2 \mathrm{H}+\mathrm{Na}]^{-}(34)$.

Enantiomerenreinheit mittels HPLC (siehe Punkt 2.1.1):

$t_{R}=6.8$ min (Gradient: $0-15 \% B^{\prime}$ in $30 \mathrm{~min}, \lambda=280 \mathrm{~nm}$ ), ee $=98 \%$.

\subsection{Synthesen von geschützten $\mathbf{N}$-methylierten Aminosäuren}

\subsection{1 (S)-N-a-tert-Butoxycarbonyl-N-methyl-benzyl-cystein (56)}<smiles>CN(C(=O)OC(C)(C)C)C(CSCc1ccccc1)C(=O)OC(C)(C)C</smiles> 
Unter Argon wurde eine Lösung aus $118 \mu \mathrm{L}$ (1.01 mmol, 2.0 eq.) Benzylmercaptan (54) in $0.92 \mu \mathrm{L}$ absolutem Dimethylsulfoxid vorgelegt. $\mathrm{Zu}$ dieser Lösung wurde innerhalb von $15 \mathrm{~min} 112 \mu \mathrm{L}$ (0.83 mmol, 1.5 eq.) DBU getropft und 15 min gerührt. Anschließend wurde eine Lösung aus $100 \mathrm{mg}$ (0.54 mmol, 1.0 eq.) (S)- $N$-Butoxycarbonyl- $N$-methyl-L-serinlacton (42) in $0.6 \mathrm{~mL}$ absolutem Dimethylsulfoxid zur Reaktionslösung getropft und über Nacht bei RT gerührt. Die Reaktion wurde mit $43 \mu \mathrm{L}$ (0.82 mmol, 1.5 eq.) Essigsäure beendet, das Lösungsmittel im Hochvakuum entfernt und der Feststoff mittels FC an Kieselgel $(20 \mathrm{~cm}, \varnothing 2 \mathrm{~cm}$; a. $200 \mathrm{~mL}$ Hexan: Essigester 2:1; b. $150 \mathrm{~mL}$ Essigester, c. $250 \mathrm{~mL}$ Essigester: Methanol 10:1 und d. Gradient $1 \%$ Essigsäure) gereinigt. Das Produkt wurde in Diethylether gelöst und mit Pentan versetzt bis eine leichte Trübung entstand. Anschließend wurde das Gemisch über Nacht auf $-28^{\circ} \mathrm{C}$ gekühlt, wobei ein weißer Niederschlag ausfiel. Das Lösungsmittel wurde dekantiert und das Produkt getrocknet. Das Rohprodukt wurde mittels FC an Kieselgel (Laufmittel: a. Hexan: Essigester 2:1 b. Essigester, c. Essigester/Methanol 10:1, d. Essigester/Methanol 10:1, Gradient: $0.1 \%$ Essigsäure) gereinigt, es wurden 79 \% (0.39 mmol, $128 \mathrm{mg})$ des gewünschten Produktes 56 erhalten.

Drehwert $[\alpha]_{D}^{20}=-68.0(\mathrm{c}=0.4 \mathrm{~g} / 100 \mathrm{~mL}$ in DMSO).

DC (Essigester/Methanol 9:1, Gradient: $0.1 \%$ Essigsäure, $254 \mathrm{~nm}) R_{\mathrm{f}}=0.43$.

${ }^{1} \mathrm{H}-\mathrm{NMR}\left(300 \mathrm{MHz},\left[\mathrm{D}_{6}\right] \mathrm{DMSO}\right)$

$\delta=1.43\left(\mathrm{~s}, 9 \mathrm{H}, \mathrm{C}\left(\mathrm{CH}_{3}\right)_{3}\right), 2.66\left(\mathrm{~s}, 3 \mathrm{H}, \mathrm{NCH}_{3}\right), 2.93-2.99(\mathrm{~m}, 1 \mathrm{H}, \alpha-\mathrm{H}), 3.74$ (s, $2 \mathrm{H}, \mathrm{NH}_{2}$ ), 4.31 (dd, $J_{1}=10.1, J_{2}=4.5 \mathrm{~Hz}, 1 \mathrm{H}, \beta-\mathrm{H}$ ), 4.58 (dd, $J_{1}=10.1$, $\left.J_{2}=4.5 \mathrm{~Hz}, 1 \mathrm{H}, \beta-\mathrm{H}\right), 7.31-7.34(\mathrm{~m}, 5 \mathrm{H}, \mathrm{Ph}-\mathrm{H}) \mathrm{ppm}$. 
${ }^{13}$ C-NMR (75 MHz, [D 6 DMSO)

$\delta=28.0\left(\mathrm{C}\left(\mathrm{CH}_{3}\right)_{3}\right), 30.534 .6(\beta-\mathrm{C}), 34.9(\beta-\mathrm{C}),(\alpha-\mathrm{C}), 57.4$ (Benzyl-C), 59.2

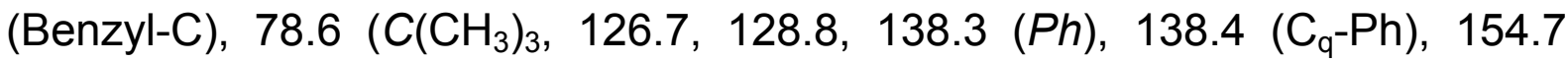
(CON), $154.3(\mathrm{CO}), 155.6(\mathrm{COOH}) \mathrm{ppm}$.

HPLC für (S)-N- $\alpha$-tert-Butoxycarbonyl- $N$-methyl-benzyl-cystein (56)

(AAV1; Gradient $0 \%$ auf $15 \%$ B' (Acetonitril $+0.1 \%$ TFA) in $30 \mathrm{~min}$, $\lambda=280 \mathrm{~nm}) t_{\mathrm{R}}=6.8 \mathrm{~min}$.

IR $(\mathrm{KBr}) \tilde{v}=3433,2976,1688,1602,1481,1453,1391,1367,1325,1251$, $1163,1071,929,702 \mathrm{~cm}^{-1}$.

UV/VIS (Methanol) $\lambda_{\max }=201 \mathrm{~nm}$.

MS (ESI) m/z (\%) $672[2 \mathrm{M}+\mathrm{Na}]^{+}(100), 348\left[^{\mathrm{M}+\mathrm{Na}]^{+}}\right.$(92), 648 [2M-Na] $^{-}(78)$, $324[\mathrm{M}-\mathrm{H}]^{-}(21)$.

\subsubsection{3-(Benzylamino)-2-(tert-butoxycarbonyl)(methyl)amino)propan-} säure $(57)^{[67 \text { a-c] }}$

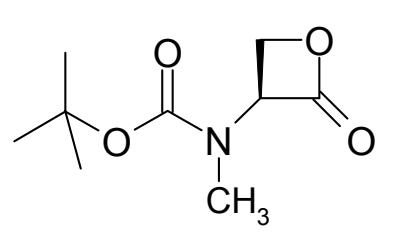

42

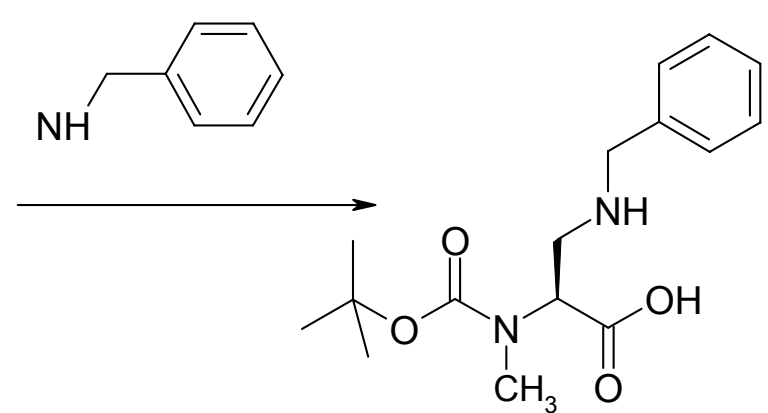

57

$\mathrm{C}_{9} \mathrm{H}_{15} \mathrm{NO}_{4}$ [201.22]

$\mathrm{C}_{7} \mathrm{H}_{8} \mathrm{~N}[106.21]$

$\mathrm{C}_{16} \mathrm{H}_{23} \mathrm{~N}_{2} \mathrm{O}_{4}$ [307.43]

Zu einer Suspension aus $47.6 \mu \mathrm{L}$ (46.8 $\mathrm{mg}, 0.43 \mathrm{mmol}, \mathrm{d}=0.98 \mathrm{~g} / \mathrm{mL}, 1.1$ eq.) Benzylamin und $1.4 \mathrm{~mL}$ absolutem Dimethylformamid wurden $9.5 \mathrm{mg}$ ( $0.40 \mathrm{mmol}, 1.0$ eq.) Natriumhydrid gegeben. Die Reaktionsmischung wurde 
$2 \mathrm{~h}$ weitergerührt, anschließend auf $-78{ }^{\circ} \mathrm{C}$ gekühlt und $80.1 \mathrm{mg}(0.40 \mathrm{mmol}$, 1.0 eq.) $\mathrm{N}$-Methylserinlacton (42), gelöst in $1.0 \mathrm{~mL}$ absolutem Dimethylformamid, innerhalb $1 \mathrm{~h}$ zugetropft. Das Lösungsmittel wurde im Hochvakuum entfernt und der Rückstand mittels $\mathrm{FC}$ an Kieselgel (Laufmittel: Essigester/Methanol (8:2), Gradient: $0.2 \%$ Essigsäure auf $1000 \mathrm{~mL}$ ) gereinigt. Es wurden $9.1 \mathrm{mg}(0.03 \mathrm{mmol}, 3 \%)$ Produkt 57 erhalten.

DC (Essigester/Methanol (9:1), $0.1 \%$ Essigsäure) $R_{f}=0.45$.

${ }^{1} \mathrm{H}-\mathrm{NMR}$ (300 MHz, [D $]$ DMSO)

$\delta=2.49(\mathrm{~s}, 9 \mathrm{H}, \mathrm{t}-\mathrm{Bu}), 3.07\left(\mathrm{~s}, 3 \mathrm{H}, \mathrm{CH}_{3}\right), 3.98-4.91\left(\mathrm{~m}, 5 \mathrm{H}, \mathrm{CH}_{2}, \alpha-\mathrm{H}, \beta-\mathrm{H}\right)$, 7.37-7.51 (m, $5 \mathrm{H}, \mathrm{Ph}) \mathrm{ppm}$.

ESI-MS $(\mathrm{m} / \mathrm{z})(\%) 639[2 \mathrm{M}+\mathrm{Na}]^{+}(34), 617[2 \mathrm{M}+\mathrm{H}]^{+}(14), 353[\mathrm{M}-\mathrm{H}+2 \mathrm{Na}]^{+}(22)$, $331[\mathrm{M}+\mathrm{Na}]^{+}(100), 309[\mathrm{M}+\mathrm{H}]^{+}, 307[\mathrm{M}-\mathrm{H}]^{-}(88)$.

\subsection{Synthese der Alanyl-Peptidnucleinsäuren (Alanyl-PNAs)}

\subsubsection{H-AlaC-AlaC-AlaT-AlaC-AlaG-AlaG-Lys- $\mathrm{NH}_{2}$ (59)}<smiles></smiles> 
Das Heptamer 59 wurde an $74.8 \mathrm{mg}(0.03 \mathrm{mmol}, 0.43 \mathrm{mmol} / \mathrm{g}, 1.0$ eq.) Boc-LLys(Z)-MBHA-Harz nach AAV3.1 aufgebaut. Die Kupplungszeit für $54.4 \mathrm{mg}$ ( $0.16 \mathrm{mmol}, 5.0$ eq.) Boc-D/L-AlaG-OH betrug $2 \mathrm{~h}$. Die Kupplungszeiten für $69.5 \mathrm{mg}$ (0.16 mmol, 5.0 eq.) Boc-D/L-AlaC(Z)-OH und $50.4 \mathrm{mg}(0.16 \mathrm{mmol}$, 5.0 eq.) Boc-L-AlaT-OH betrugen jeweils $60 \mathrm{~min}$. Als Kupplungsreagenzien wurden $55.0 \mathrm{mg}$ ( $0.14 \mathrm{mmol}, 4.5$ eq.) HATU und $21.9 \mathrm{mg}$ (0.16 mmol, 5.0 eq.) HOAt sowie $66.2 \mu \mathrm{L} \quad(0.38 \mathrm{mmol}, 12$ eq. $) \quad$ DIPEA verwendet. Alle Kupplungsschritte wurden in $600 \mu \mathrm{L}$ NMP durchgeführt. Nach der Abspaltung wurde das Oligomer aus Wasser lyophilisiert und mittels HPLC gereinigt. Es wurden $2.32 \mathrm{mg}(1.8 \mu \mathrm{mol}, 6 \%)$ des reinen Oligomers 59 enthalten.

HPLC (Gradient: 5 - $20 \%$ B' in 30 min, $254 \mathrm{~nm}, 280 \mathrm{~nm}$ ) $t_{\mathrm{R}}=19.06 \mathrm{~min}$.

MS (ESI) $(\mathrm{m} / \mathrm{z})(\%): 1322.5[\mathrm{M}+\mathrm{H}]^{+}(15), 661.5[\mathrm{M}+2 \mathrm{H}]^{2+}(44)$.

\subsubsection{H-AlaC-AlaC-AlaG-AlaT-AlaG-AlaG-Lys- $-\mathrm{NH}_{2}(60)$}<smiles>Cc1cn(C[C@H](NC(=O)C(Cn2cnc3c(=O)[nH]c(N)nc32)NC(=O)[C@H](Cn2ccc(N)nc2=O)NC(=O)[C@H](N)Cn2ccc(N)nc2=O)C(=O)N[C@@H](Cn2cnc3c(=O)[nH]c(N)nc32)C(=O)N[C@@H](Cn2cnc3nc(N)[nH]c(=O)c32)C(=O)N[C@@H](CCCCN)C(N)=O)c(=O)[nH]c1=O</smiles> 
Das komplementäre Oligomer 60 zum Oligomer 59 wurde an $51.5 \mathrm{mg}$ ( $0.03 \mathrm{mmol}, 0.6 \mathrm{mmol} / \mathrm{g}, 1.0$ eq.) Boc-D-Lys(Z)-MBHA-Harz dem Kupplungsprotokoll AVV3.1 aufgebaut. Die Kupplungszeiten für die jeweiligen AlanylNucleobasen betrugen für $52.4 \mathrm{mg}(0.15 \mathrm{mmol}, 5.0$ eq.) Boc-D/L-AlaG-OH $2 \mathrm{~h}$, für $67.0 \mathrm{mg}$ ( $0.15 \mathrm{mmol}, 5.0$ eq.) Boc-D,L-AlaC(Z)-OH sowie für $48.6 \mathrm{mg}$ ( $0.155 \mathrm{mmol}, \quad 5.0$ eq.) Boc-L-AlaT-OH jeweils $60 \mathrm{~min}$. Als Kupplungsreagenzien wurden $53.2 \mathrm{mg}(0.140 \mathrm{mmol}, 4.5$ eq. $)$ HATU und $21.0 \mathrm{mg}$ ( $0.155 \mathrm{mmol}, 5.0$ eq.) HOAt sowie $64.0 \mu \mathrm{L}$ (0.393 mmol, 12 eq.) DIPEA verwendet. Die Aktivierung erfolgte in situ am Harz. Als Reaktionslösungsmittel wurden $800 \mu \mathrm{L}$ NMP verwendet. Nach der Abspaltung wurde das Oligomer 60 aus Wasser lyophilisiert und mittels HPLC gereinigt. Es wurden $1.1 \mathrm{mg}(0.8 \mu \mathrm{mol}, 3 \%)$ des reinen Oligomers erhalten.

HPLC (Gradient: 5 - $20 \%$ B" in $30 \mathrm{~min}, 254 \mathrm{~nm}, 280 \mathrm{~nm}$ ) $t_{\mathrm{R}}=21.37 \mathrm{~min}$.

MS (ESI) $(\mathrm{m} / \mathrm{z})(\%): 1361.6[\mathrm{M}+\mathrm{H}]^{+}(8), 681.6[\mathrm{M}+2 \mathrm{H}]^{2+}(100)$. 


\subsubsection{H-AlaC-AlaC-Glu-AlaC-AlaG-AlaG-Lys- $\mathrm{NH}_{2}(61)$}<smiles>NCCCCC(NC(=O)[C@H](Cn1cnc2c(=O)[nH]c(N)nc21)NC(=O)C(Cn1cnc2c(=O)[nH]c(N)nc21)NC(=O)C(Cn1ccc(N)nc1=O)NC(=O)C(CCC(=O)O)NC(=O)C(Cn1ccc(N)nc1=O)NC(=O)C(N)Cn1ccc(N)nc1=O)C(N)=O</smiles>

61

$$
\mathrm{C}_{47} \mathrm{H}_{60} \mathrm{~N}_{28} \mathrm{O}_{14}[1241.18]
$$

Das Heptamer 61 wurde nach dem Kupplungsprotokol AVV 3.1 mit der angegebenen Ausnahme unter AVV 3.2 an $71.6 \mathrm{mg}$ (0.03 mmol, 1.0 eq., $0.43 \mathrm{mmol} / \mathrm{g}$ ) Boc-L-Lys(Z)-MBHA-Harz dargestellt. Die Kupplungszeiten für die jeweiligen Alanyl-Nucleobasen betrugen für $52.0 \mathrm{mg}(0.15 \mathrm{mmol}, 5.0$ eq.) Boc-D/L-AlaG-OH $2 \mathrm{~h}$ und für $66.5 \mathrm{mg}(0.15 \mathrm{mmol}, 5.0$ eq.) Boc-D/L-AlaC(Z)$\mathrm{OH} 60 \mathrm{~min}$. Die Kupplungszeit für $51.9 \mathrm{mg}$ ( $0.15 \mathrm{mmol}, 5.0$ eq.) Boc$\mathrm{Glu}(\mathrm{OBzl})-\mathrm{OH}$ betrug $60 \mathrm{~min}$ und wurde wie in AVV 3.2 beschrieben durchgeführt. Als Kupplungsreagenzien wurden $52.7 \mathrm{mg}$ (0.13 mmol, 4.5 eq.) HATU und $20.9 \mathrm{mg}$ ( $0.15 \mathrm{mmol}, 5.0$ eq.) HOAt sowie $62.9 \mu \mathrm{L}(0.36 \mathrm{mmol}$, 12 eq.) DIPEA sowohl für die Alanyl-Nucleobasen, als auch für die Glutaminsäure verwendet. Die Aktivierung erfolgte für die Nucleobasen in situ am Harz und für die Aminosäure mit 2 min pre-Aktivierung. Als Reaktionslösungsmittel wurden $800 \mu \mathrm{L}$ NMP verwendet. Nach der Abspaltung wurde das Oligomer 61 aus Wasser lyophilisiert und mittels HPLC gereinigt. Es wurden $3.5 \mathrm{mg}(3.1 \mu \mathrm{mol}, 9 \%)$ des reinen Oligomers erhalten.

HPLC (Gradient: 5 - $17 \%$ B"' in $25 \mathrm{~min}, 254 \mathrm{~nm}, 280 \mathrm{~nm}$ ) $t_{\mathrm{R}}=16.56 \mathrm{~min}$. 
MS (ESI) $(m / z)(\%): 1255\left[\mathrm{M}+\mathrm{NH}_{4}^{+}\right]^{+}(14), 628\left[\mathrm{M}+\mathrm{NH}_{4}{ }^{+}+\mathrm{H}\right]^{2+}(94)$.

\subsubsection{H-AlaC-AlaC-Glu-AlaC-AlaG-AlaG-Lys-Lys- $\mathrm{NH}_{2}(63)$}

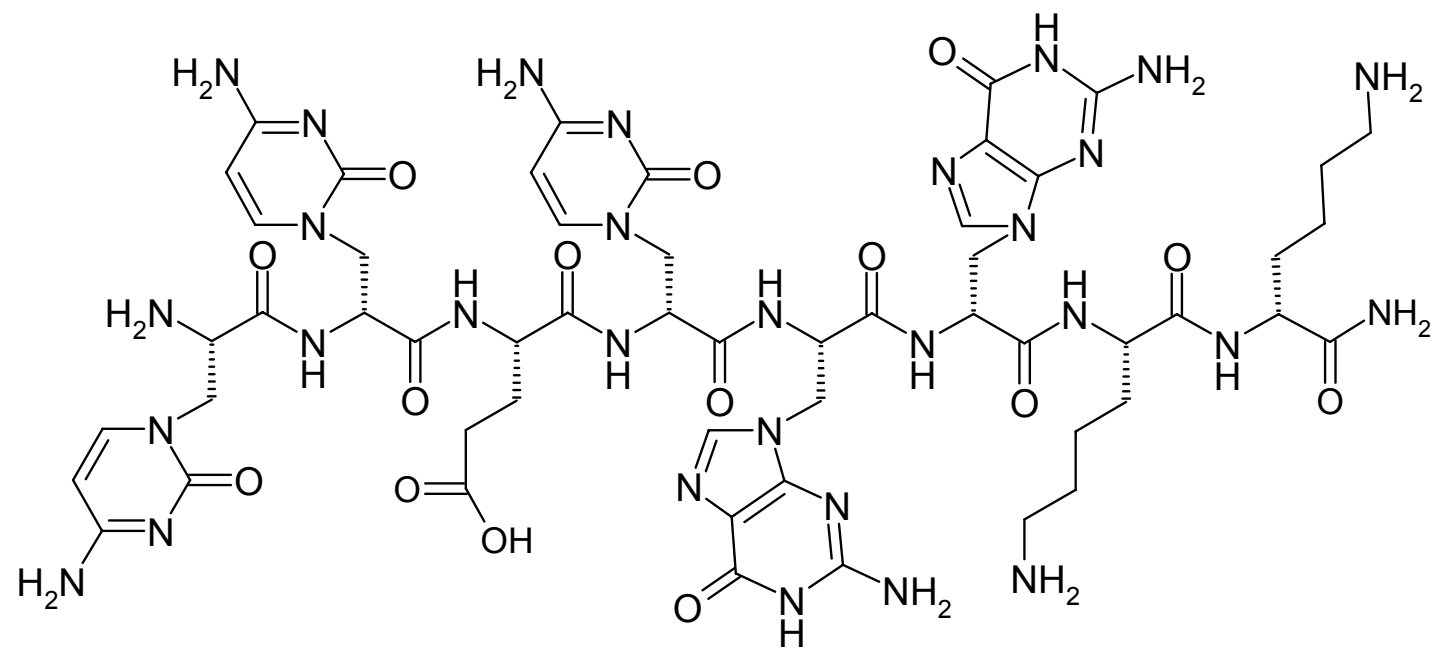

63

Das Octamer 63 wurde nach dem Kupplungsprotokoll AAV 3.1 mit der angegebenen Ausnahme unter AAV 3.2 an $55.6 \mathrm{mg}(0.03 \mathrm{mmol}, 0.6 \mathrm{mmol} / \mathrm{g}$, 1.0 eq.) Boc-D-Lys(Z)-MBHA-Harz dargestellt. Die Kupplungszeiten für die jeweiligen Alanyl-Nucleobasen betrugen, für $56.5 \mathrm{mg}(0.16 \mathrm{mmol}, 5.0$ eq.) Boc-D/L-AlaG-OH $2 \mathrm{~h}$ und für $72.2 \mathrm{mg}(0.16 \mathrm{mmol}, 5.0$ eq.) Boc-D/L-AlaC(Z)$\mathrm{OH} 60 \mathrm{~min}$. Die Kupplungszeit für $56.3 \mathrm{mg}$ ( $0.16 \mathrm{mmol}, 5.0$ eq.) BocGlu(OBzl)-OH und $69.3 \mathrm{mg}$ (0.16 mmol, 5.0 eq.) Boc-Lys(2-Cl-Z)-OH betrug 60 min und wurden nach AAV 3.2 beschrieben zur Kupplung gebracht. Als Kupplungsreagenzien wurden $57.1 \mathrm{mg}(0.15 \mathrm{mmol}, 4.5$ eq.) HATU und $22.7 \mathrm{mg}$ (0.16 mmol, 5.0 eq.) HOAt sowie $686 \mu \mathrm{L}$ ( $0.40 \mathrm{mmol}, 12$ eq.) DIPEA für die Alanyl-Nucleobasen. Für die Aminosäuren Glutamin sowie Lysin wurde $57.1 \mathrm{mg}$ ( $0.15 \mathrm{mmol}, 4.5$ eq.) HBTU und $22.7 \mathrm{mg}$ (.16 mmol, 5.0 eq.) HOBt verwendet. Die Aktivierung erfolgte für die Nucleobasen in situ am Harz und für die Aminosäure mit 2 min pre-Aktivierung. Als Reaktionslösungsmittel wurden $700 \mu \mathrm{L}$ NMP verwendet. Nach der Abspaltung wurde das Oligomer 63 
aus Wasser lyophilisiert und mittels HPLC gereinigt. Es wurden $8.8 \mathrm{mg}$ $(6.0 \mu \mathrm{mol}, 20 \%)$ des reinen Oligomers erhalten.

HPLC (Gradient: 6 - $14 \%$ B" in 23 min, $254 \mathrm{~nm}, 280 \mathrm{~nm}$ ) $t_{\mathrm{R}}=20.98 \mathrm{~min}$.

MS (ESI) $(m / z)(\%): 692.6\left[\mathrm{M}+\mathrm{NH}_{4}{ }^{+}+\mathrm{H}\right]^{2+}$.

\subsubsection{H-AlaC-AlaC-AlaG-Lys-AlaG-AlaG-Lys- $\mathrm{NH}_{2}(62)$}<smiles>NCCCC[C@H](NC(=O)[C@H](Cn1cnc2c(=O)[nH]c(N)nc21)NC(=O)[C@H](Cn1cnc2c(=O)[nH]c(N)nc21)NC(=O)[C@H](CCCCN)NC(=O)[C@H](Cn1cnc2c(=O)[nH]c(N)nc21)NC(=O)[C@H](Cn1ccc(N)nc1=O)NC(=O)[C@H](N)Cn1ccc(N)nc1=O)C(N)=O</smiles>

62

$$
\mathrm{C}_{50} \mathrm{H}_{67} \mathrm{~N}_{31} \mathrm{O}_{12} \text { [1294.29] }
$$

Der Gegenstrang 62 zum Oligomer 61 wurde an $53.6 \mathrm{mg}(0.03 \mathrm{mmol}$, $0.6 \mathrm{mmol} / \mathrm{g}, 1.0$ eq.) Boc-D-Lys(Z)-MBHA-Harz nach dem im allgemeinen Teil beschriebenen Kupplungsprotokoll AAV 3.1 für Alanyl-Nucleobasen und für die Aminosäure Lysin nach AAV 3.2 aufgebaut. Die Kupplungszeiten für die jeweiligen Alanyl-Nucleobasen betrugen, für $54.1 \mathrm{mg}(0.16 \mathrm{mmol}, 5.0$ eq.) Boc-D/L-AlaG-OH $120 \mathrm{~min}$; für $69.2 \mathrm{mg}(0.16 \mathrm{mmol}, 5.0$ eq.) Boc-D, L-AlaC(Z)$\mathrm{OH}$ und für $66.4 \mathrm{mg}(0.16 \mathrm{mmol}, 5.0$ eq.) Boc-Lys(2-Cl-Z)-OH $60 \mathrm{~min}$. Als Kupplungsreagenzien wurden $54.7 \mathrm{mg}$ ( $0.14 \mathrm{mmol}, 4.5$ eq.) HATU und $21.8 \mathrm{mg}$ (0.16 mmol, 5.0 eq.) HOAt für die Nucleoaminosäuren und für Lysin, 
sowie jeweils $65.8 \mu \mathrm{L}$ (0.38 mmol, 12 eq.) DIPEA, verwendet. Die Aktivierung erfolgte für die Nucleobausteine in situ am Harz und mit 2 min preAktivierung bei der Aminosäure. Als Reaktionslösungsmittel wurden $700 \mu \mathrm{L}$ NMP verwendet. Nach der Abspaltung wurde das Oligomer 62 aus Wasser lyophilisiert und mittels HPLC gereinigt. Es wurden $2.9 \mathrm{mg}(2.3 \mu \mathrm{mol}, 7 \%)$ des reinen Oligomers erhalten.

HPLC (Gradient: 6 - $14 \%$ B" in $24 \mathrm{~min}, 254 \mathrm{~nm}, 280 \mathrm{~nm}$ ) $t_{\mathrm{R}}=17.02 \mathrm{~min}$.

MS (ESI) $(m / z)(\%): 648.1[\mathrm{M}+2 \mathrm{H}]^{2+}$.

\subsubsection{H-Lys-AlaG-AlaC-AlaC-Glu-AlaC-AlaG-AlaG-Lys- $-\mathrm{NH}_{2}$ (65)}

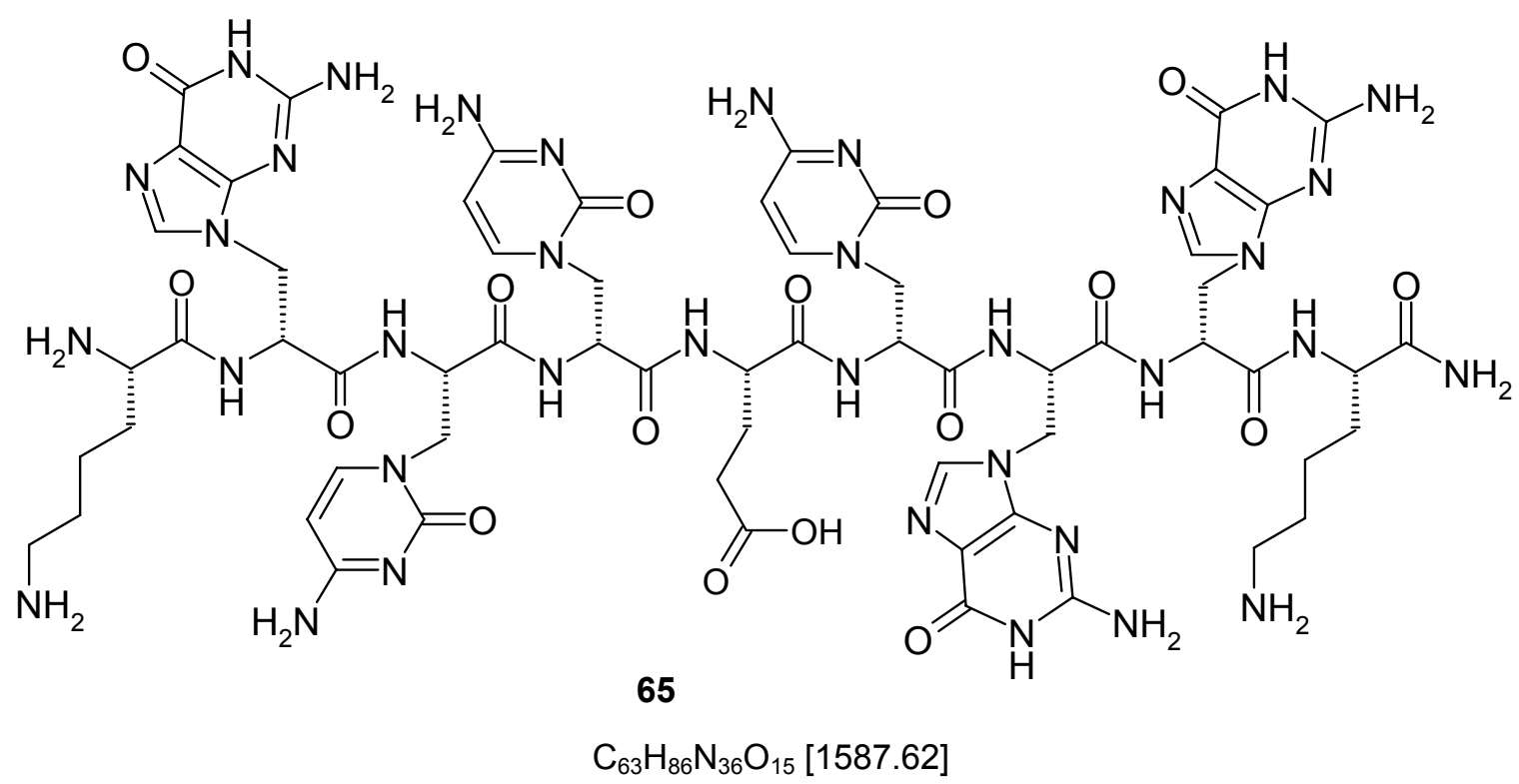

Der Alanyl-PNA-Einzelstrang 65 wurde nach AVV 3.1 an 70.6 mg $(0.03 \mathrm{mmol}$, $0.43 \mathrm{mmol} / \mathrm{g}, \quad 1.0$ eq.) Boc-L-Lys(Z)-MBHA-Harz dargestellt. Die Kupplungszeiten für die jeweiligen Alanyl-Nucleobasen betrugen, für $51.3 \mathrm{mg}$ ( $0.15 \mathrm{mmol}, 5.0$ eq.) Boc-D/L-AlaG-OH $2 \mathrm{~h}$. Für $65.6 \mathrm{mg}(0.15 \mathrm{mmol}, 5.0$ eq.) Boc-D, L-AlaC(Z)-OH, $51.2 \mathrm{mg}$ (0.15 mmol, 5.0 eq.) Boc-Glu(OBzl)-OH und $62.9 \mathrm{mg}$ ( $0.15 \mathrm{mmol}, 5.0$ eq.) Boc-Lys(2Cl-Z)-OH betrug die Kupplungszeit $60 \mathrm{~min}$. Als Kupplungsreagenzien wurden $51.9 \mathrm{mg}$ ( $0.137 \mathrm{mmol}, 4.5$ eq.) 
HATU und $21.5 \mathrm{mg}$ (0.152 mmol, 5.0 eq.) HOAt sowie je $62.1 \mu \mathrm{L}(0.364 \mathrm{mmol}$, 12 eq.) DIPEA für die Alanyl-Nucleobasen und für die Aminosäuren Glutamin und Lysin verwendet. Die Aktivierung erfolgte für die Nucleobasen in situ am Harz und für die Aminosäuren mit 2 min voraktiviert. Als Lösungsmittel wurden $800 \mu \mathrm{L}$ NMP verwendet. Nach der Abspaltung wurde das Oligomer 65 aus Wasser lyophilisiert und mittels HPLC gereinigt. Es wurden $3.2 \mathrm{mg}(2.4 \mu \mathrm{mol}$, $7 \%$ ) des reinen Oligomers erhalten.

HPLC (Gradient: 5 - $25 \%$ B” in 30 min, $254 \mathrm{~nm}, 280 \mathrm{~nm}$ ) $t_{\mathrm{R}}=17.21 \mathrm{~min}$.

MS (ESI) $(\mathrm{m} / \mathrm{z})(\%): 803\left[\mathrm{M}+\mathrm{NH}_{4}+\mathrm{H}\right]^{2+}(100)$.

\subsubsection{H-AlaC-AlaC-AlaG-Lys-AlaG-AlaG-AlaC-Lys- $-\mathrm{NH}_{2}$ (64)}<smiles>NCCCC[C@H](NC(=O)[C@H](Cn1ccc(N)nc1=O)NC(=O)[C@H](Cn1cnc2c(=O)[nH]c(N)nc21)NC(=O)[C@H](Cn1cnc2c(=O)[nH]c(N)nc21)NC(=O)[C@H](Cn1cnc2c(=O)[nH]c(N)nc21)NC(=O)[C@H](Cn1ccc(N)nc1=O)NC(=O)[C@H](N)Cn1ccc(N)nc1=O)C(N)=O</smiles>

64

$$
\mathrm{C}_{57} \mathrm{H}_{75} \mathrm{~N}_{35} \mathrm{O}_{14}[1474.26]
$$

Die Alanyl-PNA 64 stellt den Gegenstrang zum Oligomer 65 dar und wurde an

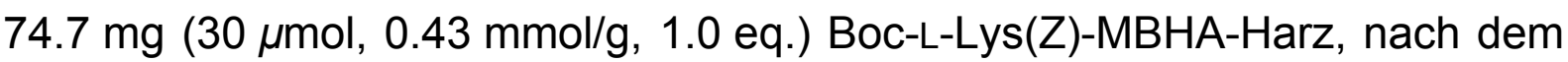
im allgemeinen Teil beschriebenen Kupplungsprotokoll AAV 3.1, für Nucleoaminosäuren und für die Aminosäure Boc-Lys(2-Cl-Z)-OH mit der Abweichung nach AAV 3.2, aufgebaut. Die Kupplungszeiten für die jeweiligen 
Alanyl-Nucleobasen betrugen für $54.3 \mathrm{mg}(0.16 \mathrm{mmol}, 5.0$ eq.) Boc-D/L-AlaG$\mathrm{OH} 2 \mathrm{~h}$, für $69.4 \mathrm{mg}(0.16 \mathrm{mmol}, 5.0$ eq.) Boc-D/L-AlaC(Z)-OH und für $66.6 \mathrm{mg}$ (0.16 mmol, 5.0 eq.) Boc-Lys(2-Cl-Z)-OH betrug die Kupplungszeit $60 \mathrm{~min}$. Als Kupplungsreagenzien wurden $54.9 \mathrm{mg}$ (0.14 mmol, 4.5 eq.) HATU und $21.9 \mathrm{mg}$ (0.16 mmol, 5.0 eq.) HOAt sowie $65.7 \mu \mathrm{L}$ (0.38 mmol, 12 eq.) DIPEA verwendet. Die Aktivierung erfolgte für die Nucleoaminosäure-Bausteine in situ am Harz und für die Aminosäure mit 2 min voraktiviert. Als Reaktionslösungsmittel wurden $700 \mu \mathrm{L}$ NMP verwendet. Nach der Abspaltung wurde das Oligomer 64 aus Wasser lyophilisiert und mittels HPLC gereinigt. Es wurden $2.4 \mathrm{mg}(2.2 \mu \mathrm{mol}, 5 \%)$ des reinen Oligomers erhalten.

HPLC (Gradient: 5 - $30 \%$ B" in $30 \mathrm{~min}, 254 \mathrm{~nm}, 280 \mathrm{~nm}$ ) $t_{\mathrm{R}}=25.81 \mathrm{~min}$.

MS (ESI) $(m / z)(\%): 738[M+2 H]^{2+}(100), 1474[M+H]^{+}(5)$.

\subsubsection{H-AlaC-AlaC-AlaG-AlaC-AlaG-AlaG-Lys-OH (80)}<smiles>NCCCCC(NC(=O)[C@H](Cn1cnc2c(=O)[nH]c(N)nc21)NC(=O)[C@H](Cn1cnc2c(=O)[nH]c(N)nc21)NC(=O)[C@H](Cn1ccc(N)nc1=O)NC(=O)[C@H](Cn1cnc2c(=O)[nH]c(N)nc21)NC(=O)[C@H](Cn1ccc(N)nc1=O)NC(=O)[C@H](N)Cn1ccc(N)nc1=O)C(=O)O</smiles> 
Das Oligomer 80 wurde an $48.0 \mathrm{mg}(0.02 \mathrm{mmol}, 0.45 \mathrm{mmol} / \mathrm{g}, 1.0$ eq.) Boc-LLys(2-Cl-Z)-Merrifield-Harz nach AAV 3.1 aufgebaut. Die Kupplungszeit für $36.5 \mathrm{mg} \quad(0.10 \mathrm{mmol}, \quad 5.0$ eq.) Boc-D/L-AlaG-OH betrug $2 \mathrm{~h} . \quad$ Die Kupplungszeiten für $46.7 \mathrm{mg}(0.10 \mathrm{mmol}, 5.0$ eq.) Boc-D/L-AlaC(Z)-OH betrug $60 \mathrm{~min}$. Als Kupplungsreagenzien wurden $36.9 \mathrm{mg}$ (0.09 mmol, 4.5 eq.) HATU und $14.7 \mathrm{mg}$ ( $0.10 \mathrm{mmol}, 5.0$ eq.) HOAt sowie $37.0 \mu \mathrm{L}$ ( $0.21 \mathrm{mmol}, 10$ eq.) DIPEA verwendet. Die einzelnen Einfachkupplungen wurden in $600 \mu \mathrm{L}$ NMP durchgeführt. Nach der Abspaltung wurde das Oligomer aus Wasser lyophilisiert und mittels HPLC gereinigt. Es wurden $4.7 \mathrm{mg}(3.6 \mu \mathrm{mol}, 16 \%)$ des reinen Oligomers $\mathbf{8 0}$ erhalten.

HPLC (Gradient: 5 - $15 \%$ B' in $30 \mathrm{~min}, 254 \mathrm{~nm}, 280 \mathrm{~nm}$ ) $t_{\mathrm{R}}=24.50 \mathrm{~min}$.

MS (ESI) $(\mathrm{m} / \mathrm{z})(\%): 674.7[\mathrm{M}+2 \mathrm{H}]^{2+}$.

\subsubsection{H-AlaC-AlaC-AlaG-Glu-AlaG-AlaG-Gly-OH (66)}<smiles></smiles>

66 
Oligomer 66 wurde an $53.3 \mathrm{mg}(0.03 \mathrm{mmol}, 0.70 \mathrm{mmol} / \mathrm{g}, 1.0$ eq.) Boc-GlyMerrifield-Harz nach AAV 3.1 aufgebaut. Die Kupplungszeit für $63.1 \mathrm{mg}$ (0.18 mmol, 5.0 eq.) Boc-D/L-AlaG-OH betrug $2 \mathrm{~h}$ und für $80.6 \mathrm{mg}(0.18 \mathrm{mmol}$, 5.0 eq.) Boc-D/L-AlaC(Z)-OH 60 min. Als Kupplungsreagenzien wurden $63.8 \mathrm{mg}$ ( $0.16 \mathrm{mmol}, 4.5$ eq.) HATU und $25.4 \mathrm{mg}(0.18 \mathrm{mmol}, 5$ eq.) HOAt sowie $76.3 \mu \mathrm{L} \quad(0.44 \mathrm{mmol}, 12$ eq. $)$ DIPEA verwendet. Die eingesetzte Aminosäure $62.9 \mathrm{mg}$ (018 mmol, 5 eq.) Boc-Glu(OBzl)-OH wurde nach AAV 3.2 mit $63.7 \mathrm{mg}$ ( $0.44 \mathrm{mmol}, 4.5$ eq.) HBTU und $25.2 \mathrm{mg}$ ( $0.18 \mathrm{mmol}, 5$ eq.) HOBt als Kupplungsreagenzien 60 min zur Reaktion gebracht. Die Menge an DIPEA wurde analog der Menge für die Nucleobasen-Bausteine gewählt. Die Einfachkupplungen wurden in $600 \mu \mathrm{L}$ NMP durchgeführt. Nach der Abspaltung wurde das Oligomer aus Wasser lyophilisiert und mittels HPLC gereinigt. Es wurden $2.06 \mathrm{mg}(2.0 \mu \mathrm{mol}, 5 \%)$ des reinen Oligomers 67 erhalten.

HPLC (Gradient: 5 - $20 \%$ B' in $30 \mathrm{~min}, 254 \mathrm{~nm}, 280 \mathrm{~nm}$ ) $t_{\mathrm{R}}=18.87 \mathrm{~min}$.

MS (ESI) $(\mathrm{m} / \mathrm{z})(\%) 1226.1[\mathrm{M}+\mathrm{H}]^{+}(8), 613.5[\mathrm{M}+2 \mathrm{H}]^{2+}(100)$.<smiles>Nc1ccn(C[C@H](NC(=O)[C@H](Cn2ccc(N)nc2=O)NC(=O)[C@H](Cn2cnc3c(=O)[nH]c(N)nc32)NC(=O)[C@H](Cn2ccc(N)nc2=O)NC(=O)[C@H](Cn2cnc3c(=O)[nH]c(N)nc32)NC(=O)[C@H](N)Cn2cnc3c(=O)[nH]c(N)nc32)C(=O)NCC(=O)O)c(=O)n1</smiles>

81 
Das Oligomer 81 wurde an $100 \mathrm{mg}(0.07 \mathrm{mmol}, 0.70 \mathrm{mmol} / \mathrm{g}, 1.0$ eq. $)$ BocGly-Merrifield-Harz nach AAV 3.1 aufgebaut. Die Kupplungszeit für $144 \mathrm{mg}$ ( $0.35 \mathrm{mmol}, 5.0$ eq.) Boc-D/L-AlaG-OH betrug $2 \mathrm{~h}$ und für $152 \mathrm{mg}(0.35 \mathrm{mmol}$, 5.0 eq.) Boc-D/L-AlaC(Z)-OH 60 min Als Kupplungsreagenzien wurden $120 \mathrm{mg}$ ( $0.31 \mathrm{mmol}, 4.5$ eq.) HATU und $47.9 \mathrm{mg}$ (0.352 mmol, 5.0 eq.) HOAt sowie $144 \mu \mathrm{L} \quad$ (0.84 mmol, 12 eq.) DIPEA verwendet. Die einzelnen Einfachkupplungen wurden in $600 \mu \mathrm{L}$ NMP durchgeführt. Nach der Abspaltung wurde das Oligomer aus Wasser lyophilisiert und mittels HPLC gereinigt. Es wurden $1.4 \mathrm{mg}(1.5 \mu \mathrm{mol}, 3 \%)$ des reinen Oligomers 81 erhalten.

HPLC (Gradient: 5 - $20 \%$ B' in $30 \mathrm{~min}, 254 \mathrm{~nm}, 280 \mathrm{~nm}$ ) $t_{\mathrm{R}}=15.54 \mathrm{~min}$.

MS (ESI) $(\mathrm{m} / \mathrm{z})(\%) 1276.4[\mathrm{M}+\mathrm{H}]^{+}(68), 638.5[\mathrm{M}+2 \mathrm{H}]^{2+}(100)$.

\section{5 .11} H-AlaT-AlaG-AlaG-AlaC-AlaG-AlaC-AlaC-Gly-OH (93)<smiles>Cc1cn(C[C@H](N)C(=O)N[C@@H](Cn2cnc3c(=O)[nH]c(N)nc32)C(=O)N[C@@H](Cn2cnc3c(=O)[nH]c(N)nc32)C(=O)N[C@@H](Cn2ccc(N)nc2=O)C(=O)N[C@@H](Cn2cnc3c(=O)[nH]c(N)nc32)C(=O)N[C@@H](Cn2ccc(N)nc2=O)C(=O)N[C@@H](Cn2ccc(N)nc2=O)C(=O)NCC(=O)O)c(=O)[nH]c1=O</smiles>

93

$\mathrm{C}_{55} \mathrm{H}_{62} \mathrm{~N}_{35} \mathrm{O}_{16}[1471.32]$

Das Oligomer 93 wurde nach AAV 3.1 an $100 \mathrm{mg}(0.07 \mathrm{mmol}, 70 \mathrm{mmol} / \mathrm{g}$, 1.0 eq.) Boc-Gly-Merrifield-Harz aufgebaut. Es wurden $54.0 \mathrm{mg}(0.17 \mathrm{mmol}$, 5.0 eq.) Boc-L-AlaT-OH mit $59.9 \mathrm{mg}(0.15 \mathrm{mmol}, 4.5$ eq.) HATU, $23.8 \mathrm{mg}$ 
(0.17 mmol, 5 eq.) HOAt und $71.6 \mu \mathrm{L} \quad(0.42 \mathrm{mmol}, 12$ eq. $)$ DIPEA als Kupplungsreagenzien $2 \mathrm{~h}$ zur Reaktion gebracht. Die Einfachkupplungen wurden in $600 \mu \mathrm{L}$ NMP durchgeführt. Nach der Abspaltung wurde das Oligomer aus Wasser lyophilisiert und mittels HPLC gereinigt. Es wurden $1.3 \mathrm{mg}(1.2 \mu \mathrm{mol}, 3 \%)$ des reinen Oligomers 93 erhalten.

HPLC (Gradient: 5 - $20 \% B^{\prime}$ in $30 \mathrm{~min}, 254 \mathrm{~nm}$ ) $t_{R}=16.65 \mathrm{~min}$.

MS (ESI) m/z (\%): $737[\mathrm{M}+2 \mathrm{H}]^{2+}(100), 1512[\mathrm{M}+43]^{+}(18)$.

\section{5 .12} $\mathrm{H}$-(Me)AlaCAlaC-AlaC-AlaC-AlaG-AlaG-Lys- $\mathrm{NH}_{2}(67)$

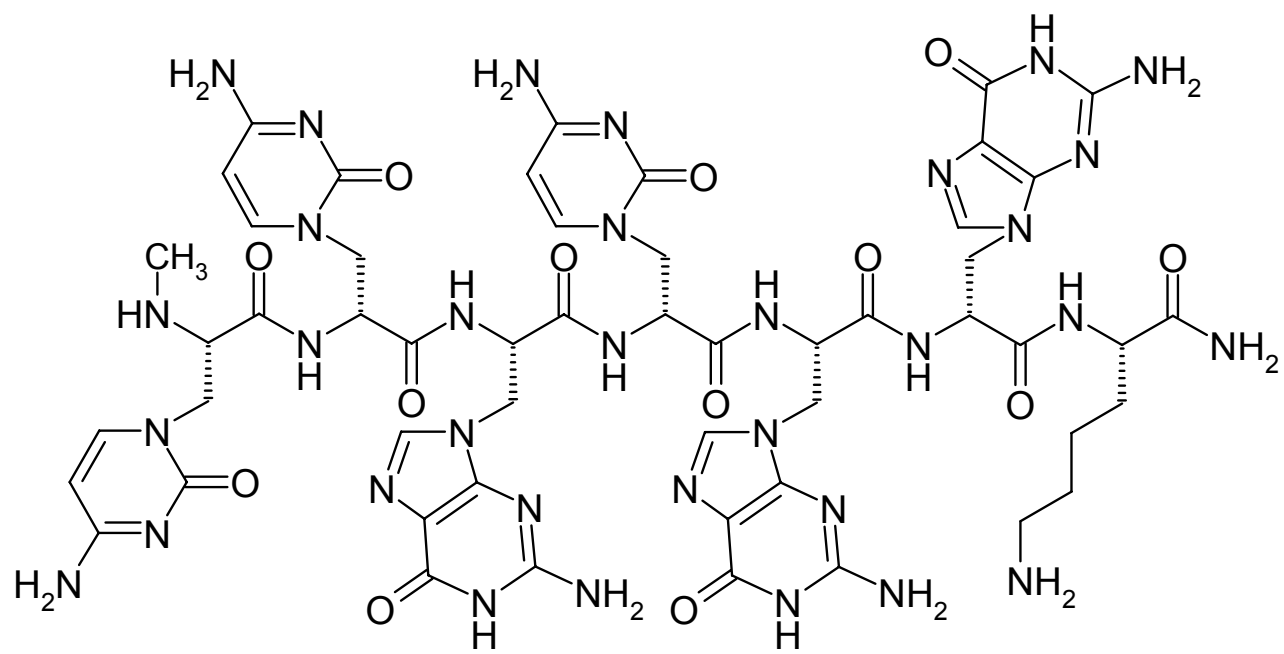

67

$$
\mathrm{C}_{52} \mathrm{H}_{65} \mathrm{~N}_{33} \mathrm{O}_{13}[1360.31]
$$

Das am Rückgrat monomethylierte Oligomer 67 wurde an $73.5 \mathrm{mg}$ (0.03 mmol, $0.43 \mathrm{mmol} / \mathrm{g}, 1.0$ eq.) Boc-Lys(2-Cl-Z)-MBHA-Harz nach AVV 3.1 aufgebaut. Die Kupplungszeit für $53.4 \mathrm{mg}$ (0.15 mmol, 5.0 eq.) Boc-D/L-AlaG$\mathrm{OH}$ betrug $2 \mathrm{~h}$ und für $68.3 \mathrm{mg}$ ( $0.15 \mathrm{mmol}, 5.0$ eq.) Boc-D/L-AlaC(Z)-OH $60 \mathrm{~min}$. Als Kupplungsreagenzien wurden $54.1 \mathrm{mg}$ (0.14 mmol, 4.5 eq.) HATU und $21.5 \mathrm{mg}$ ( $0.15 \mathrm{mmol}, 5.0$ eq.) HOAt sowie $64.6 \mu \mathrm{L}$ (0.37 mmol, 12 eq.) DIPEA verwendet. Für $68.3 \mathrm{mg} \quad(0.158 \mathrm{mmol}, 5.0$ eq. $)$ der $N$-terminal 
methylierten Nucleoaminosäure Boc-(Me)AlaC-OH wurde als Kupplungsreagenz $61.1 \mathrm{mg}(0.14 \mathrm{mmol}, 4.5$ eq.) PyCloP, sowie $64.6 \mu \mathrm{L}$ ( $0.37 \mathrm{mmol}, 12$ eq.) DIPEA, verwendet. Die Kupplungsdauer betrug $9 \mathrm{~h}$. Die Einfachkupplungen wurden in $600 \mu \mathrm{L}$ NMP durchgeführt. Nach der Abspaltung wurde das Oligomer aus Wasser lyophilisiert und mittels HPLC gereinigt. Es wurden $2.7 \mathrm{mg}(2.0 \mu \mathrm{mol}, 6 \%)$ des reinen Oligomers 67 enthalten.

HPLC (Gradient: 5 - $25 \%$ B' in $30 \mathrm{~min}, 254 \mathrm{~nm}, 280 \mathrm{~nm}$ ) $t_{R}=15.22 \mathrm{~min}$.

MS (ESI) $(m / z)(\%) 1361.3[M+H]^{+}(10), 681.1[\mathrm{M}+2 \mathrm{H}]^{2+}(100)$.

\section{5 .13}

H-AlaC-AlaC-(Me)AlaG-AlaC-AlaG-AlaG-Lys- $\mathrm{NH}_{2}$ (68)

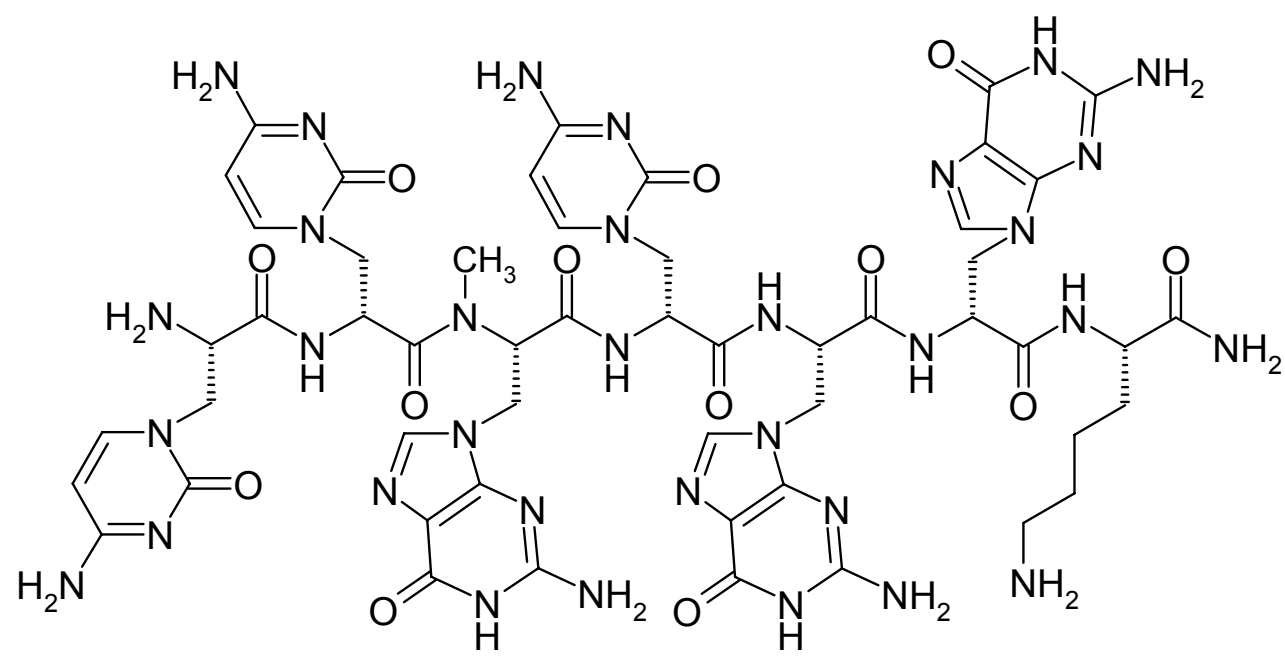

68

\section{$\mathrm{C}_{52} \mathrm{H}_{65} \mathrm{~N}_{33} \mathrm{O}_{13}[1360.31]$}

Das am Rückgrat monomethylierte Oligomer 68 wurde analog zum Oligomer 67 aufgebaut. Es wurde an $72.3 \mathrm{mg}(0.03 \mathrm{mmol}, 0.43 \mathrm{mmol} / \mathrm{g}, 1.0$ eq.) Boc-LLys(2-Cl-Z)-MBHA-Harz verwendet. Die Kupplungszeit für $52.5 \mathrm{mg}$ ( $0.15 \mathrm{mmol}, 5.0$ eq.) Boc-D/L-AlaG-OH betrug $2 \mathrm{~h}$ und für $67.1 \mathrm{mg}(0.15 \mathrm{mmol}$, 5.0 eq.) Boc-D/L-AlaC(Z)-OH 60 min Als Kupplungsreagenzien wurden $53.2 \mathrm{mg}$ ( $0.14 \mathrm{mmol}, 4.5$ eq.) HATU und $21.1 \mathrm{mg}$ (0.15 mmol, 5.0 eq.) HOAt 
sowie $63.6 \mu \mathrm{L}$ (0.37 mmol, 12 eq.) DIPEA verwendet. Für $54.8 \mathrm{mg}(0.15 \mathrm{mmol}$, 5.0 eq.) der $\mathrm{N}$-terminal methylierten Nucleoaminosäure Boc-(Me)AlaG-OH wurde als Kupplungsreagenz $60.2 \mathrm{mg}$ (0.14 mmol, 4.5 eq.) PyCloP sowie $63.6 \mu \mathrm{L}$ (0.37 mmol, 12 eq.) DIPEA, verwendet. Die Kupplungsdauer betrug $9 \mathrm{~h}$. Die auf den methylierten Baustein folgende Nucleoaminosäure Boc-DAlaC-OH wurde mittels des Aktivators PyAOP aktiviert. Es wurden $72.9 \mathrm{mg}$ ( $0.14 \mathrm{mmol}, 4.5$ eq.) PyAOP eingesetzt, die Kupplungszeit betrug zwei mal $8 \mathrm{~h}$. Die Einfachkupplungen sowie die Doppelkupplung wurden in $600 \mu \mathrm{L} \mathrm{NMP}$ durchgeführt. Nach der Abspaltung wurde das Oligomer aus Wasser lyophilisiert und mittels HPLC gereinigt. Es wurden $1.7 \mathrm{mg}(2.0 \mu \mathrm{mol}, 6 \%)$ des reinen Oligomers 68 erhalten.

HPLC (Gradient: 5 - $20 \%$ B' in $30 \mathrm{~min}, 254 \mathrm{~nm}, 280 \mathrm{~nm}$ ) $t_{R}=18.80 \mathrm{~min}$.

$\operatorname{ESI-MS~}(\mathrm{m} / \mathrm{z})(\%): 1362.3[\mathrm{M}+\mathrm{H}]^{+}(10), 681.2[\mathrm{M}+2 \mathrm{H}]^{2+}(53)$. 


\subsection{Synthese der Peptid/Alanyl-PNA Sequenz}

\subsubsection{Ac-SPGKTYTEVPGOKILQVGPGG-AlaC-AlaC-AlaG-AlaC-AlaG-AlaG- $\mathrm{K}(72)$}

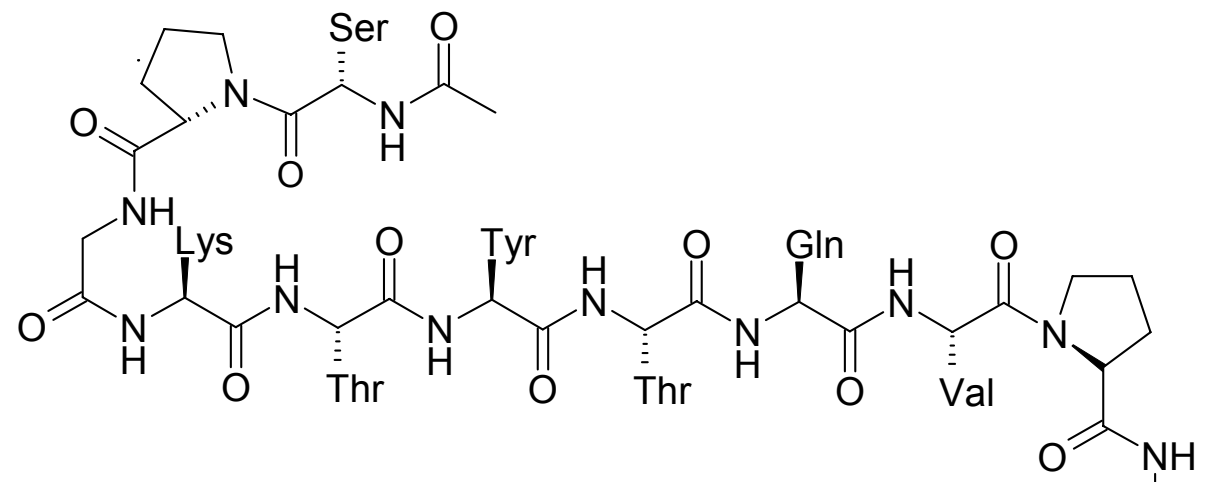

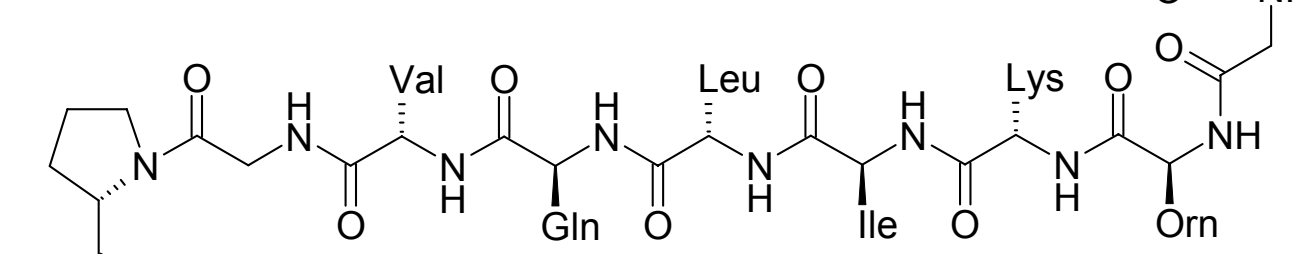

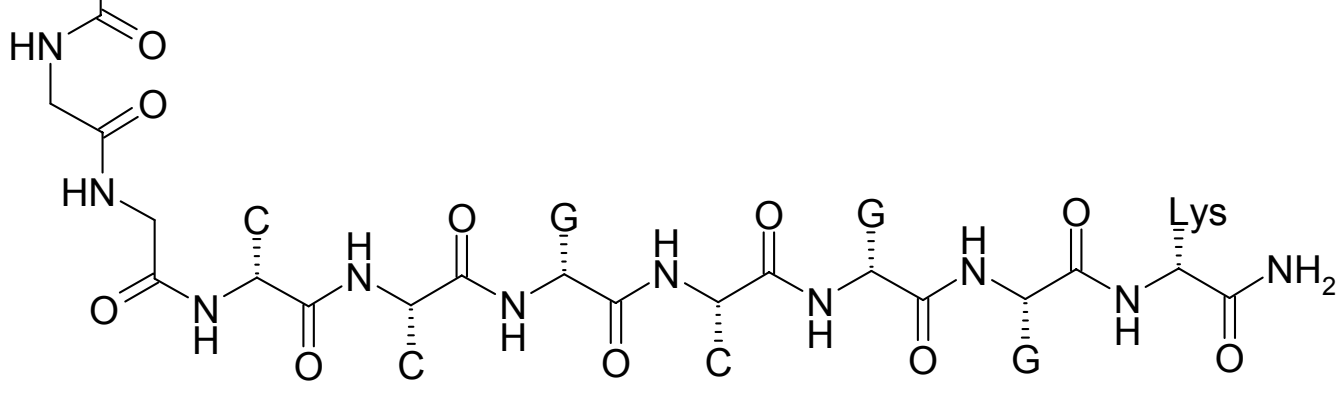
72

\section{$\mathrm{C}_{147} \mathrm{H}_{218} \mathrm{~N}_{58} \mathrm{O}_{42}$ [3466.74]}

Das Alanyl-PNA- $\beta$-Faltblatt Peptid 72 wurde bis zum AlaC-Baustein nach der Boc-Strategie AAV 3.1 und von dort nach der Fmoc-Strategie AAV 3.3 aufgebaut. Es wurde $75.4 \mathrm{mg}(0.03 \mathrm{mmol}, 0.43 \mathrm{mmol} / \mathrm{g}, 1.0$ eq.) Boc-L-Lys(2$\mathrm{Cl}-\mathrm{Z})-\mathrm{MBHA}-\mathrm{Harz}$ verwendet. Die Kupplungszeit für $54.8 \mathrm{mg}(0.16 \mathrm{mmol}$, 5.0 eq.) Boc-D/L-AlaG-OH betrug $2 \mathrm{~h}$. Die Kupplungszeiten für $69.9 \mathrm{mg}$ (0.16 mmol, 5.0 eq.) Boc-D/L-AlaC(Z)-OH betrug 60 min Als Kupplungsreagenzien wurden $55.4 \mathrm{mg}(0.14 \mathrm{mmol}, 4.5$ eq.) HATU und $22.0 \mathrm{mg}$ ( $0.16 \mathrm{mmol}, 5.0$ eq.) HOAt sowie $66.3 \mu \mathrm{L}$ (0.38 mmol, 12 eq.) DIPEA verwendet. Anschließend wurde die letzte Nucleoaminosäure Boc-L-AlaC-OH 
durch dreimal 3 min waschen mit $1 \mathrm{~mL}$ TFA $/ m$-Cresol (95:5) entschützt. Nachdem fünfmal $1 \mathrm{~mL}$ NMP und NMP/DCM (1:1) gewaschen wurde die Alanyl-PNA mit $1 \mathrm{~mL}$ Pyridin zweimal $5 \mathrm{~min}$ neutralisiert. Die Aminosäuren wurden mit den folgenden Schutzgruppen und Einwaagen verwendet; $48.2 \mathrm{mg}$ (0.16 mmol, 5.0 eq.) Fmoc-Gly-OH, 54.7 mg (0.16 mmol, 5.0 eq.) Fmoc-D-Pro$\mathrm{OH}, 54.9 \mathrm{mg}$ (0.16 mmol, 5.0 eq.) Fmoc-Val-OH, $98.9 \mathrm{mg}$ (0.16 mmol, 5.0 eq.) Fmoc-GIn(Trt)-OH, 75.9 mg (0.16 mmol, 5.0 eq.) Fmoc-Lys(Boc)-OH, $57.3 \mathrm{mg}$ ( $0.16 \mathrm{mmol}, 5.0$ eq.) Fmoc-Leu-OH, $57.3 \mathrm{mg}$ ( $0.16 \mathrm{mmol}, 5.0$ eq.) Fmoc-lle$\mathrm{OH}, 73.6 \mathrm{mg}(0.16 \mathrm{mmol}, 5.0$ eq.) Fmoc-Orn(Boc)-OH, $74.4 \mathrm{mg}(0.16 \mathrm{mmol}$, 5.0 eq.) Fmoc-Glu(OBzl)-OH, $69.9 \mathrm{mg}(0.16 \mathrm{mmol}, 5.0$ eq.) Fmoc-Thr(Bzl)$\mathrm{OH}, \quad 99.9 \mathrm{mg}$ ( $0.16 \mathrm{mmol}, \quad 5.0$ eq.) Fmoc-Tyr(2-Br-Z)-OH und $67.6 \mathrm{mg}$ ( $0.16 \mathrm{mmol}, 5.0$ eq.) Fmoc-Ser(Bzl)-OH. Die Fmoc-SPPS wurde nach der allgemeinen Vorschrift AAV 3.3 durchgeführt, wobei als Kupplungsreagenz $57.0 \mathrm{mg}$ ( $0.13 \mathrm{mmol}, 4.5$ eq.) HCTU und $20.7 \mathrm{mg}$ (0.16 mmol, 5.0 eq.) HOBt verwendet wurden. Alle Aminosäuren wurden doppelt gekuppelt. Die Kupplungsdauer für Fmoc-D-Pro-OH betrug je $2 \mathrm{~h}$, für Fmoc-Val-OH je 90 min, für die übrigen Aminosäuren wurde eine Kupplungszeit von 45 min für die erste Kupplung und 30 min für die Doppelkupplung verwendet. Die Kupplungen wurden in $700 \mu \mathrm{L}$ NMP durchgeführt. Nach der Abspaltung wurde das Oligomer aus Wasser lyophilisiert und mittels HPLC gereinigt. Es wurden $1.5 \mathrm{mg}(2 \mu \mathrm{mol}, 5 \%)$ des reinen Oligomers 72 erhalten.

HPLC (Gradient: 5 - $50 \%$ B' in $30 \mathrm{~min}, 254 \mathrm{~nm}, 280 \mathrm{~nm}$ ) $t_{\mathrm{R}}=15.42 \mathrm{~min}$.

MS (HRMS) $(\mathrm{m} / \mathrm{z}): 3467.67045[\mathrm{M}]_{0}$ (berechnet: 3467.67056), 867.92523 $[\mathrm{M}+4 \mathrm{H}]^{4+} \quad$ (berechnet: 867.92492), $694.54120 \quad[\mathrm{M}+5 \mathrm{H}]^{5+}$ (berechnet: 694.54139). 


\subsubsection{Ac-OKILQVGNGG-AlaC-AlaC-AlaG-AlaC-AlaG-AlaG-K-NH ${ }_{2}(73)$}

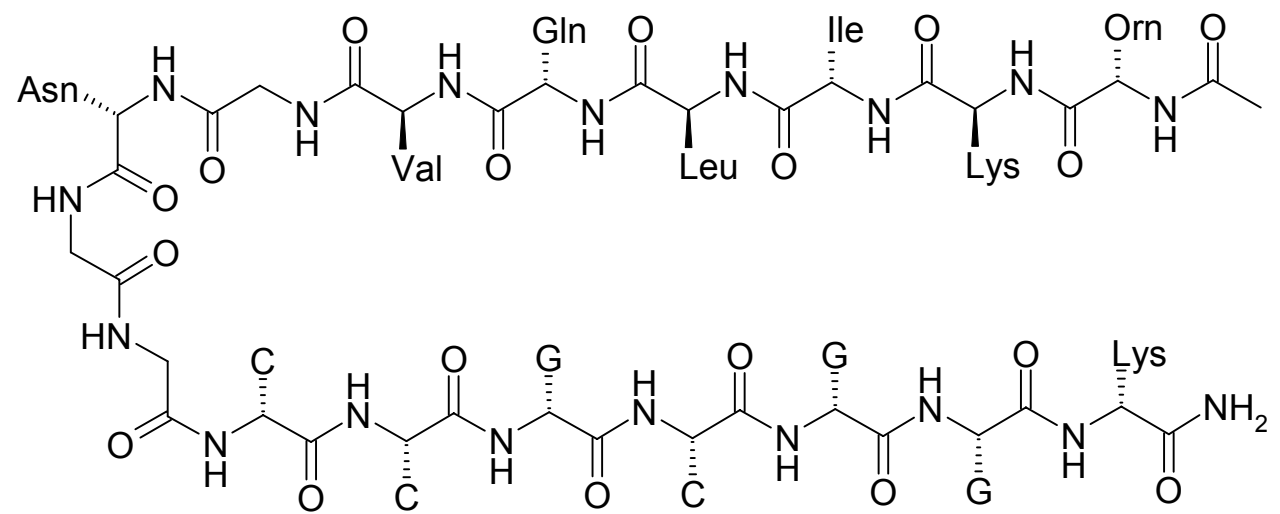

73

$$
\mathrm{C}_{97} \mathrm{H}_{143} \mathrm{~N}_{46} \mathrm{O}_{25} \text { [2353.51] }
$$

Das Alanyl-PNA- $\beta$-Faltblatt Peptid $\mathbf{7 3}$ wurde ebenfalls mittels beider Schutzgruppen-Strategien AAV 3.1 und AAV 3.3 aufgebaut. Die Sequenz, wurde bis zum AlaC-Baustein mittels der Boc-Strategie und ab dem AlaC mittels der Fmoc-Strategie aufgebaut. Es wurde $72.9 \mathrm{mg} \quad(0.03 \mathrm{mmol}$, $0.43 \mathrm{mmol} / \mathrm{g}, \quad 1.0$ eq.) Boc-L-Lys(2-Cl-Z)-MBHA-Harz verwendet. Die Kupplungszeit für $53.6 \mathrm{mg}(0.15 \mathrm{mmol}, 5.0$ eq.) Boc-D/L-AlaG-OH betrug $2 \mathrm{~h}$ und für $67.7 \mathrm{mg}$ ( $0.15 \mathrm{mmol}, 5.0$ eq.) Boc-D/L-AlaC(Z)-OH $60 \mathrm{~min}$. Als Kupplungsreagenzien wurden $53.6 \mathrm{mg}(0.14 \mathrm{mmol}, 4.5 \mathrm{eq}$.) HATU und $21.3 \mathrm{mg}$ ( $0.15 \mathrm{mmol}, 5.0$ eq.) HOAt sowie $64.2 \mu \mathrm{L}$ (0.37 mmol, 12 eq.) DIPEA verwendet. Anschließend wurde die letzte Nucleoaminosäure Boc-L-AlaC-OH durch dreimal 3 min waschen mit $1 \mathrm{~mL}$ TFA/m-Cresol (95:5) entschützt. Nach dem Waschen mit fünfmal $1 \mathrm{~mL}$ NMP und NMP/DCM (1:1) wurde die AlanylPNA mittels $1 \mathrm{~mL}$ Pyridin zweimal $5 \mathrm{~min}$ neutralisiert. Die einzelnen Aminosäuren wurden mit den unter 2.6.1 aufgeführten Schutzgruppen eingesetzt. Die Aminosäureeinwaagen (wobei 5 Äquivalente eingesetzt wurden) wurden wie folgt verwendet; $46.6 \mathrm{mg}(0.15 \mathrm{mmol}, 5.0$ eq.) Fmoc-Gly$\mathrm{OH}, 93.5 \mathrm{mg}$ ( $0.15 \mathrm{mmol}, 5.0$ eq.) Fmoc-Asn(Trt)-OH, $53.2 \mathrm{mg}(0.15 \mathrm{mmol}$, 5.0 eq.) Fmoc-Val-OH, $95.7 \mathrm{mg} \quad(0.15 \mathrm{mmol}, 5.0$ eq. $) \quad \mathrm{Fmoc}-\mathrm{G} \ln (\mathrm{Trt})-\mathrm{OH}$, $73.4 \mathrm{mg} \quad$ (0.15 mmol, 5.0 eq.) Fmoc-Lys(Boc)-OH, $55.4 \mathrm{mg} \quad(0.15 \mathrm{mmol}$, 
5.0 eq.) Fmoc-Leu-OH und ( $0.15 \mathrm{mmol}, 5.0$ eq.) Fmoc-lle-OH, sowie $71.2 \mathrm{mg}$ $(0.15 \mathrm{mmol}, 5.0$ eq.) Fmoc-Orn(Boc)-OH. Als Kupplungsreagenz wurden $58.4 \mathrm{mg}$ (0.14 mmol, 4.5 eq.) HCTU und $26.6 \mathrm{mg}$ (0.15 mmol, 5.0 eq.) $\mathrm{Cl}$ HOBt verwendet. Alle Aminosäuren wurden doppelt gekuppelt. Die Kupplungsdauer für Fmoc-L-Asn(Trt)-OH betrug je 90 min, für Fmoc-Val-OH je 60 min, für die übrigen Aminosäuren wurde eine Kupplungszeit von 40 min für die erste Kupplung und 30 min für die Doppelkupplung verwendet. Die Kupplung wurden in $700 \mu \mathrm{L}$ NMP durchgeführt. Auf die letzte Aminosäure, folgten eine Endschützung und eine anschließende Acetylierung. Die Kupplungsdauer der Acetyl-Gruppe betrug zweimal $60 \mathrm{~min}$. Nach der folgenden Abspaltung wurde das Oligomer aus Wasser lyophilisiert und mittels HPLC gereinigt. Es wurden $1.0 \mathrm{mg}(1.5 \mu \mathrm{mol}, 5 \%)$ des reinen Oligomers 73 erhalten.

HPLC (Gradient: 5 - $30 \%$ B' in $30 \mathrm{~min}, 254 \mathrm{~nm}, 280 \mathrm{~nm}$ ) $t_{\mathrm{R}}=19.22 \mathrm{~min}$.

MS (ESI) $(m / z)(\%):$ 1186. $\left[\mathrm{M}+\mathrm{NH}_{4}+\mathrm{H}\right]^{2+}(34), 790.7\left[\mathrm{M}+\mathrm{NH}_{4}+2 \mathrm{H}\right]^{3+}(100)$.

MS (HRS) m/z: 2371.13[M+NH $]^{+}$berechnet 2353.51 $\mathrm{C}_{97} \mathrm{H}_{143} \mathrm{~N}_{46} \mathrm{O}_{2}$. 


\subsubsection{Ac-SP्GKTYTEVP्GOKILQVGPGG-NH ${ }_{2}(69)$}

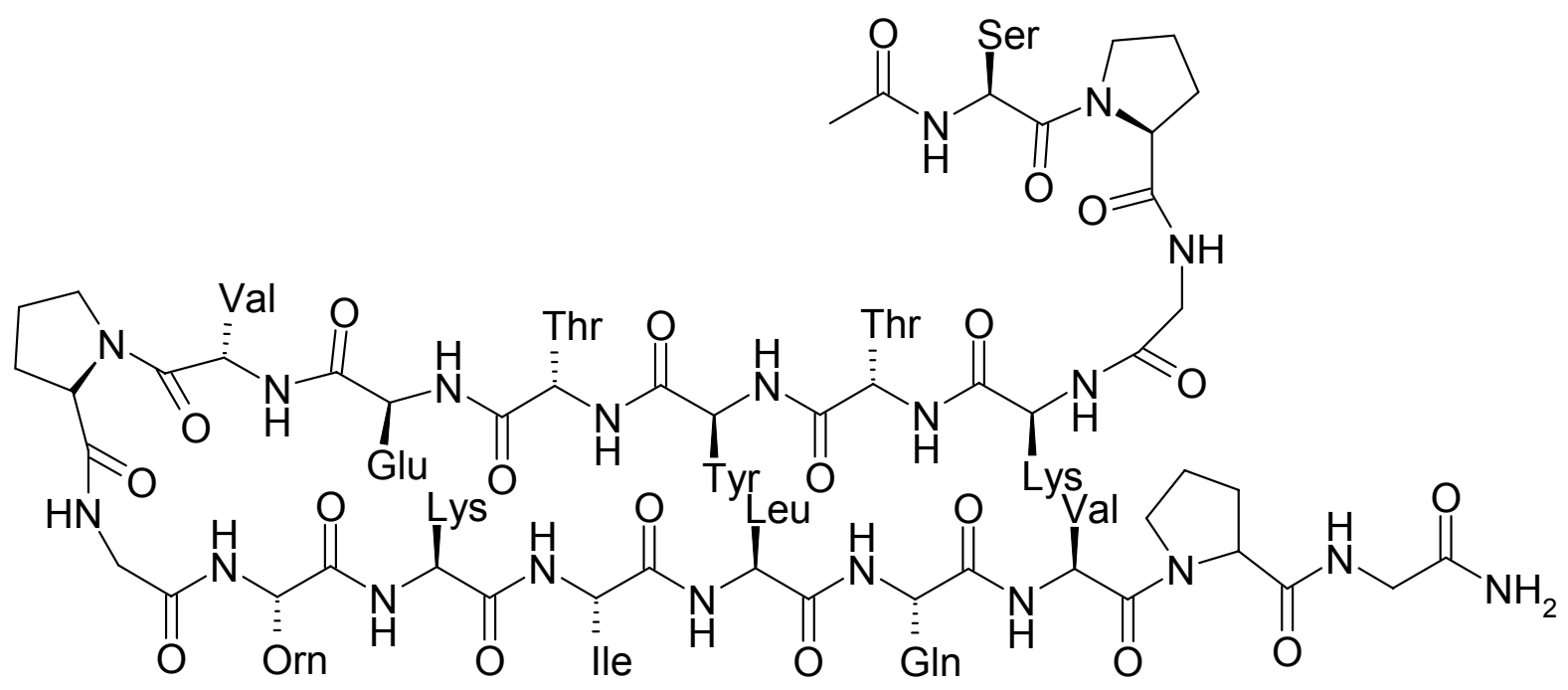

\section{$\mathrm{C}_{52} \mathrm{H}_{65} \mathrm{~N}_{33} \mathrm{O}_{13}[1360.31]$}

Das Vergleichspeptid 69 wurde mittels Boc-Strategie AAV 3.1 an $144 \mathrm{mg}$ ( $0.08 \mathrm{mmol}, \quad 0.60 \mathrm{mmol} / \mathrm{g}, \quad 1.0$ eq.) Boc-Gly-MBHA-Harz aufgebaut. Als Kupplungsreagenzien wurden $147.6 \mathrm{mg}$ ( $0.38 \mathrm{mmol}$, 4.5 eq.) HBTU und $58.4 \mathrm{mg}$ (0.43 mmol, 5.0 eq.) HOBt sowie $176.8 \mu \mathrm{L}$ (1.03 mmol, 12 eq.) DIPEA verwendet. Die einzelnen Aminosäuren wurden mit den folgenden Schutzgruppen und Einwaagen verwendet; $108.2 \mathrm{mg}$ ( $0.43 \mathrm{mmol}, 5.0$ eq.) Boc-Gly-OH, $93.1 \mathrm{mg} \quad$ (0.43 mmol, 5.0 eq.) Boc-D-Pro-OH, $93.9 \mathrm{mg}$ ( $0.43 \mathrm{mmol}, \quad 5.0$ eq.) Boc-Val-OH, $184.4 \mathrm{mg}$ (0.43 mmol, 5.0 eq.) Boc$\mathrm{GIn}($ Xan)-OH, $197.4 \mathrm{mg}$ (0.43 mmol, 5.0 eq.) Boc-Lys(2-Cl-Z)-OH, $107.8 \mathrm{mg}$ ( $0.43 \mathrm{mmol}, 5.0$ eq.) Boc-Leu-OH $\times \mathrm{H}_{2} \mathrm{O}, 100.1 \mathrm{mg}$ (0.43 mmol, 5.0 eq.) BocIle-OH $\times 1 / 2 \mathrm{H}_{2} \mathrm{O}, 158.4 \mathrm{mg}$ (0.43 mmol, 5.0 eq.) Boc-Orn(Z)-OH, $149.9 \mathrm{mg}$ ( $0.43 \mathrm{mmol}, 5.0$ eq.) Boc-Glu(OBzl)-OH, $133.8 \mathrm{mg}$ (0.43 mmol, 5.0 eq.) Boc$\operatorname{Thr}(\mathrm{Bzl})-\mathrm{OH}, 219.7 \mathrm{mg}$ (0.43 mmol, 5.0 eq.) Boc-Tyr(2-Br-Z)-OH und $127.7 \mathrm{mg}$ ( $0.43 \mathrm{mmol}, 5.0$ eq.) Boc-Ser(Bzl)-OH. Alle Aminosäuren wurden doppelt gekuppelt. Die Kupplungsdauer für Boc-D-Pro-OH betrug je $2 \mathrm{~h}$ und für BocVal-OH je 60 min, für die übrigen Aminosäuren wurde eine Kupplungszeit von 50 min für die erste Kupplung und 30 min für die Doppelkupplung verwendet. 
Die Kupplung wurden in $800 \mu \mathrm{L}$ NMP durchgeführt. Auf der letzten Aminosäure, folgten eine Endschützung und eine anschließende Acetylierung. Die Kupplungsdauer der Acetyl-Gruppe betrug zweimal 60 min. Nach der Abspaltung wurde das Oligomer aus Wasser lyophilisiert und mittels HPLC gereinigt. Es wurden $2.4 \mathrm{mg}(1.7 \mu \mathrm{mol}, 7 \%)$ des reinen Oligomers 69 enthalten.

HPLC (Gradient: 10 - $60 \%$ B' in $30 \mathrm{~min}, 254 \mathrm{~nm}, 280 \mathrm{~nm}$ ) $t_{\mathrm{R}}=16.85 \mathrm{~min}$.

ESI-MS $(m / z)(\%): 1013.9[\mathrm{M}+2 \mathrm{H}]^{2+}(30), 676.6[\mathrm{M}+3 \mathrm{H}]^{3+}(100)$.

\subsubsection{IL-8/AlanyI-PNA Derivat (76)}

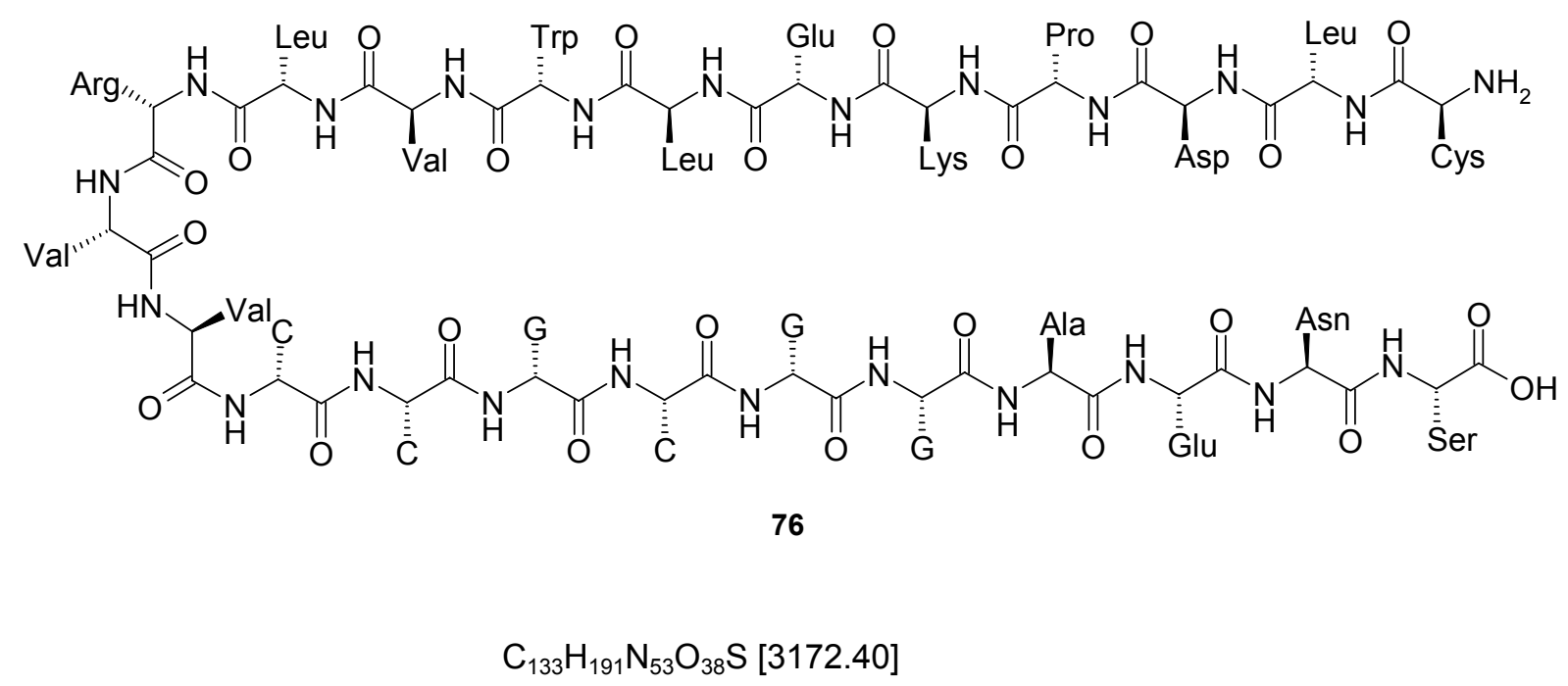

Das IL8/Alanyl-PNA Derivat $\mathbf{7 6}$ wurde mittels beider Schutzgruppen-Strategien aufgebaut. Die Sequenz bis zum AlaC-Baustein wurde mittels der BocStrategie AVV 3.1 und ab dem AlaC mittels der Fmoc-Strategie AVV 3.2 aufgebaut. Es wurde an $47.8 \mathrm{mg}(0.02 \mathrm{mmol}, 0.44 \mathrm{mmol} / \mathrm{g}, 1.0$ eq.) Boc-LSer(Bzl)-PAM-Harz verwendet. Die Kupplungszeit für $35.6 \mathrm{mg}(0.10 \mathrm{mmol}$, 5.0 eq.) Boc-D/L-AlaG-OH betrug $2 \mathrm{~h}$. Die Kupplungszeiten für $45.8 \mathrm{mg}$ ( $0.10 \mathrm{mmol}$, 5.0 eq.) Boc-D/L-AlaC(Z)-OH betrug $60 \mathrm{~min}$. Als Kupplungsreagenzien wurden $36.1 \mathrm{mg}$ ( $0.09 \mathrm{mmol}, 4.5$ eq.) HATU und 
$14.3 \mathrm{mg}$ ( $0.10 \mathrm{mmol}, 5.0$ eq.) HOAt sowie $43.2 \mu \mathrm{L}$ (0.25 mmol, 12 eq.) DIPEA verwendet. Anschließend wurde die Nucleoaminosäure Boc-L-AlaC-OH durch dreimal 3 min waschen mit $1 \mathrm{~mL}$ TFA/m-Cresol (95:5) entschützt. Nach dem Waschen mit fünf Mal $1 \mathrm{~mL}$ NMP und NMP/DCM (1:1) wurde die Alanyl-PNA mittels $1 \mathrm{~mL}$ Pyridin zweimal $5 \mathrm{~min}$ neutralisiert. Die Aminosäureeinwaagen (bezogen auf 5 eq.) wurden wie folgt verwendet $35.8 \mathrm{mg} \mathrm{Fmoc}-\mathrm{Val}-\mathrm{OH}$, $49.4 \mathrm{mg}$ Fmoc-Lys(Boc)-OH, $37.3 \mathrm{mg}$ Fmoc-Leu-OH und $55.2 \mathrm{mg}$ Fmoc$\operatorname{Trp}(\mathrm{Boc})-\mathrm{OH}, \quad 43.4 \mathrm{mg}$ Fmoc-Asp(OtBu)-OH, $35.6 \mathrm{mg}$ Fmoc-Pro-OH. Die Fmoc-SPPS wurde nach der allgemeinen Vorschrift AAV3.3 durchgeführt, wobei als Kupplungsreagenz $39.3 \mathrm{mg}$ (0.09 mmol, 4.5 eq.) HCTU und $17.9 \mathrm{mg}$ ( $0.10 \mathrm{mmol}, 5.0$ eq.) $\mathrm{Cl}-\mathrm{HOBt}$ verwendet wurden. Alle Aminosäuren wurden doppelt gekuppelt. Die Kupplungsdauer der Aminosäuren betrug 40 min für die erste Kupplung und 30 min für die Doppelkupplung. Die Kupplung wurden in $500 \mu \mathrm{L}$ NMP durchgeführt. Auf Leucin folgte die Kupplung des Fmoc-Cys(Trt)$\mathrm{OH}$, hierzu wurde $33.2 \mu \mathrm{L}(0.21,10$ eq.) DIC als Kupplungsreagenz verwendet. Die Kupplungszeit betrug bei Cystein je $2 \mathrm{~h}$. Nach der folgenden Abspaltung wurde das Oligomer aus Wasser lyophilisiert und mittels HPLC gereinigt. Die gereinigte Menge reichte Menge reichte für die Massenbestimmung.

HPLC (Gradient: 5 - $60 \%$ B' in $30 \mathrm{~min}, 254 \mathrm{~nm}, 280 \mathrm{~nm}$ ) $t_{\mathrm{R}}=11.5 \mathrm{~min}$.

MS (ESI) m/z $1072[\mathrm{M}+43+4 \mathrm{H}]^{3+}(69), 794[\mathrm{M}+4 \mathrm{H}]^{4+}(36)$. 


\subsection{Ligation nach Bordusa}<smiles>Nc1ccn(CC(N)C(=O)NC(Cn2ccc(N)nc2=O)C(=O)NC(Cn2cnc3c(=O)[nH]c(N)nc32)C(=O)NC(Cn2ccc(N)nc2=O)C(=O)NC(Cn2cnc3c(=O)[nH]c(N)nc32)C(=O)N[C@@H](Cn2cnc3c(=O)[nH]c(N)nc32)C(=O)NCC(=O)O)c(=O)n1</smiles>

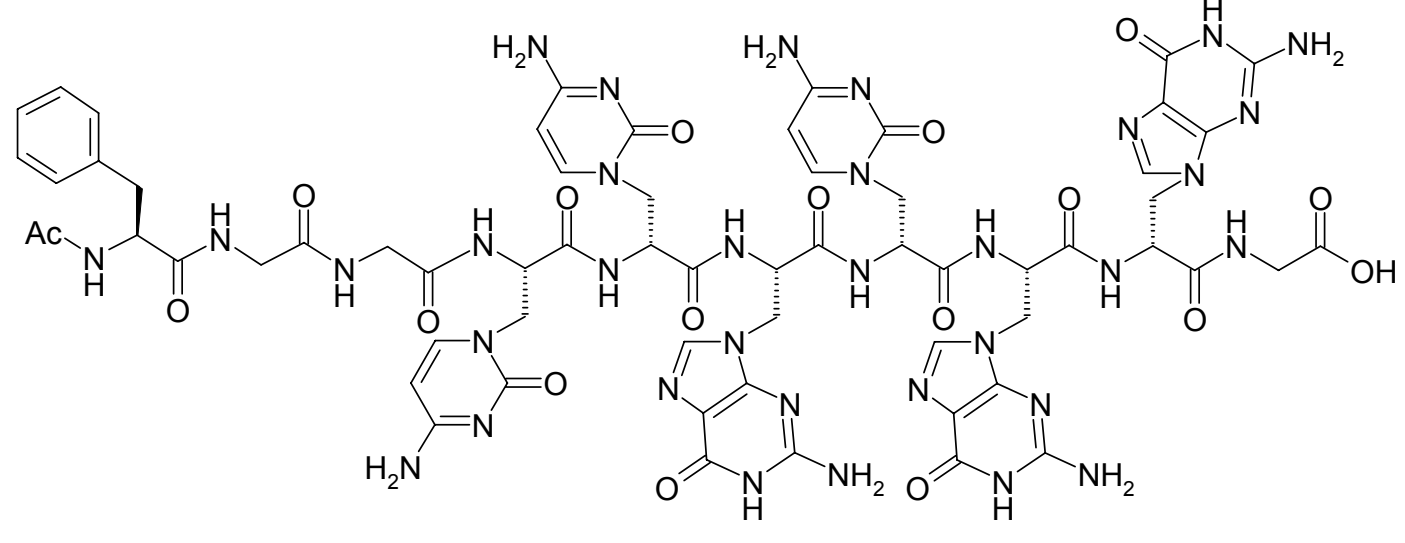

83

Die Ligationen wurden bei $25^{\circ} \mathrm{C}$ in je $0.2 \mathrm{M}$ HEPES-Puffer durchgeführt. Der Puffer wurde auf $\mathrm{pH}=8.0$ eingestell und beinhaltete $0.1 \mathrm{~mol} \mathrm{NaCl}$ und $0.01 \mathrm{~mol} \mathrm{CaCl}_{2}$. Der Ester 82 wurde in Dimethylformamid gelöst und zum Puffersystem gegeben. Die Reaktionszeiten betrugen 1-2 h. Es wurden die folgenden drei Ligationsexperimente durchgeführt,

a. $2 \mathrm{mmol}$ Boc-Phe-Gly-Gly-OGp, $4 \mathrm{mmol}$ (AlaG-AlaT) ${ }_{2}$-Lys- $\mathrm{NH}_{2}$ mit $5 \mu \mathrm{mol}$ Clostripain (Enzym). Es wurden 10-20\% des Peptides Boc-Phe-Gly-Gly(AlaG-AlaT) $)_{2}$-Lys- $\mathrm{NH}_{2}$ (79) erhalten. 
MALDI-ToF 1305,93 $[\mathrm{M}+\mathrm{H}]^{+}, 1327.92[\mathrm{M}+\mathrm{Na}]^{+}, 1343.86[\mathrm{M}+\mathrm{K}]^{+}$theoretisch $1305[\mathrm{M}]_{0}$.

b. 2 mmol Ac-Lys-Leu-Pro-Gly-Trp-Glu-Lys-Arg-Met-Ser-Arg-Ser-Ser-Gly-OGp (84) mit 4 mmol (AlaG-AlaT) ${ }_{2}$-Lys- $\mathrm{NH}_{2}$ (79) und $5 \mu \mathrm{mol}$ Clostripain (Enzym) zu 10-20 \% Produkt Ac-Lys-Leu-Pro-Gly-Trp-Glu-Lys-Arg-Met-Ser-Arg-Ser-SerGly-(AlaG-AlaT) $)_{2}$-Lys- $\mathrm{NH}_{2}$ (85) umgesetzt.

MALDI-ToF $2700.65\left[\mathrm{M}+\mathrm{NH}_{4}\right]^{+}$theoretisch $2683[\mathrm{M}]_{0}$.

c. $2 \mathrm{mmol}$ Ac-Val-Phe-Ile-Thr-Ser-Pro-Gly-Lys(Z)-Thr-Tyr-Thr-Glu-Val-ProGly-Orn-Lys(Z)-Ile-Leu-GIn-Val-Pro-Gly-OGp (86) mit 4 mmol H-AlaC-AlaCAlaG-AlaC-AlaG-AlaG-Lys-OH (80) und $20 \mu \mathrm{mol}$ Clostripain zu $9 \%$ Ac-ValPhe-Ile-Thr-Ser-Pro-Gly-Lys(Z)-Thr-Tyr-Thr-Glu-Val-Pro-Gly-Orn-Lys(Z)-IleLeu-GIn-Val-Pro-Gly-AlaC-AlaC-AlaG-AlaC-AlaG-AlaG-Lys-COOH (87).

MALDI-ToF $4110[\mathrm{M}+\mathrm{Na}]^{+}$theoretisch $4087[\mathrm{M}]_{0}$

Die enzymatischen Ansätze wurden zeitabhängig per analytische HPLC untersucht, wobei die Produkte manuell aufgefangen wurden. 


\section{Abkürzungsverzeichnis}

AAV Allgemeine Arbeitsvorschrift

Abb. Abbildung

ACN Acetonitril

Ala Alanin

AlaC $\quad N$-tert-Butoxycarbonyl- $\beta$-( $N$-4-benzyloxycarbonyl-1-cytosinyl) alanin

AlaG $\quad N$-tert-Butoxycarbonyl- $\beta$-(9-guaninyl)-alanin

Arg Arginin

AS Aminosäure

Asn Aspargin

ber. Berechnet

Boc tert-Butoxycarbonyl

br. breit

2-Br-Z 2-Bromobenzyloxycaronyl

Bzl Benzyl

BOP O-Benzotriazol-1-yloxytris(dimethylamino)phosphonium hexafluorophosphat

C Cytosin

CD Circular Dichroismus

Cys Cystein

d Dublett

dd Dublett vom Dublett

DC Dünnschichtchromatographie

DIC N,N-Dicycohexylcarbodiimid

DCM Dichlormethan

DIPEA $\quad \mathrm{N}, \mathrm{N}$-Diisopropyl-ethylamin

DMF Dimethylformamid

DMSO Dimethylsulfoxid

$\left[D_{6}\right]$ DMSO Hexadeuterodimethylsulfoxid 
DNA Desoxyribonukleinsäure

EDT 1,2-Ethandithiol

EE Essigsäureethylester

eq. Äquivalente

ESI Elektronensprayionisation

FC flash-Chromatographie

Fmoc 9-Fluorenylmethoxycarbonyl

FT Fourier-Transformation

G Guanin

GIn Glutamin

Gly Glycin

Glu Glutaminsäure

HATU N-(7-Aza-1H-benzotriazol-1-yl)-1,1,3,3-tetramethyluroniumhexafluorophosphat

HBTU N-(1H-benzotriazol-1-yl)-1,1,3,3-tetramethyluroniumhexafluorophosphat

HCTU o-(1H-6-Chlorobenzotriazole-1-yl)-1,1,3,3-tetramethyluronium hexafluorphosphat

HOAc Essigsäure

HOAt 7-Aza-1-hydroxybenzotriazol

HOBt 1-Hydroxybenzotriazol

Cl-HOBt Chlor-1-Hydroxybenzotriazol

HPLC Hochleistungsflüüsigkeitschromatographie

Ile Isoleucin

IR Infrarotspektroskopie

Leu Leucin

Lys Lysin

MBHA 4-Methylbenzyhydrylamin

$\mathrm{MeOH} \quad$ Methanol

MS Massenspektrometrie

NMP N-Methylpyrrolidin-2-on

NMR nuclear magnetic resonance 


$\begin{array}{ll}\text { OBzl } & \text { Benzyloxy } \\ \text { OtBu } & \text { t-Butoxy } \\ \text { Orn } & \text { Ornithin } \\ \text { Phe } & \text { Phenylalanin } \\ \text { PNA } & \text { Peptidnukleinsäure } \\ \text { PyAOP } & \text { 7-Azabenzotriazol-1-yloxytris(pyrrolidino)phosphonium } \\ & \text { hexafluorophosphat } \\ \text { PyCloP } & \text { Chlortripyrrolidinophosphonium-hexafluorophosphat } \\ \text { Pro } & \text { Prolin } \\ \text { PS } & \text { Polystyrol } \\ \text { q } & \text { Quartett } \\ \text { RP } & \text { reverse phase } \\ \text { RT } & \text { Raumtemperatur } \\ \text { S } & \text { Singulett } \\ \text { Schmp. } & \text { Schmelzpunkt } \\ \text { Ser } & \text { Serin } \\ \text { t } & \text { Triplett } \\ \text { tBu } & \text { tert-Butyl } \\ \text { TEA } & \text { Triethyamin } \\ \text { TFA } & \text { Trifluoressigsäure } \\ \text { TFMSA } & \text { Trifluormethansulfonsäure } \\ \text { THF } & \text { Tetrahydrofuran } \\ \text { Trp } & \text { Tryptophan } \\ \text { Trt } & \text { Trityl } \\ \text { Tyr } & \text { Tyrosin } \\ \text { UV } & \text { Ultraviolettspektroskopie } \\ \text { WC } & \text { Watson-Crick } \\ \text { Z } & \text { Benzoyloxycarbonyl } \\ & \end{array}$




\section{Literaturverzeichnis}

[1] W. H. Fremann and company, Molekular cell biology 4.0 2000, media connected.

[2] A. Mattes, O. Seitz, Angew. Chem. 2001, 113, 3277-3280.

[3] a) U. Diederichsen, Angew. Chem. Int. Ed. Engl. 1996, 35, 445-448. b) U. Diederichsen, D. Weicherding, N. Diezemann, Org. Biomol. Chem. 2005, 3, 1058-1066.

[4] a) U. Diederichsen, Bioorg. Med. Chem. Lett. 1997, 13, 1743-1746; b) U. Diederichsen, H. W. Schmitt, Angew. Chem. Int. Ed. Engl. 1998, 37, 302-305; c) U. Diederichsen, Angew. Chem. 1997, 109, 1966-1969; d)

U. Diederichsen, D. Weicherding, Synlett 1999, S1, 917-920; e) U. Diederichsen, D. P. Weicherding, E. Vockelmann, Chimia 1998, 9, 467;

f) U. Diederichsen, Bioorg. Med. Chem. Lett. 1998, 8, 165; g) U. Diederichsen, Angew. Chem. 1997, 109, 2411-2413; h) U. Diederichsen, C. M. Biro, Bioorg. Med. Chem. Lett. 2000, 10, 1417-1420.

[5] F. A. Syud, H. E. Stanger, H. Schenk Mortell, J. F. Espinosa, J. D. Fisk, C. G. Fry, S. H. Gelmann, J. Mol. Biol. 2003, 326, 553.

[6] a) R. March, curr. Med Chem. 1995, 2, 654; b) S. Zhang, T. Govender, T. Norström, P. I. Arvidsson, J. Org. Chem. 2005, 70, 6918; c) L. Aurelio, R. T. C. Brownlee, A. B. Hughes, Chem. Rev. 2004, 104, 5823; d) L. Aurelio, J. S. Box, R. T. C. Brownlee, A. B. Hughes, B. E. Sleebs, J. Org. Chem. 2003, 68, 2652.

[7] a) J. M. Ostresh, G. M. Husar, S. Blondelle, B. Dorner, P.A. Weber, R. A. Houghten, Proc. Natl. Acad. Sci. U.S.A 1994, 91, 11138; b) S. M. Miller, R. J. Simon, R. N. Zuckermann, J. M. Keer, W. H. Moos, Drug Dev. Res. 1995, 35 20; c) E. Hughes, R. M. Burke, A. J. Doig, J. Biol. Chem. 2000, 275, 25109; d) A. J. Doig, E. Hughes, R. M. Burke, T. J. Su, R. K. Heenan, J. Lu, Biochem. Soc. Trans. 2002, 30, 537; e) J. M. Mason, N. Kokkoni, K. Stott, A. J. Doig, Curr. Opin. Struct. Biol. 2003, 13, 526. 
[8] a) B. Vitoux, A. Aubry, M. T. Cung, M. Marraud, Int. J. Peptide Protein Res. 1986, 27, 617; b) S. R. Griffiths-Jones, M. S. Searle, J. Am. Chem. Soc. 2000, 122, 8350; c) T. Kortemme, M. Ramirez-Alvarado, L. Serrano, Science 1998, 281, 253.

[9] A. Aggeli, N. Boden, S. Zhang, Self-Assembling Peptide Systems in Biology, Medicine and Engineering 2001.

[10] a) B. Sommer, Curr. Opin. Pharmacol. 2002, 2, 87; b) C. Soto, Mol. Med Today 1999, 5, 343, c) P. Hammerström, R. L. Wisenman, E. T. Powers, J. W. Kelly, Science 2003, 299, 713.

[11] H. L. Schenk, S. H. Gellmann, J. Am. Chem. Soc. 1998, 120, 4869.

[12] a) H. E. Stanger, F. H. Syud, J. F. Espinosa, I. Giriat, T. Muir, S. H. Gellmann, Proc. Natl. Acad. Sci. 2001, 98, 12015; b) G. J. Sharman, M. S. Searler, J. Am. Chem. Soc. 1998, 120, 5291; c) S. R. Ragothman, S. K. Awasthi, P. Barlaman, J. Chem. Soc., Perkin Trans. 2 1998, 137.

[13] H. E. Stanger, S. H. Gellmann, J. Am. Chem. Soc. 1998, 120, 4236.

[14] M. Searle, Bioploymers 2004, 76, 185.

[15] D. Voet, J. G. Voet, .C. W. Pratt, Lehrbuch der Biochemie, Wiley VCH Verlag GmbH \& Co.KGaA., Hrsg.: A. G. Beck-Sickinger, U. Hahn, Weinheim 2002.

[16] J. Coste, E. Frerot, P. Jouin, Tetrahedron Lett. 1991, 32, 1967.

[17] C. A. Jasseway, P. Travels, Immunologie, Spektrum Verlag, 2001.

[18] a) N. Sewald, Angew. Chem. Int. 2002, 41, 4661; b) R. M. Wenger, Helv. Chim. Acta 1983, 66, 2672.

[19] a) J. Urban, T. Vaisar, R. Shen, M. S. Lee, Int. J. Peptide Protein Res. 1996, 47, 182 ; b) G. V. Reddy, G. V. Rao, D. S. lyengar, Tetrahedron Letters 1998, 39, 1985; c) U. Kertscher, M. Bienert, E. Krause, N. F. Sepetov, B. Mehlis, Int. J. Peptide Protein Res. 1993, 41, 207; d) N. F. Sepetov, M. A. Krymsky, M. V. Ovchinikov, Z. D. Bespalova, O. L. Isakova, M. Soucek, M. Lebel, Peptide Res. 1991, 4, 308.

[20] a) M. Teixido, F. Albericio, E. Giralt, J. Peptide Res. 2005, 65, 153; b) J. R. McDermott, N. L. Benoiton, Can. J. Chem. 1973, 51, 2555. 
[21] a) T. L. Lowe, A. Strzelec, L. L. Kiessling, R. M. Murphy, Biochemisty 2001, 40, 7882; b) A. Karpuniotu, A. Schmauder, K. Tenedis, J. Mol. Biol. 2002, 315, 339.

[22] D. T. S. Rijkers, J. W. M. Höppner, G. Posthuma, C. J. M. Lips, R. M. J. Liskamp, Chem. Eur. J. 2002, 8, 4285.

[23] a) P. E. Nielsen, M. Egholm, R. H. Berg, O. Buchardt, Sience 1991, 254, 1497-1500; b) B. Hyrup, P. Nielsen, Bioorg. Med. Chem. 1996, 4, 5-23; c) A. Mattes, O. Seitz, Angew. Chem. 2001, 113, 3277-3280.

[24] A. Löberding, B. Mielke, C. Schwemler, E. Schwenner, U. Stropp, W. Springer, A.Kretschmer, T. Pötter, EP 0646595 A1, 1995;

[25] A. Volbeda, A. Lahm, F. Sakiyama, D. Suck, EMBO Journal 1991, 10, 1607-1618.

[26] M. Köhn, R. Breinsbauer, Angew. Chem. 2004, 116, 3168.

[27] H. Hang, C. R. Bertozzi, Acc.Chem. Res. 2001, 34, 727.

[28] a) C. F. Lui, J. P. Tam, Proc. Natl. Acad. Sci. USA 1994, 91, 6584; b) P.

E. Dawson, T. W. Muir, I. Clark-Lewis, S. B. Kent, Science 1994, 266, 766;

c) T. W. Muir, P.E. Dawson, S. B. Kent, Methods Enzymol. 1997, 289, 266;

d) J. P. Tam, Q. Yu, Z. Miao, Biopolymers 1999, 51, 311.

[29] Y. Shin, K. A. Winans, B. J. Backes, S. B. Kent, J. A. Ellamm, C. R. Bertozzi, J. Am. Chem. Soc. 1999, 121, 11684.

[30] a) H. Paulus, Chem. Soc. Rev. 1998, 27, 375; b) H. Paulus, Annu. Rev. Biochem. 2000, 69, 447; c) R. David, M. P. O. Richter, A. G. BeckSickinger, Eur. J. Biochem. 2004, 271, 663.

[31] S. Chong, F. B. Mersha, D. G. Comb, M. E. Scott, D. Landry, L. M. Vence, F. B. Perler, J. Benner, R.-B. Kucera, C. A. Hirvonnen, J. J. Pelletier, H. Paulus, M. Q. Xu, Gene 1997, 192, 271.

[32] a) T. W. Muir, D. Sondhi, P. A. Cole, Proc. Natl. Acad. Sci. USA 1998, 95, 6705; b) G. J. Cotton, T. W. Muir, Chem. Biol. 2000, 7, 253.

[33] S. Tchertchian, O. Hartley, P. Botti, J. Org. Chem. 2004, 69, 9208.

[34] H.-D. Jakubke, Angew .Chem. 1995, 107, 189.

[35] V. Cerovky, F. Bordusa, J. Peptide Res. 2000, 55, 325. 
[36] a) M. Thormann, S. Thust, H.-J. Hofmann, F. Bordusa, Biochemistry 1999, 38, 6056; b) N. Welhofsky, F. Bordusa, FEBS Letters 1999, 443, 220.

[37] C. A. Janeway, P. Travers, Immunologie 5. Auflage, Spektrum-Verlag.

[38] K. Takeda, T. Kaisho, S. Akira, Annu. Rev. Immunol. 2003, 21, 335.

[39] a) M. Baggiolini, B. Dewald, B. Moser, Annu. Rev. Immunol., 1997, 15, 675; b) M. Baggiolini, I. Clark-Lewis, FEBS Letters 1992, 307, 97.

[40] W. Forth, D. Henschler, W. Rummel, Allgemeine und spezielle Pharmakologie und Toxikologie 9. Auflage, 2005, Urban \& Fischer.

[41] a) P. Lohse, B.Oberhauser, B. Oberhauser-Hofbauer, G. Baschang, A. Eschenmoser, Croatic Chim. Acta 1996, 69, 535; b) P. Lohse, „Synthese und Eigenschaften von oligomeren Nukleodipeptamidinium-Salzen“, Dissertation, ETH Zürich, 1992.

[42] L. D. Arnold, T.H. Kalanter, J. C. Vederas, J. Am. Chem. Soc. 1985, 107, 7105.

[43] a) L. Aurelio, T. C. Brownlee, A. B. Hughes, Chem. Rev. 2004, 104, 5823; b) S. Zhang, T. Govender, T. Norström, P. I. Arvidsson, J. Org. Chem. 2005, 70, 6918; c)J. H. Humphrey, A. R. Chamberlin, Chem. Rev. 1997, 97, 2243.

[44] P. Lohse, B.Oberhauser, B. Oberhauser-Hofbauer, G. Baschang, A. Eschenmoser, Croatic Chim. Acta 1996, 69, 535.

[45] T. M. Fletcher, B. E. Cathers, K. S. Ravikumar, B. M. Mamiya, S. M. Kerwin, Bioorganic Chemistry 2001, 29, 36.

[46] a) F. Seela, U. Lüpke, Chem. Ber. 1977, 110, 1462; b) F. Seela, A. Kehne, H.-D. Winkeler, Liebigs Ann. 1983, 137.

[47] D. Weicherding, Synthese von Alanyl- und HomoalanylPeptidnucleinsäuren -Untersuchung der Homologie, der Wechselwirkungen mit Aminosäuren und des photoinduzierten Elektronentransfers, Dissertation, TU-München, 2000 eingereicht.

[48] a) M. Christensen, O. Schou, Int. J. Peptide Protein Res. 1978, 12, 121; b) Y. Song, A. D. Sercel, D. R. Johnson, N. L. Colbry, K. L. Sun, B. D. Roth, Tetrahedron Lett. 2000, 41, 8225; c) S. T. Cheung, N. L. Benoiton, Can, J. Chem.1977, 55, 906 
[49] a) G. Solladie, Synthesis 1981, 185; b) G. H. Posner, Acc. Chem. Res. 1987, 20, 72; c) A. Griesbeck, D. Seebach, Helv. Chim. Acta 1987, 70, 1320.

[50] a) A. Griesbeck, D. Seebach, Helvetica Chimica Acta 1987, 70, 1326; b)

T. Sato, K.Naruse, T. Fui

Jisawa, Tetrahedron Lett. 1982, 23, 3587; c) T. Sato, T. Itoh, C. Hattori, T. Fujisawa, Chem. Lett. 1983, 1391.

[51] J. Urban, T. Vaisar, R. Shen, M. S. Lee, Int. J. Peptide Protein Res. 1996, 47, 182.

[52] a) J. Coste, J. P.Ferot, B. Castro, Tetrahedron Lett. 1991, 32, 1967; b) J. Coste, J. P.Ferot, J. Org. Chem. 1994, 59, 2437; c) L. Yet, Albany molecular research, Inc., Technical reports 1999, 4 (1).

[53] J. Coste, M.N. Durfour, A. Pantaloni, B. Castro, Tetraherdron Letters 1990, 31, 669 .

[54] R. D. Tung, M. K. Dhaon, D. H. Rich, J. Org. Chem. 1986, 51, 3350..

[55] F. Albericino, M. Cases, J. Alsina, S. A. Triolo, L. A. Carpino, St. A. Kent, Tetraherdron Letters 1997, 38, 4853.

[56] a) G. V. Reddy, G. V. Rao, D. S. lyengar, Tetrahedron Letters 1998, 39, 1985; b) U. Kertscher, M. Bienert, E. Krause, N. F. Sepetov, B. Mehlis, Int. J. Peptide Protein Res. 1993, 41, 207; c) N. F. Sepetov, M. A. Krymsky, M. V. Ovchinikov, Z. D. Bespalova, O. L. Isakova, M. Soucek, M. Lebel, Peptide Res. 1991, 4, 308.

[57] Johnson, T.; Quibell, M.; Owen, D.; Sheppard, R. C.; J. Chem. Soc., Chem. Commun. 1993, 369.

[58] Bedfored, J.; Hyde, C.; Johnson, T.; Jun, W.; Owen, D.; Quibell, M.; Sheppard, R. C.; Int. J. Petide Protein Res. 1992, 40, 300.

[59] M.F. Hoffmann, Induktion von Sekundärstruktutren durch den Einbau von Alanyl-PNA in Peptiden und Proteinen, Dissertation, Würzburg 2003.

[60] F. A. Syud, H. E. Stanger, H. Schenk Mortell, J. F. Espinosa, J. D. Fisk, C. G. Fry, S. H. Gellmann, J. Mol. Biol. 2003, 326, 553.

[61] a) A. Thaler, D. Seebach, F. Cardinaux, Helv. Chim. Acta 1991, 74, 617;

b) D. Seebach, A. Thaler, A. K. Beck, Helv. Chim. Acta 1989, 72, 857. 
[62] a) D. Y. Jackson, J. Burnier, C. Quan, M. Stanley, J. Tom, J. A. Wells, Science 1994, 266, 243; b) F. Bordusa, Chem. Rev .2002, 102, 4817.

[63] a) L. E. Canne, St. J. Bark, St. B. H. Kent, J. Am. Chem. Soc. 1996, 118, 5891; b) J. P. Tam, J. Xu, K. D. Ecom, Biopolymers 2001, 60, 194.

[64] a) S. Techertchian, O. Hartley, P. Botti, J. Org. Chem. 2004, 69, 9208; b) P. Botti, M. R. Carrasco, St. B. H. Kent, Tetrahedron Letters 2001, 42, 1831.

[65] M. S. Searle, Biopolymers 2004, 76, 185.

[66] a) M. Mergler, J. P. Duriex, The BACHEM practice of SPPS, Bachem AG 2000; b) R. B. Merrifield, J. Am. Chem. Soc. 1963, 85, 2149-2154; c) R. B. Merrifield, Angew. Chem. 1985, 97, 801-812.

[67] a) A. Griesbeck, D. Seebach, Helvetica Chimica Acta 1987, 70, 1326; b) T. Sato, K.Naruse, T. Fui Jisawa, Tetrahedron Lett. 1982, 23, 3587; c) T. Sato, T. Itoh, C. Hattori, T. Fujisawa, Chem. Lett. 1983, 1391. 


\section{Lebenslauf}

Name:

Ružica Ranevski

Geboren am:

02.01.1977

Geboren in:

Arnsberg/HSK

Staatsangehörigkeit:

Deutsch

08.1993 - 06. 1996

06. 1996

10. $1996-10.1999$

\section{Chemisch-Technische-Assistentin} des HSK (Olsberg; Deutschland)

Fachabitur (Olsberg; Deutschland)

Universität Essen, Deutschland, Vordiplom in Chemie October 1999

11. $1999-06.2002$

Universitä

Essen

Deutschland,

Diplom in Organischer Chemie August 2002

Diplomthema "Bestimmung der Stabilität von EisenKomplexen fluoreszierender 1,10-PhenantrolinDerivaten", unter der Leitung von: Prof. Dr. Dr. R. Sustmann und Prof. Dr. M. Matzik in Essen

10. 1996 - 08. 2002 Universität Essen, Deutschland

12. $2002-03.2006$

Georg-August-Universität am Institut für Organische und Biomolekulare Chemie der Georg-August Universität zu Göttingen, Deutschland

Dissertationsthema "Synthese und Untersuchung von Alanyl-PNA Oligomeren und deren Einfluß auf $\beta$ Faltblatt Struktur", unter der Leitung von: Prof. Dr. U. Diederichsen in Göttingen 